\title{
Hyperostosis cranialis interna
}

Citation for published version (APA):

Waterval, J. J. (2014). Hyperostosis cranialis interna. [Doctoral Thesis, Maastricht University]. Maastricht University. https://doi.org/10.26481/dis.20140613jw

Document status and date:

Published: 01/01/2014

DOI:

10.26481/dis.20140613jw

Document Version:

Publisher's PDF, also known as Version of record

\section{Please check the document version of this publication:}

- A submitted manuscript is the version of the article upon submission and before peer-review. There can be important differences between the submitted version and the official published version of record.

People interested in the research are advised to contact the author for the final version of the publication, or visit the DOI to the publisher's website.

- The final author version and the galley proof are versions of the publication after peer review.

- The final published version features the final layout of the paper including the volume, issue and page numbers.

Link to publication

\footnotetext{
General rights rights.

- You may freely distribute the URL identifying the publication in the public portal. please follow below link for the End User Agreement:

www.umlib.nl/taverne-license

Take down policy

If you believe that this document breaches copyright please contact us at:

repository@maastrichtuniversity.nl

providing details and we will investigate your claim.
}

Copyright and moral rights for the publications made accessible in the public portal are retained by the authors and/or other copyright owners and it is a condition of accessing publications that users recognise and abide by the legal requirements associated with these

- Users may download and print one copy of any publication from the public portal for the purpose of private study or research.

- You may not further distribute the material or use it for any profit-making activity or commercial gain

If the publication is distributed under the terms of Article $25 \mathrm{fa}$ of the Dutch Copyright Act, indicated by the "Taverne" license above, 
Hyperostosis cranialis interna 
Hyperostosis cranialis interna

Thesis, Maastricht University, The Netherlands

ISBN: 978-94-6182-438-7

Author: J.J. Waterval

Cover design: Off Page, concept by J.J. Waterval

Layout: Tiny Wouters

Printing: Off Page

Financial support for this thesis was kindly provided by:

Advanced Bionics Benelux, ALK Abelló B.V., ATOS Medical B.V., Bernafon Nederland B.V., Beter Horen B.V., Carl Zeiss B.V., Chipsoft B.V., Cochlear Benelux N.V., Daleco Pharma B.V., Dos Medical B.V., EmiD audiologische apparatuur, Entermed B.V., GlaxoSmithKline B.V., Olympus Nederland B.V., Specsavers International B.V., Stallergenes B.V., Streukens Hooroplossingen B.V., Van Boxtel Hoorwinkels B.V., Stichting Het Heinsius-Houbolt Fonds, Nederlandse Vereniging voor Keel-NeusOorheelkunde en Heelkunde van het Hoofd-halsgebied, Maastricht UMC+, Maastricht University.

(C) Copyright J.J. Waterval, Maastricht 2014

All rights reserved. No part of this publication may be reproduced in any form or by any means, electronically, by print or otherwise without written permission of the copyright owner. 


\title{
Hyperostosis cranialis interna
}

\author{
PROEFSCHRIFT
}

ter verkrijging van de graad van doctor aan de Universiteit Maastricht, op gezag van de Rector Magnificus, prof. dr. L.L.G. Soete volgens het besluit van het College van Decanen, in het openbaar te verdedigen, op vrijdag 13 juni 2014 om 16:00 uur

door

Jérôme Joseph Waterval 


\section{Promotores}

Prof. dr. J.J. Manni

Prof. dr. R.J. Stokroos

\section{Beoordelingscommissie}

Prof. dr. B. Kremer (voorzitter)

Prof. dr. F.E. Offeciers (European Institute for Otorhinolaryngology, Antwerpen)

Prof. dr. C.T. Stumpel

Prof. dr. J.E. Wildberger 
Voor Stephanie

Voor papa en mama 


\section{Contents}

Part I General introduction on hyperostosis cranialis interna and sclerosing bone dysplasias with craniofacial involvement

Chapter 1 General introduction and outline of the thesis

Chapter 2 Other sclerosing bone dysplasias with craniofacial involvement Bone 2013;60C:48-67

Part II Clinical, radiological and metabolic features of hyperostosis cranialis interna

Chapter 3 Phenotypic manifestations and management of hyperostosis cranialis interna Am J Med Genetic Part A 2010;152A:547-555

Chapter $4 \quad$ Neurophysiologic, audiometric and vestibular function tests in patients with hyperostosis cranialis interna

Clin Neurol Neurosurg 2013;115:1701-1708

Chapter $5 \quad$ Radiologic features and progression of hyperostosis cranialis 107 interna Am J Neuroradiol 2012;33:453-461

Chapter 6 Bone metabolic activity in hyperostosis cranialis interna measured with ${ }^{18}$ F-fluoride positron emission tomography Eur J Nucl Med Mol Imaging 2011;38:884-893

Chapter $7 \quad$ Bone turnover markers in hyperostosis cranialis interna Submitted

Part III Genetics of hyperostosis cranialis interna 159

Chapter 8 Localisation of the gene for hyperostosis cranialis interna 161 to chromosome $8 \mathrm{p} 21$ with analysis of three candidate genes Calcif Tissue Int. 2013;93:93-100

Part IV Casuistics

Chapter 9 Facial nerve decompression via middle fossa approach for 179 hyperostosis cranialis interna J Laryngol Otol 2009;123:1177-1180 
Chapter 10 Cerebral vasospasm after auditory brainstem implantation in a patient with hyperostosis cranialis interna

Clin Neurol Neurosurg 2011;113:904-908

Part V General discussion, summary and addendum

Chapter 11 General discussion, conclusions and future perspectives

Summary

Samenvatting

Dankwoord

225

Bibliography

233

About the author

237 

General introduction on hyperostosis cranialis interna and sclerosing bone dysplasias with craniofacial involvement

\section{Part 1}




\section{Chapter 1}

Outline of the thesis and general introduction 
Chapter 1 
Hyperostosis cranialis interna $(\mathrm{HCl})$ is a unique genetic bone disorder, which has never been documented in other individuals than those described in this thesis. It is a disorder in which intracranial hyperostosis and osteosclerosis occur at the level of the skull base and the skull cap. It was in the eighties that the first patient was investigated because of bilateral facial palsies, chronic headaches and decreased unilateral vision. Because of a predominant history of facial palsies, her family members were invited to be investigated as well ${ }^{1}$. Other important symptoms are also sequelae of bony entrapment of cranial nerves, especially diminished hearing and balance (vestibulocochlear nerve), facial pain or diminished facial sensation (trigeminal nerve), loss of smell (olfactory nerve) and visual problems (optic nerve). Furthermore headache was reported by several patients.

The severity of the symptoms and also the fascinating principle that a bone disorder is present only in the skull and seemingly completely absent in the rest of the body, made it a valuable topic for further research.

\section{Aim of the thesis}

The aim of this thesis is roughly twofold. On the one hand it has been our goal to investigate and meticulously describe the disorder clinically in order to counsel and treat patients as good as possible. On the other hand we actively participated in the translation of clinical research into genetic and biomedical research. Understanding the disorder genetically and biomedically eventually serves clinical practice, but is also crucial to contributing in the understanding of physiological processes in the human body and the understanding of the pathophysiology of diseases.

In chapter 2, hyperostosis cranialis interna is compared to other sclerosing bone dysplasias with involvement of the craniofacial area. Clinical, genetic and pathophysiological aspects are discussed. The embryology and ossification of the skull and skull base are described. Chapter 2 should be seen as an extension of the introduction.

From here on, the thesis focuses solely on $\mathrm{HCl}$. Part II is devoted to the clinical and imaging features of $\mathrm{HCl}$. Chapter 3 describes the symptomatology of $\mathrm{HCl}$ : the course and severity of the different symptoms. This can be seen as a sequel to the first article on $\mathrm{HCl}$ dating $1990^{1}$.

In chapter 4 the results and value of several clinical function tests are presented. The results of tone and speech audiometry and auditory brainstem responses are presented. Furthermore the results of tests evaluating trigeminal, facial and vestibular nerve functions are discussed.

In chapter 5 and 6 imaging results are reported. In chapter 5 we present the results of the computed tomography (CT) study. On the one hand it is about the specific findings on $\mathrm{CT}$ in the different areas of the skull and skull base. On the other hand, 
densitometric measurements have been performed to examine the bone quality and degree of calcification of the affected bone. To determine the metabolic activity in the affected bone - compared to other osseous references sites in the same individuals as well as control subjects - a study with Positron Emission Tomography was performed as described in chapter 6 . It is one of the first studies performed with the tracer ${ }^{18}$ F-fluoride in a bone disease with such a slow course. Histopathologic findings are illustrated in chapter 7 along with the results of investigating markers of bone metabolism in blood of patients and non-affected family members.

Chapter $\mathbf{8}$ in part III of the thesis is performed in collaboration with the department of Medical Genetics at the University of Antwerp, Belgium. The possible genetic relationship with similar genetic bone dysplasias is examined. Furthermore, the disease-causing area in the genome is determined by a linkage analysis study.

In part IV two case reports describe treatment possibilities, but also important limitations. They both address to the management of sequelae of impaired nerves within the internal auditory canal. Chapter $\mathbf{9}$ is about internal auditory canal decompression in a young patient and chapter $\mathbf{1 0}$ is about a longstanding bilaterally deaf patient who came too late for this decompression. A functional solution in the form of an auditory brainstem is presented, along with the significant imposed risks due to the primary pathology.

Chapter 11 (part V) discusses the value of the results of our research and offers recommendations for further research and clinical practice. A summary of the thesis is given in chapter 12 . In the addendum the results of an ongoing study of the department of Medical Genetics in Antwerp are presented.

Remark: a family pedigree is used in several chapters to clarify the family composition and to visualise which individuals have undergone different tests. The pedigree has undergone several changes during the past years since the study has started in 2007 because of ageing of young family members. It has been decided that the different versions of the pedigrees of each chapter within this thesis were not changed from their original version at the time the particular chapter was submitted as an article. Moreover the order of the chapters as they appear in this thesis is not chronological (see publication date of each chapter). At last it is important to realise that a genetic diagnosis has only become possible after the successful linkage analysis, which is depicted in the pedigree of chapter 8. (Unpublished) results of this study were completed in July 2011. 


\section{General Introduction}

\section{The human skull}

The human skull consists of three parts: the neurocranium surrounds and protects the brain and the brainstem, the viscerocranium (also called the splanchnocranium or facial skeleton) supports and houses the organs of the face and there is the mandible.

\section{ANTERIOR AND POSTERIOR VIEWS OF SKULL}
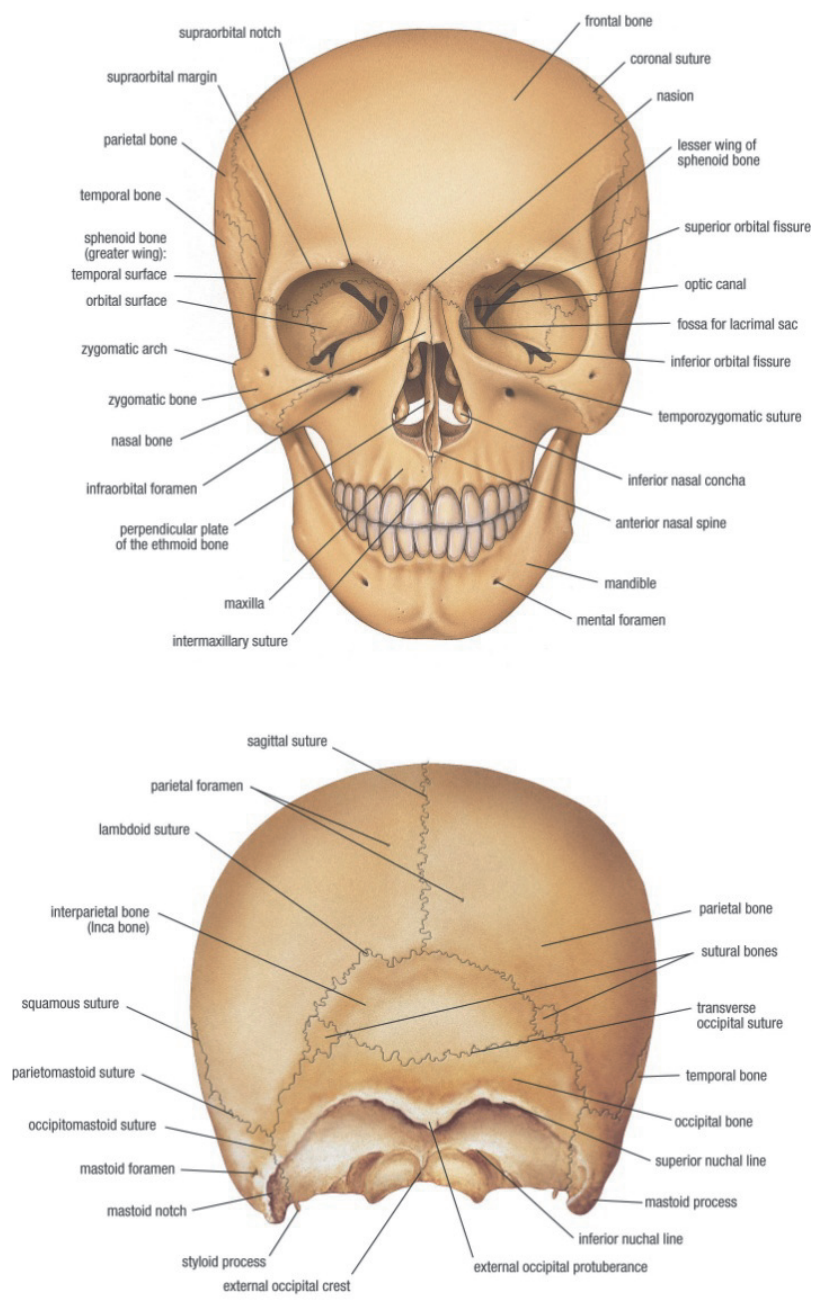

Figure 1.1 Human skull from anterior and posterior. Source: http://infothread.org. 
Except for the lower jaw (mandible) and the middle ear ossicular chain, all the other bones of the cranium are connected by sutures permitting some flexibility. The sutures are wide and open in childhood, allowing the brain to expand during growth, and close gradually in adulthood when growth is completed.

The skull gives protection to the vulnerable underlying brain. In 1943, in an article in the Lancet, it was quoted that it takes about 1 ton to reduce the diameter of the skull by $1 \mathrm{~cm}^{2}$. No reference was given within the article and the source - especially in this era - could therefore be called questionable. However, generally serving in a protective nature, the strength of the skull can sometimes be a drawback. In case of disproportional increase of the content of the skull relative to its volume, the intracranial pressure rises. This happens in case of intracranial bleeding (haemorrhage), oedema (in case of altitude sickness, metabolic disorders, concussion), an intracranial tumour or hydrocephalus. Increased intracranial pressure can lead to neurological symptoms such as headache, diminished consciousness, coma and eventually death.

Increased intracranial pressure occurs also in case of limited growth of the skull in childhood. For example, this occurs in patients with Crouzon syndrome, Apert syndrome and Pfeiffer syndrome: whereas the brain gradually increases in size, the skull sutures close too early, preventing the skull to grow further.

The last mechanism possibly causing increased intracranial pressure is when the cranial vault gradually becomes smaller as is the case in $\mathrm{HCl}$. In some other hyperostotic bone disorders the skull becomes pathologically enlarged as well leaving less space for its content (these disorders will be discussed in detail in chapter 2).

\section{Cranial nerves and cranial neuropathy}

Except for the cranial nerves, all human nerves arise from the spinal cord. There are 12 pairs of cranial nerves, all arising from the brain. The first and the second pair, olfactory and optic nerves (for the sense of smell and sight respectively), arise directly from the cerebrum, all others arise from the brainstem. The function of the cranial nerves are as follows (within the scope of the context, some minor functions are omitted):

The oculomotor (III), trochlear (IV) and abducens (VI) nerves innervate the eye muscles, the upper eye lid and the circular muscles of the iris.

The trigeminal (V) innervates the largest chewing muscle, but its major function is sensation of the facial area. It consists of three major branches, all serving different parts of the face (frontal nerve, infraorbital nerve and submandibular nerve).

The facial (NVII) nerve is the nerve that innervates most facial muscles, making smiling, blinking and knitting one's brows possible. It also receives the sense of taste from the anterior two-thirds of the tongue and provides secretory innervations to the major salivary glands (except the parotid gland) and the lacrimal glands. 
The vestibulocochlear (VIII) nerve arises as a single nerve from the brainstem, but divides into two major branches heading for their end organs within the inner ear: the vestibular nerve (balance nerve, detecting change of translation and rotation) and the cochlear nerve (hearing nerve).

The glossopharyngeal (IX) nerve transmits taste signals of the posterior one-third of the tongue, provides secretory innervation of the parotid gland and provides sensation of the tonsils, the pharynx and the middle ear, and it plays a role regulating blood pressure. The latter component of the nerve innervates the baroreceptors of the carotid sinus and chemoreceptors of the carotid body (visceral afferent information), mediating cardiovascular and respiratory reflex responses.

The vagus $(\mathrm{X})$ nerve innervates most muscles in the pharynx and the larynx, making swallowing and phonation possible. It also has an important autonomic function $(90 \%$ of the fibers is afferent): parasympathetic fibers to nearly all thoracic and many abdominal viscera.

The accessory (XI) nerve serves the sternocleidomastoid and the trapezius muscle (pure motor function).

The hypoglossal (XII) nerve innervates most muscles of the tongue.

All cranial nerves have in common that they pass a bony canal (neuroforamen) in the skull base on their course to the end organ (Table 1.1). In hyperostotic bone disorders the cranial nerves are potentially vulnerable, as they can be encroached at those locations. Much more common is cranial neuropathy (single or multiple nerves) due to infection, (autoimmune) inflammation or due to a tumour in the course of the particular nerve. Infectious causes are for example Borrelia burgdorferi, herpes zoster, varicella zoster, HIV, tuberculosis. Important inflammatory causes are sarcoidosis, Guillain-Barré syndrome and multiple sclerosis. Cholesteatoma and chronic otitis media pose the facial and vestibulocochlear nerves at risk. Tumours causing cranial nerve dysfunction can be either benign (schwannoma, glomus tumour, meningeoma) or malignant (primary tumour or metastasis) and can be originating from the nerve itself or adjacent tumours with mass effect.

The facial nerve is particularly vulnerable. It meanders through the temporal bone making two curvatures, the first and second genu ("knee"), dividing it into three parts within the temporal bone: the intralabyrinthine part (along the inner ear), the tympanic part (through the middle ear) and the mastoidal part (through the mastoid bone). In physiological circumstances it is completely covered by bone - called the Fallopian canal - starting from the exit of internal auditory canal until the stylomastoid foramen just before its intraparotid part, probably the longest neural bony canal in the body. In case of oedema due to infection or inflammation, the perineural vasculature is compromised and can cause neural dysfunction if not already caused by the pathology itself. 


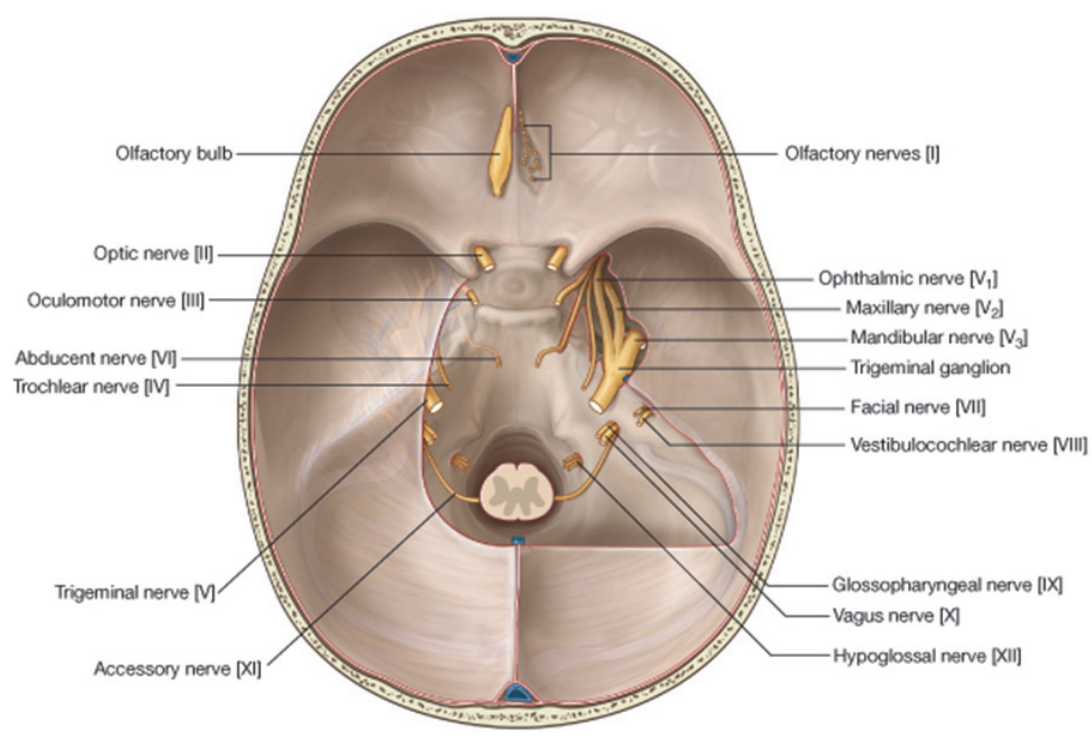

Figure 1.2 Skull base viewed from superior with all transected cranial nerves I-XII at the level of their neuroforamen. Source: Drake et al: Gray's anatomy for Students, 2nd Edition.

Table 1.1 Cranial nerves and corresponding neuroforamina.

\begin{tabular}{ll}
\hline Cranial nerve & Neuroforamen \\
\hline Olfactory & Cribriform plate \\
Optic & Optic canal \\
Oculomotor & Superior orbital fissure \\
Trochlear & Superior orbital fissure \\
Trigeminal & \\
Ophthalmic (first branch) & Superior orbital fissure \\
Maxillary (second branch) & Foramen rotundum \\
Mandibular (third branch) & Foramen ovale \\
Abducens & Superior orbital fissure \\
Vestibulocochlear & Internal auditory canal / Fallopian canal \\
Glossopharyngeal & Jugular foramen \\
Vagus & Jugular foramen \\
Accessory & Jugular foramen \\
Hypoglossus & Hypoglossal canal \\
\hline
\end{tabular}

\section{Bone homeostasis and regulation of bone remodelling}

Bone consists for $75 \%$ out of inorganic components: crystalline calcium phosphate salts (mostly hydroxyapatite (Ca)5(PO4)3OH). The other $25 \%$ are organic components: osteoblasts, osteoclasts, osteocytes, bone lining cells and osteoid (matrix consisting 
mainly of type I collagen and different other proteins ${ }^{3}$. Approximately $300 \mathrm{mg}$ of calcium from the recommended daily $1,000 \mathrm{mg}$ is absorbed in the duodenum and is storaged as hydroxyapatite. The calcium uptake is mediated by calcitriol, the active form of vitamin D.

\section{Types of bone tissue}

Macroscopically (and also on imaging) two types of bone can be differentiated: compact or cortical bone and spongious or trabecular bone (Figure 1.3). Cortical bone is dense bone without cavities or macroscopically visible pores. Spongious bone consists of trabeculae and bone marrow between the trabeculae. There is bone marrow with haematopoietic capacity (red marrow) and without haematopoietic capacity (yellow marrow, mainly fat cells between the trabuculae). The spongious bone of the calvaria (yellow marrow) is called the diploë ${ }^{4}$.
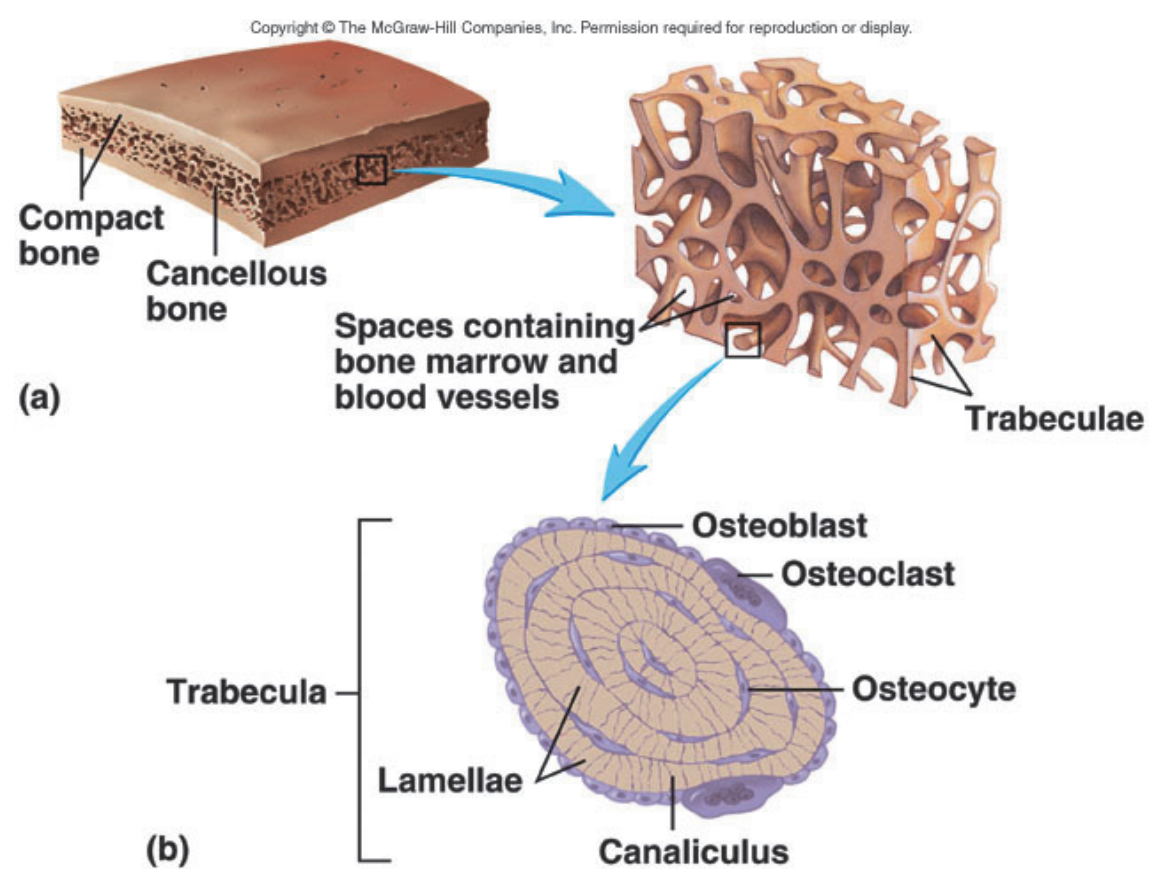

Figure 1.3 Cortical (compact) versus trabecular (cancellous) bone. 


\section{Histology and cellular structure of bone}

The "organ" bone consists of several types of cells. Osteoblasts are the bone-forming cells. These are mononucleate cells originating from osteoprogenitor cells. The latter exist in the endosteum and the periosteum, the layers of connective tissue at the inner and at the outer side of bone. Osteoblasts are arranged in rows at the surface of the bone (Figure 1.3), producing the matrix material at the endosteal side consisting of collagen type I, proteoglycans and glycoproteins: osteoid. As the amount of osteoid increases, the osteoblasts lock themselves in gradually. The matrix within the osteoid calcifies, leaving only the lacunae, the places where the osteoblasts are situated. The osteoblasts are then called osteocytes. The osteoblasts at the border eventually flatten and become inactive (Figure 1.3). The then called bone lining cells serve as barrier for certain ions. The bone lining cells can be reactivated again into active osteoblasts. Osteoblasts, as well as osteocytes and lining cells all interconnect through canaliculi. There is intercellular transport of ions and small molecules through gap junctions.

Osteoclasts are the bone-resorbing cells. They are cells originating from fusion of multiple granulocyte-marcophage progenitor cells in the bone marrow. They can be lined up against the border of bone that has to be degraded, often creating excavations where the matrix is "eaten away", called the Howship's lacunae. The bone-directed side of the cell surface of the osteoclast has a ruffled border: finger-like extensions. Within the osteoclasts there are lysosomes and secretory vesicles with collagenase and lysosomal enzymes, which can be secreted to dissolve the collagen and the calcified tissue. These phagocytic-like mechanisms are comparable to the circulating macrophages (common progenitors). Supply of bone with nutrients occurs through the many blood vessels, which are mainly situated in the aforementioned endosteum and periosteum (Volkmann's canals).

Microscopically there are two types of organisation of bone: 1. primary or woven bone and 2. secondary or lamellar bone. Primary (woven) bone has an irregular arrangement of the type I collagen fibers, has numerous osteocytes within the matrix, with a large variation of size and shape. Primary bone is more rapidly deposited (both embryologically as well as after a fracture). Secondary bone is "mature bone" characterised by the parallel orientation of collagen fibres: lamellas (Figure 1.4). The lamellas are all situated around a Haversian canal, within which lie vessels (serving the osteocytes within the concentric layers of the matrix), nerve fibers and some connective tissue. Each separate unit with these elements is called an osteon (or haversian system), depicted in Figure 1.4. An osteon is delineated by a "kit line", consisting of glycoproteins.

The presence of woven bone in the adult skeleton usually represents a pathological condition and indicates that reactive tissue has been produced in response to a form of stress in the bone. Slowly manufactured bone tends to be lamellar, whereas rapidly deposited bone is often woven. Often this finding correlates to the growth rate of a 
bone tumour or the severity of an infection as well (fast growing $\rightarrow$ woven bone, slow growing $\rightarrow$ lamellar bone) $)^{5}$.

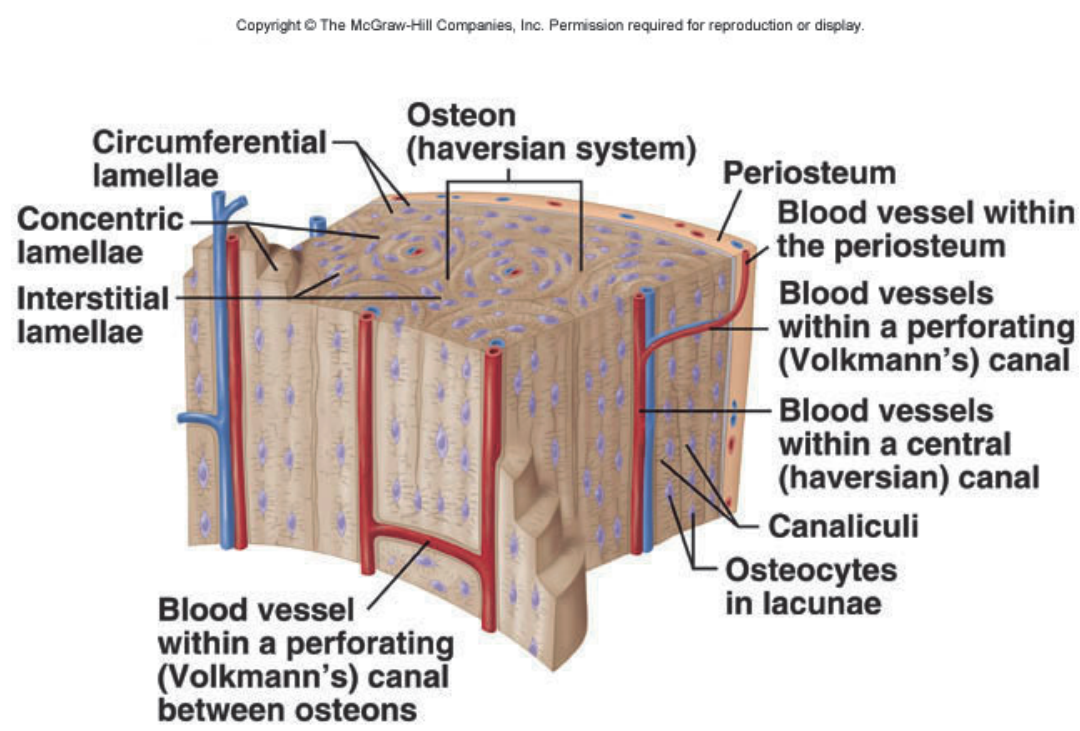

Figure 1.4 Schematic view of microscopic structure of secondary or lamellar bone.

\section{Formation of bone}

Bone can be generated in two ways: endochondral bone formation or intramembranous bone formation. In both types primary/woven bone is formed first, which is later replaced by secondary/lamellar bone. In chapter 2 this principle is applied for the bones of the skull and the mandible, illustrated with embryological images. In intramembranous bone formation bone originates directly from connective tissue, in a band shape. No cartilage is involved in this type of bone formation. The tubular bones are formed through endochondral bone formation. Endochondral ossification is the process by which the embryonic cartilaginous skeleton is replaced by bone and also the process by which most bones contribute to longitudinal growth of the body ${ }^{4}$.

\section{Bone remodelling}

Amongst others, bone remodelling takes place in response to bone stress. Twenty-five $\%$ of trabecular bone is remodelled each year in adults, whereas only $3 \%$ of cortical bone is remodelled yearly. This has important clinical implications: if a pathologic condition disturbs bone remodelling, preferentially bones with a high content of trabecular bone are affected, such as the femoral neck and the vertebral bodies. 
Remodelling is also influenced by humoural factors regulating calcium homeostasis: parathyroid hormone, vitamin $\mathrm{D}$ and calcitonin. Calcium homeostasis is carefully regulated, because small changes in concentrations can have major consequences (neurotransmitters, muscle contraction). Other hormones that indirectly influence bone integrity are glucocorticoids, thyroid hormone and gonadal steroids.

The process of remodelling takes place at the level of BMUs: basic multicellular units consisting of osteoclasts and osteoblasts. Osteoblasts are responsible for bone formation, whereas osteoclasts are responsible for bone resorption. The process begins when physical or chemical signals recruit osteoclasts, starting to excavate small cavities on the bone surface. Resorption of bone by osteoclasts occurs by enzymes like collagenase, creating an acidic micro-environment (lactic acid, carbonic acid, proton pump). This causes dissolution of the hydroxyapatite (chemical formula: $\mathrm{Ca}_{5}\left(\mathrm{PO}_{4}\right)_{3} \mathrm{OH}$ $\rightarrow 5 \mathrm{Ca}^{2+}+3 \mathrm{PO}_{4}{ }^{3-}+\mathrm{OH}^{-}$). After approximately three weeks cytokines are released from the dissolved bone matrix and begin to stimulate osteoblast proliferation, differentiation and activation. The osteoblasts eventually replace the osteoclasts in the lacunae with concentric layers: lamellae of unmineralised organic matrix (the so-called osteoid). As the cavities are filled with new osteoid, various factors essential for the process of mineralisation are secreted by the osteoblasts: alkaline phosphatase and calcium binding proteins. After mineralisation of the osteoid, osteoblasts flatten and form a layer of lining cells over the newly formed bone ${ }^{6}$. 


\section{References}

1. Manni JJ, Scaf JJ, Huygen PL, Cruysberg JR, Verhagen WI. Hyperostosis cranialis interna. A new hereditary syndrome with cranial-nerve entrapment. N Engl J Med 1990;322:450-454.

2. Holbourn A. Mechanics of head injuries. Lancet 1943;2:438-441.

3. Tashijan AH. Pharmacology of Bone Mineral Homeostasis. In: Golan DE, editor. Principles of Pharmacology: The Pathophysiologic Basis of Drug Therapy. 3rd ed. Baltimore: Lippincott Williams \& Wilkins; 2012.

4. Mescher A. Junqueira's Basic Histology. 12th ed. New York: McGraw-Hill Education; 2009.

5. Rubin E, Farber JL. Pathology. 3rd ed. Philedelphia: Lippincott - Raven; 1998.

6. Bringhurst FR. Bone and Mineral Metabolism in Health and Disease. In: Fauci AS, editor. Harrison's Principles of Internal Medicine. 17th ed. New York: McGraw-Hill; 2008. 


\section{Chapter 2}

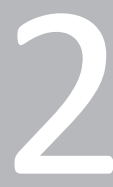

Other sclerosing bone dysplasias with craniofacial involvement

Jérôme J. Waterval

Vere M. Borra

Wim van Hul

Robert J. Stokroos

Johannes J. Manni

Bone 2013;60C:48-67 


\begin{abstract}
In this review we provide a complete overview of the existing sclerosing bone dysplasias with craniofacial involvement. Clinical presentation, disease course, the craniofacial symptoms, genetic transmission pattern and pathophysiology are discussed. There is an emphasis on radiologic features with a large collection of $\mathrm{CT}$ and MRI images. In previous reviews the craniofacial area of the sclerosing bone dysplasias was underexposed. However, craniofacial symptoms are often the first symptoms to address a physician. The embryology of the skull and skull base is explained and illustrated for a better understanding of the affected areas.
\end{abstract}




\section{Introduction}

Genetic bone dysplasias are a rare group of disorders varying in clinical presentation, severity, genetic transmission pattern and course. Differentiation and diagnosis have been facilitated by radiological and especially genetic diagnostics, but are often still extremely challenging. The craniofacial area is often involved in these disorders, leading to functional symptoms such as cranial nerve dysfunction, aesthetic problems in case of visual disfigurement and possibly life-threatening neurological symptoms in case of disturbed cerebrospinal fluid circulation or increased intracranial pressure. The goal of this paper is to review the craniofacial aspects of the sclerosing bone dysplasias to increase familiarity with both clinicians and researchers. The few papers reviewing this group of bone dysplasias only superficially discuss the craniofacial symptoms. Many papers present cases with (outdated) X-rays of the skull presenting very unspecific information such as "increased density of the skull base". We collected different craniofacial CT and MRI images of these disorders to show the radiologic characteristics of different disorders in order to facilitate diagnosis and to link pathophysiology/radiology to the clinical presentation.

\section{Normal formation and structure of the skull bones}

The skull can be roughly divided into two parts: the neurocranium and the viscerocranium. The neurocranium comprises the brain with the calvaria and skull base. The viscerocranium is the facial skeleton containing the end organs or "viscera": the eyes, the mouth and the nose. The neurocranium consists of the frontal bone (os frontale), the occipital bone (os occipitale), the ethmoid bone (os ethmoidale), the sphenoid bone (os sphenoidale), two parietal (ossa parietale) and two temporal bones (ossa temporale). The earliest ossification has been reported at as early as 8 weeks gestational age, both in the calvaria, as well as in the facial bones ${ }^{1}$. Phylogenetically, the base of the skull is one of the oldest parts of the human skeleton, the development sharing many similarities with other more primitive organisms ${ }^{2}$. The organs of the viscerocranium and the neck originate mainly from the five pairs of pharyngeal arches, each with an outer covering ectoderm, an inner covering endoderm and a core of mesenchyme (derives from mesoderm and elements of the neural crest and the somitomeres) $)^{3}$.

\subsection{Early embryology}

The embryologic origin of the facial and cranial skeleton have been extensively documented. At first, as early as in 1828, the germ-layer theory was adhered, stating that the craniofacial skeleton was of mesodermal origin ${ }^{4}$. The mixed origin of the 
mesenchyme was discovered at the end of the $19^{\text {th }}$ century when reports appeared about ectodermal involvement: mesenchymal cells in the head were believed to be derived from the ectoderm ('ectomesenchyme' or "mesectoderm") via what was later discovered (Wilhelm His 1868, chick embryos ${ }^{5}$ ) to be the neural crest ${ }^{6}$. The neural crest eventually gives rise to different cell lineages: melanocytes, smooth muscle, neurons and glia and craniofacial cartilage and bone ${ }^{7}$. The quail-chick chimaera technique introduced by Nicole Le Douarin has learned us a lot about cell migration during the development of the (avian) embryo ${ }^{8,9}$. Using this technique, (part of) a host chick's neural tube and neural crest cells are replaced with a donor quail's neural tube and neural crest cells, making it possible to investigate the developmental fate of cells within an embryo (using immunohistochemical staining). This technique confirmed that ectoderm (or better: the neural crest) is the main contributor to the embryogenesis of the vertebrate head. In 1993, the complete embryological origin of the avian skull was 'mapped' by Couly ${ }^{10}$. The frontal, parietal and squamosal bones, part of the otic capsule and the complete facial skeleton derive from the neural crest. Only the occipital bones, a major part of the otic capsules and the posterior part of the sphenoid bone are of mesoderm and somitic origin (Figure 2.1).

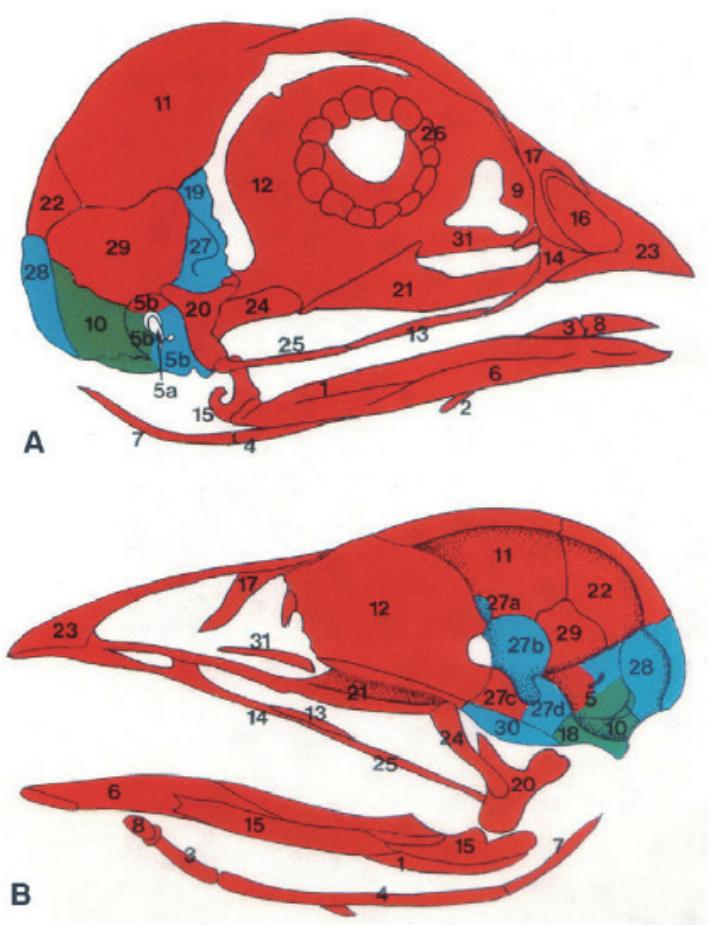

Figure 2.1 Schematic drawing of cephalic skeleton of bird (published in 1993 by Couly), republished with permission. A: Right external view. B: Right internal view. Red, skeleton of neural crest origin; blue, skeleton of cephalic mesoderm origin; green, skeleton of somitic origin ${ }^{10}$. 


\subsection{Ossification of the cranial base and the calvaria}

Eventually becoming the skull base, neural crest cells form paired cartilaginous plates as early as in the fourth week of gestational age. This is when the development of the craniofacial skeleton becomes spatially conceivable (Table 2.1, Figure 2.2). The most important cartilaginous plates are the prechordal, the hypophyseal, the lateral and the parachordal cartilages ${ }^{1}$. Endochondral ossification occurs from posterior to anterior, starting in the occipital area at 12 weeks and progresses laterally. Ossification in the orbitosphenoid and the alisphenoid (deriving from the first pharyngeal arch, vide infra section 1.3) starts at approximately 15-16 weeks forming the lesser and greater wings of the sphenoid bone respectively. The eventual derivatives of the cartilaginous centers are perfectly outlined in the study of Nemzek ${ }^{2}$. In Figure 2.3 the contrast between the two types of ossification is displayed by specifically stained foetal transections.

Table 2.1 Ossification of the anterior and posterior skull base (reprinted and modified with permission of the American Journal of Neuroradiology ${ }^{2}$ ). The origin of the major osseous structures are outlined. The different ossification centers are visualised in Figure 2.1.

\begin{tabular}{|c|c|c|}
\hline \multicolumn{3}{|l|}{ Endochondral Ossification } \\
\hline \multicolumn{3}{|l|}{ * Occipital bone } \\
\hline \multirow[t]{2}{*}{ Parachordal cartilage } & $\begin{array}{l}\text { A. Basioccipital } \\
\text { B. Exoccipital }\end{array}$ & $\begin{array}{l}\text { - Anterior clivus } \\
\text { - Anterior occipital condyle } \\
\text { - Hypoglossal canal } \\
\text { - Posterior occipital condyle } \\
\text { - Jugular tubercle }\end{array}$ \\
\hline & C. Supraoccipital & \\
\hline \multicolumn{3}{|l|}{ *Sphenoid bone } \\
\hline Hypophyseal cartilage & $\begin{array}{l}\text { A. Postsphenoid or } \\
\text { basispenoid }\end{array}$ & $\begin{array}{l}\text { - Body sphenoid (posterior to tuberculum) } \\
\text { - Posterior clivus } \\
\text { - Sella turcica } \\
\text { - Dorsum sellae }\end{array}$ \\
\hline $\begin{array}{l}\text { Prechordal cartilage } \\
\text { (anterior to notochord) }\end{array}$ & B. Presphenoid & $\begin{array}{l}\text { - Body sphenoid (anterior to tuberculum) } \\
\text { - Mesethmoid cartilage (perpendicular plate of } \\
\text { ethmoid, crista galli) }\end{array}$ \\
\hline \multirow[t]{3}{*}{ Lateral cartilage } & C. Orbitosphenoid & $\begin{array}{l}\text { - Lesser sphenoid wings } \\
\text { - Anterior clinoids } \\
\text { - Planum sphenoidale }\end{array}$ \\
\hline & D. Alisphenoid & $\begin{array}{l}\text { - Greater wing (with foramen rotundum, ovale } \\
\text { and spinosum) }\end{array}$ \\
\hline & E. Medial pterygoid & \\
\hline
\end{tabular}




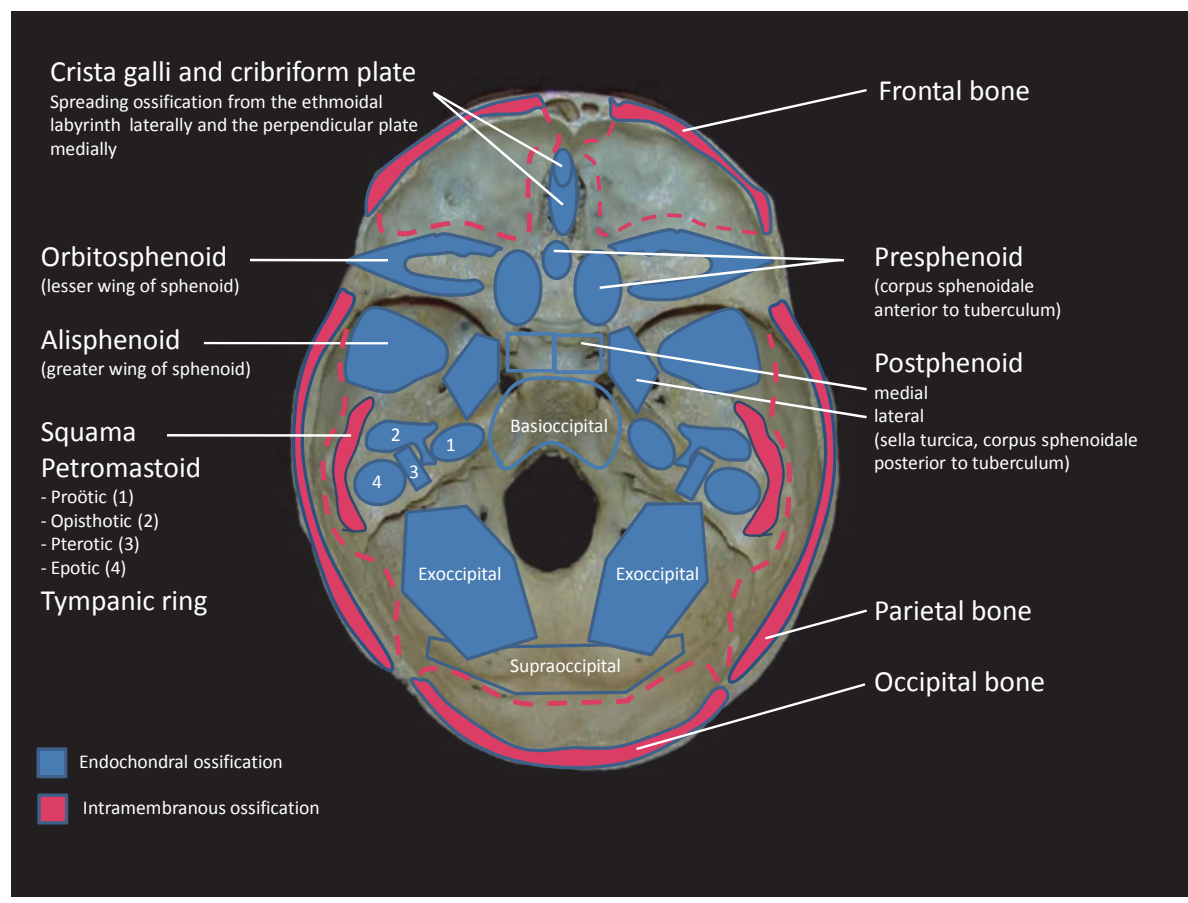

Figure 2.2 Schematic representation of calvarial and skull base ossification (reprinted and modified with permission of American Journal of Neuroradiology ${ }^{2}$. The contrast between intramembranous and endochondral is illustrated with the same colours as in Figure 2.3.

Although the ethmoid is part of the eventual anterior skull base, it is ossified within the cartilage of the nasal capsule. It is formed by three centers. There are two lateral centers that ossify first. They form what are called the labyrinths, giving rise to the ethmoidal cells, the lamina papyracea and middle turbinates (conchae media). After birth the third center starts ossifying, giving rise to the perpendicular plate (lamina perpendicularis) of the nasal septum and the crista galli (fusion takes place after approximately one year). The cribriform plate (lamina cribriformis) is ossified partly from the perpendicular plate and partly from the labyrinths.

Hardly any intramembranous ossification takes place in the skull base (only the orbital plate of the frontal bones, the lateral part of the greater wing of the sphenoid (ala major), the lateral pterygoid plate (lamina pterygoidea lateralis) and the squamous part of the occipital bone).

The squama of the occipital bone is developed in membrane, the rest is developed from cartilage. 
The parietal bone is ossified in membrane from a single center, which appears at the parietal eminence about the eighth week of foetal life. Ossification gradually extends in a radial manner from the center toward the margins of the bone.

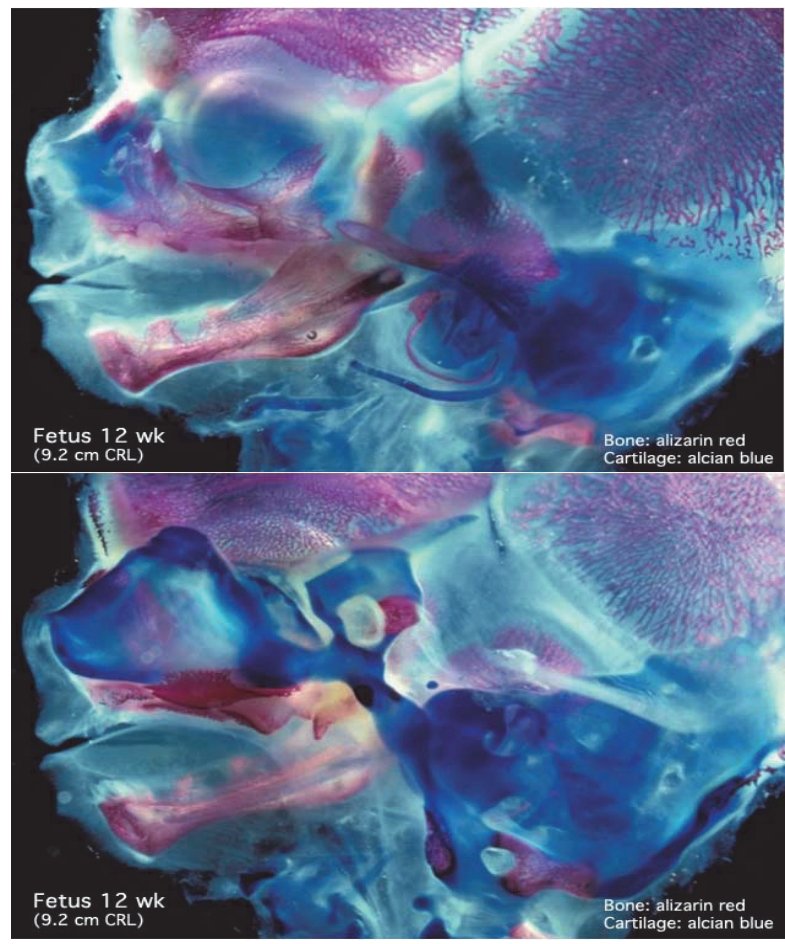

Figure 2.3 Both pictures are of the same 12-week-old human foetus head, double stained to show both cartilage (blue) and newly-formed bone (red). Both types of ossification (endochondral and intramembranous) in separate regions of the skull are displayed. In the upper - lateral (external) view, note the distribution of new bone formation by intramembranous ossification in the plates of the cranial vault, temporal bone, orbit, upper jaw (maxilla) and lower jaw (mandibula) regions. In the lower- medial (internal) view, note the distribution of cartilage from the nasal region to the base of the skull and the atlas/axis showing where endochondral ossification takes place (with new bone forming) (Reprinted with courtesy of prof. Diewert).

The frontal bone is formed through intramembranous ossification with one primary center on each side, supraorbitally. Ossification starts here at the end of the second month; it spreads cranially (calvarial bone) and internally/horizontally (orbital plate). The middle part is formed through endochondral ossification centers, one on each side of the middle line. The nasal parts and zygomatic processes form in a similar way. 
The embryology of the temporal bone (os temporale) is extremely complicated (Fig. 2.2). It is formed out of skull base ossification centers and the first and second branchial arches (ossicles, styloid part of the petrous bone). The squamous part is formed through intramembranous ossification. The two other main parts of the temporal bone are the petromastoid part and the tympanic ring. The middle ear cavity, the mastoid, the otic capsule and the petrous apex originate from four ossification centers: the proötic (roof and front of medial petrous part, part of cochlea, part of vestibule, superior semicircular canal and medial wall of tympanic cavity), the opisthotic (promontory of the cochlea, floor of the tympanic cavity and vestibule, carotid canal, lower and lateral part of the cochlea and inferior part of the medial petrous part), the pterotic (roof of tympanic cavity and antrum) and the epiotic centers (mastoid process and posterior semicircular canal). The otic capsule is the first bone to be formed in this area endochondrally, except for the modiolus of the cochlea and the spiral lamina. The otic capsule keeps its avascular structure throughout life and is not replaced by Haversian bone. Ossification of the otic capsule takes place roughly between week 16 and $23^{11-13}$. The last part of the temporal bone is the tympanic ring, which eventually encircles the tympanic membrane and later forms the bony part of the external ear canal.

\subsection{Ossification of the viscerocranium}

The first pharyngeal arch is responsible for formation of the precursors of the maxillae and the mandible: the maxillary and the mandibular prominences, containing central cartilaginous components called the palatopterygopalate bars and the Meckel's cartilages respectively. Although the abovementioned cartilages suggest that the maxilla and mandible ossify in an endochondral way, both develop in membrane. These cartilages are retained and surrounded by intramembranous bone formation covering the outer surfaces of the Meckel's cartilage. The maxillae form from two ossification centers (one for the maxilla, one for the premaxilla) ${ }^{14}$. Moreover, the maxillary cartilage forms the alisphenoid (mentioned before in section 1.2) and the incus, and the mandibular cartilage forms the malleus (endochondral) ${ }^{3}$.

The other pharyngeal arches do not contribute to the craniofacial skeleton, except for the stylomastoid processes and the stapes, both from the second pharyngeal arch.

The lacrimal bone ossifies from a single center (endochondral), as well as each nasal bone. The nasal septum initially originates as one cartilaginous plate, the ethmovomerine cartilage. The upper part ossifies into the perpendicular plate (part of the ethmoid, vide supra), two ossifying centers (one on each side) form the vomer. The palatine bone ossifies in membrane from a single center, the zygomatic bone also ossifies in membrane from three centers: one for the malar part, two for the orbital part. 


\section{Positioning of the sclerosing bone dysplasias}

In earlier days there was significant overlap between the different (craniofacial) sclerosing bone dysplasias, caused by the difficulty of differentiation. The lack of diagnostic modalities like computed tomography, molecular and genetic research contributed to this problem. This led to considerable confusion in the nomenclature and classification of this group of disorders. Initially all the sclerosing bone dysplasias were given the name osteopetroses. The first report was published as Marble bone disease in 1904 by Albers-Schönberg ${ }^{15}$. After this, numerous single cases were reported in literature, also referred to as Albers-Schönberg disease (Figure 2.4). In 1926 Karshner named this seemingly single entity osteopetrosis ${ }^{16}$. Later, this group appeared to be a very heterogeneous group of disorders. In the 1960s, a differentiation was made between "benign" (autosomal dominant) and "malignant forms" (autosomal recessive $)^{17}$. In the review of Beighton $(1977)^{18}$, the first attempt was made to differentiate different osteopetroses: 1 . Dominant and recessive forms of osteosclerosis with dominating bone sclerosis instead of changes in bone configuration (accounting both the cranium and the tubular bones), 2. Craniotubular dysplasias: abnormality of modelling of long bones associated with sclerosis of the cranium and 3. Craniotubular hyperostosis: skeletal deformity resulting from bony overgrowth.

In modern times dozens of different bone dysplasias have been described, all categorised within different subgroups, the most recent overview having been published by the International Skeletal Dysplasia Society ${ }^{19}$. In Table 2.2 an overview is given of the characteristics and features of the disorders which are discussed within this review.

June 20, the entire mandible (Fig. 2) came out through the submental opening, while dressings were being changed. Its expulsion was not followed by bleeding. Fig. 3 shows the opening six weeks later, with the tongue protruding through it.

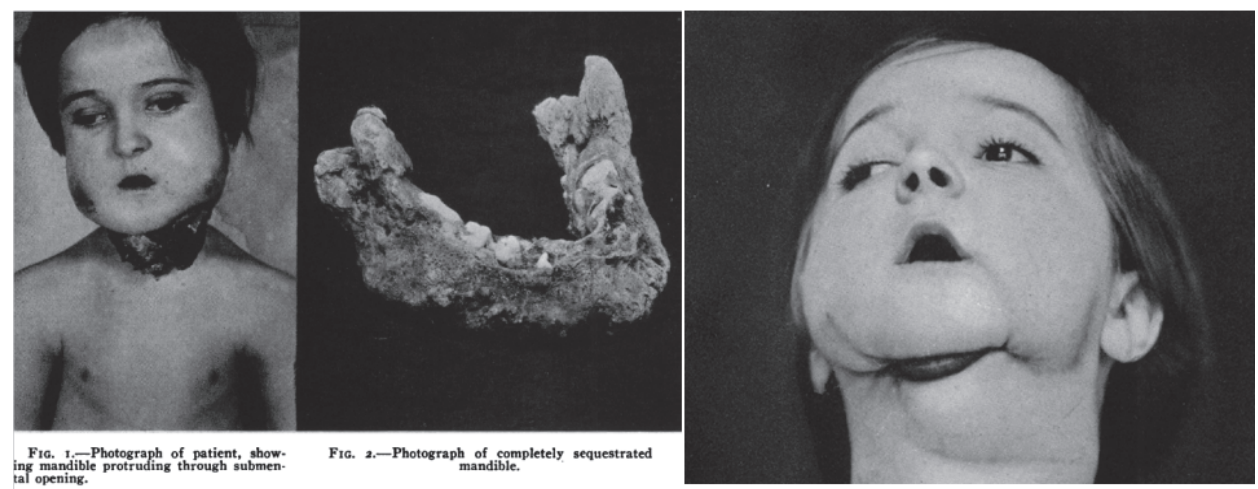

Figure 4.4 Photos of a patient with "Marble bone disease" in one of the first publications in $1934^{16}$. The original text illustrates the impotence of the physicians. 
Table 2.2 Overview of sclerosing bone dysplasias with significant craniofacial involvement.

\begin{tabular}{|c|c|c|c|c|}
\hline Disorder & $\begin{array}{l}\text { Transmission } \\
\text { pattern }\end{array}$ & $\begin{array}{l}\text { Cytogenetic } \\
\text { localisation }\end{array}$ & Gene & Protein function \\
\hline \multicolumn{5}{|l|}{ Disorders due to decreased bone resorption } \\
\hline \multicolumn{5}{|l|}{ Autosomal recessive osteopetroses } \\
\hline OPTB1: severe neonatal or infantile form & $A R$ & $11 q 13.2$ & TCIRG1 & Subunit of ATPase proton pump \\
\hline $\begin{array}{l}\text { OPTB2: intermediate form (osteoclast- } \\
\text { poor) }\end{array}$ & AR & $13 q 14.11$ & RANKL & TNF ligand superfamily \\
\hline OPTB3: with renal tubular acidosis & $A R$ & $8 q 22 / 8 q 21.1$ & CA2 & Carbonic Anhydrase 2 \\
\hline OPTB4: severe neonatal or infantile form & AR & $16 \mathrm{p} 13.3$ & CLCN7 & Chloride channel \\
\hline $\begin{array}{l}\text { OPTB5: infantile form, with nervous } \\
\text { system involvement }\end{array}$ & AR & $6 q 21$ & OSTM1 & $\begin{array}{l}\text { Osteopetrosis associated } \\
\text { transmembrane protein }\end{array}$ \\
\hline OPTB6: intermediate form & AR & $17 q 21.31$ & PLEKHM1 & $\begin{array}{l}\text { Pleckstrin homology domain- } \\
\text { containing protein }\end{array}$ \\
\hline $\begin{array}{l}\text { OPTB7: infantile form, osteoclast-poor } \\
\text { with immunoglobulin deficiency }\end{array}$ & $A R$ & $18 q 21.33$ & RANK & $\begin{array}{l}\text { Receptor activator of NF-kappa- } \\
\text { B }\end{array}$ \\
\hline OPTB8: infantile form & AR & $7 p 15.2$ & SNX10 & Sorting Nexin 10 \\
\hline \multicolumn{5}{|l|}{ Autosomal dominant osteopetroses } \\
\hline OPTA1/ADO1: late-onset form type 1 & $A D$ & $11 q 13.4$ & LRP5 & $\begin{array}{l}\text { Lowdensity lipoprotein receptor- } \\
\text { related protein } 5\end{array}$ \\
\hline $\begin{array}{l}\text { OPTA2/ADO2: late-onset form type } 2 \\
\text { (Albers-Schönberg disease) }\end{array}$ & $A D$ & $16 \mathrm{p} 13.3$ & CLCN7 & Chloride channel 7 \\
\hline Dysosteosclerosis & $A R$ & $10 q 22.1$ & SLC29A3 & $\begin{array}{l}\text { Nucleoside transporter } \\
\text { lysosomes }\end{array}$ \\
\hline Pycnodysostosis & AR & $1 q 21$ & CTSK & Cathepsin K \\
\hline \multirow[t]{2}{*}{ Craniometaphyseal dysplasia } & $A R$ or $A D$ & AR: 6q21-22 & AR: unknown & $\begin{array}{l}\text { Pyrophosphate transmembrane } \\
\text { transport, extracellular }\end{array}$ \\
\hline & & AD: $5 p .15 .2$ & AD: ANKH & inhibitor of mineralisation \\
\hline \multicolumn{5}{|l|}{ Disorders due to increased bone turnover } \\
\hline Paget's disease of bone & $A D$ & $5 q 35.3$ & SQSTM1 & Sequestosome 1 \\
\hline $\begin{array}{l}\text { Osteoectasia with hyperphosphatasia } \\
\text { (Juvenile Paget's) }\end{array}$ & AR & $8 q 24.12$ & OPG & Osteoprotegrin \\
\hline \multicolumn{5}{|l|}{ Disorders due to increased bone formation } \\
\hline $\begin{array}{l}\text { LRP5-related bone dysplasias/High bone } \\
\text { mass phenotype (including Worth disease } \\
\text { and endosteal hyperostosis) }\end{array}$ & $A D$ & $11 q 13.4$ & LRP5 & LDL receptor-related protein 5 \\
\hline Van Buchem disease & AR & $17 q 21.31$ & SOST & $\begin{array}{l}\text { Sclerostin, osteocyte-produced } \\
\text { negative regulator of bone } \\
\text { formation (inhibition of the WNT } \\
\text { pathway) }\end{array}$ \\
\hline Sclerosteosis & $A R$ & $17 q 21.31$ & SOST & Sclerostin \\
\hline $\begin{array}{l}\text { Progressive diaphyseal disease (Camurati- } \\
\text { Engelman) }\end{array}$ & $A D$ & $19 q 13$ & TGFB1 & TGF-beta-1 \\
\hline Osteopathia striata with cranial sclerosis & $X D$ & Xq11.1 & WTX & Inhibition of the WNT pathway \\
\hline Craniodiaphyseal dysplasia & $A D$ & $17 q 21.31$ & SOST & Sclerostin \\
\hline Raine syndrome & AR & $7 \mathrm{p} 22.3$ & FAM20C & $\begin{array}{l}\text { FAM } 20 \mathrm{C} \text { kinase limits bone } \\
\text { formation }\end{array}$ \\
\hline \multicolumn{5}{|l|}{ Conditions with exclusive skull involvement } \\
\hline Hyperostosis cranialis interna & $A D$ & $8 p 21$ & $?$ & $?$ \\
\hline X-linked calvarial hyperostosis & $\mathrm{XR}$ & Xq27.3-Xqter & $?$ & ? \\
\hline
\end{tabular}




\begin{tabular}{lllll}
\hline Pathogenesis & Calvaria & $\begin{array}{l}\text { Skull } \\
\text { base }\end{array}$ & $\begin{array}{l}\text { Described CN } \\
\text { involved }\end{array}$ & $\begin{array}{l}\text { Facial } \\
\text { bone }\end{array}$ \\
\end{tabular}

\begin{tabular}{|c|c|c|c|c|c|}
\hline \multirow[b]{2}{*}{$\begin{array}{l}\text { Different defective mechanisms in osteoclast } \\
\text { metabolism leading to decreased osteoclastic } \\
\text { activity (e.g. defective acidification for bone matrix } \\
\text { dissolution, defective osteoclast differentiation, } \\
\text { defective chloride transport) }\end{array}$} & \multirow{2}{*}{\multicolumn{4}{|c|}{$\begin{array}{l}\text { Calvaria, skull base and facial bones affected in all } \\
\text { types of osteopetroses to a different degree, } \\
\text { OPTB1, }-4,-5 \text { and }-8 \text { being the most severe forms } \\
\text { (mostly lethal at young age), OPTB2 and }-6 \text { the least } \\
\text { severe. Involvement of cranial nerves } 2,5,7,8,9,10 \\
\text { and } 11 \text { described }\end{array}$}} & \multirow{2}{*}{$\begin{array}{l}\text { Prenatal } \\
\text { Childhood } \\
\text { Childhood } \\
\text { Early childhood } \\
\text { Prenatal }\end{array}$} \\
\hline & & & & & \\
\hline & & & & & Early childhood \\
\hline $\begin{array}{l}\text { No longer considered as osteopetrosis as due to } \\
\text { increased bone formation }\end{array}$ & Yes & $\begin{array}{l}\text { Yes } \\
\text { (mild) }\end{array}$ & $2,5,8$ & No & Childhood \\
\hline As in AR osteopetroses & Yes (mild) & Yes & $1,2,5,7,8$ & No & Late childhood \\
\hline $\begin{array}{l}\text { Impaired lysosyme function, secondary impaired } \\
\text { osteoclast differentiation/function }\end{array}$ & $\begin{array}{l}\text { Yes, not } \\
\text { pronounced }\end{array}$ & Yes & 2,8 & Yes & Childhood \\
\hline $\begin{array}{l}\text { Decreased collagen degradation due to Cathepsin K } \\
\text { deficiency }\end{array}$ & Mild & Mild & - & Mild & Childhood \\
\hline $\begin{array}{l}\text { Defective osteoclastogenesis due to disturbed } \\
\text { pyrophosphate transmembrane transport }\end{array}$ & Yes & Yes & $2,3,4,7,8$ & Yes & Childhood \\
\hline Hyperplasia and hypertrophy of osteoclasts & Yes & Yes & 8 & Yes & $>40$ years \\
\hline Enhanced osteoclast activity & Yes & Yes & 2,8 & No & Childhood \\
\hline \multirow{3}{*}{ Due to increased WNT signalling } & Yes & Yes & 7,8 & Yes & $\begin{array}{l}\text { Generally } \\
\text { childhood }\end{array}$ \\
\hline & Yes & Yes & $1,5,7,8,12$ & Yes & First decade \\
\hline & Yes & Yes & $2,5,7,8$ & Yes & Childhood \\
\hline $\begin{array}{l}\text { Increased osteoblast activity and decreased bone } \\
\text { resorption }\end{array}$ & Yes & Yes & $1,2,5,7,8$ & No & Childhood \\
\hline $\begin{array}{l}\text { WNT pathway is a mediator in cell-cell interactions } \\
\text { during embryogenesis and tissue regeneration }\end{array}$ & Yes & $y / n$ & $2,5,6$ & Yes & Childhood \\
\hline Due to increased WNT signalling & Yes & Yes & $2,7,8$ & Yes & Birth or childhood \\
\hline $\begin{array}{l}\text { Abnormal phosphorylation of small integrin-binding } \\
\text { ligand n-linked glycoproteins }\end{array}$ & Yes & Yes & - & Yes & Birth \\
\hline Unknown & Yes & Yes & $1,2,5,7,8$ & $\begin{array}{l}\text { Exostoses } \\
\text { mandible }\end{array}$ & Childhood \\
\hline Unknown & Yes & No & - & Yes & First year \\
\hline
\end{tabular}


Table 2.2 (continued)

\begin{tabular}{|c|c|}
\hline Disorder & Craniofacial complications/facial appearance \\
\hline \multicolumn{2}{|l|}{ Disorders due to decreased bone resorption } \\
\hline \multicolumn{2}{|l|}{ Autosomal recessive osteopetroses } \\
\hline \multicolumn{2}{|l|}{ OPTB1: severe neonatal or infantile form } \\
\hline \multicolumn{2}{|l|}{ OPTB2: intermediate form (osteoclast-poor) } \\
\hline OPTB3: with renal tubular acidosis & \multirow{6}{*}{$\begin{array}{l}\text { Range of symptoms possible in different osteopetroses: frontal bossing, } \\
\text { macrocephaly, jugular foramen and intratemporal carotid canal } \\
\text { narrowing (severe cases), prognathism, dental malocclusion, intracranial } \\
\text { calcifications, hydrocephalus, mandibular osteomyelitis, hydrocephalus, } \\
\text { sleep apneas }\end{array}$} \\
\hline & \\
\hline $\begin{array}{l}\text { OPIB5: infantile form, with nervous system } \\
\text { involvement }\end{array}$ & \\
\hline OPTB6: intermediate form & \\
\hline $\begin{array}{l}\text { OPTB7: infantile form, osteoclast-poor with } \\
\text { immunoglobulin deficiency }\end{array}$ & \\
\hline OPTB8: infantile form & \\
\hline \multicolumn{2}{|l|}{ Autosomal dominant osteopetroses } \\
\hline OPTA1/ADO1: late-onset form type 1 & $\begin{array}{l}\text { Arnold Chiari (and possibly CN IX-XII dysfunction), } \uparrow \text { intracranial } \\
\text { pressure }\end{array}$ \\
\hline $\begin{array}{l}\text { OPTA2/ADO2: late-onset form type } 2 \text { (Albers- } \\
\text { Schönberg disease) }\end{array}$ & Stomatologic problems, especially osteomyelitis mandible \\
\hline Dysosteosclerosis & Frontal bossing, mid-facial hypoplasia, sleep apneas \\
\hline Pycnodysostosis & $\begin{array}{l}\text { Craniosynostosis, delayed suture closing, obtuse mandibular angle, blue } \\
\text { sclerae, dental abnormalities }\end{array}$ \\
\hline Craniometaphyseal dysplasia & $\begin{array}{l}\text { Prognathism, hypertelorism, frontonasal bossing (all due to } \\
\text { hyperostosis), hydrocephalus }\end{array}$ \\
\hline \multicolumn{2}{|l|}{ Disorders due to increased bone turnover } \\
\hline Paget's disease of bone & Middle ear pathology, jaw deformity, gingival problems \\
\hline $\begin{array}{l}\text { Osteoectasia with hyperphosphatasia (Juvenile } \\
\text { Paget's) }\end{array}$ & Macrocephaly, loss of teeth \\
\hline \multicolumn{2}{|l|}{ Disorders due to increased bone formation } \\
\hline $\begin{array}{l}\text { LRP5-related bone dysplasias/High bone mass } \\
\text { phenotype (including Worth disease and } \\
\text { endosteal hyperostosis) }\end{array}$ & Torus palatinus, mandibular hyperostosis \\
\hline Van Buchem disease & $\begin{array}{l}\text { Large mandible and skull, middle ear pathology, increased intracranial } \\
\text { pressure }\end{array}$ \\
\hline Sclerosteosis & Calvarial and mandibular overgrowth, increased intracranial pressure \\
\hline $\begin{array}{l}\text { Progressive diaphyseal disease (Camurati- } \\
\text { Engelman) }\end{array}$ & Headache \\
\hline Osteopathia striata with cranial sclerosis & $\begin{array}{l}\text { Cleft palate/Pierre Robin sequence, recurrent otitis media, } \\
\text { hypertelorism, frontal bossing, low-set ears, hydrocephalus }\end{array}$ \\
\hline Craniodiaphyseal dysplasia & $\begin{array}{l}\text { Hydrocephalus and narrowed foramen magnum, hypertelorism, torus } \\
\text { palatinus, nasolacrimal duct obstruction, choanal obstruction }\end{array}$ \\
\hline Raine syndrome & $\begin{array}{l}\text { Microcephaly, frontal bossing, proptosis, depressed nasal bridge, and } \\
\text { midface hypoplasia }\end{array}$ \\
\hline \multicolumn{2}{|l|}{ Conditions with exclusive skull involvement } \\
\hline Hyperostosis cranialis interna & Increased intracranial pressure \\
\hline X-linked calvarial hyperostosis & Lateral and frontal horns, flat nasal root, short upturned nose \\
\hline
\end{tabular}


Tendency to fracture, accounts for all AR osteopetroses

Erlenmeyer flask deformity long bones

Anaemia due to bone marrow suppression caused by hyperostosis of the cortical bone, and extramedullary haematopoiesis (secondary hepatosplenomegaly); tubular acidosis in OPTB3

Erlenmeyer flask deformity long bones

Pelvis, ribs, spine almost unaffected

Spinal endplate thickening, fractures, osteomyelitis, bone-

within-bone appearance iliac wings

Short stature, platyspondyly, metaphyseal sclerosis, diaphyseal

widening and demarcated osteosclerosis

Tendency to fracture, brachydactyly

Developmental retardation, epilepsy, red-violet skin spots

Secondary osteoporosis (AD)

Short stature, mental retardation (AR)

Involvement proximal femurs, the pelvis and lumbar spine,

None

"bowing" bones

Tendency to fracture, short stature, kyphoscoliosis, bowed extremities, diaphyseal thickening

Muscular weakness, (psycho)motoric retardation, retinal degeneration

Endosteal sclerosis of diaphyses, sclerosis pelvis

Hydrocephalus/cerebrospinal tract abnormalities, ArnoldChiari malformation

Hyperostosis clavicles, ribs, diaphyses of the tubular bones, None

Syndactyly/brachyphalangy, gigantism

Syringomyelia

Pain in extremities, diaphyseal and later on metaphyseal

Muscle weakness, pubertas tarda

hyperostosis

Metaphyseal striations tubular bones

Heart defects, retardation

Diaphyseal hyperostosis

Syringomyelia

Subperiosteal hyperostosis, chondrodysplasia punctata, sagittal Intracranial and intrarenal calcifications, multiple visceral vertebral clefting, intervertebral disc calcifications malformations

None

None

None

None 


\section{Conditions with significant involvement of the skull}

\subsection{Disorders due to decreased bone resorption}

\section{Osteopetroses}

Osteopetroses (Figure 2.5) are generalised bone dysplasias. All share features of increased bone density caused by a decreased bone resorption by osteoclasts with diffuse sclerosis of the spine and the tubular bones with metaphyseal widening. There are eight types of autosomal recessive (AR) osteopetroses (OPTB1-8) and two types of autosomal dominant osteopetroses (OPTA1 and OPTA2 or ADO 1 and ADO2). The prevalence of OPTA2 is estimated between 0.2 and $5.5 / 100,000^{20,21}$, OPTA 1 has been published about 30 times (2012), and the prevalence at birth of "malignant" autosomal recessive osteopetrosis is $0.75 / 100,000^{22}$. OPTB3, also called osteopetrosis with renal tubular acidosis, has been described 50 times. Two genetic recessive forms are clinically called intermediate osteopetroses (OPTB2 and OPTB6), which have a milder course than the other $A R$ forms of the disease ${ }^{23,24}$. The autosomal recessive subtypes are the most severe forms, often leading to stillbirth or early death. The clinical symptoms can include increased fracture rate, delayed tooth eruption, hydrocephalus, progressive neurodegeneration, pancytopenia, hepatosplenomegaly and extramedullary haematopoiesis, the last three due to displacement of bone marrow by hyperostosis ${ }^{25}$. For some AR forms, haematopoietic stem cell transplantation is the important treatment although this cannot rescue the neurodegeneration. Autosomal dominant types are milder and generally present in adulthood (Table 2.2).

In the craniofacial area there is thickening of the calvaria in all types of osteopetrosis, most distinct in malignant AR forms and OPTA1, less pronounced in OPTA2 and the intermediate AR forms. These differences were determined in a radiological study in which the patients were diagnosed clinically, not genetically ${ }^{26}$. Skull base involvement is less severe in OPTA1 compared to OPTA2. Of the cranial nerves, the optic nerve is affected most often. Optic canal stenosis is seen regularly leading to partial or complete blindness, especially in AR osteopetrosis. There is discussion whether this is caused by direct optic nerve compression or by obstruction of venous orbital outflow causing papilloedema ${ }^{27}$. In AR osteopetrosis, jugular foramen and intratemporal internal carotid artery stenosis have been described, not in the AD form. All the following symptoms can occur both in the $A R$ as well as in the $A D$ forms: not only facial palsy and (conductive) hearing loss (due to Eustachian tube encroachment), but also sensorineural hearing loss (mainly internal auditory canal narrowing). Tonsillar herniation secondary to decreased intracranial volume is common. Meningoencephalocoele has been described spontaneously in children with open fontanels, but also after decompressive craniotomies ${ }^{26}$. In our opinion after studying the numerous reports in literature, no distinction can be made between the different types of osteopetrosis on the basis of the affected cranial nerves. 

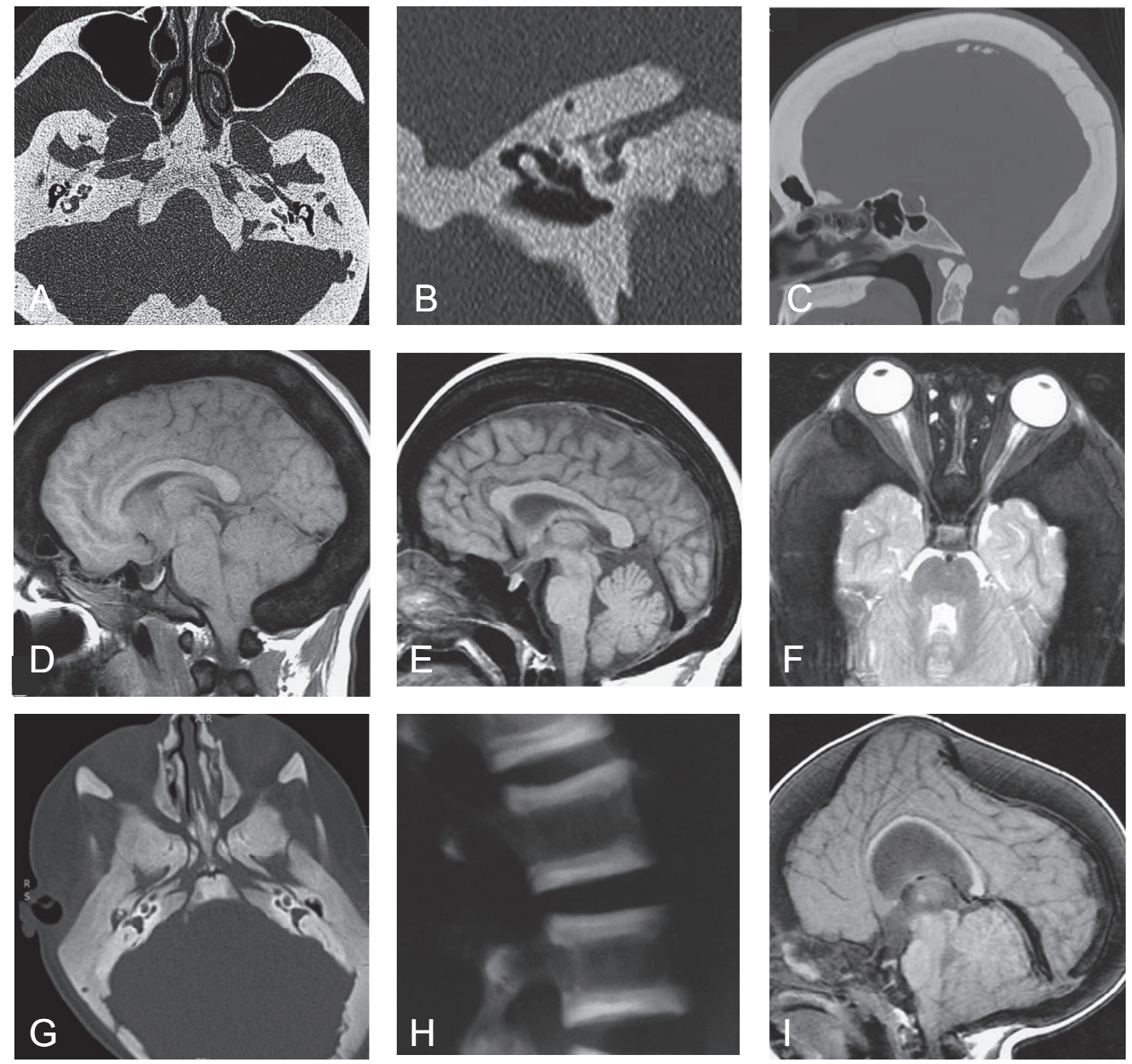

Figure 2.5 Osteopetroses. A: Axial CT of a 44-year-old lady with osteopetrosis, not stated which subtype (most probably autosomal dominant subtype). Marked thickening of the calvaria with loss of the diploë, unaffected facial bones, B: Coronal reconstruction at the level of the right temporal bone of the same patient. Normal middle ear aspect, narrowed internal auditory canal $^{142}$. C: Sagittal reconstruction of CT of a 25-year-old woman with ADO1 or intermediate autosomal dominant osteopetrosis. Note the skull base including the clivus is not affected. D: Sagittal T1weighted MRI of a patient with ADO1 shows thickening of the calvaria with cerebellar tonsillar ectopia. E: Sagittal T1-weighted MRI of a patient with ADO2 with significant more skull base involvement, compare the smaller sella turcica to E. F: Axial T2-weighted MRI image in autosomal recessive osteopetrosis shows optic canal stenosis and optic nerve atrophy ${ }^{143}$. G: Axial CT scan of 9-month-old girl with autosomal recessive osteopetrosis. There is obstructive hydrocephalus. Note the narrowed nasal cavity and the thick calvaria for the age ${ }^{144} . \mathrm{H}$ : Lateral radiograph of the spine showing a sandwich-like sclerosis of the vertebral endplates ${ }^{144}$. I: Sagittal T1-weighted image in a paediatric patient with ARO shows a spontaneous meningoencephalocoele into the anterior fontane ${ }^{143}$. 
In most types of autosomal recessive osteopetrosis there is a normal or even an increased number of osteoclasts (osteoclast-rich osteopetrosis), however the osteoclasts have an impaired capacity to acidify the extracellular compartment between the osteoclast and the bone tissue (of the primary spongiosa) ${ }^{28}$. This acidic environment is essential in the normal physiology for the dissolution of bone matrix. The underlying defect causing this problem can be loss of function mutations in carbonic anhydrase II, a subunit of the vacuolar proton pump (encoded by TCIRG1 gene) or the chloride channel CICN7 or its $\beta$-subunit OSTM $1^{29-34}$. Recently, mutations in Sorting Nexin 10 (SNX10) were found in patients with autosomal recessive osteopetrosis. SNX10 is suggested to interact with the vacuolar proton pump ${ }^{35,36}$. In addition one form of osteopetrosis was found to be due to mutations in the PLEKHM1 gene with putative involvement of vesicular transport in the osteoclast ${ }^{24}$. Two subtypes are due to abnormal osteoclast differentiation resulting in an osteoclast-poor form of osteopetrosis. Mutations were found in the genes encoding the osteoclast receptor RANK and its ligand RANKL ${ }^{28,37}$.

Two distinct radiological phenotypes of AD osteopetrosis have long been described ${ }^{38}$. Further studies characterising the two AD osteopetroses at the clinical, biochemical, histological, and biomechanical level revealed that these corresponded to two distinct disorders, OPTA1 and OPTA $2^{39}$. However unravelling the underlying molecular defects indicated that OPTA1 is rather due to an increased bone formation instead of decreased bone resorption (see below, high bone mass phenotype ${ }^{40}$ ). Therefore, technically this form can be removed from the category of osteopetroses. OPTA2 represents the classical form of Albers-Schönberg disease. It presents with a milder phenotype compared to the recessive forms but with a high variability. Also the penetrance is reduced to $60-80 \%$. The genetic defects are heterozygous missense mutations in the CLCN7 gene ${ }^{41}$.

\section{Dysosteosclerosis}

In dysosteosclerosis (Figure 2.6F), an autosomal recessive disorder, there is generalised osteosclerosis (ribs, clavicles, scapulae, mid-diaphyses) presenting in childhood, a tendency to fractures and a short stature. 17 cases have been described up to date $e^{42}$. The main craniofacial feature is skull base sclerosis. Thickness of the calvaria is normal in most cases. Blindness due to compression of the optic nerve in the optic canal is described. Often, cases are diagnosed as osteopetrosis, however patients with dysosteosclerosis generally do not have anaemia. Sensorineural hearing loss and facial nerve palsy are not reported in the children with dysosteosclerosis. There is often mental retardation and also dental problems are described (oligodontia, delayed eruption of primary teeth $)^{42,43}$. The prognosis is poor: all reported cases die in childhood; only one adult patient has been reported ${ }^{42}$. CT or MRI images of the craniofacial area are not available in the literature, but sclerosis of the mandible, maxillae, mastoids is described. 

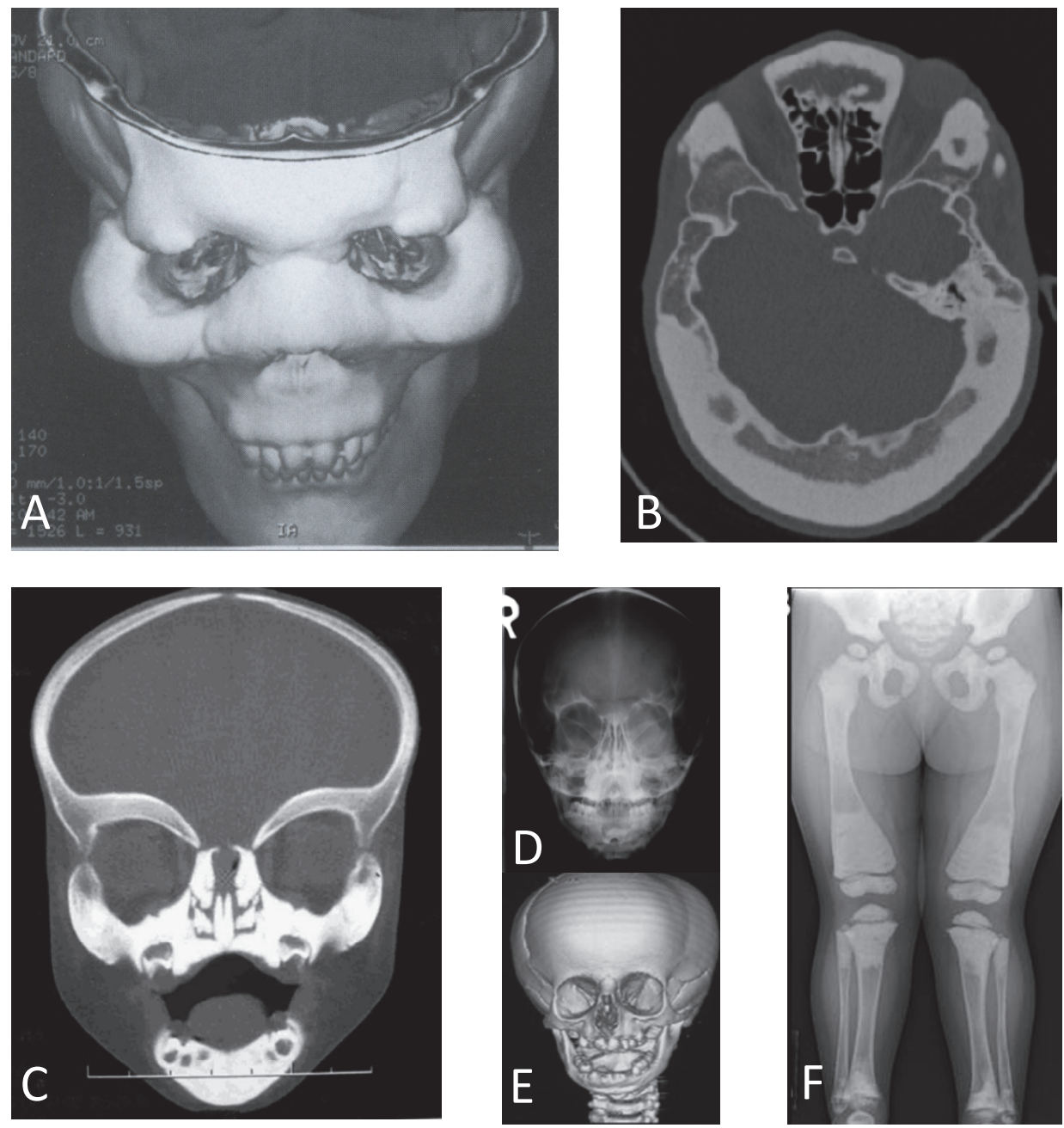

Figure 2.6 A-C: Craniometaphyseal disease. 3D-CT scan (A) showing the marked frontal, nasal and zygomatic bossing, causing facial disfigurement ${ }^{58}$. B is a preoperative scan of a patient probably with the autosomal recessive form - undergoing "skull reduction" and C illustrates the fact that nasal obstruction is one of the commonest features in this disorder ${ }^{145}$. D-E: Pycnodysostosis. D shows the dense maxilla ${ }^{47}, \mathrm{E}$ shows mandibular hypoplasia and skull dysplasia due to craniosynostosis ${ }^{146}$. F: Dysosteosclerosis. Dramatic metaphyseal expansion and osteosclerosis $^{45}$. No illustrative images of the craniofacial area could be found.

Only recently, a common gene defect in the SLC29A3 gene has been found in two cases of dysosteosclerosis ${ }^{44}$. This gene encodes a nucleoside transporter. Mutations in this gene are associated with other conditions without significant skeletal involvement: pigmented hypertrichosis with insulin-dependent diabetes (PHID) and $\mathrm{H}$ syndrome (skin 
hyperpigmentation and hypertrichosis, hepatosplenomegaly, heart anomalies, hearing loss, hypogonadism and low stature). SLC29A3 is expressed in osteoclasts. Since a reduced number of osteoclasts have been demonstrated in vivo and in vitro in patients, this protein is probably involved in osteoclast differentiation and function ${ }^{45}$.

\section{Pycnodystostosis}

Pycnodysostosis (Figure 2.6D-E) is an autosomal recessive skeletal dysplasia, first described by Maroteaux and Lamy in 1962 and also called Toulouse-Lautrec syndrome, after the French artist who was thought to be affected ${ }^{46}$. It is a rare disorder with less than 200 cases reported since 1962 . The incidence is estimated at 1.7 per one million births ${ }^{47}$. The disorder usually becomes symptomatic in childhood, often at the time of a fracture. The clinical features include short stature, increase in the bone density of long bones, pathological fractures with poor healing, stubby hands and feet with dystrophic nails, blue sclera and skull deformities with delayed suture closing, a mandible with an obtuse angle, dental abnormalities and acro-osteolysis ${ }^{46-48}$. Often there is mild calvarial and skull base osteosclerosis without obvious hyperostosis. No cranial nerve involvement has been described.

Mutations in the CTSK gene are responsible for pycnodysostosis. This gene was mapped to chromosome $1 q 21$ by genetic linkage analysis and subsequently identified as coding for Cathepsin $\mathrm{K}$ by a positional cloning strategy ${ }^{49-51}$. CTSK is critical for osteoclastmediated bone resorption and is highly expressed in osteoclasts. It is responsible for the degradation of bone matrix proteins like type I collagen, osteopontin and osteonectin. Dissolution of inorganic matrix and degradation of organic matrix occur in the extracellular lysosome under low $\mathrm{pH}$ conditions ${ }^{48}$. CTSK deficiency does not affect the function of osteoclast-mediated extracellular acidification, but the ability of osteoclasts to degrade collagen is impaired rather than the demineralisation of the extracellular matrix ${ }^{52,53}$. A total of 33 different mutations in CTSK have been reported in 59 families with pycnodysostosis, including 23 missense mutations, 4 frameshift mutations, 3 nonsense mutations, 2 splicing mutations and one termination codon mutation $^{48}$.

To date, there is no specific treatment available. Bone fractures are an important threat to patients with pycnodysostosis. It is quite important to establish a correct diagnosis as early as possible to prevent fractures and ensure a better quality of life $e^{48}$.

\section{Craniometaphyseal dysplasia}

This is one of the disorders with marked craniofacial involvement (Figure 2.6A-C). It usually becomes symptomatic in young childhood. Craniometaphyseal dysplasia (CMD) exists in an autosomal recessive and autosomal dominant form, in total seventy cases have been published ${ }^{22}$. This distinction was first made clinically by Gorlin in 1969, with the autosomal dominant form being less severe ${ }^{54}$. Nurnberg and colleagues uncovered the genetics of autosomal dominant $\mathrm{CMD}^{55,56}$. The locus for autosomal recessive $\mathrm{CMD}$ 
was mapped by lughetti in $2001^{57}$. Interestingly, in CMD the facial bones (mandible, maxilla, frontal bones) are mostly affected leading to a dysmorphic appearance. In the autosomal dominant form the craniofacial features are apparent: facial distortion and cranial nerve compression. The autosomal recessive type is characterised by an even more extensive form of sclerosis of the cranial bones. Choanal narrowing, nasal and nasolacrimal duct obstruction are often observed in both types. The skull base becomes sclerotic with marked frontonasal hyperostosis (resulting in frontal and paranasal bossing) and optic, facial and vestibulocochlear nerve involvement have been reported. Also $3^{\text {rd }}$ and $4^{\text {th }}$ cranial nerve impairment have been described ${ }^{58}$. The progression of the disease often stabilises in adult patients. Typically there is mixed or conductive hearing loss due to fixed ossicles or a fixed footplate and potentially a narrowed internal auditory canal. Often there is also hyperostosis in the middle ear cavity, causing chronic otitis media due to Eustachian tube dysfunction ${ }^{59,60}$. The long bones show flaring and abnormal modelling of the metaphyses.

In the autosomal dominant form there is a mutation in the ANKH gene (5p15.2) coding for the ankylosis (ANK) multi-pass transmembrane protein ${ }^{55}$. ANK has a function in maintaining the balance between intracellular and extracellular pyrophosphates. Pyrophosphate is a regulator of bone matrix mineralisation. Low concentrations of extracellular pyrophosphate (as hypothetised in CMD) supposedly lead to an excess of hydroxyapatite deposition, whereas high concentrations promote calcium pyrophosphate dehydrate crystal formation ${ }^{61}$. There is some evidence that there is explicit osteoclast dysfunction or reduced osteoclastogenesis in $\mathrm{CMD}^{62,63}$. The recessive form of CMD was mapped to chromosome $6 q 21-22$, however the responsible gene has not yet been discovered ${ }^{57,64}$.

\subsection{Disorders due to increased bone turnover}

\section{Paget's disease of bone}

Among the sclerosing bone disorders, Paget's disease of bone (PDB, osteitis deformans or better osteodystrophia deformans, Figure 2.7A-E) is the commonest of all, with an incidence of more than $2 \%$ in the elderly within affected populations ${ }^{65}$. Onset before the age of 40 is very rare. It is primarily an osteoclast disease. The disease is characterised by focal regions of increased bone remodelling, with abnormalities in all phases of the remodelling process. The pathogenesis is not yet completely understood, but is multifactorial with genetic, nongenetic and environmental factors playing a role ${ }^{66}$. One gene has been identified being the Sequestosome 1 (SQSTM1) gene with a mutation found in $2.5-10 \%$ of the sporadic cases and $40-50 \%$ of the patients with familial history ${ }^{67}$. Furthermore genetic association studies revealed the presence of several susceptibility loci. The most common skeletal sites of Paget's disease are: proximal part of femurs, pelvis and lumbar spine. The disease is asymptomatic in most cases, but can lead to bone pain, deformities, pathological fractures or neurological 
deficits ${ }^{66}$. The inheritance appears to be autosomal dominant with variable penetrance in some families. There are also some indications that there is a role for viral aetiology ${ }^{68}$. Histologically, an increased number of enlarged osteoclasts can be seen with too many intracellular nucleoli and typical intranuclear inclusions that are similar to nucleocapsids of paramyxoviruses ${ }^{68}$. In the early stage there is excessive bone resorption. Radiologically, this can be recognised as osteolytic lesions. Subsequently, new bone is deposited by osteoblasts, often sclerotic and poor of quality, potentially causing the symptoms. This is recognised on CT imaging as cotton wool appearance of the involved bone caused by the replacement of normal marrow with disorganised bone of low mineral density.

The skull is involved in approximately $70 \%$ of cases of Paget's disease. Involvement of the mandible or maxillary bones may result in jaw deformity, malocclusion, and periodontal disease. Often there is frontal bossing. Hearing loss is common in Paget's patients with affected temporal bones. Patients often have mixed hearing loss with high-frequency sensorineural hearing loss and a (low-frequency) air-bone gap ${ }^{69}$. Tinnitus is often reported as well. Histopathological studies have demonstrated microfractures within the otic capsule $e^{70}$. Other plausible causes of sensorineural hearing loss and vestibular impairment are involvement of the endosteal layer of the otic capsule, leakage of toxic substances into the endolymph (such as lysosymes) or possibly endolymphatic hydrops due to blockage of the cochlear and endolymphatic duct due to hyperostosis. The aetiology of the conductive hearing loss is debated. Because usually the ossicles are not affected, the conductive hearing loss could be caused by stapedial fixation. Third window laesions due to the microfractures could also contribute to conductive hearing loss (and on the same time lead to supranormal bone conduction thresholds) ${ }^{71}$. Facial nerve palsy has not been reported in Paget's disease but it is plausible that any cranial nerve can be affected when it is damaged by a Pagetic bone laesion.

Paget's disease is generally treated medically with bisphosphonates (or salmon calcitonin). Hearing is reported to stabilise after treatment ${ }^{72}$.

\section{Juvenile Paget's disease}

Hyperphosphatasia with osteoectasia, juvenile Paget's disease or chronic idiopathic hyperphosphatasemia is an autosomal recessive disorder with macrocephaly, elevated serum alkaline phosphatase and most have a short stature (Figure 2.7F-J). It was first described in $1956^{73}$ and approximately 50 cases have been described in the literature ${ }^{22}$. There is pronounced involvement of the tubular bones (widening of the diaphyses and bowing) and the vertebrae, having an osteoporotic demineralised aspect with tendency to fracture. There is a wide range of clinical severity, classified as severe (onset first 18 months), intermediate (onset after 2 years) or mild, correlating with the type of mutation $^{74}$. Affected children often display failure to thrive, progressive loss of muscular strength with delayed walking (mild/intermediate) or failure to walk (severe). 
There is calvarial hyperostosis (with a wide diploic space) and skull base thickening. Deafness is reported (even at the age of 2), both conductive (middle ear hyperostosis) as well as sensorineural (internal auditory canal encroachment) nature has been mentioned $^{75,76}$. Extensive sinonasal involvement has also been described ${ }^{77}$.
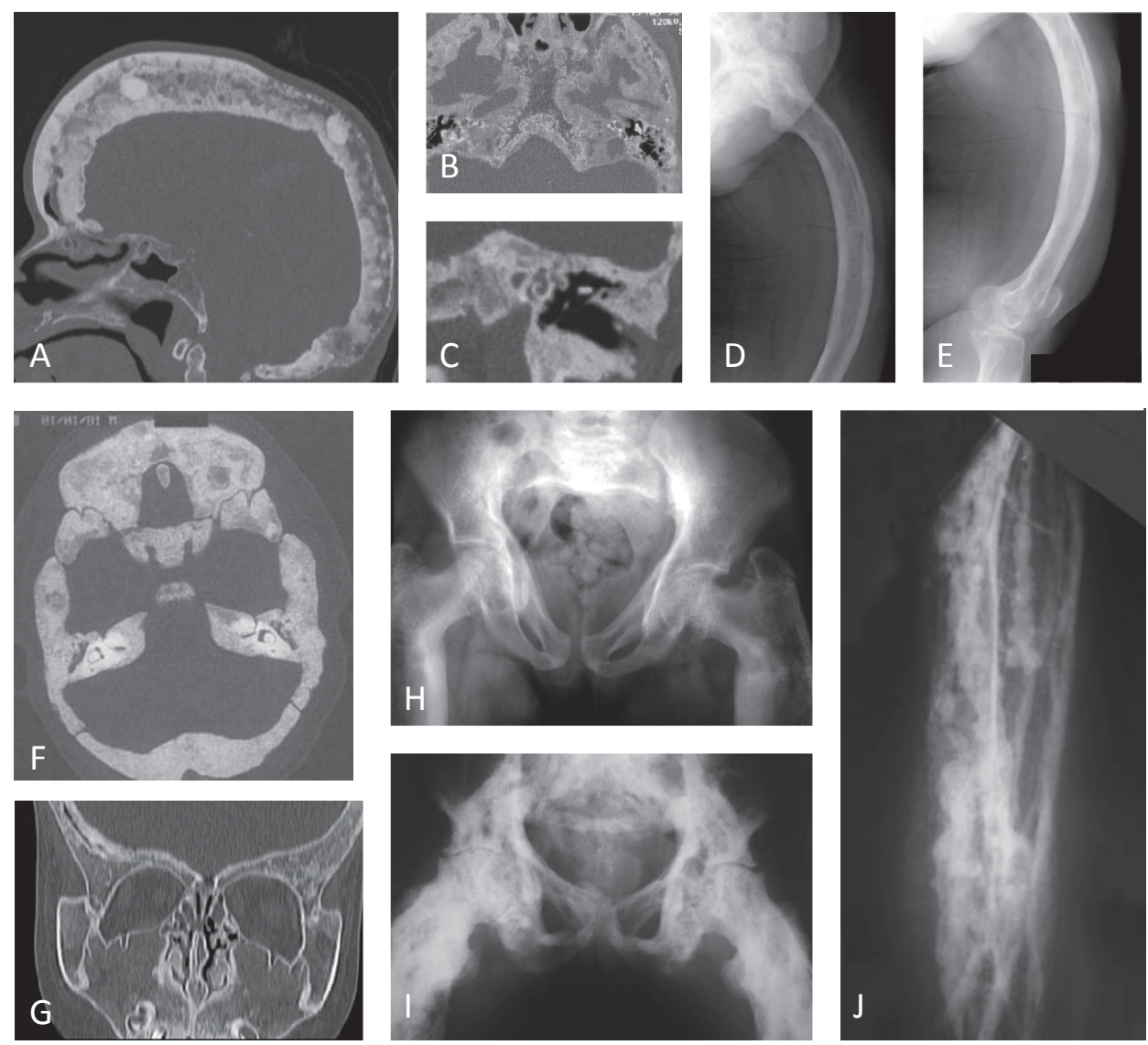

Figure 2.7 Disorders with increased bone turnover. A-E: Paget's disease of bone. A: Sagittal CT reconstruction. Frontal bossing and the so-called cotton wool aspect of bone. B: Axial CT image at the level of the skull base showing gross osteolytic laesions especially at the level of the clivus. The middle ear area is spared, the inner ears are involved ${ }^{147}$. C: Coronal reconstruction in the same patient with a severely damaged inner ear ${ }^{148}$. D and E: Frontal and lateral femur radiographs of an 81-year-old patient. Typical bowing and thickening of the cortices. F-J: Osteoectasia with hyperphosphatasia (Juvenile Paget's). F: Axial CT of 17-year-old man with severe generalised skull base hyperostosis ${ }^{76}$. G: Coronal CT image of a 25-month-old. Severe hyperostosis of the maxillar bones and the turbinates ${ }^{77}$. H: Pelvic AP radiograph (age 10 years) showing markedly widened femoral diaphyses, with thickening of the medial cortex ${ }^{149}$. I: Radiograph of the pelvis of a 45-year-old man showing extreme radiodensity with coarsening of the trabeculae. There is severe osteoarthritis of the hips. J: Same patient as F, AP radiograph of the tibia. The entire shaft is expanded (due to medullary expansion) and there are broad longitudinal radiodense striations ${ }^{150}$. 
Juvenile Paget's patients have a mutation in the TNFRSF11B gene which encodes osteoprotegerin (OPG), a member of the superfamily of tumour necrosis factor receptors. This receptor plays an important role in balancing the bone turnover. OPG belongs to the important OPG/RANK-L/RANK system that regulates osteoclastogenesis $^{78}$. OPG deficiency in juvenile Paget's disease causes a negative feedback mechanism in bone turnover to fall away, leading to an increased bone turnover. Histologically there are increased numbers of osteoclasts and osteoblasts. Oral calcitonin and bisphosphonates are reported to be effective medical treatments. These inhibit bone resorption and increases bone mineral content ${ }^{79}$.

\subsection{Disorders due to increased bone formation}

\section{High-bone-mass phenotype}

A spectrum of different disorders with similar phenotypes have recently been proposed to be categorised as high-bone-mass phenotype on the basis of their common pathophysiologic pathway: Worth disease, endosteal hyperostosis, autosomal dominant osteosclerosis, autosomal dominant osteopetrosis type I (see also section osteopetroses). Together, less than ten families have been described. The phenotype is similar in all patients and is characterised by dense bones and cortical hyperostosis, mainly affecting the skull and tubular bones. Further clinical findings range from asymptomatic to square jaw and torus laesions of the mandible ${ }^{80}$. However clinical knowledge on these disorders is limited, except for autosomal dominant osteopetrosis type I which is now not considered a type of osteopetrosis anymore ${ }^{40}$. The interest in these disorders is mainly in the genetic and biomedical field, because the responsible gene could possibly play an important role in the treatment of osteoporosis. Contemporary radiological images (other than ADO1) are not available. All disorders are caused by gain-of-function mutations in the first $\beta$-propeller domain of the LDLreceptor related protein 5 (LRP5), situated in the extracellular part of the protein ${ }^{81}$. The importance of LRP5 for bone density was initially uncovered by genetic analyses of patients with extreme bone phenotypes, like the osteoporosis pseudoglioma syndrome, an autosomal recessive disease of low bone mass ${ }^{82}$, and the high-bone-mass trait ${ }^{83,84}$. Subsequent experiments revealed that LRP5 is required for efficient Wnt signaling and $\beta$-catenin activation in osteoblasts ${ }^{85}$. Gain of function mutations in LRP5 disrupt the binding capacity to the extracellular inhibitors DKK1 or SOST, thus increasing bone formation. The finding that both activating and loss-of-function mutations in LRP5 have a severe effect on bone density indicate the importance of the $\mathrm{Wnt} / \beta$-catenin pathway in bone homeostasis ${ }^{81}$. 


\section{Van Buchem disease and sclerosteosis}

Van Buchem disease (Figure 2.8A-F) was formerly known as hyperostosis corticalis generalisata familiaris and was first described by Van Buchem ${ }^{86,87}$. It is most prevalent in an isolated population in the Netherlands (less than 50 patients described). The disease is characterised by periosteal hyperostosis which is clinically most evident in the skull and skull base, the mandible, the clavicles, the ribs and the diaphysis of the tubular bones. It is an autosomal recessive disorder that usually becomes symptomatic in the first decade of life. Facial and vestibulocochlear nerve deficits occur in almost all patients. Middle ear pathology due to Eustachian tube dysfunction is reported. The disease progresses during the entire life, also leading to increased intracranial pressure in some, olfactory dysfunction, trigeminal neuropathy and papilloedema ${ }^{88-90}$.

Sclerosteosis is a similar, usually even more severe, autosomal recessive craniotubular hyperostotic dysplasia ${ }^{91}$. The disease is mostly seen in the Afrikaner population in South-Africa (less than 100 cases), the first series being described in 1976 and $1979^{92,93}$. Clinically, patients present with headaches, gigantism and facial dysmorphisms, including mandible overgrowth and proptosis. Calvaria and skull base hyperostosis cause increased intracranial pressure and cranial nerve entrapment of mainly facial and vestibulocochlear nerves (again, also middle ear pathology due to Eustachian tube dysfunction). Stapes fixation, round window obliteration and malleus ankylation due to adjacent middle ear hyperostosis have been documented ${ }^{94}$. Furthermore syndactyly and brachyphalangy are seen in the majority of patients. Decompressive craniotomy/craniectomy is often necessary (second decade) due to raised intracranial pressure: in case of increased intracranial pressure first supratentorial decompression should be performed before posterior fossa decompression, in order to avoid downward pressure of the brain and secondary brainstem herniation ${ }^{95}$. This is the same reason why lumbar punction should never be performed in these patients with increased intracranial pressure.

In both disorders, typically there is a dense aspect of the hyperostosis, there is loss of the diploë. Eventually this results in a homogeneously thickened skull. The mastoids and possibly the sinuses become sclerotic.

In the 1970s and 1980s several articles about sclerosteosis and Van Buchem disease were published, both regarded as "craniotubular hyperostosis". In 1984, Beighton et al. described the main clinical similarities and differences between these two disorders. They concluded that "it is tempting to postulate that sclerosteosis and Van Buchem disease are the same disorder, and that their separation is an artificial concept based upon clinical differences which are really reflections of varying expression of the same abnormal genotype ${ }^{\prime \prime 6}$. Indeed, in 1998 the candidate region of the genetic defect for Van Buchem disease was localised: $17 q 12-q 21^{97}$. In 1999, Balemans et al. confirmed that the candidate region for the sclerosteosis overlaps the Van Buchem-region ${ }^{98}$. In 2001 , the SOST gene encoding sclerostin was identified and loss of function mutation was demonstrated in sclerosteosis ${ }^{99}$. In Van Buchem disease, the mutation is a $52 \mathrm{~Kb}$ 
deletion downstream of the SOST gene, which causes a down-regulation of the SOST gene $^{100}$. Sclerostin is a cystine knot-containing protein secreted by osteocytes ${ }^{101}$. It can bind to the co-receptor LRP5/6 preventing the formation of the LRP-Fz-wnt complex and thus inhibiting the induction of Wnt-signalling. In both sclerosteosis and Van Buchem disease this impaired inhibitory feedback mechanism results in increased bone formation.

\section{Camurati-Engelmann disease}

In Camurati-Engelmann disease (also called progressive diaphyseal dysplasia) the osteoclast resorption and the osteoblastic bone formation are both disturbed (Figure 2.8G-J). It is an autosomal dominant condition (about 200 cases described $^{22}$ ), in which hyperostosis usually starts at the diaphyses of the femora and tibiae. Later on, it progresses to the fibulae and also the upper extremities. Typically the epiphyses are spared. The metaphyses may become affected in a later stage ${ }^{102}$. Muscle weakness, muscle wasting and limb pain are the most prominent symptoms ${ }^{103}$. The first symptoms occur usually in childhood.

Skull base and calvarial involvement are both present in severe cases (over 50\%) and an excellent overview has been given by Carlson and colleagues in a retrospective study of as much as 306 patients ${ }^{104}$. Cranial neuropathy of the olfactory, optic, trigeminal and facial nerves are described, however are present in less than $5 \%$ of the patients. Hearing loss, whether conductive, mixed or sensorineural of nature is more frequent (19\% in total). Chronic headache is reported in over $10 \%$. Radiographically the skull bones look more heterogeneous and ribbed than in Van Buchem disease and sclerosteosis. The diploë is also disappeared. There is no involvement of the facial bones, except mandibular exostoses can be present.

The molecular basis of Camurati-Engelmann disease is a mutation in the TGFB1 gene encoding the transforming growth factor $\beta 1$ molecule. TGF- $\beta 1$ normally stimulates bone formation at the periosteal side (of the diaphyses of the long bones) by osteoblasts and suppresses bone resorption by osteoclasts at the endosteal side ${ }^{105}$. Most of the known mutations are thought to negatively affect the capacity of the socalled latency associated peptide to keep the mature TGF- $\beta 1$ inactive ${ }^{106}$. This causes premature or facilitated activation of the mature peptide. The balance between bone formation and resorption is disturbed, causing an increase in bone formation. The phenotype of Camurati-Engelmann disease, especially obliteration of the medulla, is in line with this pathogenesis. 

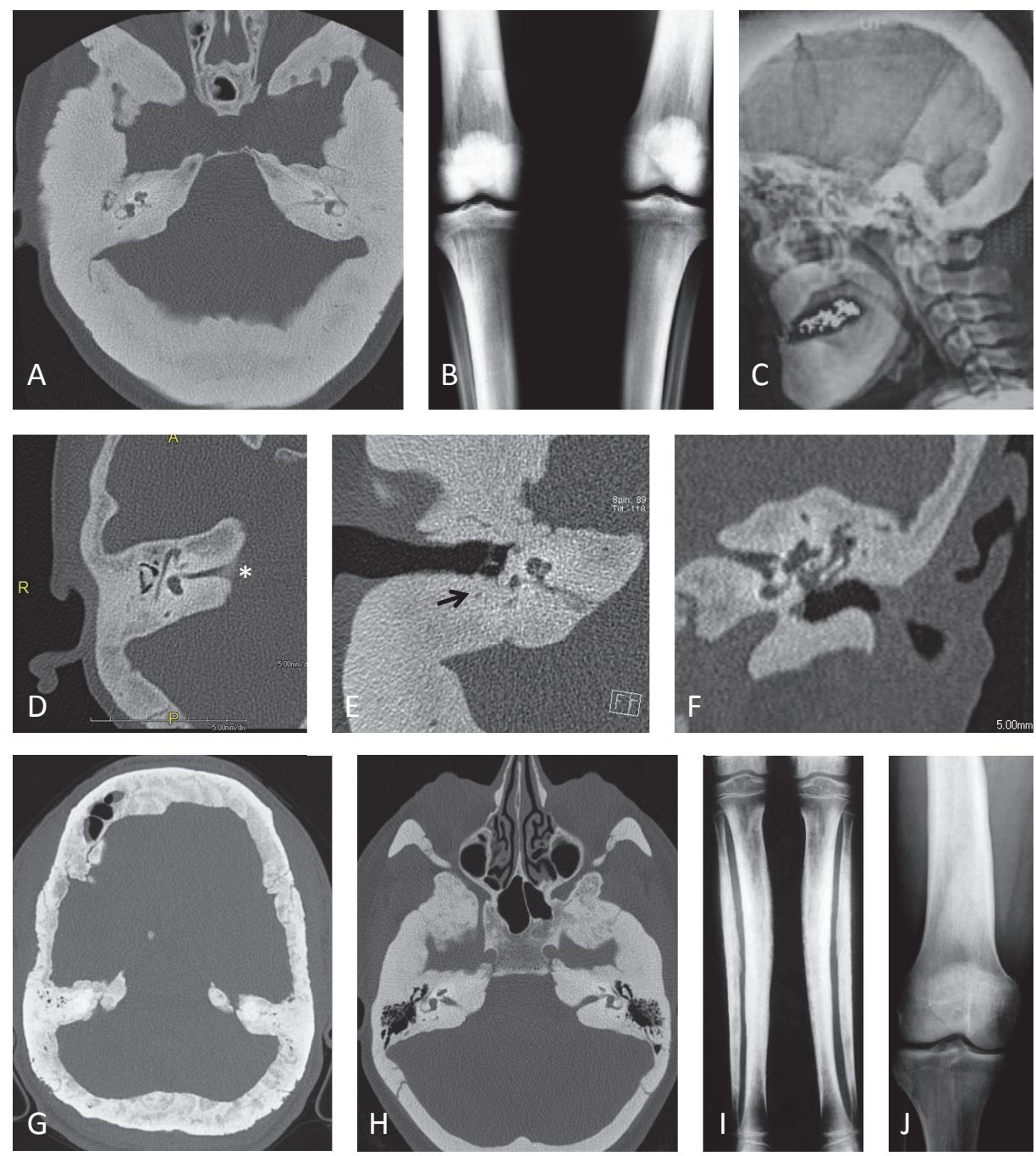

Figure 2.8 Disorders with increased bone formation (1). A-F: Van Buchem Disease. A: Axial CT scan of a 43-year-old man with multiple cranial nerve palsies, obvious loss of the diploë. B: AP Radiograph showing cortical thickening with narrowing of the medullary cavity, especially at the diaphyses. There are vertical striations are at the diaphyses and metaphysis of the long bones, comparable to osteopathia striata ${ }^{97}$. C: Lateral X-ray of an adult patient with typical mandibular hyperostosis. D: Axial CT of right temporal bone of an 8-year-old patient with facial nerve palsy. The middle ear and the internal auditory canal $\left({ }^{*}\right)$ are extremely narrowed. E: Axial CT of right temporal bone, same patient as A. Vertical part of the facial nerve is hardly visible (arrow). Contralateral temporal bone of $\mathrm{D}$, coronal reconstruction, with middle ear inflammation due to Eustachian tube encroachment. G-J: Camurati-Engelmann Disease. G: Axial CT of an adult patient. There is a more heterogeneous aspect of the bone. Loss of the diploë. H: Axial CT scan at the level of the skull base. The mastoid and the middle ears are still aerated. The facial bones are spared. I: AP radiograph showing cortical thickening and a severe modelling defect at the diaphysis of both tibiae and fibulae. J: AP radiograph of a right femur, sparing of the metaphysis and epiphysis ${ }^{103}$. 


\section{Osteopathia striata with cranial sclerosis}

The name osteopathia striata with cranial sclerosis (OSCS) refers to the typical radiodense longitudinal striations at the metaphyseal regions of the tubular bones on X-ray, first described in 1924 (Figure 2.9E-H). It is an X-linked dominant disorder and also called Voorhoeve syndrome, approximately 100 cases have been described ${ }^{22}$. The striations are usually observed between five months and six years after birth, the hyperostotic skull base is often present at birth ${ }^{107}$. The severity of the disease is very heterogeneous. Most of the affected individuals are symptomatic due to the "cranial stenosis": craniofacial hyperostosis leading to dysmorphic features (enlarged nasal bridge with hypertelorism and palatal abnormalities), nasal obstruction, cranial neuropathies due to nerve encroachment by bone overgrowth, and macrocephaly are often present. Rare findings are Pierre Robin sequence, laryngotracheomalacia, holoprosencephaly, and hypoplasia of the corpus callosum. Heart defects, scoliosis, rib, and vertebral anomalies may also be present. Radiologically the striations are obvious in the tubular bones, but have also been described in the mandible and the maxilla ${ }^{108}$. Conductive hearing loss usually occurs due to Eustachian tube encroachment with consecutive tympanic membrane atelectasis, and ossicular chain fixation ${ }^{109,110}$. No internal auditory canal abnormalities or inner ear abnormalities have been reported, although multiple publications report on mixed or sensorineural hearing loss ${ }^{111-114}$. None of the articles reporting on sensorineural hearing loss provide high-quality images proving disease-related cochlear or neural impairment, or originate from an era when CT scans were not yet available. To our knowledge, sensorineural hearing loss originates from chronic (disease-related) middle ear inflammation until otherwise proven. Trigeminal (maxillary branch) and oculomotor nerve deficits have been described $^{114}$.

The abnormalities are due to increased osteoblast activity, caused by a mutation in the gene encoding for the WTX protein. WTX is an inhibitor of the canonical WNT signaling pathway, which plays an important role as mediator in cell-cell interactions during embryogenesis and tissue regeneration ${ }^{108,115}$. WTX promotes $\beta$-catenin degradation. On the other hand, upon WNT stimulation, it may act as a scaffold protein promoting LRP6 phosphorylation and thus activating WNT signaling ${ }^{116}$. WTX has been found mutated in several types of cancer, such as Wilms tumor, acute myeloid leukemia or colorectal cancer. However, these are somatic mutations. Germline mutations or mosaicism in OSCS patients do not seem to predispose to tumour genesis ${ }^{108,117,118}$.

\section{Craniodiaphyseal dysplasia}

Craniodiaphyseal dysplasia (CDD, Figure 2.9A-D) is a severe autosomal dominant disorder that presents in early childhood with a combination of neurological symptoms due to cranial abnormalities and diaphyseal tubular bone sclerosis and hyperostosis. Less than 20 cases have been described. Therapeutic options are only symptomatic and 
most patients die in childhood. Neurological symptoms are secondary to massive diffuse hyperostosis of the calvaria and the skull base: CSF circulation can be severely impaired due to a small foramen magnum, leading to hydrocephalus and syringomyelia. Brain stem compression as well as cranial nerve compression $\left(2^{\text {nd }}, 7^{\text {th }}\right.$ and $\left.8^{\text {th }}\right)$ can occur $^{119}$. Non-neurological craniofacial manifestations are choanal obstruction, obstruction of the nasolacrimal ducts and mandibular overgrowth. Hypertelorism is characteristic, torus palatinus has also been described ${ }^{120}$. The long bones show hyperostosis and sclerosis of the diaphyses.

Only recently, craniodiaphyseal dysplasia has also been linked to the SOST gene. Mutations were found in two separate CDD cases, both at the same location, in the secretion signal of the SOST gene. It was demonstrated that these mutations prevent secretion of sclerostin, however the exact pathogenesis is not yet understood ${ }^{121}$. In CDD the hyperostosis of the facial bones is much more prominent than in Van Buchem disease and sclerosteosis. The facial aspect is referred to as "leontiasis ossea" (lion-like appearance).

\section{Raine syndrome}

Lethal osteosclerotic bone dysplasia or Raine syndrome is characterised by generalised diffuse osteosclerosis, characteristic facial dysmorphism and brain abnormalities including intracerebral calcifications. Not more than 20 reports are available and the disease is symptomatic and also generally lethal at birth or soon thereafter. There is a generalised increase in the density of all bones and a marked increase in the ossification of the skull, leading to a typical phenotype: a narrow and prominent forehead, proptosis, depressed nasal bridge, and midface hypoplasia. Bilateral choanal obstruction is described ${ }^{122}$. Periosteal bone formation is characteristic for this disorder. It appears to be inherited in an autosomal recessive fashion ${ }^{123,124}$.

Raine syndrome is caused by mutations in FAM20C, which encodes a Golgi-localised protein kinase. FAM20C kinase activity is essential for limiting bone formation in humans. Members of the Small Integrin Binding Ligand $\mathrm{N}$ linked Glycoproteins (SIBLING) protein family can modulate biomineralisation. Their ability to do so is based on their phosphorylation status and they can be phosphorylated by FAM20C. The increased bone density of Raine syndrome patients could be accounted for by decreased phosphorylation of SIBLING proteins ${ }^{125}$. 

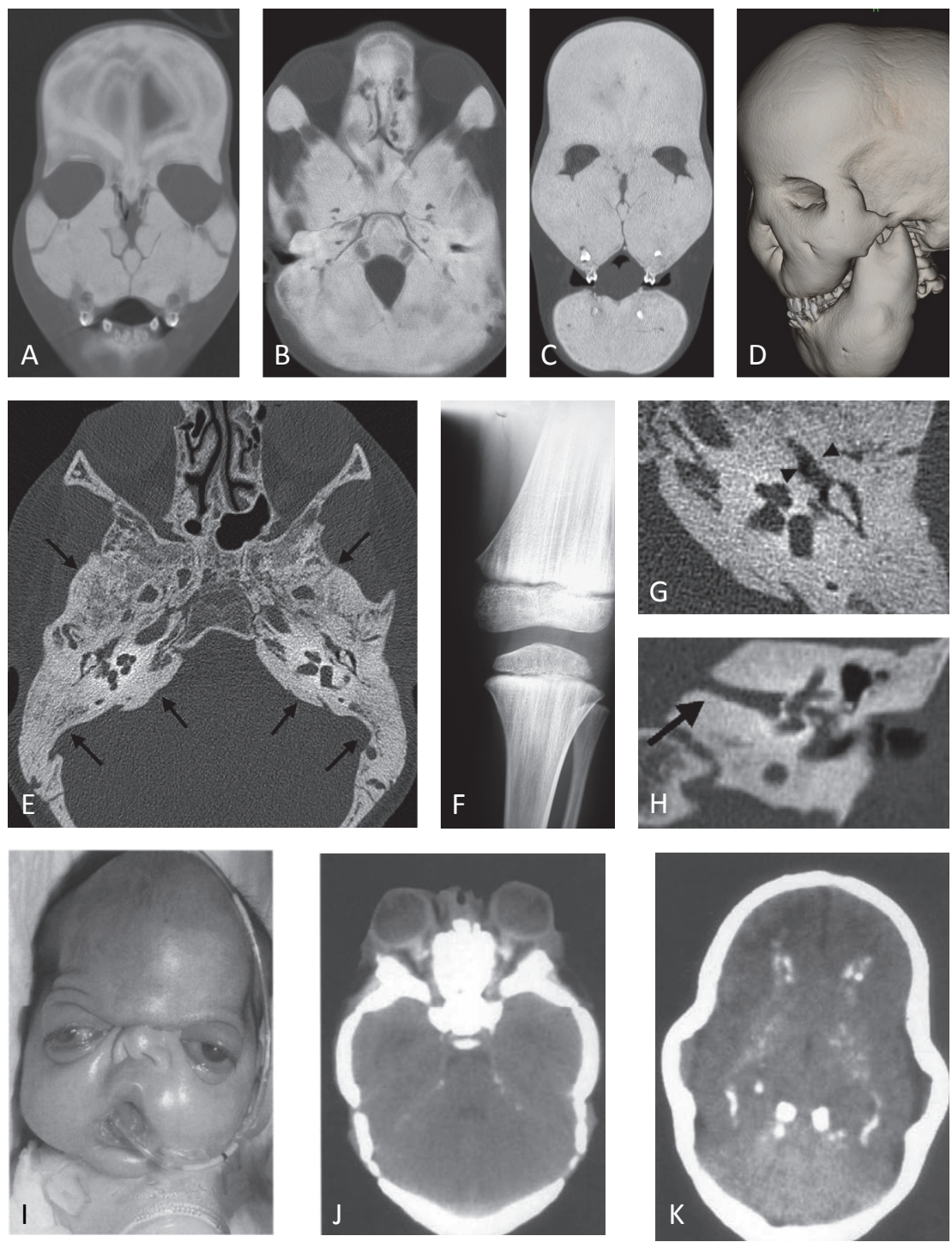

Figure 2.9 Disorders with increased bone formation (2). A-D: Craniodiaphyseal disease. A and B: Coronal and axial CT of 20-month-old child. Extreme hyperostosis of the facial bones, the calvaria and the skull base. C and D: coronal CT and 3D-reconstruction of the same child at 9 years. E-H: Osteopathia striata with cranial stenosis. E: Axial CT of an adult patient. There is moderate hyperostosis at the level of the skull base (arrows). In this patient, the visualised neuroforamina are patent. F: AP Radiograph of femur. Pathognomonic longitudinal striations. G: Detailed view of a left axial temporal bone with soft tissues in the middle ear due to Eustachian tube encroachment. $\mathrm{H}$ : Coronal reconstruction of left temporal bone (same patient as G) demonstrating a patent internal auditory canal (arrow) ${ }^{109}$. I-K: Raine syndrome. I: Typical phenotype with proptosis, depressed nasal bridge, bowed upper lip and micrognathia. J: marked calvarial and anterior skull base hyperostosis with bilateral choanal obstruction, proptosis. K: Typical periventricular calcifications ${ }^{122}$. 


\section{Conditions with exclusive skull involvement}

\section{Hyperostosis cranialis interna}

$\mathrm{HCl}$ is a disorder with an autosomal dominant transmission pattern so far only described in 15 cases in the Netherlands ${ }^{126,127}$. The disorder is characterised by progressive hyperostosis and osteosclerosis of the skull base as well as the calvaria (Figure 2.10A-B). The calvaria and skull base display typical irregular endosteal hyperostosis. The diploë is not obliterated and hyperostosis seems to be less dense than normal cortical bone.

The disorder generally becomes symptomatologic in childhood or adulthood, whereas the first radiologic abnormalities are generally seen late in the first decade ${ }^{128}$. The disease is slowly progressive, however hyperostosis generally settles down after the fourth decade. Women tend to be more severely affected. Most frequently the first symptoms derive from internal auditory canal encroachment. Facial nerve palsy is the most common symptom patients address to the physician with. Prior to this, vestibulocochlear nerve dysfunction might be present subclinically ${ }^{129}$. Later on, olfactory, optic, and trigeminal nerve dysfunctions are seen, also due to encroachment of the corresponding neuroforamina. Also, headache and potentially eventually elevated intracranial pressure can occur due to decreased intracranial volume. Patients develop mandibular exostoses facing intra-orally without clinical consequences. The facial bones and tubular bones are not affected. The facial appearance is normal.

LRP4, LRP5, SOST and TGFB1 are excluded as causative genes based on linkage studies and mutation analysis, and the region of the causative gene has been delineated: $8 \mathrm{p} 21^{130}$.

\section{Hyperostosis frontalis interna}

Hyperostosis frontalis interna (HFI) is not a genetic bone dysplasia, not even a disease (Figure 2.10C-D). However it is listed in this review, because it is important for clinicians to know about the innocence of HFI to avoid unnecessary diagnostics and even treatment.

In contemporary medical history it is mostly described as a coincidental finding, in up to $5-12 \%$ of the general population (varying degrees), so it cannot be denied. It is mentioned here because to some extent it mimics hyperostosis cranialis interna or other disorders. It is defined as bony overgrowth of the internal table of the frontal bone in various degrees, ranging from isolated, elevated bony islands to continuous bony overgrowth involving more than $50 \%$ of the frontal endocranial surface ${ }^{131}$. In the vast majority of cases it is an asymptomatic condition. In the anatomical, anthropological and forensic literature HFI is discussed as well. Cadaver studies demonstrate that $\mathrm{HFI}$ is present in a considerable number of ancient skulls ${ }^{131-133}$. 

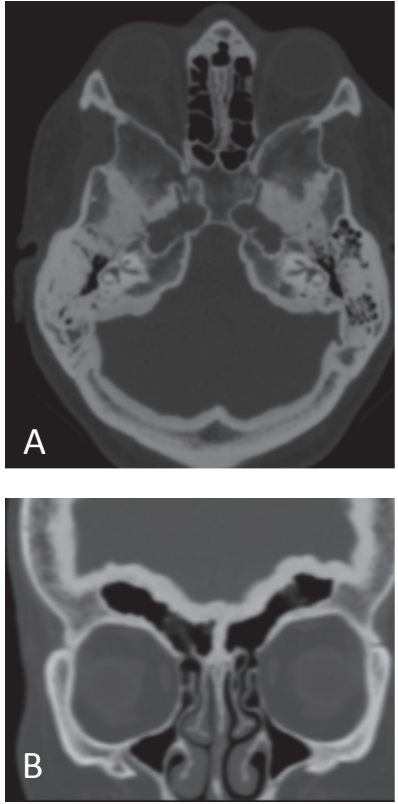
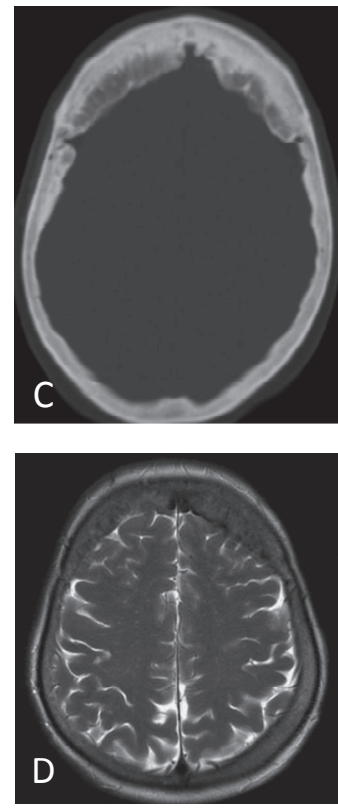
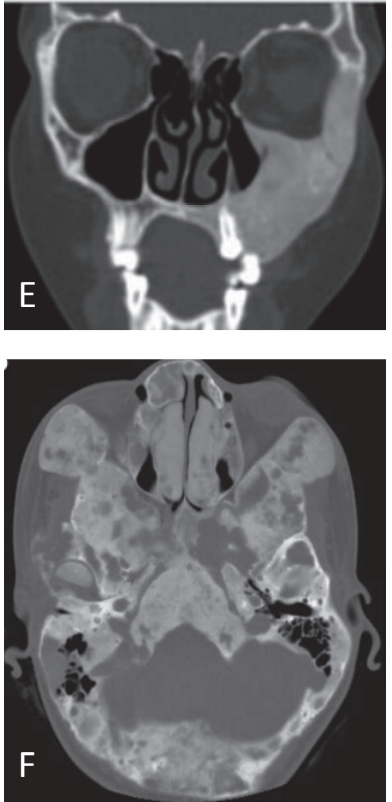

Figure 2.10 Disorders with exclusive skull involvement, fibrous dysplasia and McCune Albright syndrome. A: Axial CT image of an adult patient with hyperostosis cranialis interna. Hyperostosis of the endosteal layer of calvarial bone (images of own collection) B: Coronal CT reconstruction in a patient with hyperostosis cranialis interna at the level of the frontal sinuses and orbitae. Note the sparing of the facial bones, the diploë and the outer cortex of the calvaria. C and D: Axial CT and T2-weighted MR images of patients with hyperostosis frontalis interna. Incidental findings. E: An 11-year-old female with monostotic fibrous dysplasia of the left zygomatic-maxillary region. Ground-glass aspect ${ }^{151}$. F: Axial CT at the level of the skull base in a patient with McCune Albright Syndrome ${ }^{152}$. Fibrous dysplasia (FD) and McCune Albright Syndrome (MAS) are mentioned separately because, unlike the other disorders, it is not purely a bone dysplasia and there is no familial occurrence. It is reviewed and illustrated because craniofacial involvement is very common in FD and MAS. It is due to a postzygotic mutation in the guanine nucleotide stimulatory protein (GNAS1) gene at a very early stage of embryonic development. Cells carrying the mutation (mosaicism) can be present in endocrine glands, skin, or bone tissue. The mutation leads to hyperfunction of skeletal progenitor cells and abnormal osteoblasts. Bone is replaced by fibrous connective tissue and poorly formed trabecular bone. Patients almost always become symptomatic before the age of 30 and disease progression tends to slow down in the course of life. In case of monostotic laesions (75-80\%) it is called FD, in case of polyostotic laesions it is called MAS (20-25\%). Craniofacial involvement is reported in over $90 \%$ in patients with MAS. In FD the zygomatic-maxillary complex and the proximal femur are the most commonly involved sites. Monostotic laesions are obviously easy to differentiate from other symmetrical - skeletal dysplasias. Polyostotic craniofacial laesions can be so generalised that the whole skull base is affected. Radiologically affected bone a has ground glass appearance. Craniofacial symptoms - depending on the location - can be visual impairment, hearing loss (due to ossicle fixation or internal auditory canal narrowing), facial deformity, nasal obstruction, pain and dental malocclusion ${ }^{151}$. Treatment of craniofacial symptoms is generally surgical. 
Sporadically it has been published in case reports to be associated with neurological/cognitive dysfunction ${ }^{134,135}$, endocrinopathies including obesity or hirsutism $^{136}$ but the significance of these findings is doubtful. It is postulated that cognitive function is caused by frontal dysfunction by pressure of the bony masses ${ }^{137}$. If $\mathrm{HFI}$ is accompanied with a combination of neuropsychiatric symptoms, persistent headache, obesity and endocrinopathies, it is also called the Morgagni-Stewart-Morel syndrome ${ }^{138}$. Again, a causative relationship between the different abnormalities has never been demonstrated.

\section{X-linked calvarial hyperostosis}

In 1986 Pagon et al. described a family with an X-linked recessive disorder characterised by isolated calvarial thickening. Symptoms were prominent frontoparietal bones, flat nasal root and short upturned nose, frontal bossing with ridging of the metopic and sagittal sutures, and lateral frontal prominences. The mandible was normal, as were the clavicles, pelvis and long bones. The thickened bone in the skull appeared to be softer than normal bone. Histological examination of the hyperostotic calvarial bone and a bone marrow biopsy showed dense trabecular bone separated by stroma packed with large, morphologically unusual histiocytes.

The transmission pattern seems to be X-linked recessive. Female carriers show no clinical symptoms. Despite calvarial hyperostosis, increased intracranial pressure and cranial nerve entrapment did not occur. The major disability appears to be cosmetic ${ }^{139}$. To date, this is the only family that has been described with X-linked calvarial hyperostosis. A causal gene has not yet been found. Recently the gene has been localised to a small region on chromosome Xq27.3-Xqter ${ }^{140}$.

\section{Discussion / conclusion}

Sclerosing bone dysplasias have long been categorised with the emphasis on phenotypic and radiologic characteristics. Along with the detection of dozens of genetic underlying causes of the different disorders and with the upcoming clinical availability of genetic analysis, gradually a shift is seen towards division into genetic cause of the disease. However, it should not be forgotten that a patient initially presents with a symptom, not a diagnosis. It is therefore important that not only geneticists, but also clinicians should be aware of different bone dysplasias. Although we are about to enter an era of diagnostic whole-genome sequencing, the clinical symptoms and radiologic characteristics should be easily accessible to facilitate the diagnosis.

A definite clinical diagnosis remains challenging especially if the (radiological) symptoms are subtle in children and mildly affected individuals. Patients often address a specialist in the field corresponding with symptoms, e.g. otolaryngologist, neurologist or orthopaedic surgeon. However, if a (genetic) bone dysplasia is suspected, complete 
skeletal survey should be performed, preferably coordinated by a paediatrician or bone specialist. Family history is important, also in case consanguinity is suspected. A clinical geneticist is of crucial value, in the first place if the diagnosis is uncertain and - later on - in case there are questions about heredity.

Making a correct diagnosis has been proven to be difficult in many cases. For many disorders, the number of published cases is very limited. Furthermore, in many diseases there is a clinical and radiological overlap which makes it even harder to make a correct diagnosis. Table 2.3 can be a guideline in making a correct diagnosis based on clinical and radiological findings. Once a presumed diagnosis is made, genetic and molecular analysis should be performed to confirm the diagnosis, especially if there is a recurrence risk or if treatment issues (e.g. in case of osteopetrosis) are under consideration $^{141}$.

Also, important pathways in bone metabolism, such as the WNT, TGF $\beta$ and NFKB pathways are now better understood. This allows comparison of different disorders with respect to these mechanisms.

Although many genes and pathways involved in bone metabolism are already known, there are still many rare bone dysplasias where the responsible gene is unknown. Identification of such genes may lead to important information to further unravel the complex process of bone homeostasis.

\section{Acknowledgements}

We kindly want to thank prof. Virginia Diewert (maxillofacial surgeon, University of British Columbia, Vancouver) for the permission to use of figure 3, dr. Juergens, dr. Kornak and dr. Nuernberg for the use of figure 6B, dr. Frank Gaillard (Radiopaedia.org) for the use of figure 7A, 10C and 9D, LearningRadiology.com for the permission to publish figure 7D and 7E, prof. Martina Wegenroth (neuroradiologist, University of Heidelberg Medical School) for supplying figures $8 \mathrm{~A}$ and $8 \mathrm{C}$, dr. Linda Postma (neuroradiologist, Maastricht University Medical Center) for supplying figures 8D-F, dr. Matthew Carlson (otolaryngologist, Rochester, Minnesota) for figure $8 \mathrm{G}$ and $8 \mathrm{H}$, prof. Dong-Kyu Jin and dr. Sung Yoon Cho (paediatricians, Samsung Medical Center, Sungkyunkwan University School of Medicine, Seoul) for providing figures 9A-D. Permission for all other figures (except figures from own collection, 10A and 10B) was obtained through publishers of prior articles.

This work was supported by a grant from the FWO (Fund for scientific Research) Vlaanderen (G0197.12N) to W. Van Hul and by a Ph.D. grant of the Agency for Innovation by Science and Technology (IWT) to V.M. Borra. 


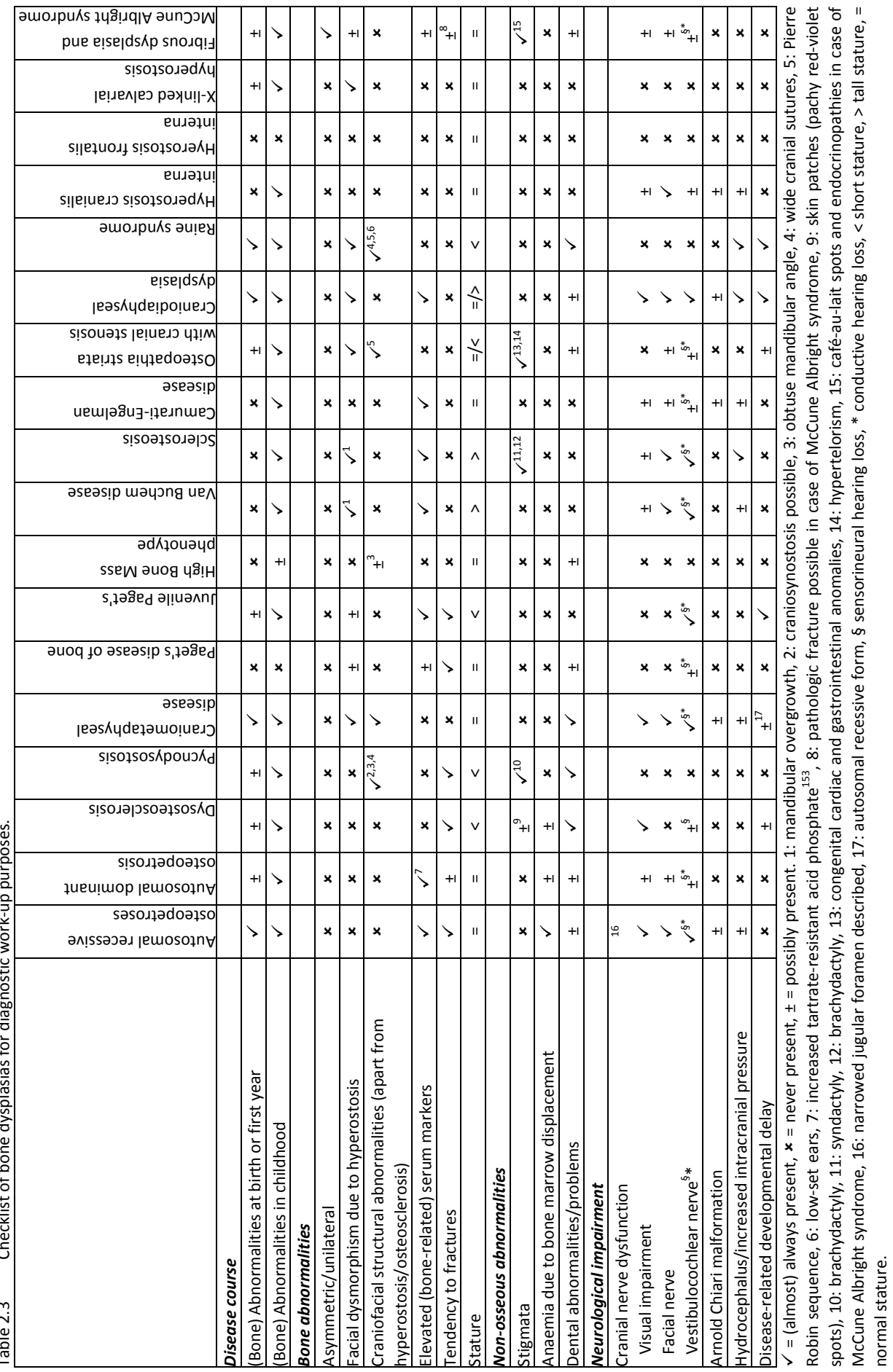




\section{References}

1. Ricciardelli EJ. Embryology and anatomy of the cranial base. Clin Plast Surg 1995;22:361-372.

2. Nemzek WR, Brodie HA, Hecht ST, Chong BW, Babcook CJ, Seibert JA. MR, CT, and plain film imaging of the developing skull base in fetal specimens. Am J Neuroradiol 2000;21:1699-1706.

3. Larsen WJ. Development of the Head, the Neck, the Eyes, and the Ears. In: Human Embryology. 3rd ed. Philadelphia: Elsevier; 2009.

4. Von Baer KE. Ueber Entwicklungsgeschichte der Tiere. Borneträger, Königsberg 1828.

5. His W. Untersuchung über die Ersteanlage des Wirbeltierleibes. Die erste Entwicklung des Hünchens. Leipzig. Vogel 1868.

6. Platt JB. Ectodermic origin of the cartilages of the head. Anat Anz 1893;8:506-509.

7. Huang $X$, Saint-Jeannet JP. Induction of the neural crest and the opportunities of life on the edge. Dev Biol 2004;275:1-11.

8. Le Douarin N. A biological cell labeling technique and its use in experimental embryology. Dev Biol 1973;30:217-222.

9. Le Douarin NM. The ontogeny of the neural crest in avian embryo chimaeras. Nature 1980;286: 663-669.

10. Couly GF, Coltey PM, Le Douarin NM. The triple origin of skull in higher vertebrates: a study in quailchick chimeras. Development 1993;117:409-429.

11. Scheuer L. Chapter 5: The head, neck and dentition. In: Developmental Juvenile Osteology. 1st ed. Oxford: Elsevier; 2000.

12. Gray H. Part 2: Osteology. In: Anatomy of the human body. 36th ed. Edinburgh: Churchill Livingstone; 1980.

13. Gulya A. Chapter 1: Developmental anatomy of the temporal bone and skull base. In: Glasscock Shambaugh Surgery of the Ear. 6th ed. Shelton: People's Medical Publishing House - USA; 2010.

14. Fawcett. The Development of the Human Maxilla, Vomer, and Paraseptal Cartilages. J Anat Physiol 1911;45:378-405.

15. Albers-Schönberg G. Röntgenbilder einer seltenen Knochenerkrankung. Munch Med Wochenschr 1904;51:365-368.

16. Shallow TA, Davis WB, Farrell JT. Osteopetrosis. Ann Surg 1934;100:512-517.

17. Hamersma H. Osteopetrosis (Marble bone disease) of the temporal bone. Laryngoscope 1970;80: 1518-1539.

18. Beighton P, Horan F, Hamersma H. A review of the osteopetroses. Postgrad Med J 1977;53:507-516.

19. Warman ML, Cormier-Daire V, Hall C, Krakow D, Lachman R, LeMerrer M, Mortier G, Mundlos S, Nishimura G, Rimoin DL, Robertson S, Savarirayan R, Sillence D, Spranger J, Unger S, Zabel B, SupertiFurga A. Nosology and classification of genetic skeletal disorders: 2010 revision. Am J Med Genet A 2011;155A:943-968.

20. Bollerslev J. Osteopetrosis. A genetic and epidemiological study. Clin Genet 1987;31:86-90.

21. Salzano FM. Osteopetrosis: review of dominant cases and frequency in a Brazilian state. Acta Genet Med Gemellol (Roma) 1961;10:353-358.

22. Orphanet. http://www.orpha.net/orphacom/cahiers/docs/GB/Prevalence_of_rare_diseases_by_alphabetical_list.pdf; 2012.

23. Sobacchi $C$, Frattini A, Guerrini MM, Abinun M, Pangrazio A, Susani L, Bredius R, Mancini G, Cant A, Bishop N, Grabowski P, Del Fattore A, Messina C, Errigo G, Coxon FP, Scott DI, Teti A, Rogers MJ, Vezzoni P, Villa A, Helfrich MH. Osteoclast-poor human osteopetrosis due to mutations in the gene encoding RANKL. Nat Genet 2007;39:960-962.

24. Van Wesenbeeck L, Odgren PR, Coxon FP, Frattini A, Moens P, Perdu B, MacKay CA, Van Hul E, Timmermans JP, Vanhoenacker F, Jacobs R, Peruzzi B, Teti A, Helfrich MH, Rogers MJ, Villa A, Van Hul W. Involvement of PLEKHM1 in osteoclastic vesicular transport and osteopetrosis in incisors absent rats and humans. J Clin Invest 2007;117:919-930.

25. Wilson CJ, Vellodi A. Autosomal recessive osteopetrosis: diagnosis, management, and outcome. Arch Dis Child 2000;83:449-452. 
26. Cure JK, Key LL, Goltra DD, VanTassel P. Cranial MR imaging of osteopetrosis. Am J Neuroradiol 2000;21:1110-1115.

27. Steward CG. Neurological aspects of osteopetrosis. Neuropathol Appl Neurobiol 2003;29:87-97.

28. Del Fattore A, Cappariello A, Teti A. Genetics, pathogenesis and complications of osteopetrosis. Bone 2008;42:19-29.

29. Sly WS, Whyte MP, Sundaram V, Tashian RE, Hewett-Emmett D, Guibaud P, Vainsel M, Baluarte HJ, Gruskin A, Al-Mosawi M, et al. Carbonic anhydrase II deficiency in 12 families with the autosomal recessive syndrome of osteopetrosis with renal tubular acidosis and cerebral calcification. $N$ Engl J Med 1985;313:139-145.

30. Pangrazio A, Poliani PL, Megarbane A, Lefranc G, Lanino E, Di Rocco M, Rucci F, Lucchini F, Ravanini M, Facchetti F, Abinun M, Vezzoni P, Villa A, Frattini A. Mutations in OSTM1 (grey lethal) define a particularly severe form of autosomal recessive osteopetrosis with neural involvement. J Bone Miner Res 2006;21:1098-1105.

31. Kornak U, Schulz A, Friedrich W, Uhlhaas S, Kremens B, Voit T, Hasan C, Bode U, Jentsch TJ, Kubisch C. Mutations in the a3 subunit of the vacuolar $\mathrm{H}(+)$-ATPase cause infantile malignant osteopetrosis. Hum Mol Genet 2000;9:2059-2063.

32. Kornak U, Kasper D, Bosl MR, Kaiser E, Schweizer M, Schulz A, Friedrich W, Delling G, Jentsch TJ. Loss of the CIC-7 chloride channel leads to osteopetrosis in mice and man. Cell 2001;104:205-215.

33. Chalhoub N, Benachenhou N, Rajapurohitam V, Pata M, Ferron M, Frattini A, Villa A, Vacher J. Greylethal mutation induces severe malignant autosomal recessive osteopetrosis in mouse and human. Nat Med 2003;9:399-406.

34. Pangrazio A, Caldana ME, Lo lacono N, Mantero S, Vezzoni P, Villa A, Sobacchi C. Autosomal recessive osteopetrosis: report of 41 novel mutations in the TCIRG1 gene and diagnostic implications. Osteoporos Int 2012;23:2713-2718.

35. Aker M, Rouvinski A, Hashavia S, Ta-Shma A, Shaag A, Zenvirt S, Israel S, Weintraub M, Taraboulos A, Bar-Shavit Z, Elpeleg O. An SNX10 mutation causes malignant osteopetrosis of infancy. J Med Genet 2012;49:221-226.

36. Megarbane A, Pangrazio A, Villa A, Chouery E, Maarawi J, Sabbagh S, Lefranc G, Sobacchi C. Homozygous stop mutation in the SNX10 gene in a consanguineous Iraqi boy with osteopetrosis and corpus callosum hypoplasia. Eur J Med Genet 2013;56:32-35.

37. Helfrich MH. Osteoclast diseases. Microsc Res Tech 2003;61:514-532.

38. Andersen PE, Jr., Bollerslev J. Heterogeneity of autosomal dominant osteopetrosis. Radiology 1987;164: 223-225.

39. Bollerslev J, Andersen PE, Jr. Radiological, biochemical and hereditary evidence of two types of autosomal dominant osteopetrosis. Bone 1988;9:7-13.

40. Bollerslev J, Henriksen K, Frost Nielsen M, Brixen K, Van Hul W. Autosomal dominant osteopetrosis revisited: lessons from recent studies. Eur J Endocrinol 2013;169:R39-57.

41. Cleiren E, Benichou O, Van Hul E, Gram J, Bollerslev J, Singer FR, Beaverson K, Aledo A, Whyte MP, Yoneyama T, deVernejoul MC, Van Hul W. Albers-Schönberg disease (autosomal dominant osteopetrosis, type II) results from mutations in the CICN7 chloride channel gene. Hum Mol Genet 2001;10:2861-2867.

42. Lemire EG, Wiebe $\mathrm{S}$. Clinical and radiologic findings in an adult male with dysosteosclerosis. Am J Med Genet A 2008;146A:474-478.

43. Elcioglu NH, Vellodi A, Hall CM. Dysosteosclerosis: a report of three new cases and evolution of the radiological findings. J Med Genet 2002;39:603-607.

44. Campeau PM, Lu JT, Sule G, Jiang MM, Bae Y, Madan S, Hogler W, Shaw NJ, Mumm S, Gibbs RA, Whyte $\mathrm{MP}$, Lee $\mathrm{BH}$. Whole-exome sequencing identifies mutations in the nucleoside transporter gene SLC29A3 in dysosteosclerosis, a form of osteopetrosis. Hum Mol Genet 2012;21:4904-4909.

45. Whyte MP, Wenkert D, McAlister WH, Novack DV, Nenninger AR, Zhang X, Huskey M, Mumm S. Dysosteosclerosis presents as an "osteoclast-poor" form of osteopetrosis: comprehensive investigation of a 3-year-old girl and literature review. J Bone Miner Res 2010;25:2527-2539.

46. Lamy M, Maroteaux P. Pycnodysostosis. Rev Esp Pediatr 1965;21:433-437. 
47. Kamak H, Kamak G, Yavuz I. Clinical, radiographic, diagnostic and cephalometric features of pycnodysostosis in comparison with Turkish cephalometric norms: A case report. Eur J Dent 2012;6: 454-459.

48. Xue Y, Cai T, Shi S, Wang W, Zhang Y, Mao T, Duan X. Clinical and animal research findings in pycnodysostosis and gene mutations of cathepsin K from 1996 to 2011. Orphanet J Rare Dis 2011;6:20.

49. Gelb BD, Edelson JG, Desnick RJ. Linkage of pycnodysostosis to chromosome 1q21 by homozygosity mapping. Nat Genet 1995;10:235-237.

50. Gelb BD, Shi GP, Chapman HA, Desnick RJ. Pycnodysostosis, a lysosomal disease caused by cathepsin K deficiency. Science 1996;273:1236-1238.

51. Polymeropoulos MH, Ortiz De Luna RI, Ide SE, Torres R, Rubenstein J, Francomano CA. The gene for pycnodysostosis maps to human chromosome 1cen-q21. Nat Genet 1995;10:238-239.

52. Chen W, Yang S, Abe Y, Li M, Wang Y, Shao J, Li E, Li YP. Novel pycnodysostosis mouse model uncovers cathepsin $\mathrm{K}$ function as a potential regulator of osteoclast apoptosis and senescence. Hum Mol Genet 2007;16:410-423.

53. Li CY, Jepsen KJ, Majeska RJ, Zhang J, Ni R, Gelb BD, Schaffler MB. Mice lacking cathepsin K maintain bone remodeling but develop bone fragility despite high bone mass. J Bone Miner Res 2006;21: 865-875.

54. Gorlin RJ, Spranger, J., Koszalka, MF. Genetic craniotubular bone dysplasias and hyperostoses: a critical analysis. Birth Defects Orig Art Ser 1969;5:79-95.

55. Nurnberg $P$, Thiele $H$, Chandler D, Hohne W, Cunningham ML, Ritter H, Leschik G, Uhlmann K, Mischung C, Harrop K, Goldblatt J, Borochowitz ZU, Kotzot D, Westermann F, Mundlos S, Braun HS, Laing N, Tinschert S. Heterozygous mutations in ANKH, the human ortholog of the mouse progressive ankylosis gene, result in craniometaphyseal dysplasia. Nat Genet 2001;28:37-41.

56. Nurnberg P, Tinschert S, Mrug M, Hampe J, Muller CR, Fuhrmann E, Braun HS, Reis A. The gene for autosomal dominant craniometaphyseal dysplasia maps to chromosome $5 p$ and is distinct from the growth hormone-receptor gene. Am J Hum Genet 1997;61:918-923.

57. lughetti P, Alonso LG, Wilcox W, Alonso N, Passos-Bueno MR. Mapping of the autosomal recessive (AR) craniometaphyseal dysplasia locus to chromosome region 6q21-22 and confirmation of genetic heterogeneity for mild AR spondylocostal dysplasia. Am J Med Genet 2000;95:482-491.

58. McKay DR, Fialkov JA. Autosomal dominant craniometaphyseal dysplasia with atypical features. $B r J$ Plast Surg 2002;55:144-148.

59. Shea J, Gerbe R, Ayani N. Craniometaphyseal dysplasia: the first successful surgical treatment for associated hearing loss. Laryngoscope 1981;91:1369-1374.

60. Richards A, Brain C, Dillon MJ, Bailey CM. Craniometaphyseal and craniodiaphyseal dysplasia, head and neck manifestations and management. J Laryngol Otol 1996;110:328-338.

61. Ho AM, Johnson MD, Kingsley DM. Role of the mouse ank gene in control of tissue calcification and arthritis. Science 2000;289:265-270.

62. Yamamoto T, Kurihara N, Yamaoka K, Ozono K, Okada M, Yamamoto K, Matsumoto S, Michigami T, Ono J, Okada S. Bone marrow-derived osteoclast-like cells from a patient with craniometaphyseal dysplasia lack expression of osteoclast-reactive vacuolar proton pump. J Clin Invest 1993;91:362-367.

63. Chen IP, Wang L, Jiang X, Aguila HL, Reichenberger EJ. A Phe377del mutation in ANK leads to impaired osteoblastogenesis and osteoclastogenesis in a mouse model for craniometaphyseal dysplasia (CMD). Hum Mol Genet 2011;20:948-961.

64. Prontera P, Rogaia D, Sobacchi C, Tavares VL, Mazzotta G, Passos-Bueno MR, Donti E. Craniometaphyseal dysplasia with severe craniofacial involvement shows homozygosity at 6q21-22.1 locus. Am J Med Genet A 2011;155A:1106-1108.

65. Altman Rd, Bloch DA, Hochberg MC, Murphy WA. Prevalence of pelvic Paget's disease of bone in the United States. J Bone Miner Res 2000;15:461-465.

66. Roodman GD, Windle JJ. Paget disease of bone. J Clin Invest 2005;115:200-208.

67. Ralston SH, Layfield R. Pathogenesis of Paget disease of bone. Calcif Tissue Int 2012;91:97-113.

68. Rebel A, Basle M, Pouplard A, Malkani K, Filmon R, Lepatezour A. Towards a viral etiology for Paget's disease of bone. Metab Bone Dis Relat Res 1981;3:235-238.

69. Monsell EM. The mechanism of hearing loss in Paget's disease of bone. Laryngoscope 2004;114: 598-606. 
70. Bahmad F, Jr., Merchant SN. Paget disease of the temporal bone. Otol Neurotol 2007;28:1157-1158.

71. Merchant SN, Rosowski JJ. Conductive hearing loss caused by third-window lesions of the inner ear. Otol Neurotol 2008;29:282-289.

72. Singer FR. Clinical efficacy of salmon calcitonin in Paget's disease of bone. Calcif Tissue Int 1991;49 Suppl 2:S7-8.

73. Bakwin H, Eiger MS. Fragile bones and macrocranium. J Pediatr 1956;49:558-564.

74. Chong B, Hegde M, Fawkner M, Simonet S, Cassinelli H, Coker M, Kanis J, Seidel J, Tau C, Tuysuz B, Yuksel B, Love D. Idiopathic hyperphosphatasia and TNFRSF11B mutations: relationships between phenotype and genotype. J Bone Miner Res 2003;18:2095-2104.

75. Brunetti G, Marzano F, Colucci S, Ventura A, Cavallo L, Grano M, Faienza MF. Genotype-phenotype correlation in juvenile Paget disease: role of molecular alterations of the TNFRSF11B gene. Endocrine 2012;42:266-271.

76. Sennaroglu L, Sozeri B, Sungur A. Otological findings in idiopathic hyperphosphatasia. J Laryngol Otol 1999;113:158-160.

77. Bae KB, Kwon JH, Kim YH, Jung TY, Cho JH. Juvenile Paget's disease with paranasal sinus aplasia. Clin Exp Otorhinolaryngol 2008;1:224-226.

78. Khosla S. Minireview: the OPG/RANKL/RANK system. Endocrinology 2001;142:5050-5055.

79. Tuysuz B, Mercimek S, Ungur S, Deniz M. Calcitonin treatment in osteoectasia with hyperphosphatasia (juvenile Paget's disease): radiographic changes after treatment. Pediatr Radiol 1999;29:838-841.

80. Payne K, Dickenson A. Worth syndrome as a diagnosis for mandibular osteosclerosis. Dentomaxillofac Radiol 2011;40:531-533.

81. Perdu B, Van Hul W. Sclerosing bone disorders: too much of a good thing. Crit Rev Eukaryot Gene Expr 2010;20:195-212.

82. Gong Y, Slee RB, Fukai N, Rawadi G, Roman-Roman S, Reginato AM, Wang H, Cundy T, Glorieux FH, Lev D, Zacharin M, Oexle K, Marcelino J, Suwairi W, Heeger S, Sabatakos G, Apte S, Adkins WN, Allgrove J, Arslan-Kirchner M, Batch JA, Beighton P, Black GC, Boles RG, Boon LM, Borrone C, Brunner HG, Carle GF, Dallapiccola B, De Paepe A, Floege B, Halfhide ML, Hall B, Hennekam RC, Hirose T, Jans A, Juppner H, Kim CA, Keppler-Noreuil K, Kohlschuetter A, LaCombe D, Lambert M, Lemyre E, Letteboer T, Peltonen L, Ramesar RS, Romanengo M, Somer H, Steichen-Gersdorf E, Steinmann B, Sullivan B, Superti-Furga A, Swoboda W, van den Boogaard MJ, Van Hul W, Vikkula M, Votruba M, Zabel B, Garcia T, Baron R, Olsen BR, Warman ML. LDL receptor-related protein 5 (LRP5) affects bone accrual and eye development. Cell 2001;107:513-523.

83. Boyden LM, Mao J, Belsky J, Mitzner L, Farhi A, Mitnick MA, Wu D, Insogna K, Lifton RP. High bone density due to a mutation in LDL-receptor-related protein 5. N Engl J Med 2002;346:1513-1521.

84. Little RD, Carulli JP, Del Mastro RG, Dupuis J, Osborne M, Folz C, Manning SP, Swain PM, Zhao SC, Eustace B, Lappe MM, Spitzer L, Zweier S, Braunschweiger K, Benchekroun Y, Hu X, Adair R, Chee L, FitzGerald MG, Tulig C, Caruso A, Tzellas N, Bawa A, Franklin B, McGuire S, Nogues X, Gong G, Allen KM, Anisowicz A, Morales AJ, Lomedico PT, Recker SM, Van Eerdewegh P, Recker RR, Johnson ML. A mutation in the LDL receptor-related protein 5 gene results in the autosomal dominant high-bone-mass trait. Am J Hum Genet 2002;70:11-19.

85. Monroe DG, McGee-Lawrence ME, Oursler MJ, Westendorf JJ. Update on Wnt signaling in bone cell biology and bone disease. Gene 2012;492:1-18.

86. Van Buchem FS, Hadders HN, Ubbens R. An uncommon familial systemic disease of the skeleton: hyperostosis corticalis generalisata familiaris. Acta Radiol 1955;44:109-120.

87. van Buchem FS. Hyperostosis corticalis generalisata. Eight new cases. Acta Med Scand 1971;189: 257-267.

88. Vanhoenacker FM, Balemans W, Tan GJ, Dikkers FG, De Schepper AM, Mathysen DG, Bernaerts A, Hul WV. Van Buchem disease: lifetime evolution of radioclinical features. Skeletal Radiol 2003;32: 708-18.

89. van Lierop AH, Hamdy NA, van Egmond ME, Bakker E, Dikkers FG, Papapoulos SE. Van Buchem disease: Clinical, biochemical, and densitometric features of patients and disease carriers. $J$ Bone Miner Res 2013;28:848-854.

90. van Egmond ME, Dikkers FG, Boot AM, van Lierop AH, Papapoulos SE, Brouwer OF. A rare cause of facial nerve palsy in children: hyperostosis corticalis generalisata (Van Buchem disease). Three new pediatric cases and a literature review. Eur J Paediatr Neurol 2012;16:740-743. 
91. Hamersma H, Gardner J, Beighton P. The natural history of sclerosteosis. Clin Genet 2003;63:192-197.

92. Beighton P, Hamersma H. Sclerosteosis in South Africa. S Afr Med J 1979;55:783-788.

93. Beighton P, Durr L, Hamersma H. The clinical features of sclerosteosis. A review of the manifestations in twenty-five affected individuals. Ann Intern Med 1976;84:393-397.

94. Schucknecht H. Disorders of bone. In: Pathology of the Ear. 2nd ed. Philadelphia: Lea \& Febiger; 1993: 365-414.

95. du Plessis JJ. Sclerosteosis: neurosurgical experience with 14 cases. J Neurosurg 1993;78:388-392.

96. Beighton $\mathrm{P}$, Barnard A, Hamersma $\mathrm{H}$, van der Wouden A. The syndromic status of sclerosteosis and van Buchem disease. Clin Genet 1984;25:175-181.

97. Van Hul W, Balemans W, Van Hul E, Dikkers FG, Obee H, Stokroos RJ, Hildering P, Vanhoenacker F, Van Camp G, Willems PJ. Van Buchem disease (hyperostosis corticalis generalisata) maps to chromosome 17q12-q21. Am J Hum Genet 1998;62:391-399.

98. Balemans W, Van Den Ende J, Freire Paes-Alves A, Dikkers FG, Willems PJ, Vanhoenacker F, de AlmeidaMelo N, Alves CF, Stratakis CA, Hill SC, Van Hul W. Localization of the gene for sclerosteosis to the van Buchem disease-gene region on chromosome 17q12-q21. Am J Hum Genet 1999;64:1661-1669.

99. Balemans W, Ebeling M, Patel N, Van Hul E, Olson P, Dioszegi M, Lacza C, Wuyts W, Van Den Ende J, Willems P, Paes-Alves AF, Hill S, Bueno M, Ramos FJ, Tacconi P, Dikkers FG, Stratakis C, Lindpaintner K, Vickery B, Foernzler D, Van Hul W. Increased bone density in sclerosteosis is due to the deficiency of a novel secreted protein (SOST). Hum Mol Genet 2001;10:537-543.

100. Balemans W, Patel N, Ebeling M, Van Hul E, Wuyts W, Lacza C, Dioszegi M, Dikkers FG, Hildering P, Willems PJ, Verheij JB, Lindpaintner K, Vickery B, Foernzler D, Van Hul W. Identification of a $52 \mathrm{~kb}$ deletion downstream of the SOST gene in patients with van Buchem disease. J Med Genet 2002;39: 91-97.

101. Brunkow ME, Gardner JC, Van Ness J, Paeper BW, Kovacevich BR, Proll S, Skonier JE, Zhao L, Sabo PJ, Fu Y, Alisch RS, Gillett L, Colbert T, Tacconi P, Galas D, Hamersma H, Beighton P, Mulligan J. Bone dysplasia sclerosteosis results from loss of the SOST gene product, a novel cystine knot-containing protein. Am J Hum Genet 2001;68:577-589.

102. Sparkes RS, Graham CB. Camurati-Engelmann disease. Genetics and clinical manifestations with a review of the literature. J Med Genet 1972;9:73-85.

103. Janssens K, Vanhoenacker F, Bonduelle M, Verbruggen L, Van Maldergem L, Ralston S, Guanabens $N$, Migone N, Wientroub S, Divizia MT, Bergmann C, Bennett C, Simsek S, Melancon S, Cundy T, Van Hul W. Camurati-Engelmann disease: review of the clinical, radiological, and molecular data of 24 families and implications for diagnosis and treatment. J Med Genet 2006;43:1-11.

104. Carlson ML, Beatty CW, Neff BA, Link MJ, Driscoll CL. Skull base manifestations of Camurati-Engelmann disease. Arch Otolaryngol Head Neck Surg 2010;136:566-575.

105. Janssens K, ten Dijke P, Janssens S, Van Hul W. Transforming growth factor-beta1 to the bone. Endocr Rev 2005;26:743-774.

106. Janssens K, ten Dijke P, Ralston SH, Bergmann C, Van Hul W. Transforming growth factor-beta 1 mutations in Camurati-Engelmann disease lead to increased signaling by altering either activation or secretion of the mutant protein. J Biol Chem 2003;278:7718-7724.

107. Viot G, Lacombe D, David A, Mathieu M, de Broca A, Faivre L, Gigarel N, Munnich A, Lyonnet S, Le Merrer M, Cormier-Daire V. Osteopathia striata cranial sclerosis: non-random X-inactivation suggestive of X-linked dominant inheritance. Am J Med Genet 2002;107:1-4.

108. Perdu B, de Freitas F, Frints SG, Schouten M, Schrander-Stumpel C, Barbosa M, Pinto-Basto J, Reis-Lima M, de Vernejoul MC, Becker K, Freckmann ML, Keymolen K, Haan E, Savarirayan R, Koenig R, Zabel B, Vanhoenacker FM, Van Hul W. Osteopathia striata with cranial sclerosis owing to WTX gene defect. $J$ Bone Miner Res 2010;25:82-90.

109. Magliulo G, Parrotto D, Zicari AM, Zappala D, Lo Mele L, Primicerio P, Marini M. Osteopathia striatacranial sclerosis: otorhinolaryngologic clinical presentation and radiologic findings. Am J Otolaryngol 2007;28:59-63.

110. Odrezin GT, Krasikov N. CT of the temporal bone in a patient with osteopathia striata and cranial sclerosis. Am J Neuroradiol 1993;14:72-75. 
111. Ward LM, Rauch F, Travers R, Roy M, Montes J, Chabot G, Glorieux FH. Osteopathia striata with cranial sclerosis: clinical, radiological, and bone histological findings in an adolescent girl. Am J Med Genet $A$ 2004;129A:8-12.

112. Bass HN, Weiner JR, Goldman A, Smith LE, Sparkes RS, Crandall BF. Osteopathia striata syndrome. Clinical, genetic and radiologic considerations. Clin Pediatr (Phila) 1980;19:369-373.

113. Luerssen K, Ptok M. Osteopathia striata with cranial sclerosis and hearing loss. Eur Arch Otorhinolaryngol 2006;263: 123-126.

114. De Keyser J, Bruyland M, De Greve J, Leemans J, Potvliege R, Six R, Ebinger G. Osteopathia striata with cranial sclerosis. Report of a case and review of the literature. Clin Neurol Neurosurg 1983;85:41-48.

115. Hurt RL. Osteopathia striata-Voorhoeve's disease; report of a case presenting the features of osteopathia striata and osteopetrosis. J Bone Joint Surg Br 1953;35-B:89-96.

116. Tanneberger K, Pfister AS, Brauburger K, Schneikert J, Hadjihannas MV, Kriz V, Schulte G, Bryja V, Behrens J. Amer1/WTX couples Wnt-induced formation of PtdIns(4,5)P2 to LRP6 phosphorylation. EMBO J 2011;30:1433-1443.

117. Jenkins ZA, van Kogelenberg M, Morgan T, Jeffs A, Fukuzawa R, Pearl E, Thaller C, Hing AV, Porteous ME, Garcia-Minaur S, Bohring A, Lacombe D, Stewart F, Fiskerstrand T, Bindoff L, Berland S, Ades LC, Tchan M, David A, Wilson LC, Hennekam RC, Donnai D, Mansour S, Cormier-Daire V, Robertson SP. Germline mutations in WTX cause a sclerosing skeletal dysplasia but do not predispose to tumorigenesis. Nat Genet 2009;41:95-100.

118. Chenier S, Noor A, Dupuis L, Stavropoulos DJ, Mendoza-Londono R. Osteopathia striata with cranial sclerosis and developmental delay in a male with a mosaic deletion in chromosome region Xq11.2. Am J Med Genet A 2012;158A:2946-2952.

119. Marden FA, Wippold FJ, 2nd. MR imaging features of craniodiaphyseal dysplasia. Pediatr Radiol 2004;34:167-170.

120. Janssens K, Thompson E, Vanhoenacker F, Savarirayan R, Morris L, Dobbie A, Van Hul W. Macrocephaly and sclerosis of the tubular bones in an isolated patient: a mild case of craniodiaphyseal dysplasia? Clin Dysmorphol 2003;12:245-250.

121. Kim SJ, Bieganski T, Sohn YB, Kozlowski K, Semenov M, Okamoto N, Kim CH, Ko AR, Ahn GH, Choi YL, Park SW, Ki CS, Kim OH, Nishimura G, Unger S, Superti-Furga A, Jin DK. Identification of signal peptide domain SOST mutations in autosomal dominant craniodiaphyseal dysplasia. Hum Genet 2011;129: 497-502.

122. Al Mane KA, Coates RK, McDonald P. Intracranial calcification in Raine syndrome. Pediatr Radiol 1996;26:55-58.

123. Chitayat D, Shannon P, Keating S, Toi A, Blaser S, Friedberg T, Superti-Furga A, Chong K, Unger S. Raine syndrome: a rare lethal osteosclerotic bone dysplasia. Prenatal diagnosis, autopsy, and neuropathological findings. Am J Med Genet A 2007;143A:3280-3285.

124. Simpson MA, Hsu R, Keir LS, Hao J, Sivapalan G, Ernst LM, Zackai EH, Al-Gazali LI, Hulskamp G, Kingston HM, Prescott TE, Ion A, Patton MA, Murday V, George A, Crosby AH. Mutations in FAM20C are associated with lethal osteosclerotic bone dysplasia (Raine syndrome), highlighting a crucial molecule in bone development. Am J Hum Genet 2007;81:906-912.

125. Ishikawa HO, Xu A, Ogura E, Manning G, Irvine KD. The Raine syndrome protein FAM20C is a Golgi kinase that phosphorylates bio-mineralization proteins. PLoS One 2012;7:e42988.

126. Manni JJ, Scaf JJ, Huygen PL, Cruysberg JR, Verhagen WI. Hyperostosis cranialis interna. A new hereditary syndrome with cranial-nerve entrapment. N Engl J Med 1990;322:450-454.

127. Waterval JJ, Stokroos RJ, Bauer NJ, De Bondt RB, Manni JJ. Phenotypic manifestations and management of hyperostosis cranialis interna, a hereditary bone dysplasia affecting the calvaria and the skull base. Am J Med Genet A 2010;152A:547-555.

128. Waterval JJ, van Dongen TM, Stokroos RJ, De Bondt BJ, Chenault MN, Manni JJ. Imaging features and progression of hyperostosis cranialis interna. Am J Neuroradiol 2012;33:453-461.

129. Waterval JJ, Bischoff MP, Stokroos RJ, Anteunis L, Hilkman DM, Kingma H, Manni JJ. Neurophysiologic, audiometric and vestibular function tests in patients with hyperostosis cranialis interna. Clin Neurol Neurosurg 2013;115:1701-1708. 
130. Borra VM, Waterval JJ, Stokroos RJ, Manni JJ, Van Hul W. Localization of the Gene for Hyperostosis Cranialis Interna to Chromosome 8p21 with Analysis of Three Candidate Genes. Calcif Tissue Int 2013;93:93-100

131. Hershkovitz I, Greenwald C, Rothschild BM, Latimer B, Dutour O, Jellema LM, Wish-Baratz S. Hyperostosis frontalis interna: an anthropological perspective. Am J Phys Anthropol 1999;109: 303-25.

132. Mulhern DM, Wilczak CA, Dudar JC. Brief communication: unusual finding at Pueblo Bonito: multiple cases of hyperostosis frontalis interna. Am J Phys Anthropol 2006;130:480-484.

133. Hajdu T, Fothi E, Bernert Z, Molnar E, Lovasz G, Kovari I, Kohler K, Marcsik A. Appearance of hyperostosis frontalis interna in some osteoarcheological series from Hungary. Homo 2009;60: 185-205.

134. Waclawik AJ. Hyperostosis frontalis interna. Arch Neurol 2006;63:291.

135. Koller MF, Papassotiropoulos A, Henke K, Behrends B, Noda S, Kratzer A, Hock C, Hofmann M. Evidence of a genetic basis of Morgagni-Stewart-Morel syndrome. A case report of identical twins. Neurodegener Dis 2005;2:56-60.

136. She R, Szakacs J. Hyperostosis frontalis interna: case report and review of literature. Ann Clin Lab Sci 2004;34:206-208.

137. de Zubicaray GI, Chalk JB, Rose SE, Semple J, Smith GA. Deficits on self ordered tasks associated with hyperostosis frontalis interna. J Neurol Neurosurg Psychiatry 1997;63:309-314.

138. Pedersen J. Hyperostosis cranialis interna; the Morgagni and Stewart-Morel syndromes; examination of females suffering from diabetes mellitus and other endocrine disorders as well as female epileptics. Acta Med Scand 1947;128:71-102.

139. Pagon RA, Beckwith JB, Ward BH. Calvarial hyperostosis: a benign X-linked recessive disorder. Clin Genet 1986;29:73-78.

140. Borra VM, Steenackers E, de Freitas F, Van Hul E, Glass I, Van Hul W. Localization of the gene for Xlinked calvarial hyperostosis to chromosome Xq27.3-Xqter. Bone 2013;58C:67-71.

141. Perdu B, Van Hul W. Sclerosing bone disorders. In: Genetics of bone biology and skeletal disease: Elsevier; 2013:361-374.

142. Abdel-Aziz T, Upile T, Scholtz LU, Sudhoff HH. Osteopetrosis of the temporal bone. Otol Neurotol 2012;33:e45-46.

143. Cure JK, Key LL, Goltra DD, VanTassel P. Cranial MR imaging of osteopetrosis. AJNR Am J Neuroradiol 2000;21:1110-1115.

144. Dhamija B, Pettorini BL, Solanki G. Endoscopic third ventriculostomy for the treatment of osteopetrosisrelated hydrocephalus: a case-based update. Childs Nerv Syst 2011;27:1861-1865.

145. Sheppard WM, Shprintzen RJ, Tatum SA, Woods CI. Craniometaphyseal dysplasia: a case report and review of medical and surgical management. Int J Pediatr Otorhinolaryngol 2003;67:71-77.

146. Caracas HP, Figueiredo PS, Mestrinho HD, Acevedo AC, Leite AF. Pycnodysostosis with craniosynostosis: case report of the craniofacial and oral features. Clin Dysmorphol 2012;21:19-21.

147. Uppal HS, D'Souza AR, Proops DW. Osseo-integration in Paget's disease: the bone-anchored hearing aid in the rehabilitation of Pagetic deafness. J Laryngol Otol 2001;115:903-906.

148. Shonka DC, Jr., Kesser BW. Paget's disease of the temporal bone. Otol Neurotol 2006;27:1199-1200.

149. Cundy T, Hegde M, Naot D, Chong B, King A, Wallace R, Mulley J, Love DR, Seidel J, Fawkner M, Banovic $T$, Callon KE, Grey AB, Reid IR, Middleton-Hardie CA, Cornish J. A mutation in the gene TNFRSF11B encoding osteoprotegerin causes an idiopathic hyperphosphatasia phenotype. Hum Mol Genet 2002;11:2119-2127.

150. McCarthy EF, Sack GH. Hyperphosphatasia with massive osteoectasia: a 45-year follow-up. Skeletal Radiol 2007;36 Suppl 1:S2-6.

151. Lee JS, FitzGibbon EJ, Chen YR, Kim HJ, Lustig LR, Akintoye SO, Collins MT, Kaban LB. Clinical guidelines for the management of craniofacial fibrous dysplasia. Orphanet J Rare Dis 2012;7 Suppl 1:S2.

152. Bulakbasi N, Bozlar U, Karademir I, Kocaoglu M, Somuncu I. CT and MRI in the evaluation of craniospinal involvement with polyostotic fibrous dysplasia in McCune-Albright syndrome. Diagn Interv Radiol 2008;14:177-181. 
153. Waguespack SG, Hui SL, White KE, Buckwalter KA, Econs MJ. Measurement of tartrate-resistant acid phosphatase and the brain isoenzyme of creatine kinase accurately diagnoses type II autosomal dominant osteopetrosis but does not identify gene carriers. J Clin Endocrinol Metab 2002;87: 2212-2217. 
Clinical, radiological and metabolic features of Clinical, radiological and metabolic features of

(n)

Part II

\section{Clinical, radiological and metabolic features of
hyperostosis cranialis interna}

a

Part

t

C 


\section{Chapter}

Phenotypic manifestations and management of hyperostosis cranialis interna

Jérôme J. Waterval

Robert J. Stokroos

Noël J.C. Bauer

R. Bert-Jan de Bondt

Johannes J. Manni

American Journal of Medical Genetics - Part A. 2010;152A(3):547-555 


\begin{abstract}
Hyperostosis cranialis interna is a hereditary bone disorder that is characterised by endosteal hyperostosis and osteosclerosis of the calvaria and the skull base (OMIM 144755). The progressive bone overgrowth causes entrapment and dysfunction of cranial nerves I, II, V, VII and VIII, its first symptoms often presenting during the first two decades. This study analyses the clinical course of 13 affected individuals of three related subfamilies (32 individuals). The disorder has an autosomal dominant transmission pattern. Facial and vestibulocochlear nerve dysfunction are most frequently reported. Surgical decompression of the impaired cranial nerves is advised in the early symptomatic period or even in the presymptomatic period in high-risk individuals.
\end{abstract}




\section{Introduction}

Hyperostosis cranialis interna $(\mathrm{HCl})$ is a hereditary disorder that is characterised by endosteal hyperostosis and osteosclerosis of the calvaria and the skull base (OMIM 144755), first described by Manni et al. ${ }^{1}$. The progressive bone overgrowth causes entrapment and dysfunction of cranial nerves I, II, V, VII and VIII. There is resemblance with sclerosteosis and Van Buchem disease, especially the endosteal aspect of the hyperostosis $^{2-4}$. Individuals with Camurati-Engelmann disease present with similar (endosteal) cranial abnormalities, however most patients have predominant radiological skeletal abnormalities ${ }^{5,6}$. There are some striking similarities to hyperostosis frontalis interna (HFI). HFI comprises benign isolated frontal endosteal hyperostosis with the same pattern as $\mathrm{HCl}^{7,8}$. In $\mathrm{HCl}$ the viscerocranium and the tubular bones are explicitly not involved. The facial appearance is normal. Within the international classification of genetic skeletal disorders $\mathrm{HCl}$ matches in the group of disorders with increased bone density with metaphyseal and/or diaphyseal involvement ${ }^{9}$.

In this study we describe three related subfamilies with common progenitors affected with $\mathrm{HCl}$ to analyse the course of the disorder. The older generations were initially investigated in $1985^{1}$. The interval between both studies may give insight in the initiation and the evolution of the disease and may create basic principles to facilitate decisions in counselling and interventions concerning the affected patients.

\section{Materials and methods}

The medical history was recorded through a standardised checklist. Examination was performed by two doctors. Neuro-otological examination included a routine ENTexamination with special attention to skull and facial abnormalities and evaluation of the cranial nerve functions. Smell and taste were tested bilaterally using Sniffin' sticks ${ }^{10}$. Balance was tested clinically using Unterberger, Romberg and head impulse tests. The morphology of the face and the head was photographed. Patients were inspected for other skeletal anomalies.

Pure tone and speech audiometry were obtained. The results are reported as pure tone average (PTA), the average of thresholds at 1, 2 and $4 \mathrm{kHz}$. Acoustic impedance and stapedial muscle reflexes were measured as well as click-evoked otoacoustic emissions and auditory brainstem responses.

Vestibular examination comprised oculomotor function assessment and electronystagmography by caloric and rotational chair provocation. In this paper, the general results of tone audiometry and vestibular examination are reported; a detailed report of audiological and vestibular data will appear in a separate article. 
Visual acuity, manifest refraction, colour vision and pupillary reaction were examined by the same ophthalmologist and fundoscopy was performed. Additionally, orthoptic evaluation (including eye movements) and perimetric tests were performed. The intraocular pressure was measured by an applanation tonometer. If indicated, an ultrasonogram of the optic nerve was made.

All examined patients underwent computed tomography scanning. In this paper, radiological data are only used to confirm or exclude $\mathrm{HCl}$ and to assess radiological progression. Details of radiological imaging will appear in a separate article.

Three related Dutch families, comprising 32 related individuals, have common progenitors (Figure 3.1), three deceased. The first known affected individual was born in 1904. Information regarding her was obtained through her children. Nine of 11 affected individuals who were investigated in 1985 have been investigated again in this study (two deceased). In the present study, a total of 22 individuals have been examined, of 28 living family members. Six children were not examined yet because the parents considered them being too young (all under the age of four); there was no history of complaints related to $\mathrm{HCl}$. There was no consanguinity between spouses.

An individual without radiographic abnormalities is considered unaffected when the age of 18 is reached. Twelve individuals (without abnormalities) have not yet reached this age.

\section{Results and clinical reports}

In total 13 individuals are radiologically affected, 2 of them are asymptomatic. Six family members are definitively unaffected.

The case reports of affected individuals will be described per family. We mainly focus on abnormal symptoms and findings. Individuals are given a case number, consisting of a Roman number (generation) and an Arabic number, corresponding with the pedigree (Figure 3.1). If possible the actual symptoms are compared to those in 1985 as well as the degree of radiological progression. The chronology and the severity of their symptoms can easily be traced in Figure 3.2 and Table 3.1.

The first known affected common family member (individual I.1), born in 1904, was the great-great-grandmother of the youngest generation. She was known to have a right facial palsy since she was 19 . She had frequent severe headaches, impaired vision and impaired smell. She died at the age of 39. 


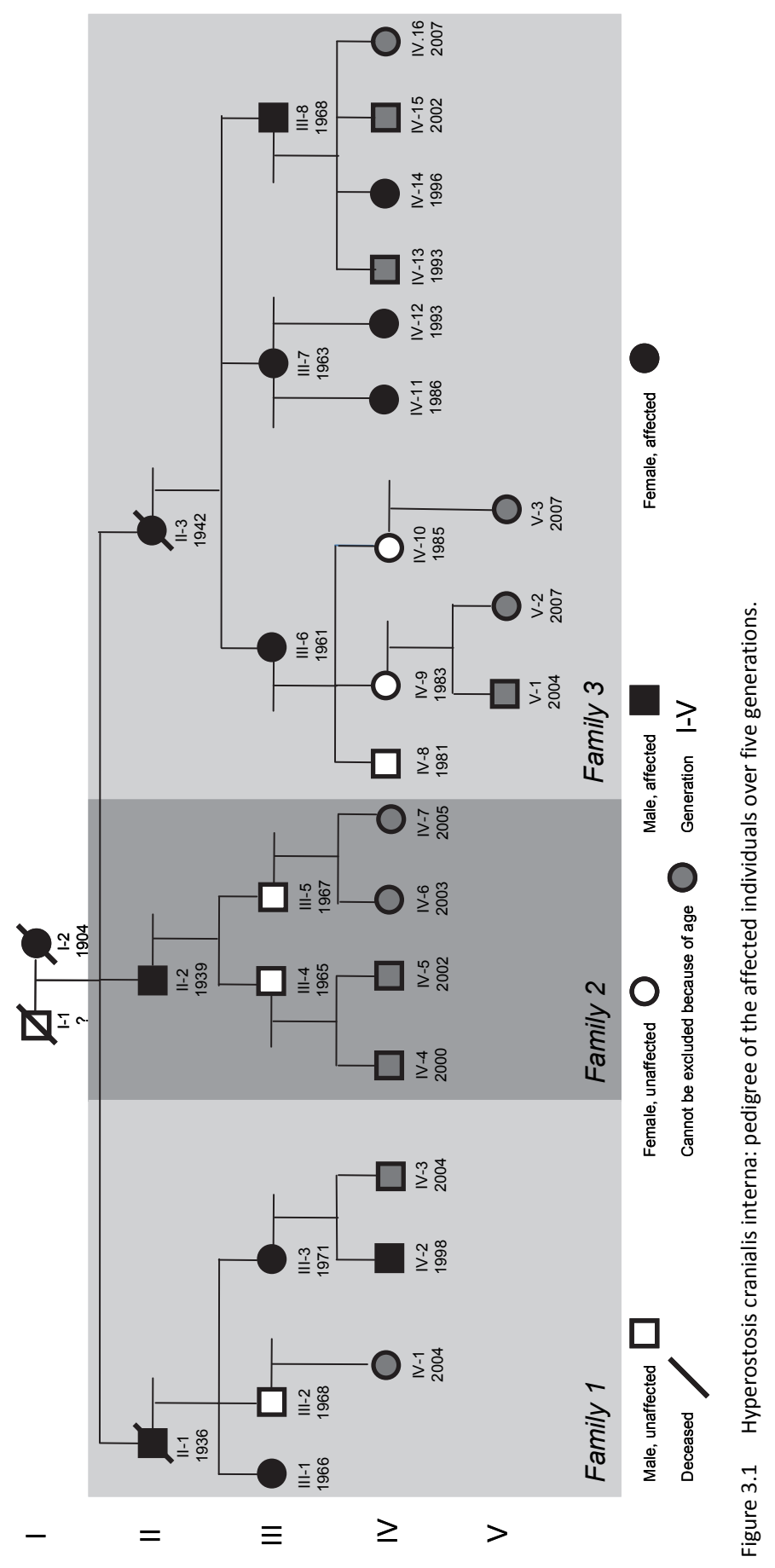




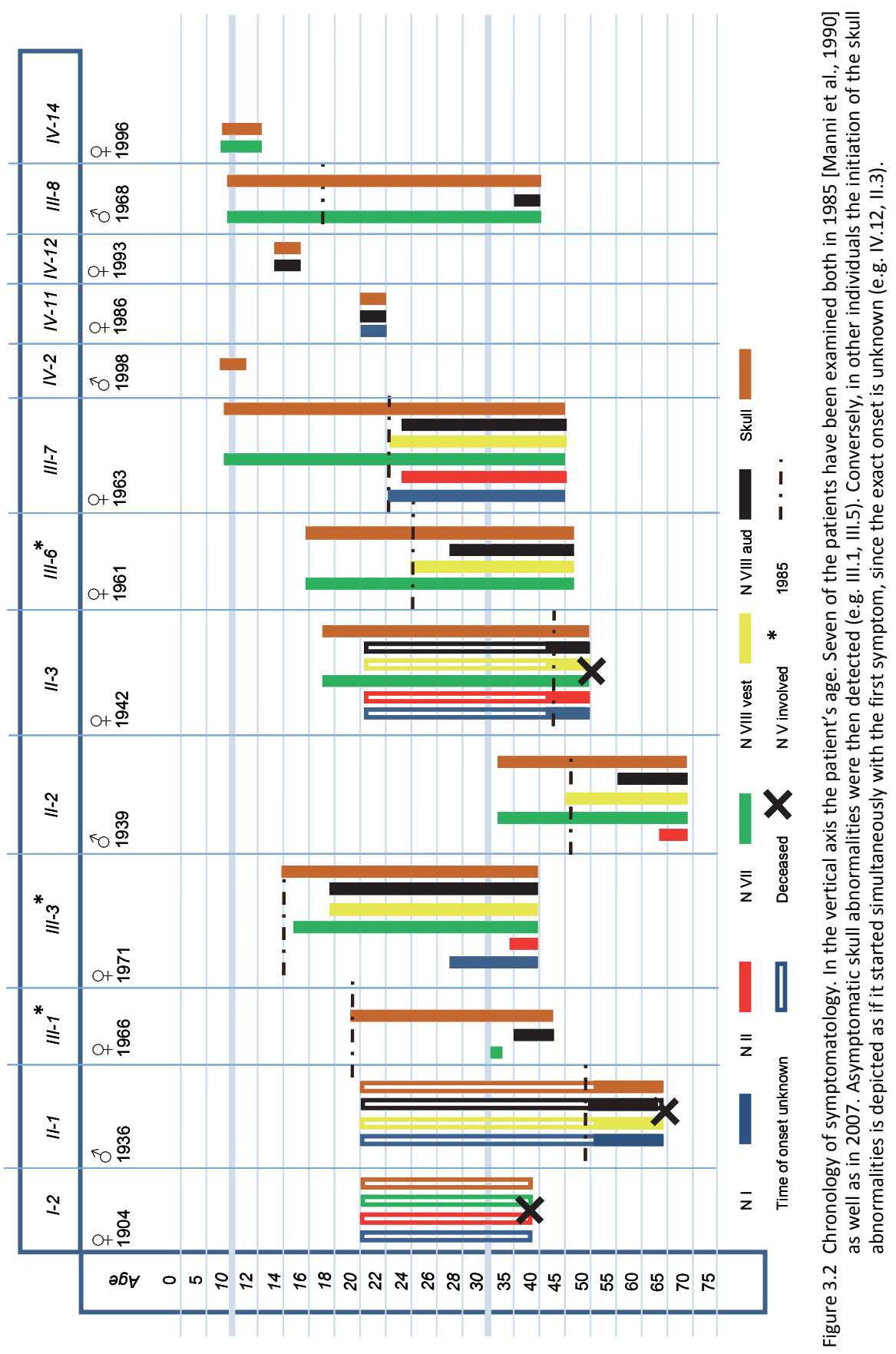




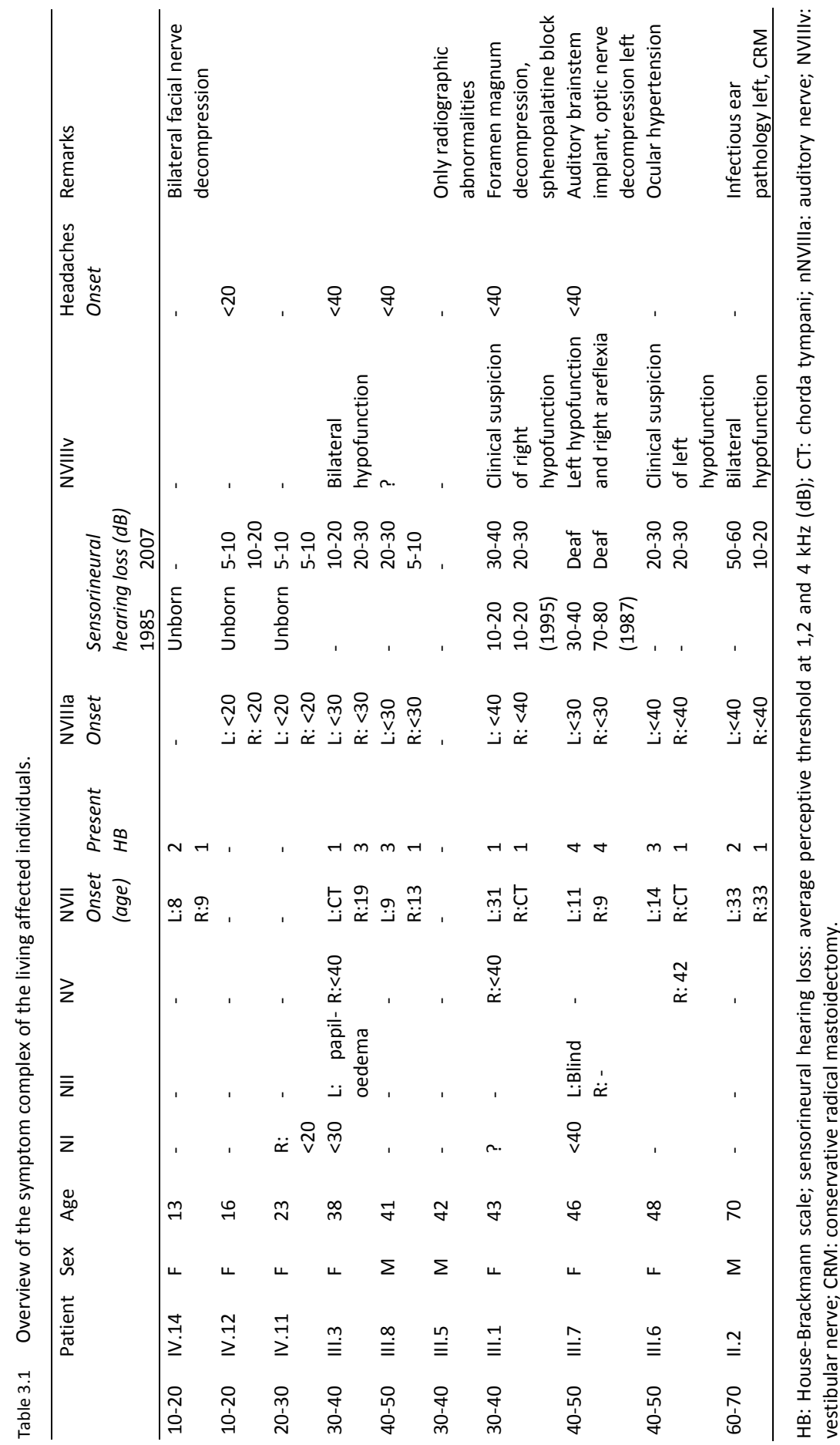




\section{Family 1}

Individual II.1, ô 1936. This person was moderately affected. Since childhood there had been chronic otitis media. In 1985 he had left-sided olfactory impairment, moderate bilateral sensorineural and conductive hearing loss (the latter due to middle ear surgery) and bilateral diminished vestibular function ${ }^{1}$. There was explicitly no history of facial nerve involvement. CT scanning revealed extensive hyperostosis and sclerosis of the calvaria and the skull base. The disease has remained clinically stable until his death at the age of 69 (unrelated to $\mathrm{HCl}$ ).

Individual III.1, 1966. At the age of 19 (1985), she had asymptomatic radiological skull abnormalities ${ }^{1}$. Ever since, there have been remarkable clinical and radiological progression. This individual is now severely affected. At the age of 31 , she had a complete left facial nerve palsy during one week, which recovered completely. In her mid 30s she developed severe right-sided trigeminal neuralgia (all branches). She underwent a foramen magnum decompression at the age of 40 in another hospital because of a Chiari I malformation with concurrent headache, nausea and swallowing difficulties since 1 year. Her complaints resolved for only 1 year. After the operation she developed a feeling of disequilibrium and staggering gait without vertigo. Recently the trigeminal neuralgia increased despite percutaneous Gasser ganglion blockage and radiofrequency treatment. On current physical examination there is anosmia (Figure 3.3F), bilateral anaesthesia of the tongue and normal facial sensibility. Facial mimic function is intact. Audiometry reveals bilateral sensorineural hearing loss (PTA $30 \mathrm{~dB}$ ). Vestibular function on clinical evaluation is diminished on the right side. Ophthalmologic assessment is normal.

Individual III.3, 1971 (Figure 3.3B and 3.3C). She was examined in 1985 and had asymptomatic radiological skull abnormalities ${ }^{1}$. There has been fairly rapid radiological progression since then as opposed to moderate clinical progression. The radiological abnormalities are now extensive. At the age of 15 she developed a sudden facial paralysis at the right side. With conservative treatment her facial nerve function recovered to House-Brackmann (HB) grade III in half a year. During her first pregnancy (age 27) she developed total anosmia, which recovered thereafter and again she lost her sense of smell during her second pregnancy. Sporadically, there is temporary hyposmia. Hearing at the right side is worse and is accompanied with continuous tinnitus since 7 years. She experiences severe headaches, especially during menstruation. Upon current examination senses of smell and taste are completely lost bilaterally. Left trigeminal sensible function is absent in all branches without a history of neuralgia. There is a right facial nerve palsy HB grade III. Audiometry reveals mild sensorineural hearing loss (PTA of 25 and $15 \mathrm{~dB}$, respectively). There is bilateral hyporeflexia of the vestibular apparatus. Ophthalmologic examination reveals rightsided asymptomatic papilloedema on fundoscopy as well as ultrasonography. 
Individual IV.2, 0 1998. This individual is asymptomatic, but the CT scan reveals subtle sclerotic changes in the skull base suggesting $\mathrm{HCl}$. 


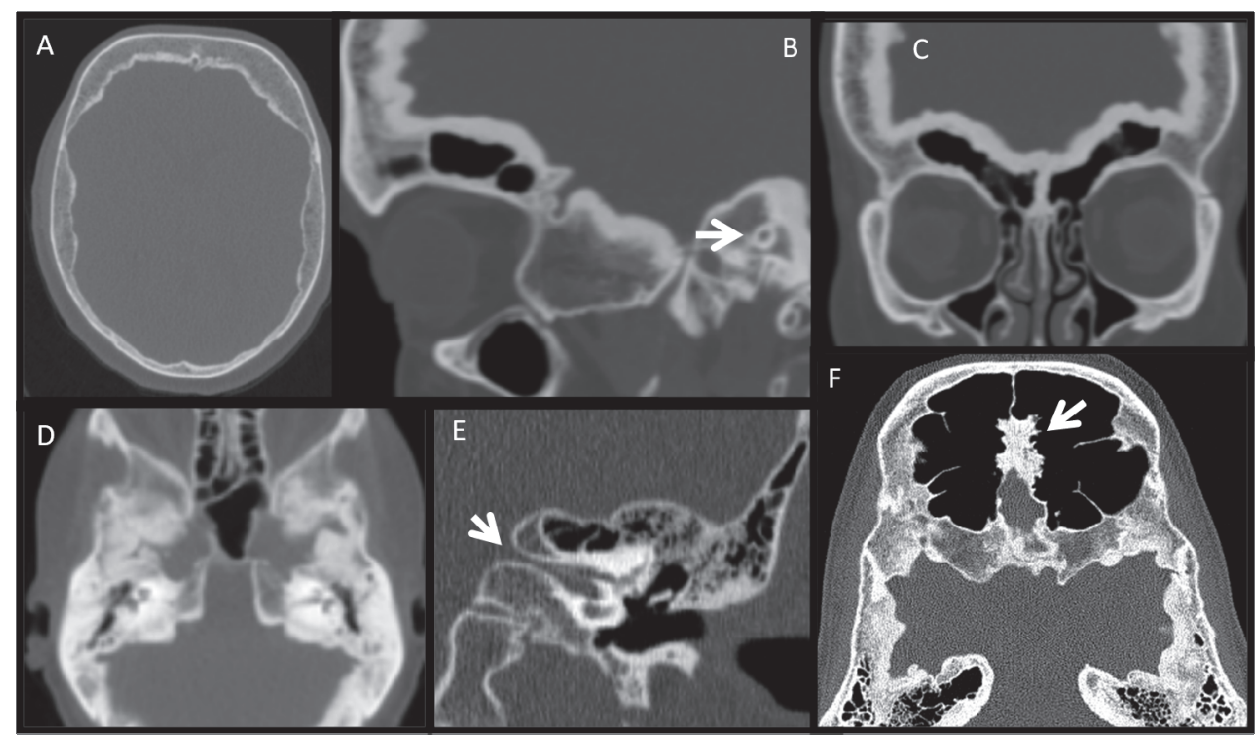

Figure 3.3 CT-imaging. A: Axial image of III.8. Note the frontal and parietal bones are affected. Note the diploë is not obliterated. B and C: Sagittal and coronal reconstructions of III.3. Evident endosteal apposition of bone at the base of skull, whereas the facial bones are unaffected. Arrow: narrowed internal auditory canal. D: Axial image of III.6. Typically the region of the greater wing of the sphenoid bone and the squama temporalis are most severely affected. E: Narrowing of the internal auditory canal due to endosteal apposition (arrow) in IV.14. F: Axial image of the anterior and middle fossa of III.1. Arrow: osteosclerosis of the olfactory region.

\section{Family 2}

Individual II.2, 1939 . In this individual, there is late and mild onset of the disease. Although in 1985 obvious radiological abnormalities were present, there were only moderate symptoms. Since then symptoms have stayed relatively stable. At the age of 32 this individual had intermittent facial nerve impairment at the right side. There was no recurrence of sudden palsies after this event. In the course of his life, he suffered from progressive headaches. He underwent a conservative radical mastoidectomy for chronic mastoiditis at the left side (not related to bony encroachment of the Eustachian tube). In $1985^{1}$, there was bilateral diminished function of both labyrinths. Currently, he experiences continuous tinnitus at the right side. On current physical examination, there is a residual left facial nerve palsy (HB II). There is bilateral epiphora and no sense of taste. Audiometry reveals mixed bilateral hearing loss (PTA $70 \mathrm{~dB}$ at the left, $45 \mathrm{~dB}$ at the right, air-bone gap $25 \mathrm{~dB}$ ). Ophthalmologic assessment reveals diffuse loss of peripheral visual acuity. 


\section{Family 3}

Individual II.3, $q$ 1942. This individual has deceased and was severely affected. At the age of 18 she developed a left facial nerve palsy, which recovered and recurred 3 years later. She was examined in 1985 at the age of $43^{1}$. Then, there was anosmia, she had bilateral proptosis, central scotomas, bilateral optic atrophy and hence absence of visual evoked potentials. Her left facial nerve function revealed synkineses (HB II) and she had left ageusis. She was deaf at the left side and had moderate sensorineural hearing loss at the right side. Vestibular function was absent at the left and diminished at the right side. She deceased after a diagnostic lumbal puncture at the age of 55, due to brainstem herniation. In the last months of her life she was increasingly somnolent and even subcomatose during her last days with concurrent headaches. There were no other symptoms of increased intracranial pressure such as papilloedema or focal neurological signs.

Individual III.6, $\subsetneq 1961$ (Figure 3.3D). This individual had moderate clinical symptoms and moderate radiological skull abnormalities in 1985. Although radiological progression is evident since then, symptomatology has remained relatively stable. She presented with left facial nerve paralysis at the age of 16 and right facial nerve paralysis at the age of 20. The left facial nerve function recovered within 6 months to HB grade III with conservative treatment, the right function completely recovered, except for the taste function. In $1985^{1}$, at the age of 22 , there was bilateral vestibular hyporeflexia. Three years later, there was a sudden sensorineural hearing loss at the left side, accompanied with an episode of vertigo. The hearing recovered after conservative treatment. At present, she has bilateral stabbing ocular pain, frequent headaches and episodes of right trigeminal neuralgia. She has episodes of paroxysmal vertigo with full aural feeling and hyperacusis at the left side. She experiences progressive bilateral hearing loss since 10 years and bilateral tinnitus. On physical examination, there is right-sided hypesthaesia in the first and third trigeminal branches. There is a left HB grade III facial nerve palsy; the sense of taste is completely lost bilaterally. Clinical vestibular examination reveals residual function of the left labyrinth. There is mild symmetric sensorineural hearing loss (PTA $20 \mathrm{~dB}$ ). There is a frontal exostosis. Ophthalmologic examination reveals ocular hypertension.

Individual III.7, $\rightarrow$ 1963. This individual had extensive radiological abnormalities in 1985 along with severe symptoms. Recent CT scanning reveals progressive radiological abnormalities. The severity of symptoms has proceeded as well. She developed a right facial nerve paralysis when she was 9 and a left paralysis when she was 11 . At the age of 23, during her first pregnancy, she suddenly became deaf at the right side $(1985)^{1}$. This did not recover under steroid therapy. There was also right vestibular areflexia. One year later, she developed mild left-sided sensorineural hearing loss, responding under steroid therapy. Her left ear became deaf at the age of 36. At that time, she had total anosmia and right-sided opticopathy with impaired vision. She underwent a rightsided optic nerve decompression because of further visual deterioration (age 38). 
Visual acuity was reduced to light perception, which did not change after the procedure. At the age of 44 an auditory brainstem implant was placed at the left side, with very good auditory results. At present, she has severe headaches and stabbing facial pains and visible facial dystonias. Recent physical examination reveals total anosmia and ageusia. The facial nerve function is grade IV/VI at both sides. Clinical vestibular examination suggests residual function of the left vestibular apparatus. Ophthalmologic investigation has not changed.

Individual IV.11, + 1986. Her medical history is uneventful, her complaint is hearing deterioration. Physical examination reveals the inability of smell discrimination at the right side. Audiometry reveals mild symmetric sensorineural hearing loss (PTA 8dB). Radiological imaging confirms $\mathrm{HCl}$.

Individual IV.12, + 1993. Experiences frequent progressive mild headaches, but has no other complaints. On physical examination, no abnormalities are found. Audiometry reveals mild asymmetric sensorineural hearing loss (PTA $8 \mathrm{~dB}$ at the left and $13 \mathrm{~dB}$ at the right side). Radiological imaging confirms $\mathrm{HCl}$.

Individual III.8, đ 1968 (Figure 3.3A). In 1985 there were mild symptoms along with moderate radiological abnormalities. Although there is some radiological progression, his sympomts have remained relatively stable. He had facial paralyses at the age of 9 (left) and 13 (right). Moreover, he suffers from recurrent headaches. Hearing is worse at the left side since the age of 30 along with continuous tinnitus. Recent examination reveals symmetric exostoses of the anterior wall of the external acoustic meatus and exostoses of the left frontal bone and the mandible at the left side. Facial nerve function is HB grade I and III at right and left side, respectively. Taste function is impaired at the left side. Audiometry reveals mild left-sided sensorineural hearing loss (PTA 20dB). Apart from amblyopia, no other abnormalities on ophthalmologic examination are found.

Individual IV.14, + 1996. This individual developed sudden facial paralysis at the age of 8 and 9. Both sides responded only partially to steroid therapy (right side HB IV, left side HB III). Bilateral facial nerve decompression via middle fossa approach with one year interval were performed in our institute. Only the intrameatal part of the facial nerve was compressed (Figure 3.3E). Facial nerve function recovered within one year to $\mathrm{HB} I$ at the right and HB II at the left side. She experiences continuous bilateral tinnitus. Audiometry reveals normal hearing levels.

\section{Facial nerve}

In total 9 individuals have had fifteen facial nerve palsies. Facial nerve impairment also was their first symptom. It occurred between 8 and 30 years of age in females $(n=7)$ and between 9 and 33 years of age $(n=2)$ in males. In only 3 patients the facial nerve impairment occurred unilaterally (II.2, III.1 and III.3). Typically, there is a rapidly evolving initial paralysis, followed by a partial and sometimes complete recovery under steroid therapy (Figure 3.4). Mimic function recovered to HB grade I in 4 of the palsies 
and to $\mathrm{HB}$ grade II in 3 of the palsies after conservative treatment. In the remaining 5 palsies facial nerve function recovered to HB grade III or IV, with severe synkineses. None of the subjects experienced delayed deterioration of mimic function after stabilisation of the facial nerve function, despite progressive intrameatal encroachment according to radiological data. Facial nerve decompression via middle fossa approach by opening the internal auditory canal has been performed bilaterally in one patient (IV.14) at the age of 9 with good outcome. Outcome of taste function is much poorer: it recovered bilaterally in the individual in which surgical decompression was performed but remained absent in all other individuals. Three individuals have unilateral taste impairment without a history homolateral facial palsy.

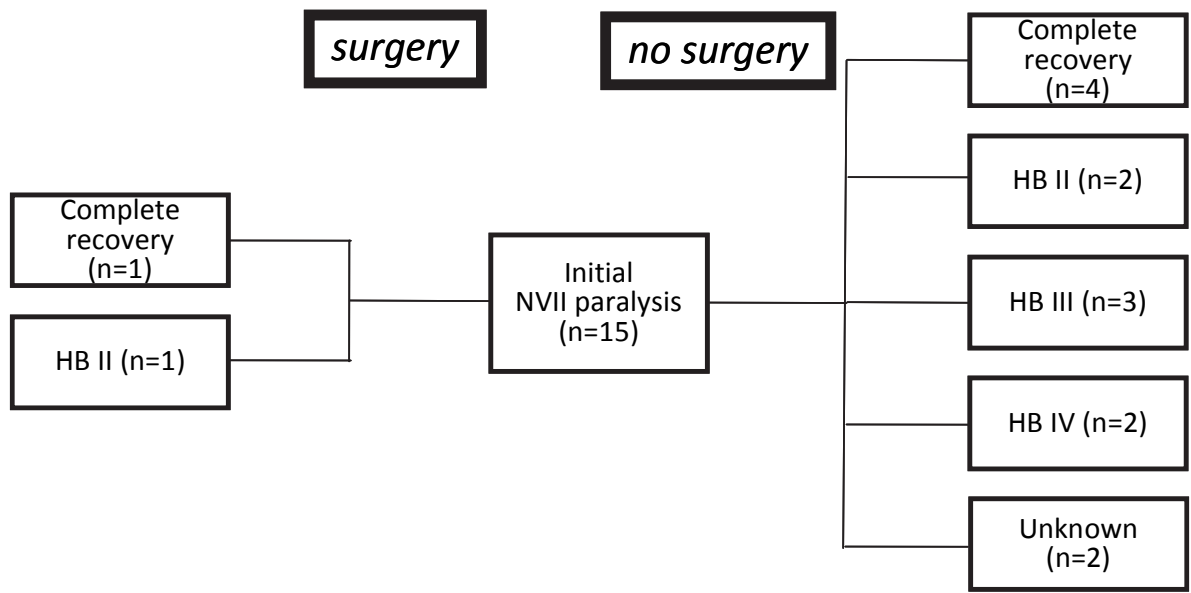

Figure 3.4 Evolution of the 15 facial nerve palsies among 9 patients.

\section{Vestibulocochlear nerve}

Ten individuals have confirmed vestibulocochlear nerve dysfunction. Six of them have vestibular dysfunction. The onset of vestibulocochlear nerve impairment can be slumbering, characterised by tinnitus, sensorineural hearing loss and increasing balance problems. In some individuals the onset was subclinical. On the other hand, four individuals had a sudden sensorineural hearing loss, all female and all linked to hormonal events, such as pregnancy, oral contraceptive use and ovulation. None of the patients have $\mathrm{HCl}$-related conductive hearing loss. There are two patients with a history of sudden vestibular nerve impairment (III.6, III.7), both during a sudden sensorineural hearing loss event but without simultaneous facial nerve symptoms. In two patients there has been a slowly progressive vestibular function decrease (II.2 and III.3), characterised by the absence of vertiginous symptoms. 


\section{Other symptoms}

The loss of the sense of smell is registered in six patients. The onset is generally in the third decade, either subclinical, or linked to hormonal changes.

Ocular symptoms occur later in life $(n=5)$. Ocular hypertension is seen in one patient and is not supposed to be $\mathrm{HCl}$-related.

Trigeminal impairment is reported in three patients and consists of facial and tongue numbness or severe trigeminal neuralgia. It can occur in separate branches of the nerve suggesting impingement at the level of the corresponding foramen or the nerve as a whole suggesting proximal encroachment.

The most severely affected patients suffer from intermittent headaches $(n=5)$. In none of the patients with available CT-scans hydrocephalus is seen. One of the family members (II.3) died after a lumbar puncture during diagnostic work-up for severe headaches.

\section{Discussion}

\section{Transmission and gender pattern}

The pedigree has been identified until the beginning of the $20^{\text {th }}$ century, because the parents of individual I.1 could not be traced. Within the pedigree there exists explicitly no consanguinity, nevertheless this cannot be confirmed for previous generations. The transmission pattern is autosomal dominant. In total five male individuals and nine female individuals have been affected.

Clinical comparison of the affected individuals suggests different degrees of severity of the disease. The difference between male and female patients is most remarkable. Females are more severely affected than males. None of the three symptomatic male patients are experiencing severe symptoms. The three female patients under 20 have serious skull abnormalities and are symptomatic. The four middle-aged living female patients all have multiple cranial nerve deficits including total deafness, single-sided blindness and severe trigeminal neuralgia. The reason for this evident sex difference remains unclear, but we suppose a hormonal influence on bone metabolism may play a role. This sex-difference displays remarkable similarities compared to $\mathrm{HFI}$, women being more often and more severely affected ${ }^{7}$. Temporary differences in female patients are also remarkable: ovulation and pregnancy are reported to impair the sense of smell temporarily in several cases, probably due to progesterone-induced tissue edema of the perineurium. 


\section{Onset of disease, different symptoms}

First symptoms often present in adolescence, the median age being 14 . Early symptoms are an ominous prognostic factor for severe progression of the disease. Figure 3.2 shows an overview of the course of the disease throughout life. Radiological skull abnormalities are found before they become symptomatic, mainly in the sphenoid wings and the frontal bones where hyperostosis can occur relatively harmless. Facial nerve involvement is the most frequent first symptom, occurring mainly in adolescence. This is followed by sensorineural hearing loss. These nerves are affected first because of the endosteal apposition of bone near the internal auditory canal, noticed from the age of 7 .

It was demonstrated that the first audiological signs appear first as prolonged latencies on brainstem evoked auditory potentials ${ }^{11}$. In some cases vestibulocochlear nerve function gradually deteriorates, in other patients there are events of sudden sensorineural hearing loss or vertigo. Like in facial nerve dysfunction, it is remarkable that progressive hyperostosis in the region of the porus of the internal auditory canal results in moderate non-progressive hearing loss only in several patients.

Olfactory nerve and trigeminal nerve dysfunction generally occur in the third and fourth decade due to progressive osteosclerosis of the anterior fossa. Opticopathy occurs in a late stage if at all, due to bony encroachment at the level of the optic canal.

\section{Progression of the disease}

Six of the patients have been examined both in 1985 as well as in 2007, which gives better insight in the course of the disease. The degree of progression of the clinical symptoms of the disorder throughout life plays a key role in the discussion and decision whether or not to intervene in certain cases. Clinical progression generally occurs until the age of 40. After the fourth decade, progressive cranial nerve dysfunction is uncommon in most and radiological progression is minimal. Nevertheless in severely affected cases, untimely death may occur due to decreased intracranial volume. If possible, operative cranial nerve decompression is advised in the early symptomatic period. It is assumed that the effect of an operation will last until the active hyperostosis is moderated.

In older patients, progressive headaches are often mentioned, a feeling of pressure in the head. Whether the exact pathogenesis is raised intracranial pressure due to diminished cerebrospinal fluid drainage or the direct compression of the brain by the thickened bone remains unclear. Besides, it is difficult to verify whether this symptom is disease-specific, especially since the patients are aware of their own disease, which is a psychological burden for many.

Apart from radiological progression, which is a measurable value, it appears that there are not many independent reliable clinical factors to predict the clinical course. Olfactory and taste function are either unaffected or completely lost. Facial movement 
impairment is characterised by sudden paralysis and followed by a stable partial recovery. The course of vestibulocochlear nerve damage is usually progressive but cannot be predicted (Table 3.1). Therefore periodical radiological imaging is necessary for assessment of disease progression.

\section{Treatment}

A causative treatment is not available for $\mathrm{HCl}$. Nevertheless, except for support and counselling, there are several important therapeutic interventions. Female patients experiencing fluctuation of their symptoms during their hormonal cycles, such as anosmia, can benefit from continuous use of oral contraceptives to avoid high blood concentration of progestagens. Moderate sensorineural hearing loss can be revalidated with hearing aids. Decompressive operations can be performed. Facial and vestibulocochlear nerve compression, in this disorder likely limited to the intreameatal part of the nerves, can be treated by decompressing the internal auditory canal via middle fossa approach ${ }^{12}$. This intervention should be performed at young age when hyperostosis and ostseosclerosis are expected to be minimal. In our patient this procedure is performed after bilateral facial palsies, however prophylactic decompression in high-risk individuals with beginning internal auditory canal encroachment can also be considered. Optic nerve decompression can be performed in case of threatened vision due to optic canal narrowing. For auditory revalidation in deaf patients an auditory brainstem implant can be considered, carefully assessing the distortion of the anatomy due to hyperostosis. Trigeminal neuropathy can be treated medically, by a percutaneous nerve block, radiofrequency ablation or by radiosurgery. There is scarce literature about the resolution of trigeminal neuralgia associated with Chiari-I malformation ${ }^{13,14}$ through foramen magnum decompression. If hyperostosis is the cause of downward herniation of the brain, a decompressive crianotomy might better be considered ${ }^{15}$. A decompressive craniotomy has not been performed in one of the patients but can be indicated in severe hyperostosis and maybe combined with one of the aforementioned interventions.

\section{Conclusion}

$\mathrm{HCl}$ should be suspected in case of adult or childhood onset of familiar facial nerve or vestibulocochlear nerve impairment. Besides audiometry, a lateral skull radiograph will often be the initial diagnostic investigation (Figure 3.5). To confirm the diagnosis a CT scan is performed (Figure 3.3). Patients generally become symptomatic in their second and third decade. Early decompressive operations of the optic, facial, and vestibulocochlear nerves are advised. 


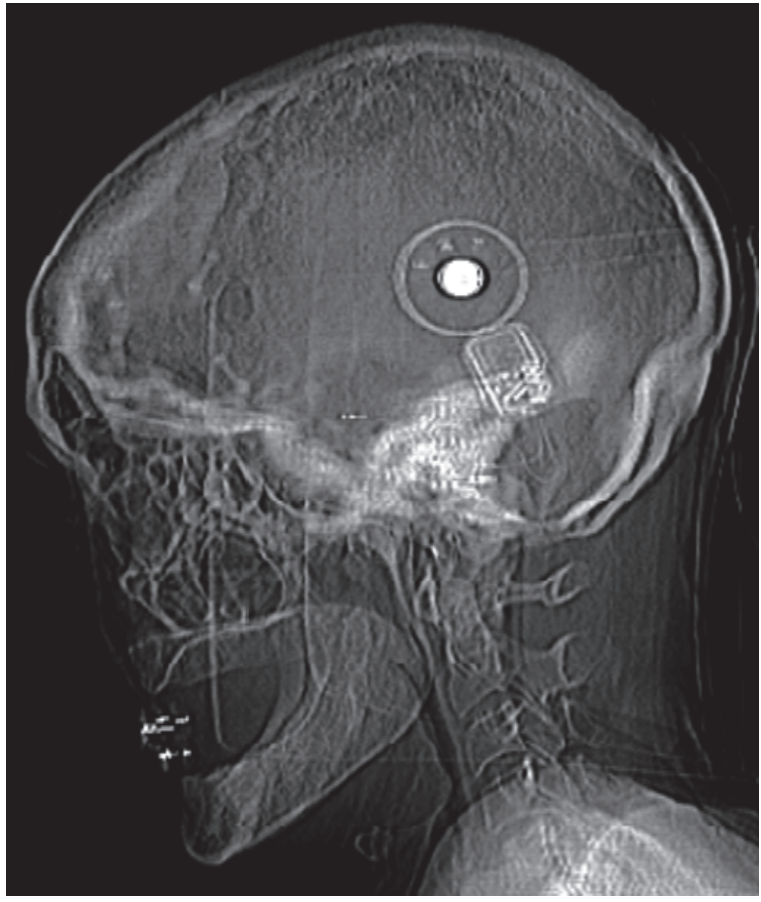

Figure 3.5 Lateral skull radiograph of individual III-7 (i.e., scout view of a CT scan). The skull base and frontal hyperostosis are the most remarkable abnormalities. The auditory brainstem implant and osteosynthesis material of the optic nerve decompression operation are visible. 


\section{References}

1. Manni JJ, Scaf JJ, Huygen PL, Cruysberg JR, Verhagen WI. Hyperostosis cranialis interna. A new hereditary syndrome with cranial-nerve entrapment. N Engl J Med 1990;322: 450-454.

2. Van Buchem FS. The pathogenesis of hyperostosis corticalis generalisata and calcitonin. Proc K Ned Akad Wet C 1970;73: 243-253.

3. van Buchem FS. Hyperostosis corticalis generalisata. Eight new cases. Acta Med Scand 1971;189: 257-267.

4. Hamersma H, Gardner J, Beighton P. The natural history of sclerosteosis. Clin Genet 2003;63:192-197.

5. Vanhoenacker FM, Janssens K, Van Hul W, Gershoni-Baruch R, Brik R, De Schepper AM. CamuratiEngelmann disease. Review of radioclinical features. Acta Radiol 2003;44:430-434.

6. Janssens K, Vanhoenacker F, Bonduelle M, Verbruggen L, Van Maldergem L, Ralston S, Guanabens N, Migone N, Wientroub S, Divizia MT, Bergmann C, Bennett C, Simsek S, Melancon S, Cundy T, Van Hul W. Camurati-Engelmann disease: review of the clinical, radiological, and molecular data of 24 families and implications for diagnosis and treatment. J Med Genet 2006;43:1-11.

7. Hershkovitz I, Greenwald C, Rothschild BM, Latimer B, Dutour O, Jellema LM, Wish-Baratz S. Hyperostosis frontalis interna: an anthropological perspective. Am J Phys Anthropol 1999;109: 303-325.

8. Talarico EF, Jr., Prather AD, Hardt KD. A case of extensive hyperostosis frontalis interna in an 87-yearold female human cadaver. Clin Anat 2008;21:259-268.

9. Superti-Furga A, Unger S. Nosology and classification of genetic skeletal disorders: 2006 revision. Am J Med Genet A 2007;143:1-18.

10. Hummel T, Sekinger B, Wolf SR, Pauli E, Kobal G. 'Sniffin' sticks': olfactory performance assessed by the combined testing of odor identification, odor discrimination and olfactory threshold. Chem Senses 1997;22:39-52.

11. Manni JJ, Huygen PL, Noten JF, Kuijpers W. Eighth cranial nerve dysfunction in hyperostosis cranialis interna. Acta Otolaryngol 1992;112:75-82.

12. Waterval JJ, Stokroos RJ, De Bondt RB, Manni JJ. Facial nerve decompression via middle fossa approach for hyperostosis cranialis interna: a feasible therapeutic approach. J Laryngol Otol 2009;123:1177-1180.

13. Dandy WE. The Treatment of Trigeminal Neuralgia by the Cerebellar Route. Ann Surg 1932;96:787-795.

14. Papanastassiou AM, Schwartz RB, Friedlander RM. Chiari I malformation as a cause of trigeminal neuralgia: case report. Neurosurgery 2008;63: E614-615; discussion E615.

15. Albert L, Jr., Hirschfeld A. Acquired Chiari malformation secondary to hyperostosis of the skull: a case report and literature review. Surg Neurol 2009;72:157-161. 


\section{Chapter 4}

Neurophysiologic, audiometric and vestibular function tests in patients with hyperostosis cranialis interna

Jérôme J. Waterval

Martijn P.H. Bischoff

Robert J. Stokroos

Lucien Anteunis

Danny Hilkman

Herman Kingma

Johannes J. Manni

Clinical Neurology and Neurosurgery 2013;115:1701-1708 


\section{Abstract}

\section{Introduction}

Hyperostosis Cranialis Interna $(\mathrm{HCl})$ is an autosomal dominant sclerosing bone dysplasia affecting the skull base and the calvaria, characterised by cranial nerve deficits due to stenosis of neuroforamina. The aim of this study is to describe the value of several neurophysiological, audiometric and vestibular tests related to the clinical course of the disorder.

\section{Methods}

Ten affected subjects and 13 unaffected family members were recruited and tested with visual evoked potentials, masseter reflex, blink reflex, pure tone and speech audiometry, stapedial reflexes, otoacoustic emissions, brainstem evoked response audiometry and electronystagmography.

\section{Results}

Due to the symmetrical bilateral nature of this disease, the sensitivity of Visual Evoked Potentials (VEPs), masseter reflex and blink reflex is decreased (25-37.5\%), therefore reducing the value of single registration. Increased hearing thresholds and increased BERA latency times were found in $60-70 \%$. The inter-peak latency I-V parameter in BERA has the ability to determine nerve encroachment reliably. $50 \%$ of the patients had vestibular abnormalities. No patient had diseaserelated absence of otoacoustic emissions, because the cochlea is not affected.

\section{Conclusion}

In patients with $\mathrm{HCl}$ and similar craniofacial sclerosing bone dysplasias we advise monitoring of vestibulocochlear nerve function with tone and speech audiometry, BERA and vestibular tests. VEPs are important to monitor optic nerve function in combination with radiological and ophthalmologic examination. We do not advise the routine use of blink and masseter reflex. 


\section{Introduction}

Hyperostosis cranialis interna $(\mathrm{HCl})$ is a hereditary bone dysplasia (Online Mendelian Inheritance in Man 144755) first described in $1990^{1}$ and is characterised by hyperostosis and osteosclerosis of the calvaria and skull base. This process leads to narrowing of various neuroforamina, causing cranial nerve entrapment and dysfunction of cranial nerves I, II, V, VII and VIII. Only one large Dutch family has been diagnosed with $\mathrm{HCl}$ to date, a pedigree is depicted in Figure 4.1. $\mathrm{HCl}$ has an autosomal dominant transmission pattern.

To evaluate the function of the involved cranial nerves, patients underwent a series of function tests. The goal of this paper is to correlate symptomatology to various cranial nerve function tests. In this descriptive report, we will present an overview of the results of the tests of the affected individuals (see Figure 4.2).

The test battery consisted of clinical neurophysiologic testing: visual evoked potentials (VEP); blink reflex and masseter reflex; audiometric testing: pure tone and speech audiometry, stapedial reflexes, otoacoustic emissions (OAE) and brainstem evoked response audiometry (BERA); and vestibular testing: electronystagmography (ENG).

Correspondence between objective cranial nerve tests and symptomatology or disease stage could be of prognostic value, could help for optimising treatment planning and improve counselling.

\section{Materials and methods}

\section{Subjects}

Twenty-two family members were examined, 10 of which are affected. The same patients were examined as in the earlier study about the course of the disease and the symptomatology, except the individuals indicated with \# in Figure $4.1^{2}$. The main reason was that the concerning children were considered to be too young. Function tests were performed in research setting. The individuals were aged 5 to 68 years at the time of examination. Written informed consent was obtained for all tested individuals. 


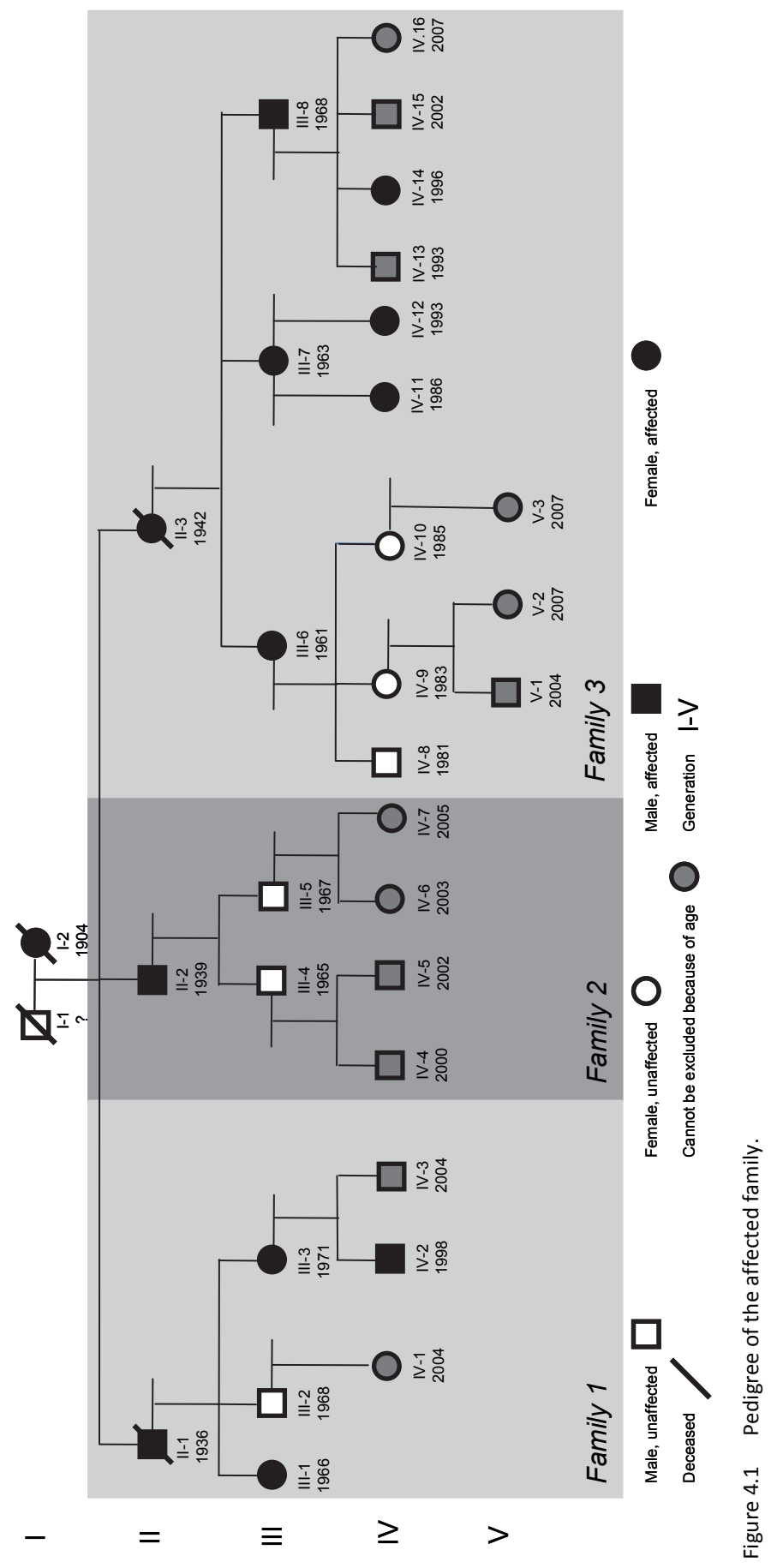




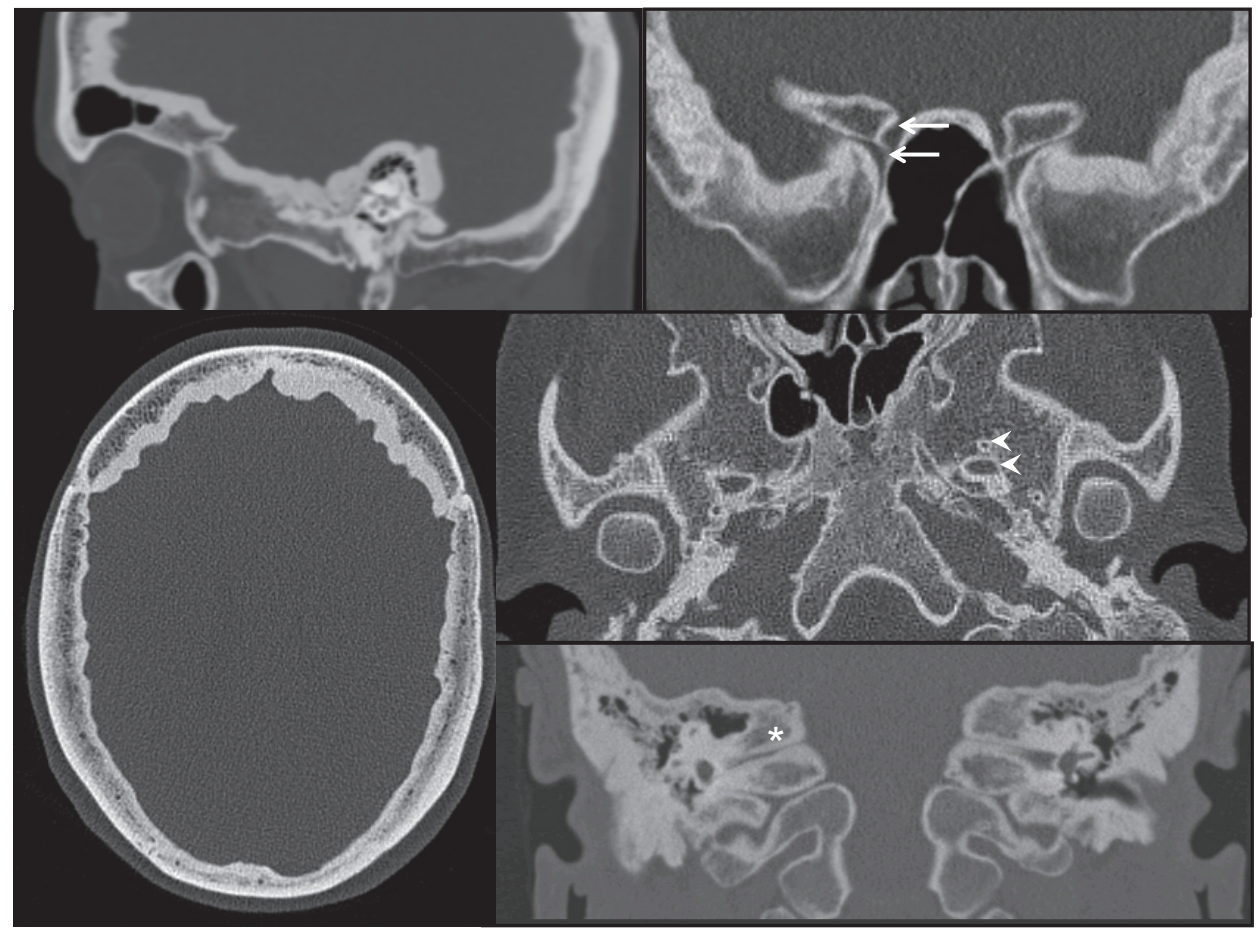

Figure 4.2 Multiple CT images of patients affected with hyperostosis cranialis interna. Upper left: sagittal image of the skull base and calvaria at the level of the inner ear. An hyperostotic endosteal layer can be seen (female mid-30s). Lower left: axial image of a markedly thickened skull. Upper right: coronal image (23-year-old female) of the greater and lesser sphenoid wings. Note narrowing of the optic canal (upper arrow) and the superior orbital fissure (lower arrow). Middle right: axial image showing the foramen rotundum (upper arrowhead) and the foramen ovale (lower arrowhead) in an 18-year-old female. Lower right: bilateral narrowing of the internal auditory canal in a 16-year-old patient (asterisk, coronal reconstruction).

\section{Optic nerve}

Optic nerve function was tested with pattern reversal VEP (ISCEV standard for clinical visual evoked potentials) ${ }^{3,4}$, each eye stimulated individually. Seven electrodes were placed on the scalp to register potentials. Peak latencies N75, P100 and N145 were recorded. The P100 latencies were compared to laboratory reference values and classified accordingly as normal or as possible optic neuropathy and VEP outcome was correlated to clinical ophthalmologic examination.

\section{Trigeminal and facial nerve}

Trigeminal nerve function was assessed using both the masseter reflex and the blink reflex (afferent limb). To assess the masseter reflex, an active electrode was placed 
bilaterally on the masseter muscle belly and a reference electrode below the mandibular angle. The reflex was elicited by a tap on the chin with a reflex hammer and recordings were made simultaneously from the right and left masseter muscles. Latencies and amplitude were recorded repeatedly and the averaged signal was measured. Prolonged latencies and left-right differences were primary outcome measures (reference value: $\leq 8.7 \mathrm{~ms}$ ).

The efferent limb of the blink reflex was used as a parameter to assess facial nerve function and was evoked by electrical stimulation of the supraorbital nerve transcutaneously over the supraorbital foramen. Responses from both orbicularis oculi muscles were recorded with two pairs of electrodes (bilaterally, placed two $\mathrm{cm}$ under the eyes) and a ground electrode under the chin. The registration consisted of latencies from an early ipsilateral response to the stimulated nerve (R1-peak) and a late bilateral response (R2-peak). Waveforms were analysed and left-right differences were compared with laboratory reference values (reference values $\mathrm{R} 1 \leq 13.0 \mathrm{~ms}, \mathrm{R} 2_{\text {ipsi }} \leq 40.0$ $\mathrm{ms}, \mathrm{R} 2_{\text {contra }} \leq 41.0 \mathrm{~ms}$ ). The House-Brackmann (HB) score ${ }^{5}$ was assessed by two trained clinicians in all cases. The outcome was correlated to the HB score and the presence of stapedial reflexes.

\section{Vestibulocochlear nerve}

\section{Pure tone and speech audiometry}

Patients underwent pure tone air and bone conduction audiometry to determine hearing threshold levels. Frequencies ranged from $250 \mathrm{~Hz}$ to $8.0 \mathrm{kHz}$. Intensities were measured in $\mathrm{dB}$ HL (ISO 1975). Pure Tone Average (PTA) was determined as the average threshold at 1.0, 2.0 and $4.0 \mathrm{kHz}$. For speech audiometry we used validated Dutch lists of monosyllabic words (consonant-vowel-consonant words, Dutch Association of Audiology). The subject listened to one list of words at a set sound level. The percentage of phonemes repeated correctly was scored and followed by a different list at 10 to $20 \mathrm{~dB}$ intervals until maximum phoneme recognition percentage was achieved. The Speech Reception Threshold (SRT) was defined as the sound intensity required for the subject to repeat $50 \%$ of the presented phonemes correctly.

\section{Tympanography, stapedial reflexes and otoacoustic emissions}

Tympanometry was performed using a $226 \mathrm{~Hz}$ probe tone at $65 \mathrm{~dB}$ SPL. The results are not related to $\mathrm{HCl}$, but can influence $\mathrm{OAE}$ and stapedial reflex results. Reflexes were elicited at $0.5,1.0,2.0$ and $4.0 \mathrm{kHz}$, with stimulation levels between 70 and $110 \mathrm{~dB} \mathrm{HL}$ (hearing level). Click-evoked otoacoustic emissions (CEOAEs) were recorded. We presented clicks at 80-85 dB SPL, tested frequencies were 1.0, 1.4, 2.0, 2.8 and $4.0 \mathrm{kHz}$. CEOAEs were considered normal if deemed present on at least two frequency bands. 


\section{Brainstem evoked response audiometry}

Rarefaction polarity, and in two patients alternating polarity, click stimuli of $100 \mathrm{~ms}$ were presented monaurally through headphones at sound intensity levels varying from 70 to $85 \mathrm{~dB} \mathrm{nHL}$ at a rate of 11.7 to $15.7 / \mathrm{s}$. Subjects underwent three to five runs of 1,000 to 1,500 clicks per ear. Filter settings were $30 \mathrm{~Hz}-3.0 \mathrm{kHz}$. The analysis time window was $20 \mathrm{~ms}$. One electrode was placed on the vertex and electrodes were placed on the mastoid process bilaterally to register responses. Responses were averaged for each run and inter-peak latencies were calculated and compared to normative values ${ }^{6}$. The main interest was in the latency interval between peaks I and $\mathrm{V}^{7}$.

\section{Vestibular function tests}

Smooth pursuit, optokinetic nystagmus, saccades, torsion swing, velocity step and caloric testing were performed. Eight electrodes were placed on all four sides of both eyes to detect the corneoretinal potential when smooth pursuit, optokinetic nystagmus, saccades, torsion swing, velocity step and caloric testing were performed. The reference electrode was placed on the forehead.

Smooth pursuit was tested with a sinusoidally moving target $(\mathrm{f}=0.2 \mathrm{~Hz}$, peak amplitude $10^{\circ}$ ) Primary measures were position gain and phase.

Spontaneous, fixation and gaze evoked eye movements were quantified. Optokinetic nystagmus was tested with a horizontally moving random dot pattern on the wall. Velocities applied were $5 \%$ up to $35 \%$ with intervals of $5 \%$ s. Each velocity, both leftwards and rightwards, was presented for 1 minute. To evaluate the vestibulo-ocular reflex in complete darkness with eyes open, rotational testing was performed. The torsion swing rotation test (with and without fixation to score the fixation suppression index) was applied using a stimulus frequency of $0.1 \mathrm{~Hz}$ with a peak velocity of $60^{\circ} / \mathrm{s}$. The second rotational test stimulus was using a velocity step test profile, both clockwise and anti-clockwise. A subthreshold acceleration of $1.5^{\circ} / \mathrm{s}^{2}$ was applied until a peak velocity of $100^{\circ} / \mathrm{s}$ was achieved. This velocity was sustained until 10 seconds after the perrotatory nystagmus had disappeared completely and then a deceleration impulse of $100 \% \mathrm{~s}^{2}$ was applied until standstill. The post-rotatory gain, time constant and response symmetry (contrast function comparing clock-wise and anti-clockwise responses) were calculated.

Caloric testing was performed to evaluate horizontal semicircular canal function. The patient was in supine position, with the head tilted $30^{\circ}$ in flexion. Each ear was irrigated with water for 30 seconds $\left(30^{\circ} \mathrm{C}\right.$ and $\left.44^{\circ} \mathrm{C}\right)$ with a total volume of $250 \mathrm{ml}$. Nystagmus preponderance and side difference were calculated according to the Jongkees formula ${ }^{8}$. Excitability was considered reduced when the sum of responses to the cold and warm irrigation on one side was below $15 \%$ s. A nystagmus preponderance of more than $25 \%$ and a side difference of more than $20 \%$ were considered pathological. 
Box 1. The course of disease of patient III-3 $(q, 1971)$ is exemplary for $\mathrm{HCl}$. At the age of 15 she developed a right-sided facial nerve paralysis, recovering to House-Brackmann grade III in six months and still present today. She has subjective hearing loss and tinnitus since age 18 . She reported total anosmia during both pregnancies and currently her sense of smell and taste are bilaterally absent. Left trigeminal nerve function is lost without signs of trigeminal neuralgia. Visual symptoms were never reported.

Radiological skull abnormalities had been observed since age 14. A thick inner table and a narrowed internal acoustic canal, foramen ovale and superior orbital fissure were seen bilaterally. Testing revealed mild hearing loss with a pure tone average of 25 (right side) and $15 \mathrm{~dB} H \mathrm{HL}$ (left side), with an increased speech reception threshold at the right side and an abnormal BERA. CEOAEs were present bilaterally indicating normal cochlear function. Vestibular testing revealed right labyrinth hyporeflexia. The absent blink and stapedial reflexes on the right side indicate facial nerve dysfunction. Fundoscopy and ultrasonography revealed right-sided asymptomatic papilloedema. Masseter reflex was normal.

The general order of pathological onset, either by symptoms or testing, is summarised as follows: skull thickening, subclinical vestibulocochlear nerve dysfunction, facial nerve palsy, clinical vestibulocochlear nerve dysfunction and - in a random order ophthalmic nerve, trigeminal nerve and optic nerve dysfunction.

\section{Results}

\section{Optic nerve}

Eight out of ten patients were tested using pattern reversal VEPs (Figure 4.3). Two patients did not take part. Moreover, due to $\mathrm{HCl}$ related blindness, it was not possible to obtain a right-sided VEP from patient III-7 (q, 1963); patient IV-1 (q, 2004) underwent a flash VEP test because of her young age (normal response). None of the examined patients had a visual acuity lower than 20/25 cum correctione. 


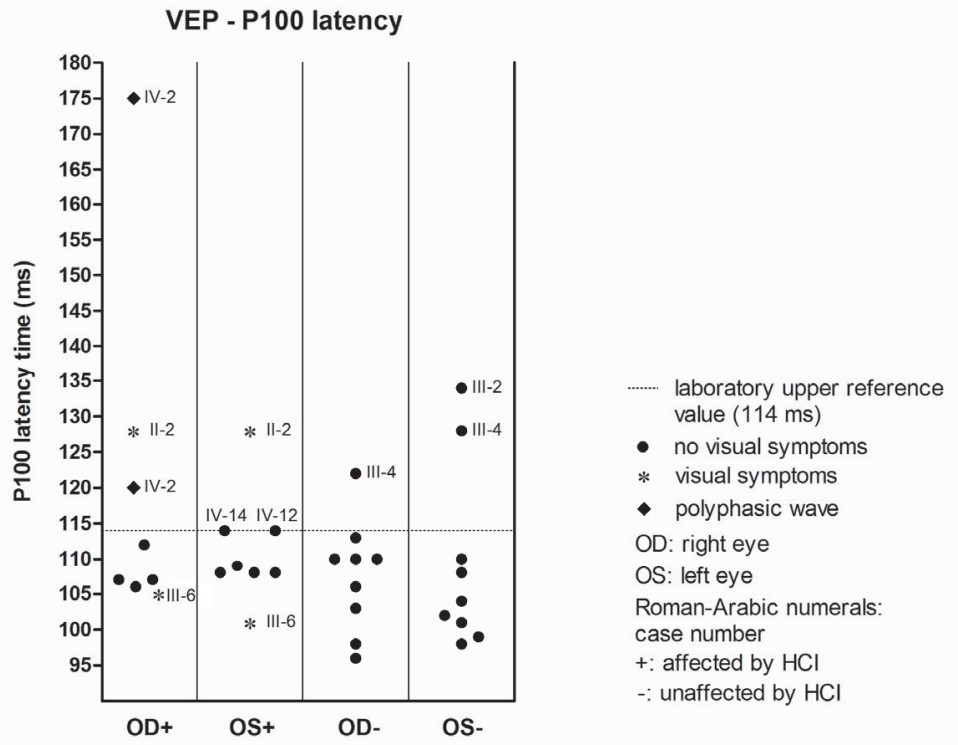

Figure 4.3 Scatter plot of VEP results in patients and the unaffected family members.

Two of the unaffected family members had unexplained increased latency times, one of his left optic nerve (III-2, $\widehat{O}, 1968)$ and one bilaterally (III-4, $\widehat{O}, 1965)$.

Patient IV-2 $(\hat{\sigma}, 1998)$ showed a pathological double VEP P100 waveform from his right eye (visual acuity of $20 / 25$, refractory origin, no other symptoms). The optic canals were not extremely narrowed on CT scan, leaving no explanation that could link the VEP results to $\mathrm{HCl}$-related compression neuropathy. Patient II-2 $(\lesssim, 1939)$ had bilaterally prolonged VEP latency times and diffuse loss of peripheral vision. The CT scan showed mild encroachment of the right optic canal but no abnormalities of the left optic canal. On the other hand, one patient with a nearly obliterated left optic canal (diameter $0.7 \mathrm{~mm}$ ) on the CT scan $(\mathrm{III}-7,+, 1963)$ had no visual symptoms and a normal P100 latency.

\section{Trigeminal and facial nerve}

All masseter and blink reflexes were normal in the unaffected group. Eight out of ten patients underwent masseter and blink reflex testing (Figure 4.4). Three individuals, all female, reported trigeminal nerve related complaints. One patient had an abnormal masseter reflex latency time unilaterally. Patient III-7 $(9,1963)$ had trigeminal nerve symptomatology and a unilateral prolonged latency. Patient IV-11 $(q, 1986)$ had bilaterally prolonged masseter reflex latencies and she reported new-onset bilateral trigeminal nerve symptoms in the follow-up period. Concerning the masseter reflex, a 
trend was observed of latencies near the upper level of normality in the affected group as opposed to the unaffected subjects.

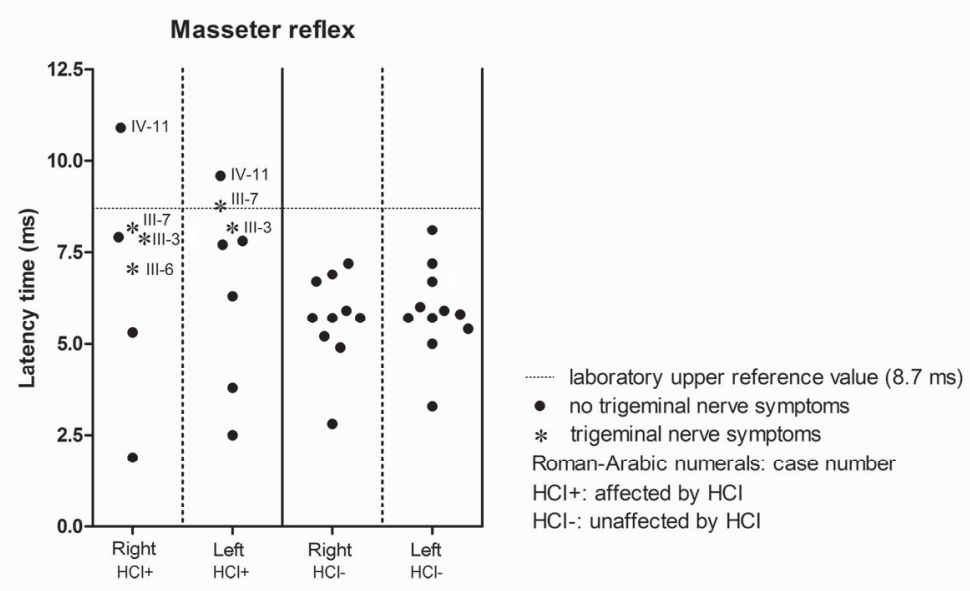

Figure 4.4 Scatter plot of masseter reflex results in patients and the unaffected family members.

The blink reflex revealed abnormalities in three patients (symptomatic individuals III-7 and III-3 and asymptomatic patient IV-2). In these individuals the tests results could be deducted to facial nerve dysfunction (efferent limb) rather than trigeminal nerve dysfunction. At the time of the investigations there were 5 patients with unilateral and 1 with bilateral clinical facial nerve dysfunction (Table 4.1).

Individual III-7 did not show R1 responses (bilaterally) on blink reflex registration, indicating a laesion of both facial nerves. According to Aramideh et al., absent R1 and present $\mathrm{R} 2$ responses can occur in brainstem laesions and partially recovered facial neuropathies. The combination of nearly obliterated internal acoustic canals on CT scan and a history of facial palsy makes the latter most likely ${ }^{9}$. Stapedial reflexes could not be elicited due to deafness. Blink reflexes were also abnormal for patients III-3 ( 9 , 1971, polyphasic R1 response on the right) and IV-2, $(\hat{O}, 1998$, left-sided latencies elongated compared to the right side). Patient IV-14 $(q, 1996)$ underwent bilateral internal auditory canal decompression to prevent deterioration of facial nerve function. Post-operatively she has an HB score of 1 (right) and 2 (left), normal blink reflex and stapedial reflex activity. No pre-operative blink reflex or stapedial reflex test results were available for her. 
Table 4.1 Clinical data on facial and vestibulocochlear nerves.

\begin{tabular}{|c|c|c|c|c|c|c|c|}
\hline Case & Sex & $\begin{array}{c}\text { Age } \\
\text { during } \\
\text { testing }\end{array}$ & $\begin{array}{c}\text { House- } \\
\text { Brackmann } \\
(\mathrm{R} / \mathrm{L})\end{array}$ & $\begin{array}{c}\text { Subjective } \\
\text { hearing loss } \\
(\mathrm{R} / \mathrm{L})\end{array}$ & $\begin{array}{l}\text { Tinnitus } \\
\text { (R/L) }\end{array}$ & $\begin{array}{c}\text { Loss of balance } \\
\text { and/or unsteady } \\
\text { gait }\end{array}$ & Remarks \\
\hline IV-2 & $M$ & 9 & $1 / 1$ & $-1-$ & $-1-$ & - & \\
\hline IV-14 & $\mathrm{F}$ & 11 & $1+/ 2$ & $-1-$ & $+1+$ & - & $\begin{array}{l}\text { Internal auditory canal } \\
\text { decompression } L+R\end{array}$ \\
\hline IV-12 & $\mathrm{F}$ & 14 & $1 / 1$ & $-1-$ & $-1-$ & - & \\
\hline IV-11 & $\mathrm{F}$ & 21 & $1 / 1$ & $-/-$ & $-/-$ & - & \\
\hline III-3 & $\mathrm{F}$ & 36 & $3 / 1$ & $+1-$ & $+1-$ & - & Ageusia \\
\hline III-8 & $M$ & 39 & $1+/ 2$ & $-/+$ & $-/+$ & - & Dysgeusia left \\
\hline III-1 & $\mathrm{F}$ & 41 & $1 / 1+$ & $+/+$ & $-1-$ & + & Bilateral dysgeusia \\
\hline III-7 & $\mathrm{F}$ & 44 & $4 / 4$ & $+/+$ & $-/-$ & + & $\begin{array}{l}\text { Facial synkinesis, } \\
\text { ageusia, deaf due to } \\
\mathrm{HCl} \text {, auditory } \\
\text { brainstem implant }\end{array}$ \\
\hline III-6 & $\mathrm{F}$ & 45 & $1+/ 2$ & $+/+$ & $+/+$ & + & Epiphora, ageusia \\
\hline$\| 1-2$ & M & 68 & $2 / 1$ & $+1+$ & $+/-$ & - & $\begin{array}{l}\text { Epiphora, radical } \\
\text { mastoidectomy AS }\end{array}$ \\
\hline
\end{tabular}

† Recovered completely after prior facial nerve palsy.

\section{Vestibulocochlear nerve}

\section{Pure-tone audiometry and speech audiometry}

Six out of 10 patients were diagnosed with disease-related neural hearing loss (described in Table 4.1). No specific frequency range was most commonly affected. Speech intelligibility is congruent to PTA results, no roll-over has been observed.

\section{Tympanography and OAES}

Three patients had a hypermobile tympanic membrane (maximal compliance of the tympanic membrane $>1.6 \mathrm{cc}$ at tympanic peak pressure), one patient showed a bilaterally flat tympanogram (II-2, Ō, 1939, modified radical mastoidectomy) and one had a negative middle ear pressure. OAEs were assessed in nine people. Absent OAEs could in no case be deducted to an abnormal tympanogram. Emissions were completely absent in one out of nine subjects (age-related hearing loss).

\section{Stapedial reflexes}

Nine patients were tested, four did not have stapedial reflexes: patient II-2 $(\hat{\sigma}, 1939)$ because of a bilaterally flat tympanogram (and radical mastoidectomy), patient III-7 ( $O$, 1963) due to bilateral deafness, IV-2 ( $\partial, 1998$, left-sided absence) with an ipsilateral hypermobile tympanic membrane (possibly explaining the absence of stapedial reflexes) and patient III-3 $(q, 1971)$ with absent reflexes at the right side (facial palsy) and the left side (hypermobile tympanogram). Only the latter patient had an absent 
stapedial reflex that could not be explained by deafness or abnormalities found using tympanography, indicating dysfunction of the ipsilateral facial nerve and/or bilateral vestibulocochlear nerves for the tested frequencies.

\section{BERA}

Eight patients underwent BERA examination. We defined prolonged latency times as being more than two standard deviations from normal values according to Stockard et $a l^{6}$. Inter-peak latencies I-V were prolonged bilaterally in four patients and unilaterally in one patient (Figure 4.5). BERA abnormalities occurred earlier than PTA abnormalities in all patients, except for patient III-6 $(\%, 1961)$.

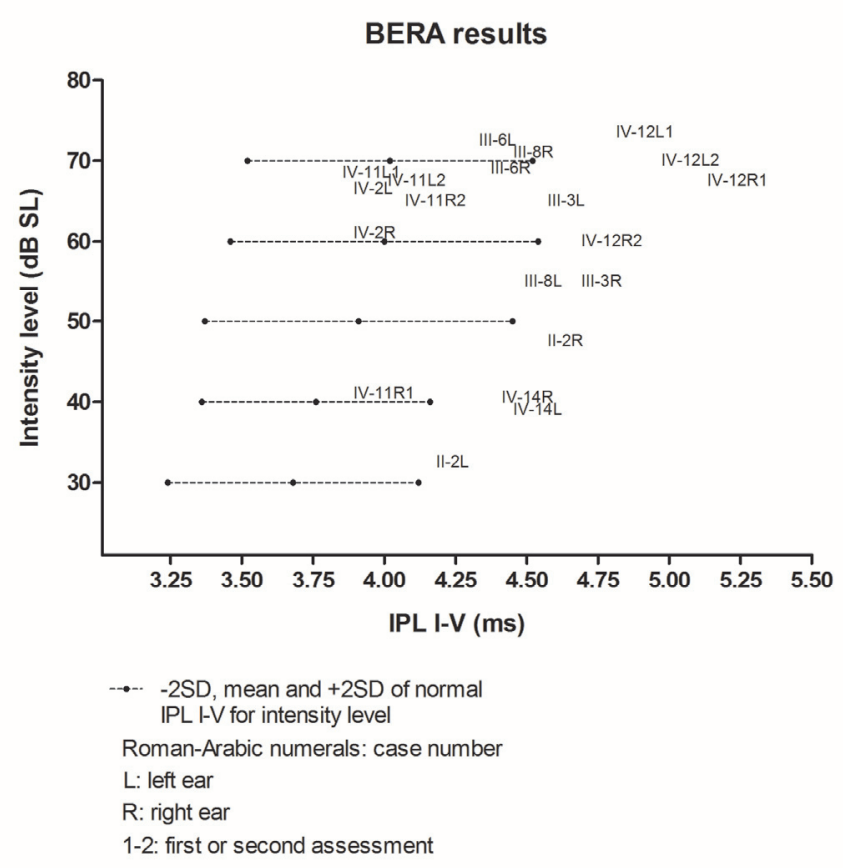

Figure 4.5 BERA results in tested patients.

\section{Vestibulogy}

Vestibular testing in all seven tested patients revealed no central pathology. We did not find a spontaneous or gaze evoked nystagmus. The optokinetic nystagmus, smooth pursuit and saccade testing were normal for all. One-sided hypofunction of the labyrinth was found in one patient, three patients had a bilateral hypofunction and two had normal test results (Figure 4.6). Abnormal test results consisted of subnormal 
calorisation, yet with normal rotational tests. Test quality in one subject was dissatisfactory and as such mild lateral canal hyporeflexia could not be excluded. Bilateral absence of vestibular function was clinically diagnosed in patient III-7 ( 9,1963 , positive head impulse tests, deaf).

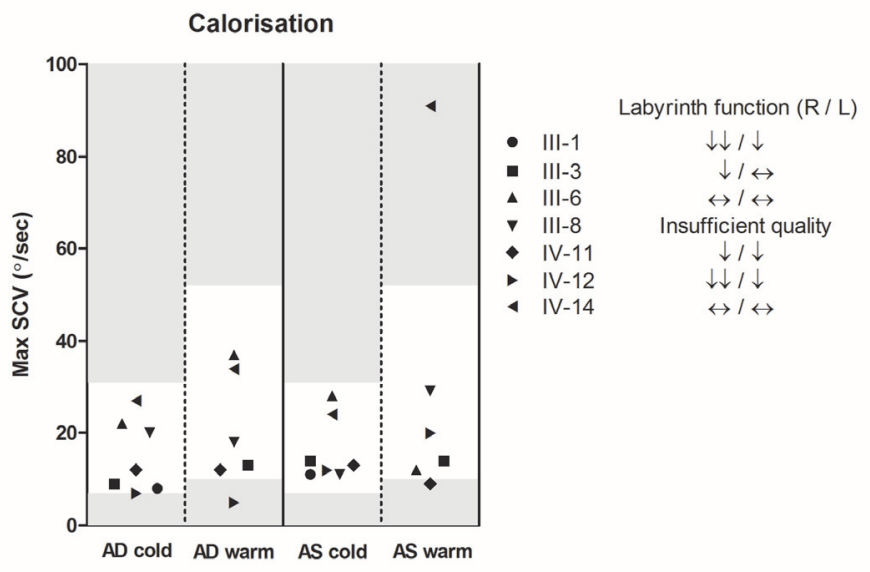

Figure 4.6 Calorisation in affected patients.

\section{Discussion}

\section{Optic nerve}

The use of VEPs does not seem to be clear-cut, since some patients without radiological abnormalities have VEP abnormalities and vice versa. Prolonged VEP latencies with significant radiographic optic canal involvement justifies strict follow-up. On the other hand, prolonged VEP latencies without significant optic canal encroachment have been observed as well. This could be a predictor for future symptoms or a false positive finding.

Earlier literature concerning compressive opticopathy report VEPs as a highly sensitive screening tool for optic pathway gliomas ${ }^{10}$, detecting pathology prior to radiological modalities, however leading to many false positives ${ }^{11}$. Haines et al. and Thompson et al. demonstrated that VEP abnormalities often precede clinical symptoms or neuroimaging signs in osteopetrosis ${ }^{12,13}$. On the other hand, Tsaloumas et al. found a low VEP sensitivity in patients with dysthyroid optic neuropathy with only $23 \%$ of affected eyes having a delayed P100 component ${ }^{14}$. 
It seems that a single P100 latency registration without radiographic signs of nerve compression cannot be used as a general predictor of nerve function in different compressive optic nerve disorders. A longitudinal follow-up with VEP examination, combined with symptomatology and regular imaging, would be valuable to monitor progressive compression of the nerve due to occlusion of the optic canals. We advise VEP testing whenever a patient reports (increased) visual complaints or the CT scan shows significant decrease in optic canal diameter. We advise surgical intervention (optic nerve decompression) in two circumstances. In the first place in case of (sub)acute vision loss with proven radiographic optic canal encroachment. Furthermore we advise decompression even when vision seems to be stable, however when there is significant deterioration of the VEP results, again with radiographic proof of optic canal narrowing. To perform decompression in case of radiologic narrowing of the canal alone, is not advised. This is in line with the consensus about the management of optic canal involvement in patients with fibrous dysplasia or McCune Albright syndrome ${ }^{15}$.

\section{Trigeminal nerve}

Although trigeminal nerve symptomatology is not very common in $\mathrm{HCl}$ patients, the masseter and blink reflexes offer relatively easy screening of the involvement of this cranial nerve. Since all patients with trigeminal nerve symptoms experienced impairment of at least the mandibular nerve $\left(\mathrm{NV}_{3}\right)$, a combination of the masseter and blink reflex should readily demonstrate trigeminal abnormalities in our patient group $^{9,16}$.

Several compressive trigeminal neuropathies are known, most notably neurovascular conflicts (often by the superior cerebellar artery) ${ }^{17,18}$ and cerebellopontine angle tumors ${ }^{16}$. No literature was found on the systematic use of masseter reflex testing in patients with trigeminal nerve compression. Slightly more is known about the blink reflex. Kimura reported abnormalities in $59 \%$ of the responses with a compressive lesion of the trigeminal nerve ${ }^{19}$. Eisen and Danon described blink reflex abnormalities in ten patients with cerebellopontine angle tumours $(\geq 20 \mathrm{~mm})$ and trigeminal nerve symptoms. Blink reflex results confirmed trigeminal dysfunction in $80 \%$ of these patients $(8 / 10)^{20}$.

Most compressive processes are unilateral and left-right latency differences are observed. Since $\mathrm{HCl}$ is a bilateral symmetrical process, equally prolonged latency times are measured bilaterally, decreasing sensitivity of both masseter and blink reflex. In the case of the masseter reflex, we did notice a trend that most of our patients, especially when symptomatic, had latencies near the upper reference value. A single neurophysiologic evaluation of the trigeminal nerve seems to add little value to clinical assessment and imaging. Serial measurements (combined with clinical and imaging) could be useful to detect progressive dysfunction of the trigeminal nerve. 


\section{Facial and vestibulocochlear nerve}

There is a significant decrease in size of both the porus and fundus of the internal acoustic canal of $\mathrm{HCl}$ affected patients ${ }^{21}$. Due to the slow progression of the condition, few patients describe a loss of hearing or vertiginous signs, the latter mostly because of central compensation of the decreased labyrinth function. Facial nerve palsy is the first clinical symptom reported by most $\mathrm{HCl}$ patients, occurring between 8 and 33 years ${ }^{2}$. Based on the fact that encroachment of the facial nerve is located primarily in the internal acoustic canal ${ }^{22}$, all nerve functions are expected to be affected equally.

Facial and subjective vestibulocochlear nerve complaints are very common in our patients as the age increases (Table 4.1). The sidedness of facial nerve dysfunction is in agreement with vestibulocochlear symptoms. The facial nerve palsy is an acute symptom and therefore noticed much easier than the slowly decreasing function of hearing and the vestibular apparatus. In the literature, the stapedial reflex has been reported to be preserved during an episode of facial palsy. The lower susceptibility of the stapedial nerve is probably due to the smaller diameter of stapedial nerve fibers than those in the facial nerve trunk ${ }^{23}$. In general, the order of dysfunction due to internal auditory canal narrowing would be: subclinical vestibulocochlear dysfunction, followed by acute facial palsy and later clinical vestibulocochlear dysfunction. This pattern is reflected by our results.

No patients with recovered facial nerve function after prior facial palsy had prolonged blink reflexes. Out of the 5 patients with (4 unilateral, 1 bilateral) facial nerve symptoms at the time of investigation, 3 reflexes indicated facial neuropathy (sensitivity $3 / 6$ : $50 \%$ ). These results are similar to blink reflex outcome for different indications, for example vestibular schwannomas. These studies show that the difference in R1 latency between left and right was the most useful parameter to illustrate the effect of chronic compression, concluding to a sensitivity of $56 \%$. However, as opposed to (most) schwannomas, $\mathrm{HCl}$ is a more or less bilaterally symmetrical process and will therefore yield equally prolonged latency times. According to Normand et al. - left-right differences are not taken into account - this would decrease the sensitivity to less than $40 \%{ }^{24}$.

BERA results are a relatively adequate reflection of the internal auditory canal diameter (Figure 4.7). As the internal auditory canal diameter is decreased to less than $2 \mathrm{~mm}$, latency times increase pathologically. Even with functional hearing, abnormal BERA results are registered when the canal size is severely decreased. Therefore BERA is useful to monitor cochlear nerve function and it is an essential diagnostic test in this disease. 


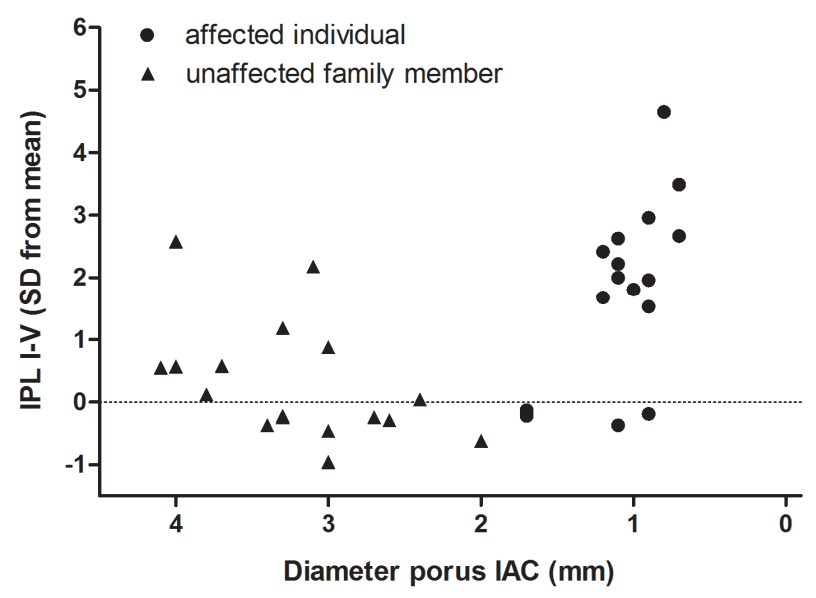

Figure 4.7 BERA IPL I-V times versus internal auditory canal (IAC) diameter.

The use of BERA is widespread and its value is undisputed, however with the increasing availability of MRI the use of BERA declines. In the literature, its sensitivity for diagnosing vestibular schwannomas ranges from $58 \%$ to $100 \%$, depending on the amount of compression on the vestibulocochlear nerve $\mathrm{e}^{25-27}$.

Central vestibular pathology is not expected in $\mathrm{HCl}$. Repeated calorisation is a useful method to monitor vestibular nerve function until complete vestibular areflexia. In case of vestibular areflexia residual function might be found upon rotational tests. Vestibular testing using calorisation has revealed sensitivity of $77-86 \%$ for vestibular schwannomas $\%^{25,28,29}$, although Marangos et al. found a sensitivity of $40 \%$ for cerebellopontine angle tumours in general $^{27}$ (see Table 4.2).

As OAEs are a measure of outer hair cell function and not cochlear nerve function, emissions are present in patients even with neural disease-related hearing loss ${ }^{30-33}$. 
Table 4.2 Test data on facial and vestibulocochlear nerves.

\begin{tabular}{|c|c|c|c|c|c|c|c|c|}
\hline \multirow[t]{2}{*}{ Case } & \multirow{2}{*}{$\begin{array}{c}\text { Blink } \\
\text { reflex* } \\
(\mathrm{R} / \mathrm{L})\end{array}$} & \multirow{2}{*}{$\begin{array}{c}\text { Stapedial } \\
\text { reflex* }^{*} \\
(\mathrm{R} / \mathrm{L})\end{array}$} & \multicolumn{2}{|c|}{$\begin{array}{c}\text { PTA bone } \\
\text { threshold }{ }^{\S}(\mathrm{dB})\end{array}$} & $\begin{array}{c}\text { Speech } \\
\text { intelligibility }\end{array}$ & \multirow[t]{2}{*}{$\begin{array}{l}\text { OAEs* } \\
(\mathrm{R} / \mathrm{L})\end{array}$} & \multirow{2}{*}{$\begin{array}{c}\text { BERA } \\
\text { (IPL I-V) } \\
(\mathrm{R} / \mathrm{L})\end{array}$} & \multirow{2}{*}{$\begin{array}{l}\text { Labyrinth } \\
\text { function } \\
\text { (R / L) }\end{array}$} \\
\hline & & & $A D$ & AS & $A D$ & & & \\
\hline $\mathrm{II}-2$ & $+1+$ & $\mathrm{N} / \mathrm{A}$ & \multicolumn{2}{|c|}{$0-45$} & $5-50$ & $\begin{array}{c}\text { Congruent } \\
\text { to PTA }\end{array}$ & $-1-$ & $\uparrow / \uparrow$ \\
\hline IV -2 & $+1-$ & $+/+$ & \multicolumn{2}{|c|}{ Normal } & Normal & $+/+$ & $\leftrightarrow / \leftrightarrow$ & N/A \\
\hline IV-14 & $+1+$ & $+/+$ & \multicolumn{2}{|c|}{ Normal } & Normal & $+/+$ & $\uparrow / \uparrow$ & $\leftrightarrow / \leftrightarrow$ \\
\hline IV-12 & $+1+$ & $+/+$ & $5-15$ & $0-20$ & $\begin{array}{c}\text { Congruent to } \\
\text { PTA }\end{array}$ & $+1+$ & $\uparrow / \uparrow$ & $\downarrow \downarrow / \downarrow$ \\
\hline IV-11 & $+/+$ & $+/+$ & \multicolumn{2}{|c|}{ Normal } & Normal & $+/+$ & $\leftrightarrow / \leftrightarrow$ & $\downarrow / \downarrow$ \\
\hline III-3 & $-1+$ & $-/+$ & $5-25$ & Normal & Normal & $+1+$ & $\uparrow / \uparrow$ & $\downarrow / \leftrightarrow$ \\
\hline III-8 & N/A & N/A & \multicolumn{2}{|c|}{ Normal } & Normal & $\ddagger / \ddagger$ & $\leftrightarrow / \uparrow$ & $\begin{array}{l}\text { Insufficient } \\
\text { test quality }\end{array}$ \\
\hline III-1 & $\mathrm{N} / \mathrm{A}$ & N/A & $10-35$ & $25-40$ & N/A & $\mathrm{N} / \mathrm{A}$ & $\mathrm{N} / \mathrm{A}$ & $\downarrow / \downarrow$ \\
\hline III-7 & $-1-$ & $-1-$ & \multicolumn{2}{|c|}{ Deaf } & Deaf & N/A & No response & N/A \\
\hline III-6 & $+/+$ & $+/+$ & $10-30$ & $5-40$ & $\begin{array}{c}\text { Congruent to } \\
\text { PTA }\end{array}$ & $+/ \ddagger$ & $\leftrightarrow / \leftrightarrow$ & $\leftrightarrow / \leftrightarrow$ \\
\hline
\end{tabular}

* + normal registration, - absent or abnormal registration; § bone conduction threshold was used, because there were individuals with non-disease related conductive hearing loss; PTA pure tone average; $†$ absent reflex, possibly due to tympanographic abnormality; ¥ OAE response in one frequency band only; $\leftrightarrow$ normal IPL or calorisation; $\uparrow$ or $\downarrow$ increased or decreased latency or calorisation; N/A not assessed.

\section{Conclusion}

In summary, selected function tests in $\mathrm{HCl}$ are useful. We advise yearly monitoring of vestibulocochlear nerve function with tone and speech audiometry, BERA and vestibular function tests in young patients. In case of acute deterioration of tone and/or speech audiometry or in case of acute facial nerve palsy in combination with radiographically proven internal auditory canal narrowing decompression is advised. We advise to perform internal auditory canal decompression - even without (further) hearing loss - in case of deterioration of BERA and/or deterioration of the vestibular function test results in combination with radiographic proof of internal auditory canal encroachment. Facial nerve palsy at young age due to internal auditory canal encroachment is so common in $\mathrm{HCl}$ that decompression can even be considered preventively, when internal auditory canal narrowing is first observed in young individuals ${ }^{34}$. Analogous to the facial and vestibulocochlear nerve management, optic nerve decompression is advised in case of acute vision loss with proven optic canal narrowing in a (sub)acute setting or in case of deterioration of serial VEP results in combination with proven radiographic narrowing of the optic canal. Yearly performed visual evoked potentials are advised to monitor the optic nerve function, in case of marked narrowing of the optic canal/superior orbital fissure (CT) or in case diseasespecific abnormalities upon ophthalmologic examination. We do not advise the routine use of blink and masseter reflex. 


\section{References}

1. Manni JJ, Scaf JJ, Huygen PL, Cruysberg JR, Verhagen WI. Hyperostosis cranialis interna. A new hereditary syndrome with cranial-nerve entrapment. N Engl J Med 1990;322:450-454.

2. Waterval JJ, Stokroos RJ, Bauer NJ, De Bondt RB, Manni JJ. Phenotypic manifestations and management of hyperostosis cranialis interna, a hereditary bone dysplasia affecting the calvaria and the skull base. Am J Med Genet A 2010;152A:547-555.

3. Odom JV, Bach M, Barber C, Brigell M, Marmor MF, Tormene AP, Holder GE, Vaegan. Visual evoked potentials standard (2004). Doc Ophthalmol 2004;108:115-123.

4. Odom JV, Bach M, Brigell M, Holder GE, McCulloch DL, Tormene AP, Vaegan. ISCEV standard for clinical visual evoked potentials (2009 update). Doc Ophthalmol 2010;120:111-119.

5. House JW, Brackmann DE. Facial nerve grading system. Otolaryngol Head Neck Surg 1985;93:146-147.

6. Stockard JE, Stockard JJ, Westmoreland BF, Corfits JL. Brainstem auditory-evoked responses. Normal variation as a function of stimulus and subject characteristics. Arch Neurol 1979;36:823-831.

7. Coats AC, Martin JL. Human auditory nerve action potentials and brain stem evoked responses: effects of audiogram shape and lesion location. Arch Otolaryngol 1977;103:605-622.

8. Jongkees LB, Maas JP, Philipszoon AJ. Clinical nystagmography. A detailed study of electronystagmography in 341 patients with vertigo. Pract Otorhinolaryngol (Basel) 1962;24:65-93.

9. Aramideh M, Ongerboer de Visser BW. Brainstem reflexes: electrodiagnostic techniques, physiology, normative data, and clinical applications. Muscle Nerve 2002;26:14-30.

10. Holder GE, Gale RP, Acheson JF, Robson AG. Electrodiagnostic assessment in optic nerve disease. Curr Opin Neurol 2009;22:3-10.

11. Listernick R, Ferner RE, Liu GT, Gutmann DH. Optic pathway gliomas in neurofibromatosis-1: controversies and recommendations. Ann Neurol 2007;61:189-198.

12. Haines SJ, Erickson DL, Wirtschafter JD. Optic nerve decompression for osteopetrosis in early childhood. Neurosurgery 1988;23:470-475.

13. Thompson DA, Kriss A, Taylor D, Russell-Eggitt I, Hodgkins P, Morgan G, Vellodi A, Gerritsen EJ. Early VEP and ERG evidence of visual dysfunction in autosomal recessive osteopetrosis. Neuropediatrics 1998;29:137-144.

14. Tsaloumas MD, Good PA, Burdon MA, Misson GP. Flash and pattern visual evoked potentials in the diagnosis and monitoring of dysthyroid optic neuropathy. Eye (Lond) 1994;8:638-645.

15. Lee JS, FitzGibbon E, Butman JA, Dufresne CR, Kushner H, Wientroub S, Robey PG, Collins MT. Normal vision despite narrowing of the optic canal in fibrous dysplasia. N Engl J Med 2002;347:1670-1676.

16. Kennelly KD. Electrophysiological evaluation of cranial neuropathies. Neurologist 2006;12:188-203.

17. Jannetta PJ. Arterial compression of the trigeminal nerve at the pons in patients with trigeminal neuralgia. J Neurosurg 1967;26: Suppl:159-162.

18. Sindou M, Leston J, Decullier E, Chapuis F. Microvascular decompression for primary trigeminal neuralgia: long-term effectiveness and prognostic factors in a series of 362 consecutive patients with clear-cut neurovascular conflicts who underwent pure decompression. J Neurosurg 2007;107: 1144-1153.

19. Kimura J. Electrodiagnosis of the cranial nerves. Acta Neurol Taiwan 2006;15:2-12.

20. Eisen A, Danon J. The orbicularis oculi reflex in acoustic neuromas: a clinical and electrodiagnostic evaluation. Neurology 1974;24:306-311.

21. Waterval JJ, van Dongen TM, Stokroos RJ, De Bondt BJ, Chenault MN, Manni JJ. Imaging features and progression of hyperostosis cranialis interna. AJNR Am J Neuroradiol 2012;33:453-461.

22. Manni JJ, Huygen PL, Noten JF, Kuijpers W. Eighth cranial nerve dysfunction in hyperostosis cranialis interna. Acta Otolaryngol 1992;112:75-82.

23. Matsumoto $\mathrm{Y}$, Yanagihara N, Murakami S, Fujita $\mathrm{H}$. Effects of facial nerve compression on the stapedial nerve. Ann Otol Rhinol Laryngol Suppl 1984;111:7-11.

24. Normand MM, Daube JR. Cranial nerve conduction and needle electromyography in patients with acoustic neuromas: a model of compression neuropathy. Muscle Nerve 1994;17:1401-1406. 
25. Bozorg Grayeli A, Refass A, Smail M, Elgarem H, Kalamarides M, Bouccara D, Sterkers O. Diagnostic value of auditory brainstem responses in cerebellopontine angle tumours. Acta Otolaryngol 2008;128: 1096-1100.

26. Kishore A, O'Reilly BF. A clinical study of vestibular schwannomas in type 2 neurofibromatosis. Clin Otolaryngol Allied Sci 2000;25:561-565.

27. Marangos N, Maier W, Merz R, Laszig R. Brainstem response in cerebellopontine angle tumors. Otol Neurotol 2001;22:95-99.

28. Okada Y, Takahashi M, Saito A, Kanzaki J. Electronystagmographic findings in 147 patients with acoustic neuroma. Acta Otolaryngol Suppl 1991;487:150-156.

29. Tringali S, Charpiot A, Ould MB, Dubreuil C, Ferber-Viart C. Characteristics of 629 vestibular schwannomas according to preoperative caloric responses. Otol Neurotol 2010;31:467-472.

30. Matsumoto M, Sekiya T, Kojima K, Ito J. An animal experimental model of auditory neuropathy induced in rats by auditory nerve compression. Exp Neurol 2008;210:248-256.

31. Berlin $\mathrm{Cl}$, Morlet T, Hood LJ. Auditory neuropathy/dyssynchrony: its diagnosis and management. Pediatr Clin North Am 2003;50:331-340, vii-viii.

32. Ferri GG, Modugno GC, Calbucci F, Ceroni AR, Pirodda A. Hearing loss in vestibular schwannomas: analysis of cochlear function by means of distortion-product otoacoustic emissions. Auris Nasus Larynx 2009;36:644-648.

33. Cane MA, Lutman ME, O'Donoghue GM. Transiently evoked otoacoustic emissions in patients with cerebellopontine angle tumors. Am J Otol 1994;15:207-216.

34. Waterval JJ, Stokroos RJ, De Bondt RB, Manni JJ. Facial nerve decompression via middle fossa approach for hyperostosis cranialis interna: a feasible therapeutic approach. J Laryngol Otol 2009;123: 1177-1180. 


\section{Chapter}

Imaging features and progression of hyperostosis cranialis interna

Jérôme J. Waterval

Thijs M. van Dongen

Robert J. Stokroos

Bert-Jan de Bondt

Michelene N. Chenault

Johannes J. Manni

American Journal of Neuroradiology 2012;33:453-461 


\section{Abstract}

\section{Introduction}

Hyperostosis cranialis interna $(\mathrm{HCl})$ is an autosomal dominant sclerosing bone dysplasia affecting the skull base and the calvaria, characterised by cranial nerve deficits due to stenosis of neuroforamina, whereby the mandible is affected to a lesser extent. The aim of this study is to describe the specific radiologic characteristics and course of the disorder.

\section{Methods}

Computed tomography scans of affected individuals within 1 family were analysed and compared with scans of their unaffected family members and with an age- and gender-matched control group. Linear measurements were performed of the inner table (tabula interna), the medulla (diploë) and the outer table (tabula externa) of different skull locations, and attenuation (density) measurements of the same regions were recorded. Neuroforamina widths were recorded as well.

\section{Results}

There is significant thickening of the skull in the frontal, parietal, temporal and occipital regions, which is mainly due to thickening of the inner table of the skull. The density of the deposited hyperostotic bone is lower than normal cortical bone.

\section{Conclusion}

$\mathrm{HCl}$ is a bone dysplasia with abnormalities confined to the craniofacial area. The hyperostotic bone is less dense than normal cortical bone. The observed radiological abnormalities explain the possible impairment of the olfactory, optic, trigeminal, facial and vestibulocochlear nerves. 


\section{Introduction}

Hyperostosis cranialis interna $(\mathrm{HCl})$ is a hereditary bone disorder characterised by progressive skull base osteosclerosis and endosteal hyperostosis of the calvaria (Figure 5.1). Clinical features and the course of the disorder are described in one kindred (Figure 5.2) in the Netherlands ${ }^{1,2}$. Patients generally become symptomatic in their late first, second or third decade due to cranial nerve entrapment. Facial palsy, sensorineural hearing loss, vestibular symptoms, olfactory impairment, optic impairment and trigeminal neuralgia are the observed symptoms.

Although the emphasis in research of bone dysplasias dysplasias is shifting towards detection of the genetic and molecular underlying defects ${ }^{3}$, knowledge of the radiologic features is crucial to diagnose the disorder and to assess progression. The international classification of bone dysplasias is still based on radiologic hallmarks ${ }^{4}$.

The aim of this study is to describe the initiation of the abnormalities in young patients, to describe the evolution of these abnormalities throughout life and to quantify differences between $\mathrm{HCl}$ patients and control subjects to facilitate early diagnosis. Moreover better counselling can be provided if the course of the disorder can be more precisely predicted.

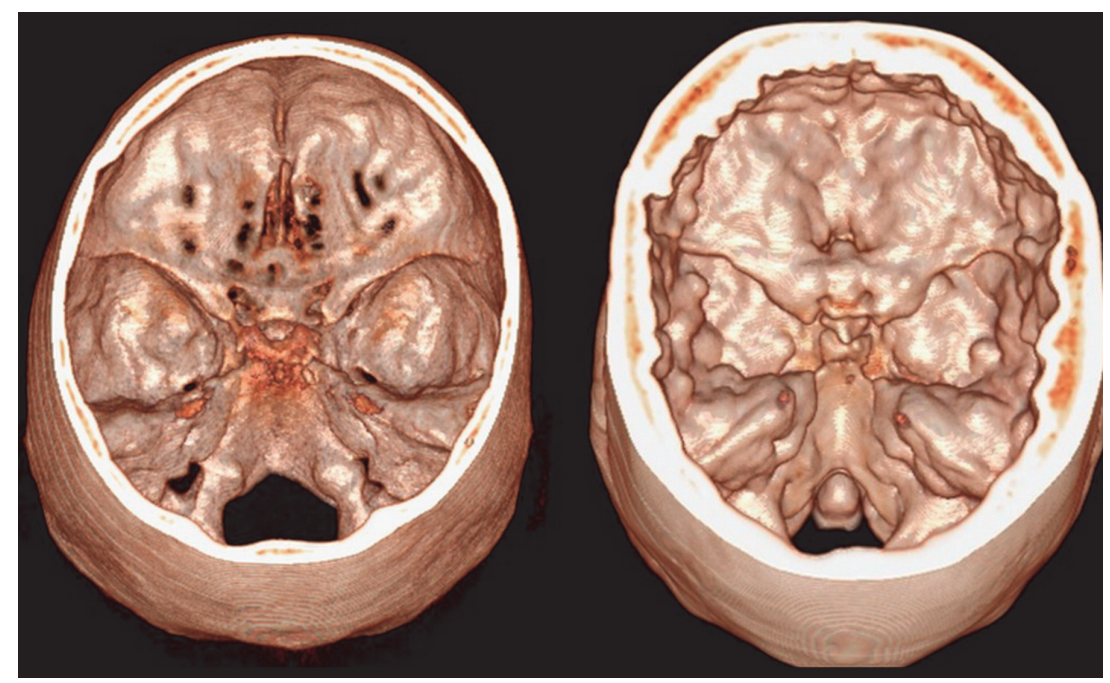

Figure 5.1 3D-reconstruction of a normal skull base and one of a patient with hyperostosis cranialis interna. The left image is an unaffected individual in which all neuroforamina can be identified. The right image is an affected individual with thickened calvaria and a bulgy skull base; neuroforamina are hardly visible. 


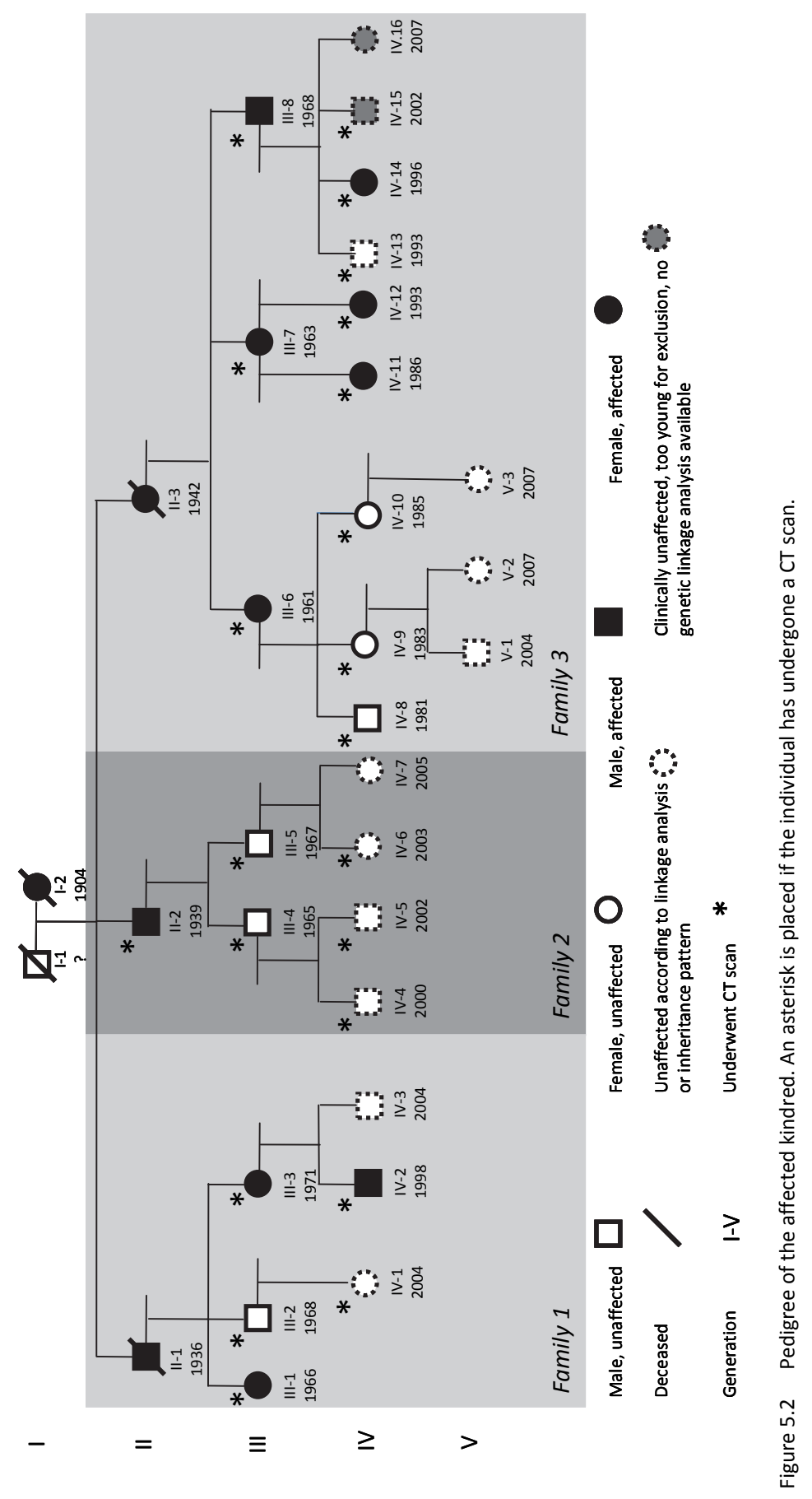




\section{Methods}

\section{Subjects}

Twenty-two family members - affected group 1 and unaffected group 2 - underwent a high-resolution CT. Twenty-one control subjects were selected retrospectively, matching for gender and age: group 3 matching group 1 and group 4 matching group 2 . These CT scans were selected from the hospital database, scans performed with appropriate settings ( $\leq 1 \mathrm{~mm}$ slice thickness) and without bone abnormalities were considered suitable. The local medical ethics committee approved the protocol (09-4-050.4/pl). All HCl family members gave written informed consent.

\section{CT imaging and analysis}

CT scans were performed using helical scanners with $\leq 1 \mathrm{~mm}$ slice thickness in the axial plane. The local Picture Archiving and Communications System (PACS) was used for analysis. A protocol for standard measuring was used as follows. Thickness of the frontal, parietal and occipital regions of the skull were measured in the median line and 10 and $20 \mathrm{~mm}$ to the right. This was done at various heights resulting in 10-15 measurements per region under magnification to avoid measuring errors. Thickness of the inner table and outer table of the skull were measured at the same locations. In addition, skull thicknesses were measured at the coronal and lambdoid sutures in the axial plane. Thickness of the inner table of the frontal skull base was measured (sagittal plane, level of the orbital apex), as well as the middle fossa inner table (coronal plane, level of optic chiasm), clivus, and dorsal foramen magnum (sagittal plane, midline).

The diameter of a selection of cranial nerve foramina were measured: the porus and fundus of the internal auditory canal, the optic canal (coronal plane) and the Vidian nerve canal (axial plane) (Figure 5.3).

Bone density was determined in Hounsfield units (HU) in different regions of interest (ROI). Screening measurements were performed in ROIs in all bone layers: frontal and occipital bone (axial plane, halfway between skull base and vertex, left, right and median), parietal bone (coronal plane, bilaterally, superior to the mastoid, and halfway skull base to vertex), greater wing of the sphenoid and apex of the petrosal bone (axial plane, bilaterally). To rule out the influence of regional heterogeneous bone density, specific regions were measured (if identifiable) with freehand ROIs (Figure 5.3C): inner table, outer table and diploë of both the frontal and parietal bones, diploë and inner table of the greater sphenoid wing, (medulla of) clivus, (medulla of) lateral orbit, and sphenotemporal and tympanosquamosal suture and, if present, exostoses of the mandible. 


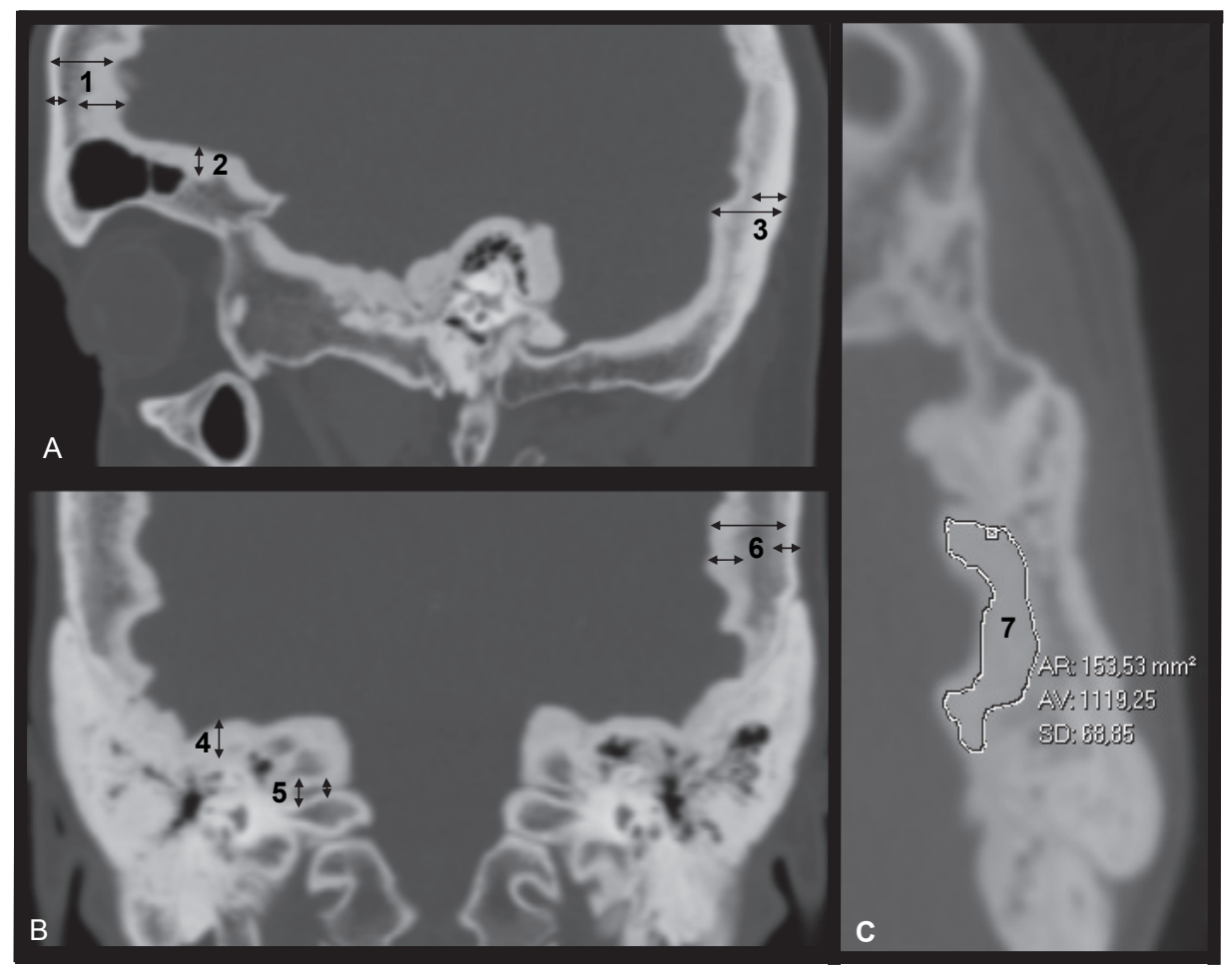

Figure 5.3 Simplified examples of different measurements. A and B: linear measurements of skull thickness and neuroforamen width. C: density measurement of freehand ROI at the inner table of parietal bone. 1: frontal bone measurements, 2: frontal skull base inner table thickness, 3 : occipital bone measurements, 4: middle skull base inner table thickness, 5: internal auditory canal measurements, fundus = lateral part, porus = medial part, 6: parietal bone measurements and 7: parietal inner table density measurement.

\section{Statistical analysis}

The study group was divided into group 1 and 2, based on diagnosis. Group means of metric measurements (thicknesses and widths) and density measurements were calculated. The Kolmogorov-Smirnov test was applied to test whether variables with continuous metric values had a normal distribution. Groups 1 and 3, and groups 2 and 4, were compared applying Kruskal-Wallis and Mann-Whitney rank tests when the data could not be considered as normally distributed, otherwise with paired $t$ tests. To account for physiologic differences in the size of male and female skulls, the same analyses were performed with the ratio inner table: total thickness for the same locations. In addition, the same analyses were repeated after censoring the individuals under age 18 to rule out the effect of obvious skull (base) thickening not yet being present in young affected individuals. 
The influence of age was assessed with the Pearson correlation or Spearman rank coefficient correlation test, depending on whether normality could be assumed. Analysis of covariance was performed (univariate ANCOVA) to assess the influence of gender. Due to the small group sizes, adjustment for gender and age did not occur simultaneously.

Bone density was analysed in the same manner as the linear measurements. Group 1 and 3 were compared using paired $t$ tests. The inner table of the greater sphenoid wing and the 3 components of the parietal bone could not be separately measured, in most cases, in group 3 and therefore we chose to consider the frontal bone (inner table) values of group 3 as reference values.

All data were analysed with SPSS version 16 (SPSS, Chicago, Illinois).

\section{Results}

Ten family members displayed abnormalities on their CT scan (group 1, mean age 32.8, range 9-68), whereas 12 family members did not (group 2, range 3 to 42). Of these 12 family members in group 2, 6 were children under the age of 18 years, which is the age an individual is considered to be unaffected, in cases in which radiological abnormalities are absent (Table 5.1). Based on genetic linkage analysis, 5 can be considered unaffected. No genetic analysis was available for individual IV.15; hence, this individual was excluded. The mean age of group 2 was 20.3. The control group that matches the affected family members is group 3 (mean age 30.8, range 7 to 67). The group that match the unaffected family members is group 4 (mean age 17.0, range 3 to 45).

\section{Linear measurements}

Mean measurements of each location are listed by group in Table 5.2. Mean values were found to be significantly higher in $\mathrm{HCl}$ patients compared with their control group for the following outcome parameters: frontal total, frontal inner table, frontal outer table, parietal total, parietal outer table, occipital total, occipital inner table, frontal skull base, middle skull base, foramen magnum, coronoid suture and lambdoid suture. Significantly lower mean values were found in the porus of IAC and the fundus of IAC. For 7 outcome parameters group 2 had significantly higher mean values than group 4: frontal inner table, frontal outer table, occipital inner table, frontal skull base, middle skull base, foramen magnum, and clivus. 
Table 5.1 Baseline characteristics.

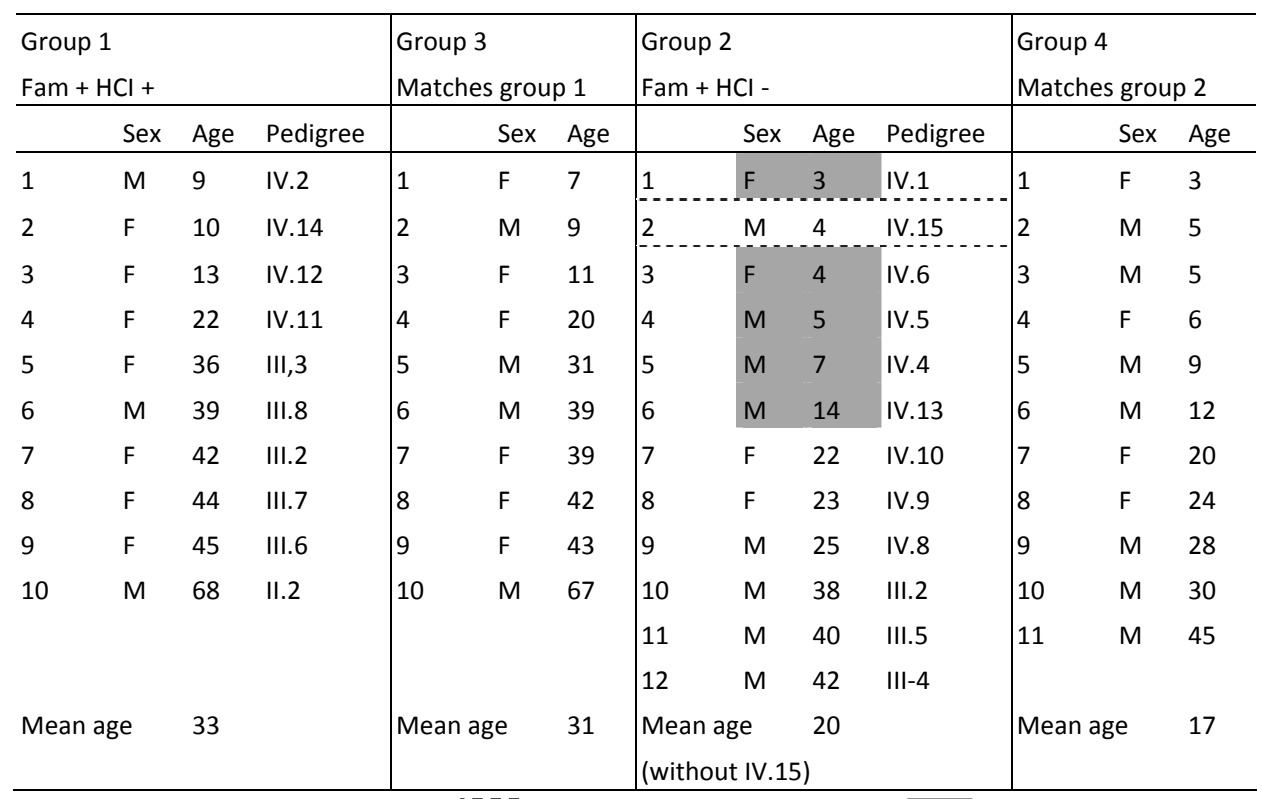

$\mathrm{M}=$ male; $\mathrm{F}=$ female; Age=age of scan; : $-\ldots$ excluded, diagnosis uncertain; genetic linkage analysis; Fam = family member

All total skull thickness measurements (frontal, parietal and occipital mean values) were found to be higher for males in group 2, 3 and 4. In group 1, the female group had higher mean values, however these differences were not statistically significant. Inner table : total thickness ratios to rule out gender influence did not show any different results for the 3 locations. Censoring of the minor individuals did not change any results.

To compare the disease progression throughout life at various anatomical locations scatterplots with outcome values versus age to compare groups 1 and 3 (Figure 5.4). There is frontal, parietal and occipital skull thickening throughout life in the affected group. Whereas inner table thickening is mainly responsible for this in the frontal bone, in the parietal bone there is mainly thickening of the diploë (the inner and outer table are stable throughout life, Figure 5.4B). In the occipital bone there is thickening of all three layers. The middle and frontal skull base show progressive hyperostosis, in contrast to the clivus and foramen magnum (Figure 5.4D). Narrowing of the porus region of the internal auditory canal is one of the first pathologic changes to occur. No decline in group 1 porus width is visualised, because the youngest subjects already have a markedly narrowed porus (less than $1.5 \mathrm{~mm}$ ). Fundus narrowing continues until later in life and is observed to a lesser extent in the control population as well. 
Table 5.2 Overview of different distance measurements.

\begin{tabular}{|c|c|c|c|c|c|c|c|c|c|}
\hline \multirow[t]{2}{*}{ Location } & \multirow{2}{*}{ 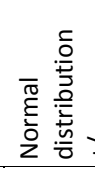 } & \multicolumn{2}{|l|}{$\begin{array}{l}\text { Group } 1 \\
\text { Fam + HC }\end{array}$} & \multicolumn{2}{|c|}{$\begin{array}{l}\text { Group } 3 \\
\text { Controls matched } \\
\text { with group } 1\end{array}$} & \multicolumn{2}{|l|}{$\begin{array}{l}\text { Group } 2 \\
\text { Fam + HCl - }\end{array}$} & \multicolumn{2}{|c|}{$\begin{array}{l}\text { Group } 4 \\
\text { Controls matched } \\
\text { with group } 2\end{array}$} \\
\hline & & + Mean $(\mathrm{mm})$ & SD & Mean $(\mathrm{mm})$ & SD & Mean (mm) & SD & Mean (mm) & SD \\
\hline Frontal Total & + & $11.2+\dagger$ & 3.2 & $5.9++$ & 1.4 & 5.6 & 1.4 & 5.5 & 1.8 \\
\hline Frontal Inner table & - & $3.2+\dagger$ & 1.8 & $1.2+\dagger$ & 0.7 & $1.5 \ddagger$ & 0.4 & $1.1 \ddagger$ & 0.4 \\
\hline Frontal Outer table & + & $2.0++$ & 0.5 & $1.1+\dagger$ & 0.3 & $1.6 \ddagger \ddagger$ & 0.4 & $1.1 \neq \ddagger$ & 0.5 \\
\hline Paietal Total & - & $9.4+\dagger$ & 3.7 & $2.2+\dagger$ & 1.1 & 2.8 & 0.7 & 2.4 & 1.1 \\
\hline Parietal Inner table & + & 1.7 & 1.0 & 1.1 & 0.4 & 1.5 & 0.4 & 0.8 & 0.4 \\
\hline Parietal Outer table & + & $1.9+$ & 0.6 & $1.0+$ & 0.4 & 1.4 & 0.5 & 1.2 & 0.7 \\
\hline Occipital Total & + & $7.6++$ & 2.1 & $4.9+\dagger$ & 1.5 & 5.6 & 1.2 & 5.0 & 2.0 \\
\hline Occipital Inner table & + & $1.9+$ & 0.9 & $0.9+$ & 0.2 & $1.2 \ddagger$ & 0.3 & $0.9 \ddagger$ & 0.3 \\
\hline Occipital Outer table & + & 2.4 & 0.8 & 2.0 & 0.5 & 1.7 & 0.5 & 1.6 & 0.6 \\
\hline Frontal Skull base & - & $2.9+\dagger$ & 2.0 & $0.8+\dagger$ & 0.1 & $1.6 \ddagger \ddagger$ & 0.6 & $0.8 \ddagger \ddagger$ & 0.2 \\
\hline Middle Skull base & - & $4.3+\dagger$ & 1.9 & $0.7+\dagger$ & 0.1 & $1.3 \ddagger \ddagger$ & 0.4 & $0.6 \neq \ddagger$ & 0.1 \\
\hline Foramen magnum & + & $1.9++$ & 0.3 & $1.3++$ & 0.4 & $1.8 \ddagger \ddagger$ & 0.4 & $1.2 \ddagger \ddagger$ & 0.2 \\
\hline Clivus Inner table & + & 1.1 & 0.4 & 0.8 & 0.2 & $1.2 \ddagger \ddagger$ & 0.3 & 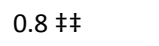 & 0.3 \\
\hline Porus IAC & - & $1.1+\dagger$ & 0.4 & $4.1+\dagger$ & 0.6 & 4.0 & 0.7 & 4.3 & 0.8 \\
\hline Fundus IAC & + & $2.8++$ & 1.1 & $5.3+\dagger$ & 1.0 & 5.1 & 0.5 & 5.1 & 0.7 \\
\hline Optic canal & + & 3.7 & 1.6 & 4.2 & 0.8 & 4.1 & 0.5 & 4.0 & 0.8 \\
\hline Vidian canal & + & 1.0 & 0.5 & 0.9 & 0.3 & 1.2 & 0.4 & 1.0 & 0.3 \\
\hline Coronoid suture & + & $4.6+$ & 1.2 & $3.0+$ & 0.9 & 2.7 & 1.7 & 4.0 & 1.5 \\
\hline Lambdoid suture & + & $7.0++$ & 2.4 & $4.0+t$ & 1.4 & 3.9 & 1.5 & 4.5 & 1.6 \\
\hline
\end{tabular}

† paired T-test 1-3 $\mathrm{p} \leq 0.05$

‡ paired T-test $2-4 \mathrm{p} \leq 0.05$

++ paired T-test 2-4 $\mathrm{p} \leq 0.005$

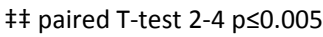

\section{Density measurements}

The assumption of normality could be made for all density measurements so that the paired sample $t$ test could be applied. For general measurements (frontal, parietal, occipital, and petrous bone, and greater wing of the sphenoid bone) there were no significant differences between group 1 and 3 or between group 2 and 4 . Groups 2, 3, and 4 display a trend of gradually decreasing density values throughout life, as expected in normal bone tissue ${ }^{5}$. 

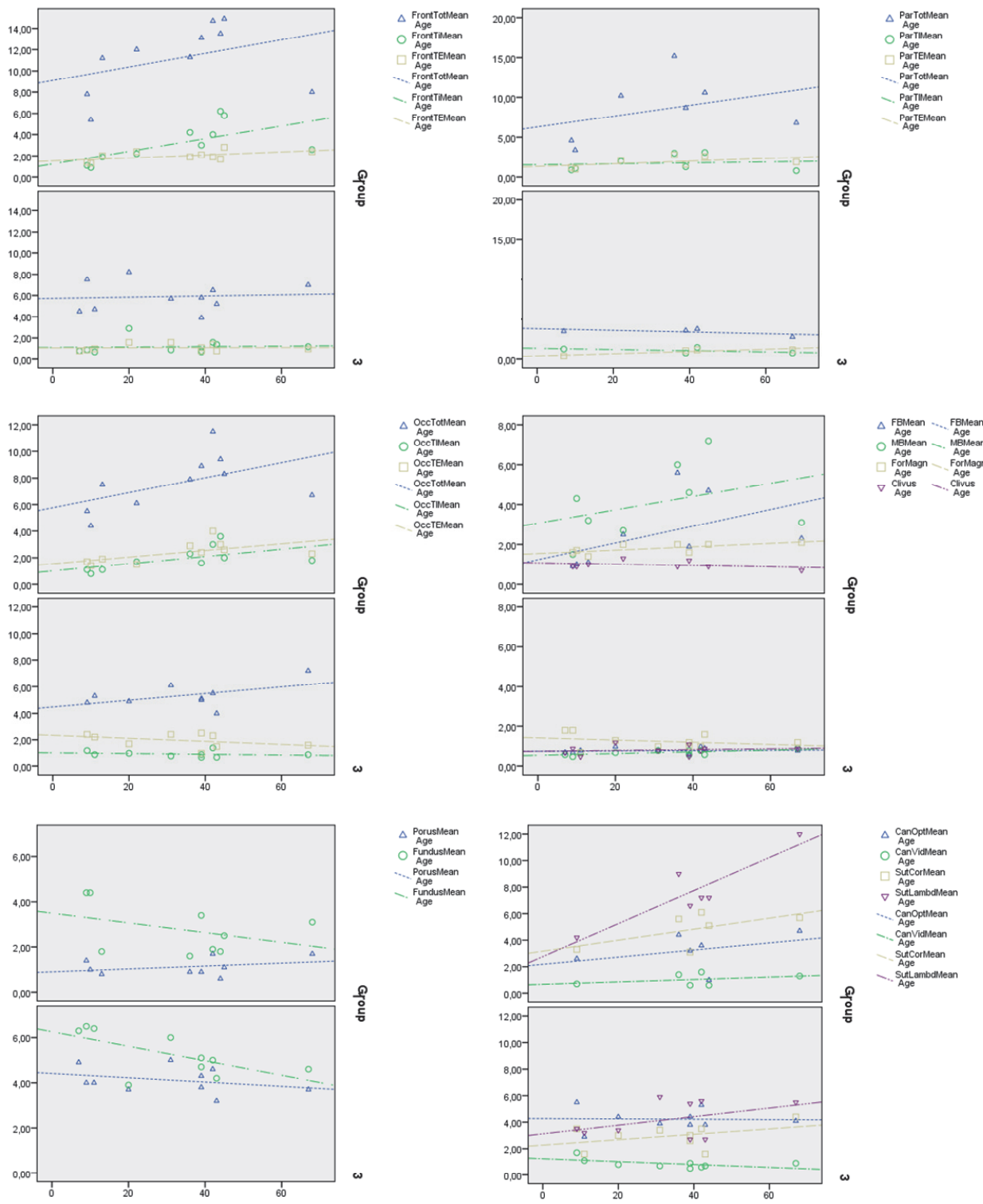

Figure 5.4 Evolution of groups 1 and 3 per anatomic region. A: frontal bone, B: parietal bone, C: occipital bone, D: skull base, E: internal auditory canal and $\mathrm{F}$ : miscellaneous. $\mathrm{X}$-axis = age, $\mathrm{Y}$-axis = distance $(\mathrm{mm})$. TI = inner table (tabula interna), TE = outer table (tabula externa).

Significantly lower densities were found in group 1 in all inner table areas: greater sphenoid wing, frontal bone, parietal bone and occipital bone compared with group 3 (Table 5.3). No differences were found in any trabecular/medullar bone areas. No 
statistical differences were found in outer table areas, although affected individuals tended to have denser outer table bone than unaffected individuals. Inner table density measurements are lower in affected individuals than outer table density, in contrast to unaffected individuals (Figure 5.5). Skull sutures in affected individuals generally have a lower density than control subjects.

Table 5.3 Specific density measurements.

\begin{tabular}{|c|c|c|c|c|}
\hline $\begin{array}{l}\text { Location affected group } 1 \text { - } \\
\text { Reference location matched group } 3\end{array}$ & $\begin{array}{l}\text { Mean density } \\
\text { group } 1- \\
\text { Mean density } \\
\text { group } 3 \text { (HU) }\end{array}$ & $\begin{array}{c}\text { Mean } \\
1-3 \\
(\mathrm{HU})\end{array}$ & SD & $\begin{array}{c}\text { Paired } \\
t \text { test } \\
\text { (p) }\end{array}$ \\
\hline $\begin{array}{l}\text { Sphenoid Inner table } 1 \\
\text { Sphenoid Innter table } 3\end{array}$ & $\begin{array}{l}1022.6 \\
1382.1\end{array}$ & -359.5 & 231.8 & 0.001 \\
\hline $\begin{array}{l}\text { Sphenoid Diploë } 1 \\
\text { Sphenoid Diploë } 3\end{array}$ & $\begin{array}{l}115.5 \\
138.6\end{array}$ & -23.1 & 92.0 & 0.448 \\
\hline $\begin{array}{l}\text { Frontal Inner table } 1 \\
\text { Frontal Inner table } 3\end{array}$ & $\begin{array}{l}1191.9 \\
1350.6\end{array}$ & -158.8 & 60.2 & 0.000 \\
\hline $\begin{array}{l}\text { Frontal Diploë } 1 \\
\text { Frontal Diploë } 3\end{array}$ & $\begin{array}{l}427.8 \\
325.7\end{array}$ & 102.1 & 176.8 & 0.101 \\
\hline $\begin{array}{l}\text { Frontal Outer table } 1 \\
\text { Frontal Outer table } 3\end{array}$ & $\begin{array}{l}1489.4 \\
1347.6\end{array}$ & 141.8 & 199.4 & 0.084 \\
\hline $\begin{array}{l}\text { Parietal Inner table } 1 \\
\text { Frontal Inner table } 3 *\end{array}$ & $\begin{array}{l}1115.0 \\
1350.6\end{array}$ & -235.6 & 196.1 & 0.011 \\
\hline $\begin{array}{l}\text { Parietal Diploë } 1 \text { * } \\
\text { Frontal Diploë } 3\end{array}$ & $\begin{array}{l}397.2 \\
334.0\end{array}$ & 63.2 & 250.0 & 0.470 \\
\hline $\begin{array}{l}\text { Parietal Outer table } 1 \\
\text { Frontal Outer table } 3\end{array}$ & $\begin{array}{l}1442.5 \\
1347.6\end{array}$ & 94.9 & 149.0 & 0.115 \\
\hline $\begin{array}{l}\text { Occipital Inner table } 1^{*} \\
\text { Frontal Inner table } 3\end{array}$ & $\begin{array}{l}1136.8 \\
1353.4\end{array}$ & -216.6 & 82.0 & 0.000 \\
\hline $\begin{array}{l}\text { Clivus } 1 \\
\text { Clivus } 3\end{array}$ & $\begin{array}{l}235.6 \\
204.6\end{array}$ & 31.0 & 110.2 & 0.397 \\
\hline $\begin{array}{l}\text { Sphenopetrosal suture } 1 \\
\text { Sphenopetrosal suture } 3\end{array}$ & $\begin{array}{l}1176.2 \\
1206.7\end{array}$ & -30.5 & 186.6 & 0.618 \\
\hline $\begin{array}{l}\text { Tympanosquamosal suture } 1 \\
\text { Tympanosquamosal suture } 3\end{array}$ & $\begin{array}{l}1393.8 \\
1484.3\end{array}$ & -90.5 & 86.9 & 0.009 \\
\hline $\begin{array}{l}\text { Medulla lateral orbita } 1 \\
\text { Medulla lateral orbita } 3\end{array}$ & $\begin{array}{l}271.1 \\
265.3\end{array}$ & 5.8 & 128.3 & 0.889 \\
\hline Exostoses mandible 1 & 1340.0 & N/A & 86.0 & N/A \\
\hline
\end{tabular}

Comparison of bone density of specific location between group 1 and 3 . Areas indicated with * in group 3 were too small to be measured separately. Therefore, the frontal area was used as reference. 


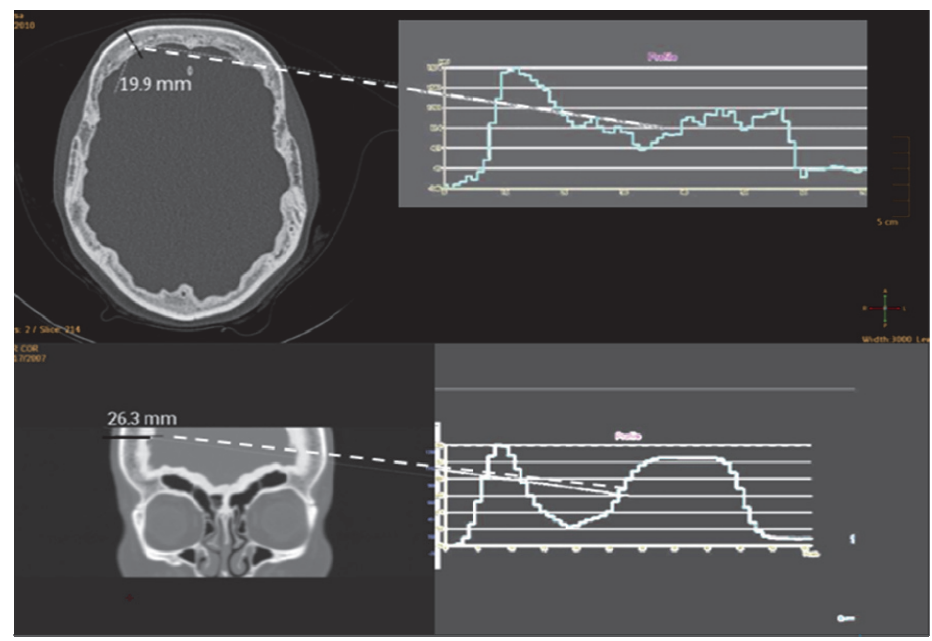

Figure 5.5 Density profiles of skull transections in frontal (upper) and frontotemporal (lower) bone (upper) region. X-axis: distance, $\mathrm{Y}$-axis: density $(\mathrm{HU})$. The higher peak correlates with the outer table. Inner table density measurements are found to be lower in affected individuals than outer table density, in contrast to unaffected individuals.

\section{Descriptive analysis per affected region}

\section{Frontal bone, frontal sinus \& anterior skull base}

Late in the first decade, radiological abnormalities become visible in the frontal bone. The first changes are small hypodense islands in the medulla, both medial as well as lateral toward the temporal line (Figure 5.6). These expand towards the outer table in a balloon-like manner, accompanied with a general thickening of the diploë. Then, focal hyperdense sclerotic spots arise at the border of inner table and the inner diploë initially without significant thickening of the inner table. In puberty, the hyperdense spots merge and circularly augment from the inner table inward, resembling tree rings. The inner border of the significantly thickened diploë stays hypodense at the border with the enlarging inner table. The sclerotic circular layers of hyperdense augment gradually and fuse in the second or third decade. The inner surface becomes more rugose, and from the fourth decade on there is generally no more significant growth.

Pneumatisation of the frontal sinus occurs earlier and is more extensive than average. The inner table of the frontal sinus, as well as the internal frontal beak (inner aspect of the glabella/nasofrontal area) display hyperostotic changes late in the second decade. There is limited thickening of the outer table at the level of the sinus and the frontal bone as well. 


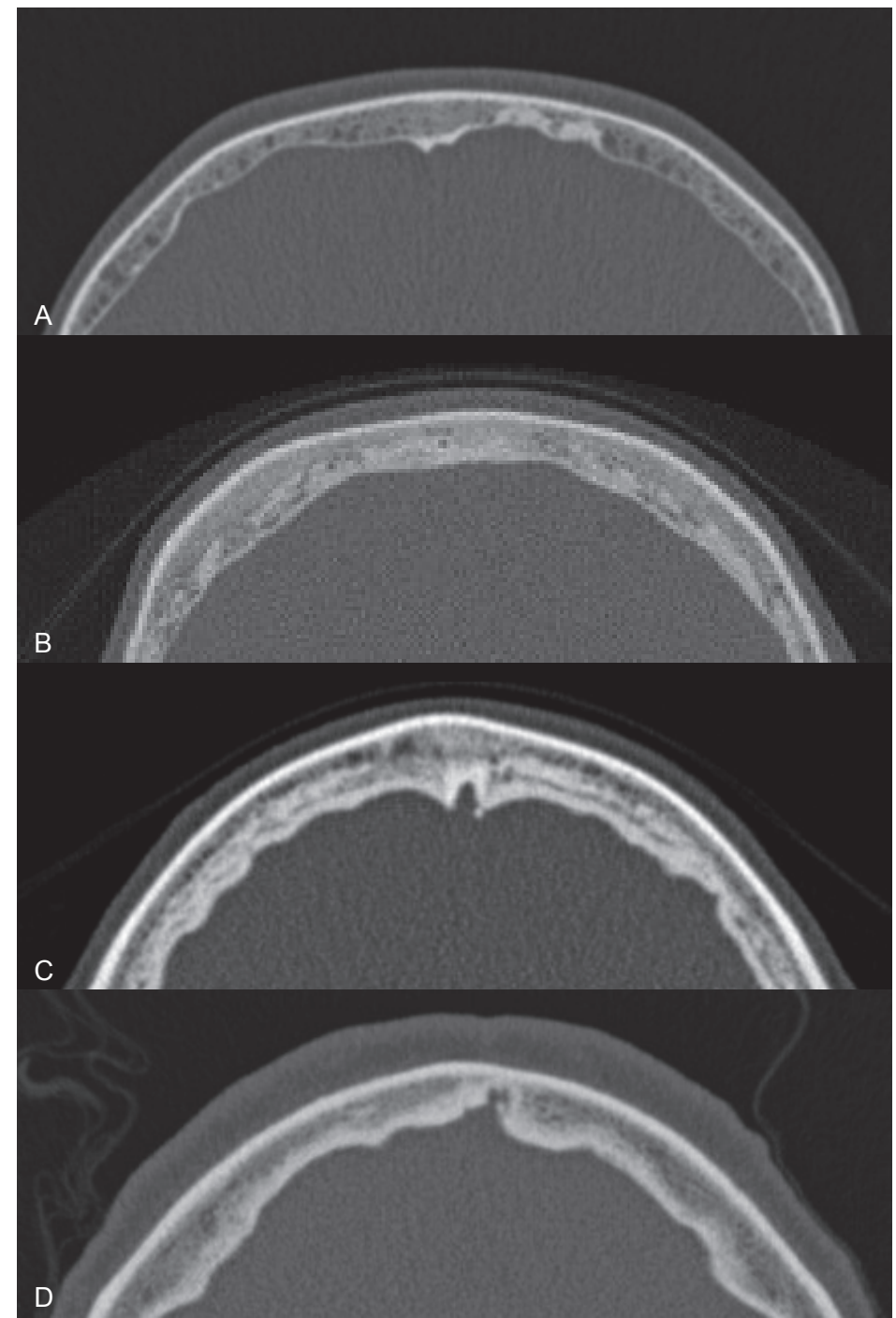

Figure 5.6 Development of abnormalities in the frontal bone, axial images. A: age 9. B: age 16. C: age 23 and D: age 68.

\section{Parietal \& temporal bones}

Abnormalities in the parietal bone start off as early as in the frontal bone. Hypodense areas arise at the endosteal side of the diploë from the age of 8. Initially, only the diploë grows thicker and the inner surface becomes irregular, without obvious thickening of the inner table. The petrosquamous suture lines become sclerotic, in this 
area the three bone layers (inner table, outer table and diploë) cannot not be differentiated. In the second and third decade there is further thickening of the diploë and hyperostosis of the inner table becomes apparent. The same pattern as in the frontal bone is observed: a hypodense demarcation between inner table and diploë. In contrary to the frontal bone, the hyperostotic layer does not have a circularly layered aspect. From this age, disease progression is variable per individual.

The temporal bone (Figure 5.7) is generally extensively pneumatised, also towards the petrous apex and the zygomatic root. The first temporal bone abnormalities are visible by the age of 10 . The lateral mastoid, just cranial to the external ear canal has a sclerotic aspect in all individuals, seemingly a sclerotic petrosquamous suture. In the second decade the sclerosis of the petrosquamous suture (or Körner's septum in the mastoid) expands, causing obliteration of the lateral mastoid and air cells around the zygomatic root.

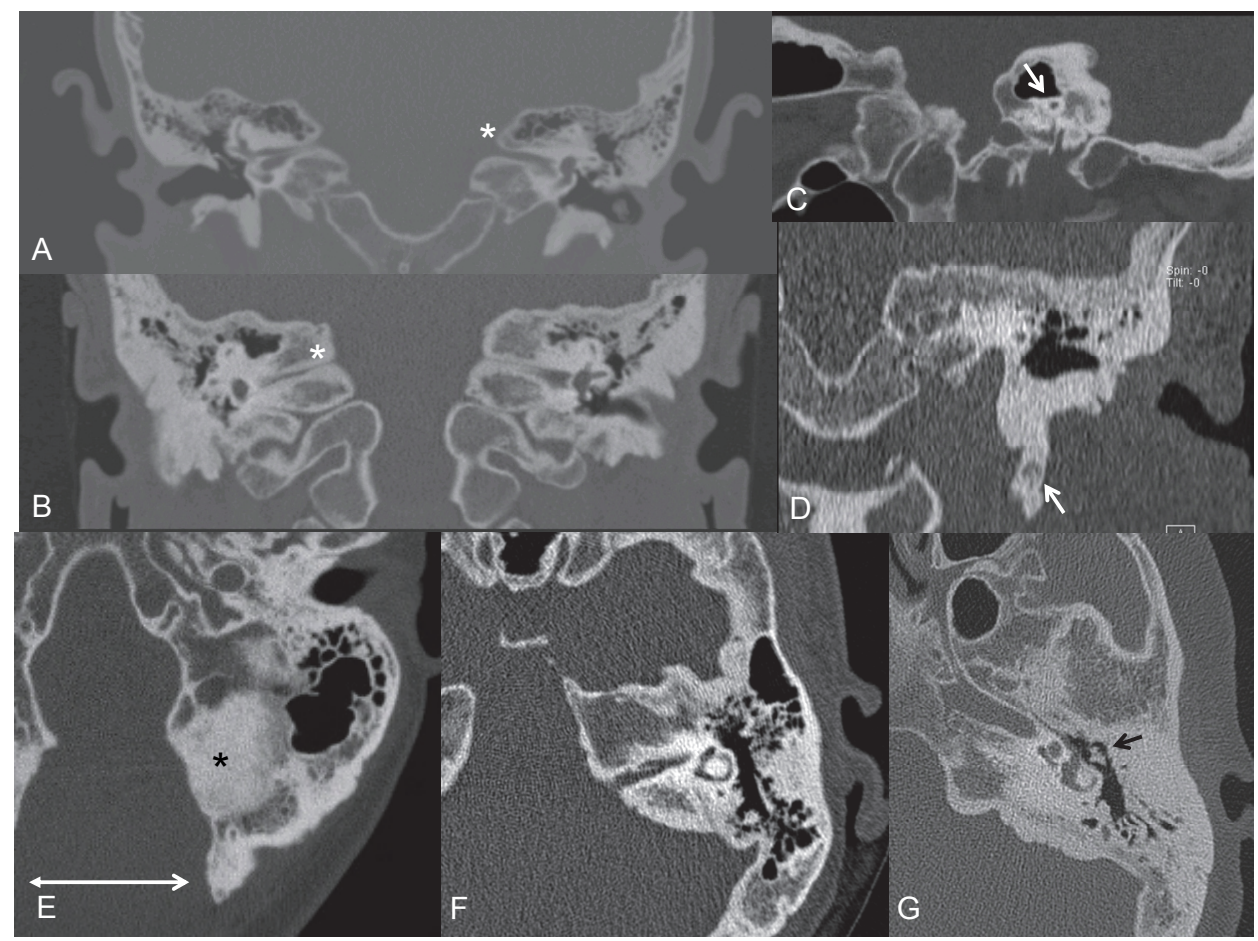

Figure 5.7 Temporal bone. A: 9-year-old boy. Hyperostotic superior (asterisk) and inferior lip of the internal auditory canal (coronal reconstruction). B: 41-year-old female. Pinpoint internal auditory canal (arrow, sagittal reconstruction). C: Progressive bilateral narrowing of the IAC in a 16-year-old girl (asterisk, coronal reconstruction). D: hyperostotic stylomastoid process in a 44year-old woman (arrow, coronal reconstruction). E-G: axial images of left temporal bones with extensive hyperostosis in posterior fossa (asterisk) after foramen magnum decompression (double-headed arrow) (E, 41-year-old woman), extensive pneumatisation progressively substituted by sclerotic bone ( $F$ and $G$ ). Note the middle ear space is not affected (arrow $G$ ). 
Endosteal thickening of the temporal bone starts at the posterior aspect and the internal auditory canal region in the late first or early second decade, first as small hyperdense speckles. A clear endosteal hyperostotic margin becomes visible later in the second decade, now also including the anterior and superior aspect of the petrous bone.

Internal auditory canal narrowing is invariably visible at the level of the porus in the late first decade. The petrous apex, even when initially pneumatised, becomes sclerotic. There is thickening of both the inferior and superior lip of the canal; however, bone accretion of the superior lip seems to contribute most of the narrowing. The canal size decreases until a pinpoint lumen $(0.5-1 \mathrm{~mm})^{6}$.

The sclerotic stylomastoid process becomes hyperostotic and sclerotic in older individuals as well.

\section{Sphenoid and ethmoid bones}

The endocranial side of the greater sphenoid wing displays the same abnormalities as the frontal bone: hypodense areas of the diploë and sclerotic endosteal foci appearing late in the first decade. Fusion sites with other adjacent osseous structures have a sclerotic aspect as well: the sphenosquamous suture (connection with temporal bone), sphenofrontal suture, and sphenozygomatic sutures. Fusion with the clivus is not yet established at this age. The lamina cribrosa and the ethmoid cells are, as yet, unaffected. The anterior midline aspect of the sphenoid bone, the jugum, or corpus sphenoidale facing the ethmoid sinuses becomes sclerotic even before the sphenoid sinus is fully pneumatised. When the sphenoid sinus is developed, the anterolateral wall of the sinus becomes more explicitly thickened than in unaffected individuals. In the second decade this hyperostosis becomes more evident and the (anterior portion of the) lamina papyracea becomes involved as well. The clivus fuses with the sphenoid bone without any evident sclerosis at this fusion site. Until the mid-20s, there is significant progression of disease at the endocranial side of the greater and lesser sphenoid wing (Figure 5.8A). The sclerotic endosteal borders transform into a welldefined hyperdense hyperostotic bone layer, which becomes continuous with the parietal and petrous bone. Remarkably, the endocranial side of the corpus of the sphenoid and the tuberculum sellae are spared.

If an individual is severely affected the patency of the superior orbital fissure is potentially compromised due to hyperostosis of both the superior aspect of the greater sphenoid and the inferior aspect of the lesser sphenoid wing. The patency of the optic canal is specifically at risk at the narrowest part where hyperostosis of the superolateral aspect of the sphenoid sinus and hyperostosis of the medial side of the lesser sphenoid wing occur (Figure 5.8D). 

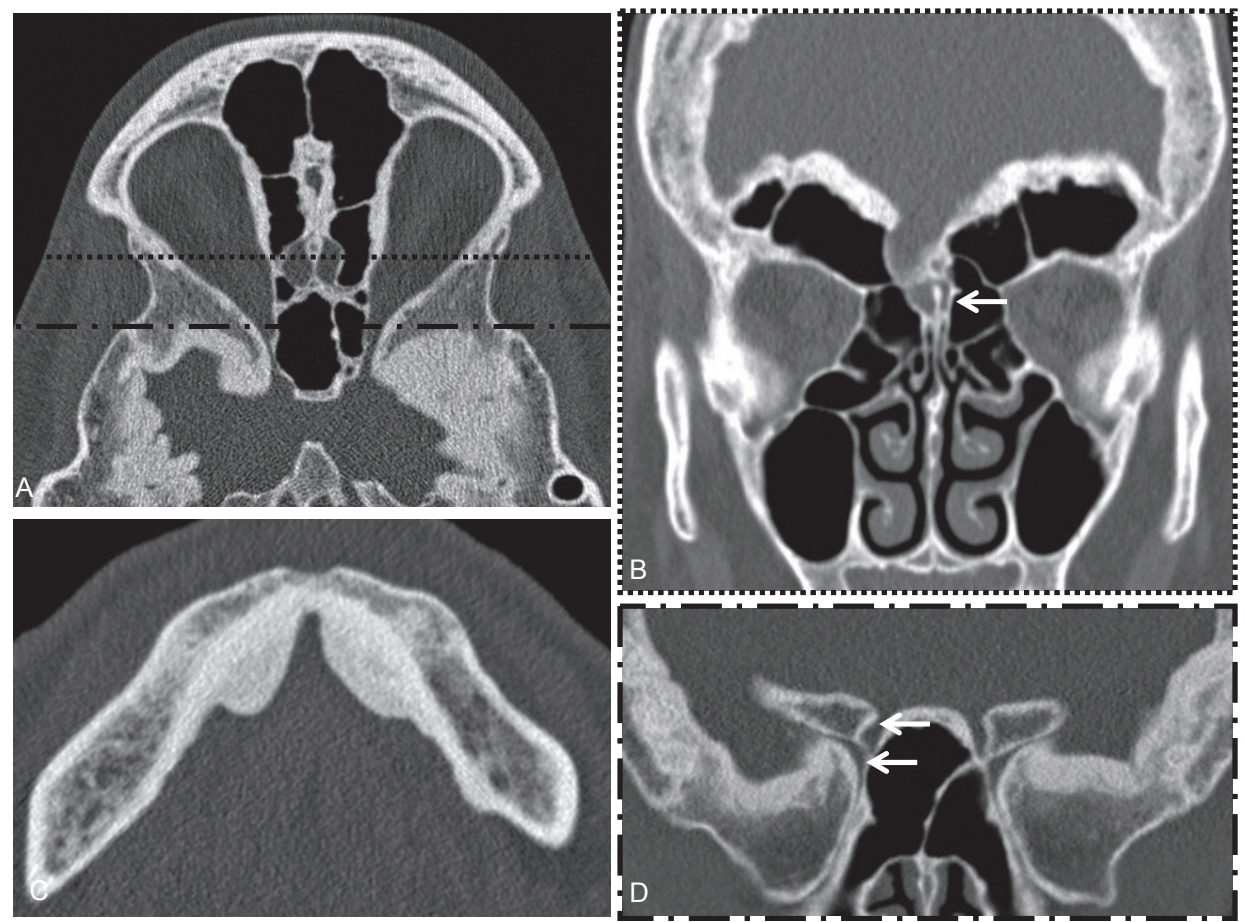

Figure 5.8 Sphenoid, ethmoid, mandible. A: axial image of 23-year-old woman. Hyperostosis of endosteal greater sphenoid wing, decreased space in temporal lobe area. Hyperostotic lamina papyracea and lamina cribrosa area. Anterior line corresponds with coronal image B (different patient), posterior line corresponds with the coronal image D (same patient). B: coronal image of 41-year-old woman showing extensive supraorbital pneumatisation and inclusion of unaffected crista galli (arrow). C: axial image of mandibular exostoses in a 68-year-old patient. Note that the inner table of the mandible has a normal aspect. D: coronal image (same patient as A) of the greater and lesser sphenoid wings. Note narrowing of the optic canal (upper arrow) and the superior orbital fissure (lower arrow).

\section{Middle and posterior skull base}

Symptomatology of neural and vascular structures passing the various middle skull base neuroforamina is dependent on the degree of encroachment. The foramen rotundum and ovale can be narrowed in their proximal part, leading to dysfunction of the second and third branches of the trigeminal nerve in severely affected individuals. The Vidian nerve and pterygopalatine fossa are never narrowed. The carotid canal is not affected at all whereas asymptomatic sigmoid sinus narrowing is present in individuals with extensive posterior fossa hyperostosis. The jugular foramen is not narrowed. The foramen spinosum and hypoglossal canal are patent in all patients. 


\section{Skull sutures}

Skull sutures are affected to a various extent from late childhood. There is explicitly no endosteal hyperostosis at the fusion sites, however osteosclerosis occurs parallel to the suture in the direction of the connecting plates.

\section{Mandible}

Changes occur to the mandible later in life (Figure 5.8C). There is smooth delineated ellipsoid deposition of bone at the inner (oral) side of the anterior half of the mandible, sparing the midline. The density is lower than cortical bone, similar to the cranial abnormalities. This is only observed from the age of 36 onward. Unlike abnormalities of the frontal region and the skull base region, the otherwise intact inner cortex can still be differentiated from the disease-related bone deposition.

\section{Discussion}

In $\mathrm{HCl}$, endosteal hyperostosis occurs in the parietal, the frontal, the occipital, the sphenoid, the ethmoid and the temporal bones, without obliteration of the diploë. The most marked change is thickening of the inner table of the calvaria, except for the parietal region, where broadening of the diploë is more explicit. The reason for this difference is unclear. The appearance of the outer table of the patient group is not disturbed, but is slightly thickened in the adult affected individuals. The cranial nerve deficits are caused by hyperostosis of the skull base. Furthermore, skull sutures become more sclerotic than in unaffected individuals, and the lateral parts of the mastoids and the petrous apices undergo sclerotic changes. The stylomastoid process is affected showing broadening and exostoses. All patients develop mandibular exostoses at the interior surface of the anterior half of the mandible at a later age. Clinically and upon descriptive radiologic examination, female patients are more severely affected than male. There is no statistical support for this phenomenon. The diploë never obliterates because the bone accretion seems to take place at the endosteal side of a hypodense circular "front", with ballooning spongeous spots in the diploë and net bone growth follows an inward (endosteal) direction. In similar sclerosing bone dysplasias, like Camurati-Engelmann disease, Van Buchem disease and sclerosteosis there is obliteration of the diploë. However, whether this bone accretion actually takes place at the outside of the inner table or at the inside of the diploë can only be proven histologically.

The outcome of the analyses of the internal auditory canal confirm the management as has earlier been proposed by our group. Narrowing of the porus occurs at a very young age to a size that causes dysfunction of the facial and vestibulocochlear nerves in 
almost all patients. Early intervention (decompression) is advised ${ }^{6}$. The fundus narrows gradually at a later age (down to $2 \mathrm{~mm}$ ), just as it does in the normal population $(4 \mathrm{~mm})$. For the optic system it is harder to arrive at a straightforward conclusion. Although there is no statistically significant difference between the width of the optic canal in affected and unaffected individuals, the difference is apparent with a greater individual variation as seen in the larger standard deviation. Impairment of the optic nerve, if any, occurs at the narrowest point of the optic canal, due to hyperostosis of the medial lesser sphenoid wing, as depicted in Figure 5.8A and 5.8D. Another plausible option could be impairment of venous outflow of the ophthalmic vein due to a narrowed superior orbital fissure (due to hyperostosis of the medial greater sphenoid wing, Figure 5.8D).

Paranasal sinus and petrous bone pneumatisation is remarkably extensive in all young patients, however this could be a non-disease-specific coincidental finding (fig. 9B). The young affected individuals have a fully developed frontal sinus at the age of 7 , whereas normally the sinus does not appear before this age. The early extensive petrous bone pneumatisation is generally replaced by secondary sclerosis.

In the available literature little is found about reference values of bone density in the skull. In oral implantologic studies have been performed to optimise implant osseointegration by correlating the density to the bone strength. Misch et al. have proposed the following classification: dense cortical (D1, >1250 $\mathrm{HU}$ ), porous cortical (D2, 850-1250 HU), coarse trabecular (D3, 350-850 HU) and fine trabecular bone (D4, $<400 \mathrm{HU})^{7}$. The hyperostotic bone in $\mathrm{HCl}$ has the appearance and also the densitometric characteristics of porous cortical bone (D2), resembling the density of abnormalities in Paget's disease and fibrous dysplasia.

The outer table of the patient's calvaria have similar density values as the unaffected population and the control patients. The trabecular bone (diploë) at different sites of patients is similar to mandibular trabecular bone as described in oral implantology literature $(240-380 \mathrm{HU})^{8}$. The density degradation can be compared to the process that is visible in otosclerosis, where dense (D1) cortical bone of the otic pit is transformed into porous cortical bone containing more fibrous and less calcified tissue ${ }^{9,10}$.

There is not yet a definite explanation why some particular areas are involved and others not. Given the fact that only the craniofacial area is involved, there must be a local factor that causes bone metabolic disturbance. The inward (endosteal) hyperostosis pleas for a potential role of the dura mater, which is known to produce signalling substances involved in bone metabolic pathways ${ }^{11}$. However, not all structures adjacent to dura are affected equally: the occipital area is less affected than the temporal area, there is hardly any hyperostosis in the area of the clivus and foramen magnum and the spine is not affected at all. Besides, the stylomastoid process 
and the mandible display abnormalities, not being adjacent to dura. The course of the disease could also give a clue about the pathogenesis. Abnormalities are not seen before the late first decade. If regional (dural) factors do induce abnormal growth, different gene expression in juvenile and in adult dura possibly explain why abnormal growth does not occur in all stages of life ${ }^{12}$. Different cellular pathways are described that control the growth pace of the skull and the appropriate timing of skull suture closure $^{13}$. Defects in one of these mechanisms occur in disorders in the group of craniosynsostoses (e.g. Crouzon and Apert syndromes) as well ${ }^{4}$.

Although the genetic transmission pattern is clearly autosomal dominant and "unaffected family members" obviously have no abnormal radiological hallmarks and no symptomatology, there are some significant differences in contrast to their control group. This reminds of incomplete dominance, however this can only be proven after the detection of the underlying genetic defect.

\section{Conclusion}

Hyperostosis cranialis interna is a bone dysplasia with abnormalities limited to the craniofacial area. The hyperostotic bone is less dense than normal cortical bone. The observed radiological abnormalities match the possible impairment of the olfactory, optic, trigeminal, facial and vestibulocochlear nerves. The pathogenesis remains obscure until the underlying genetic defect is found, but disturbance in local bone metabolic pathways appear to be involved. 


\section{References}

1. Manni JJ, Scaf JJ, Huygen PL, Cruysberg JR, Verhagen WI. Hyperostosis cranialis interna. A new hereditary syndrome with cranial-nerve entrapment. N Engl J Med 1990;322:450-454.

2. Waterval JJ, Stokroos RJ, Bauer NJ, De Bondt RB, Manni JJ. Phenotypic manifestations and management of hyperostosis cranialis interna, a hereditary bone dysplasia affecting the calvaria and the skull base. Am J Med Genet A 2010;152A:547-555.

3. Rimoin DL, Cohn D, Krakow D, Wilcox W, Lachman RS, Alanay Y. The skeletal dysplasias: clinicalmolecular correlations. Ann N Y Acad Sci 2007;1117:302-309.

4. Superti-Furga A, Unger S. Nosology and classification of genetic skeletal disorders: 2006 revision. Am J Med Genet A 2007;143:1-18.

5. Skrzat J, Brzegowy P, Walocha J, Wojciechowski W. Age dependent changes of the diploe in the human skull. Folia Morphol (Warsz) 2004;63:67-70.

6. Waterval JJ, Stokroos RJ, De Bondt RB, Manni JJ. Facial nerve decompression via middle fossa approach for hyperostosis cranialis interna: a feasible therapeutic approach. J Laryngol Otol 2009;123:1177-80.

7. Misch CE, Dietsh-Misch F, Hoar J, Beck G, Hazen R, Misch CM. A bone quality-based implant system: first year of prosthetic loading. J Oral Implantol 1999;25:185-197.

8. de Oliveira RC, Leles CR, Normanha LM, Lindh C, Ribeiro-Rotta RF. Assessments of trabecular bone density at implant sites on CT images. Oral Surg Oral Med Oral Pathol Oral Radiol Endod 2008;105: 231-238.

9. Kawase S, Naganawa S, Sone M, Ikeda M, Ishigaki T. Relationship between CT densitometry with a slice thickness of $0.5 \mathrm{~mm}$ and audiometry in otosclerosis. Eur Radiol 2006;16:1367-1373.

10. Grayeli AB, Yrieix CS, Imauchi Y, Cyna-Gorse F, Ferrary E, Sterkers O. Temporal bone density measurements using CT in otosclerosis. Acta Otolaryngol 2004;124:1136-1140.

11. Warren SM, Greenwald JA, Nacamuli RP, Fong KD, Song HJ, Fang TD, Mathy JA, Longaker MT. Regional dura mater differentially regulates osteoblast gene expression. J Craniofac Surg 2003;14:363-370.

12. Wan DC, Aalami OO, Wang Z, Nacamuli RP, Lorget F, Derynck R, Longaker MT. Differential gene expression between juvenile and adult dura mater: a window into what genes play a role in the regeneration of membranous bone. Plast Reconstr Surg 2006;118:851-861.

13. Opperman LA, Adab K, Gakunga PT. Transforming growth factor-beta 2 and TGF-beta 3 regulate fetal rat cranial suture morphogenesis by regulating rates of cell proliferation and apoptosis. Dev Dyn 2000;219:237-247. 


\section{Chapter}

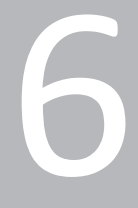

Bone metabolic activity in hyperostosis cranialis interna measured with ${ }^{18}$ F-fluoride PET

Jérôme J. Waterval

Thijs M.A. Van Dongen

Robert J. Stokroos

Jaap G.J. Teule

Gerrit J. Kemerink

Boudewijn Brans

Fred H.M. Nieman

Johannes J. Manni

European Journal of Nuclear Medicine and Molecular Imaging 2011;38:884-893 


\begin{abstract}
Introduction

${ }^{18}$ F-fluoride PET/CT is a relatively undervalued diagnostic test to measure bone metabolism in bone diseases. Hyperostosis Cranialis Interna $(\mathrm{HCl})$ is a (hereditary) bone disease characterised by endosteal hyperostosis and osteosclerosis of the skull and the skull base. Bone overgrowth causes entrapment and dysfunction of several cranial nerves. The aim of this study is to compare standardised uptake values (SUVS) at different sites in order to quantify bone metabolism in the affected anatomic regions in $\mathrm{HCl}$ patients.
\end{abstract}

\title{
Methods
}

Nine affected family members, 7 non-affected family members and 9 non-HCl-non-family members underwent ${ }^{18} \mathrm{~F}$-fluoride PET/CT scans. SUVs were systematically measured in the different regions of interest: frontal bone, sphenoid bone, petrous bone and clivus. Moreover the average ${ }^{18} \mathrm{~F}$-fluoride uptake in the entire skull was measured by assessing the uptake in axial slides. Visual assessment of the PET scans of affected individuals was performed to discover the process of disturbed bone metabolism in $\mathrm{HCl}$.

\section{Results}

${ }^{18} \mathrm{~F}$-fluoride uptake is statistically significant higher in the sphenoid bone and clivus regions of affected family members. Visual assessment of the scans of $\mathrm{HCl}$ patients is relevant in detecting disease severity and the pattern of disturbed bone metabolism throughout life.

\section{Conclusion}

${ }^{18}$ F-fluoride PET/CT is useful in quantifying the metabolic activity in $\mathrm{HCl}$ and provides information about the process of disturbed bone metabolism in this specific disorder. Limitations are a narrow window between normal and pathologic activity and the influence of age. This study emphasises that ${ }^{18} \mathrm{~F}$-fluoride PET/CT may also be a promising diagnostic tool for other metabolic bone disorders, even those with an indolent course. 


\section{Introduction}

Hyperostosis cranialis interna ( $\mathrm{HCl}$ ) (OMIM 144755) is a disorder which was first described in 1990 and is characterised by hyperostosis and osteosclerosis of the calvaria and skull base (Figure 6.1) ${ }^{1}$.
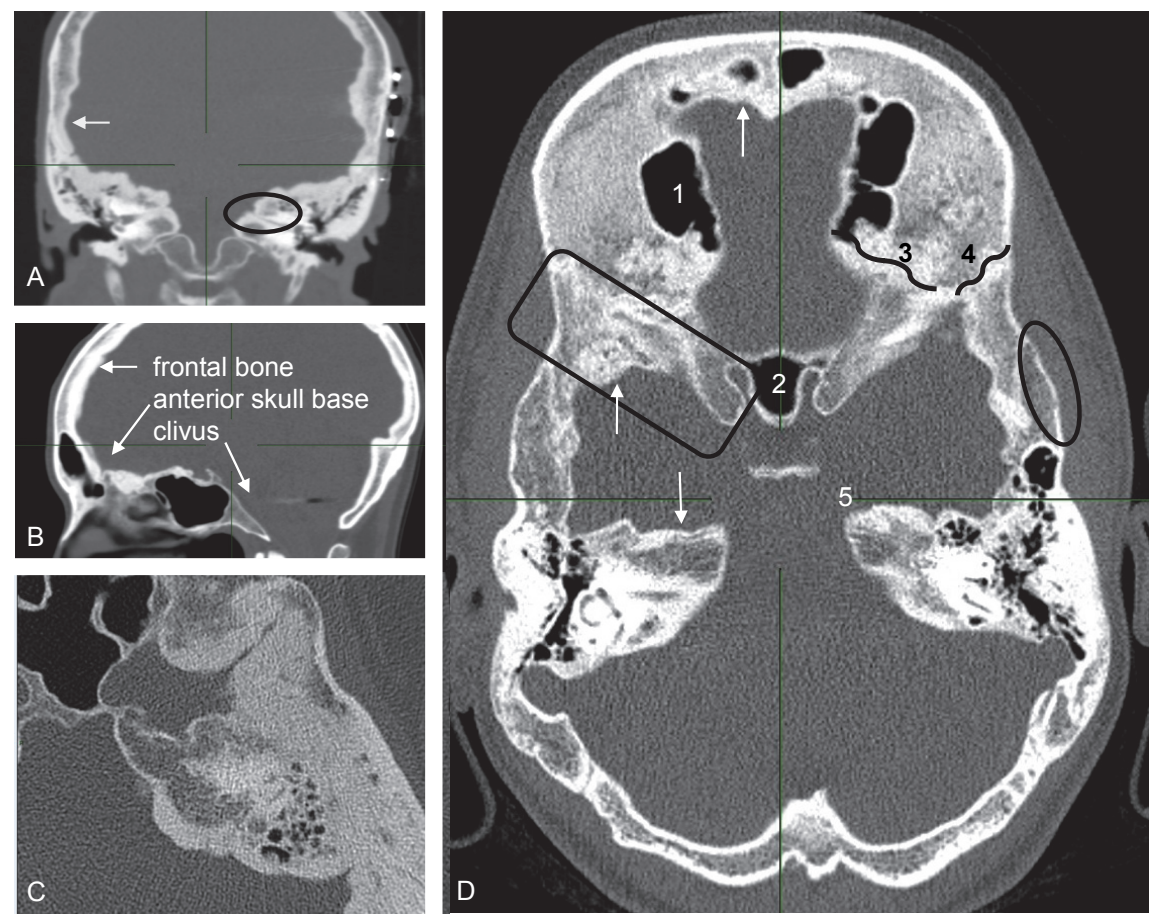

Figure 6.1 CT Images of affected individuals. (A) Coronal reconstruction of the middle skull base with neartotal obliteration of the internal auditory canaly (oval), endosteally thickened parietal area (arrow). Note the subcutaneous wires of auditory brainstem implantation (left). (B) Paramedian sagittal reconstruction. Frontal bone and anterior skull base are moderately affected. Vertebral column, nasal bones and clivus show no hyperostosis. (C) Axial image of the temporoparietal area revealing exorbitant endosteal hyperostosis. (D) Axial overview of a-24-year-old affected woman: 1. right frontal sinus 2. sphenoid sinus 3. sphenofrontal suture 4. sphenoparietal suture 5. apex of the petrous bone. Arrows: apposition of excessive endosteal bone. Oval: normal configuration of outer cortex. Square: greater sphenoid wing.

This leads to a narrowing of cranial nerve foramina causing entrapment and dysfunction of cranial nerves I, II, V, VII and VIII. Facial palsy and vestibulocochlear dysfunction occur at young age, mainly in the second and third decades. Smell and vision impairment and trigeminal neuralgia may occur later. It is a hereditary disorder that, to date, has been diagnosed in three related Dutch families only ${ }^{2}$. Besides $\mathrm{HCl}$, 
numerous bone dysplasias with skull base and calvarial hyperostosis and osteosclerosis exist. Van Buchem disease ${ }^{3,4}$, Camurati-Engelmann disease ${ }^{5}$ and sclerosteosis $^{6}$ are examples of similar disorders with increased bone density, however with metaphyseal and/or diaphyseal involvement. An overview of different (genetic) skeletal disorders is provided by the International Skeletal Dysplasia Society ${ }^{7} . \mathrm{HCl}$ and $\mathrm{X}$-linked calvarial hyperostosis are the only bone disorders affecting solely the skull.

The diagnosis $\mathrm{HCl}$ is suspected by family history and physical examination and confirmed by computed tomography (CT). Analysis of sequential CT scans of affected individuals gives the impression that the frontal bone and the (medial part of the) petrous bone are affected first, in the late first or early second decade. This process seems to continue until the age of 40 . In the greater sphenoid wing hyperdense areas are visible in adolescence (comparable to the frontal bone region), however usually obvious hyperostosis starts later ( $3^{\text {rd }}$ decade) and progresses until later in life. Findings for the parietal bone are similar, becoming pathologically dense and hyperostotic from the $3^{\text {rd }}$ decade on. The anterior and middle skull base are affected, whereas the occipital region is hardly involved (Figure 6.1). $\mathrm{In} \mathrm{HCl}$ there is no involvement of the tubular bones. An additional dynamic bone imaging technique, ${ }^{18} \mathrm{~F}$-fluoride PositronEmission Tomography (PET), could provide valuable information in analysing and quantifying bone metabolism.

${ }^{18} \mathrm{~F}$-fluoride was described as a tracer for bone imaging by Blau et al. in 1962 and 1972 (conventional scintigraphy), but fell into disuse ${ }^{8,9}$. In 1992, PET scans using ${ }^{18}$ F-fluoride were introduced to quantify bone formation ${ }^{10}$. Compared to conventional gamma cameras including SPECT, PET scans have higher spatial resolution and a greater sensitivity than gamma cameras and offer direct quantification of bone imaging studies. Grant et al. reviewed the available studies about clinical utility of ${ }^{18} \mathrm{~F}$-fluoride PET/CT scanning ${ }^{11}$. Although the specific bone uptake is similar for both radionuclides, there is less plasma protein-binding of ${ }^{18} \mathrm{~F}$-fluoride ${ }^{12}$ and the half-life is considerably shorter (110 minutes and 6 hours respectively). ${ }^{18}$ F-fluoride PET scanning offers shorter study times and is therefore more convenient for patient and physician. The effective dose of ${ }^{18} \mathrm{~F}$-fluoride PET is somewhat higher compared to ${ }^{99 \mathrm{~m}} \mathrm{Tc}$ bone scanning $(4.0$ versus $3.0 \mathrm{mSv}$ resp. $)^{11}$. ${ }^{18} \mathrm{~F}$-fluoride PET is more accurate than planar imaging or SPECT with ${ }^{99 \mathrm{~m}} \mathrm{Tc}-\mathrm{MDP}$ for the detection of small focal laesions, such as metastases ${ }^{13}$. Because of its easier quantification capabilities, ${ }^{18} \mathrm{~F}$-fluoride is very useful for the assessment of bone metabolism.

With ${ }^{18} \mathrm{~F}$-fluoride PET differences in bone metabolism between affected $\mathrm{HCl}$ patients, unaffected family members and unaffected control subjects are visualised and quantified in different anatomic subsites. The aims of this study are 1 . to provide additional information about the early stage of $\mathrm{HCl}$ and, 2. to monitor disease activity at different anatomic subsites and predict disease progression which can be important for treatment decisions. 


\section{Materials and methods}

\section{Subjects}

The 3 related families have common progenitors and consist of 31 individuals (Figure 6.2), 3 of whom have deceased. One individual did not participate because of a psychiatric condition at the time of the study. A total of 11 children (all under 5 years old) did not undergo a PET/CT scan because of their age. The remaining 16 were included: 9 family members with proven CT abnormalities (group 1) and 7 family members without CT abnormalities (group 2).

The control group consisted of 9 patients (group 3), mainly examined for orthopaedic diagnostic reasons (without symptoms or a disease history in the head and neck region). The medical ethics committee of the Maastricht University Medical Centre approved the research protocol (document number MUMC 09-4-050.4/PL) and all patients gave their written informed consent. All individuals underwent a ${ }^{18} \mathrm{~F}$-fluoride PET/CT scan between August 2007 and November 2008.

\section{PET imaging}

The average ${ }^{18} \mathrm{~F}$-fluoride activity administered to all patients was approximately $200 \mathrm{MBq}$ (effective dose $5.4 \mathrm{mSv}$ ). PET/CT scans of the head and upper torso were made after 1 hour, acquiring data for $4 \mathrm{~min}$ per bed position. A PET/CT scanner with a 64-slice CT component (Gemini TF; Philips, Best, The Netherlands) was used. In all cases, low-dose CT (30 mAs, $0.5 \mathrm{mSv}$ ) was performed. If needed for diagnostic reasons, high-resolution CT was performed as well. Using the standard Philips time-of-flight ordered subsets expectation maximisation reconstruction (33 subsets, 3 iterations), images corrected for random events, scattered radiation, and attenuation were obtained. The PET matrix size was 144 , resulting in a voxel size of $4 \times 4 \times 4 \mathrm{~mm}^{3}$.

\section{Visual assessment}

All PET scans were visually analysed and compared to the complementary CT scans with Philips Extended Brilliance ${ }^{\mathrm{TM}}$ Workspace in order to assess their clinical value. This program is used for assessment of PET/CT scans in everyday clinical practice at our institute. The PET scans were fused with the $4 \mathrm{~mm} \mathrm{CT} \mathrm{scans} \mathrm{and} \mathrm{depicted} \mathrm{in} \mathrm{"thermal"}$ colour scale setting and compared to high-resolution CT scans of the skull base. The areas of interest were analysed by displaying identical settings: the low-level filter was set at standardised uptake value $(S U V)=1.3$, the upper-level filter at SUV=12.0. Additionally, hot spots were detected by visual scoring of the scans and by assessing the SUV $V_{\text {max }}$ of each slice. 


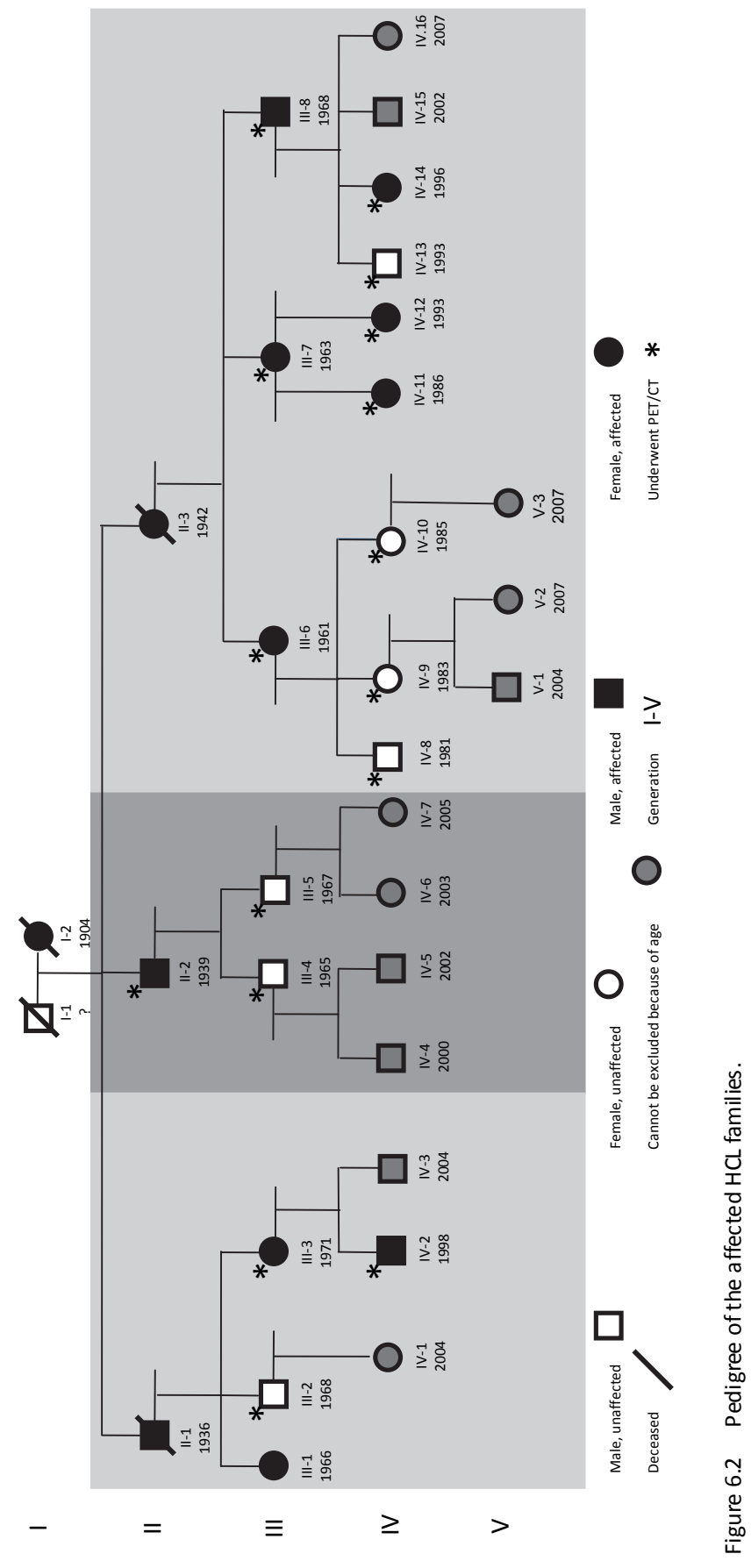




\section{Standardised measurements}

The scans were analysed using PMOD 2.95 (PMOD Technologies Ltd., Zurich, Switzerland). A region of interest (ROI) with a radius of $5 \mathrm{~mm}$ was placed in the axial plane around the maximal activity in different anatomical regions: greater sphenoid wing (left and right), frontal bone (cranial to orbita or frontal sinus), apex of the petrous bone (left and right) and clivus. First, in each of these anatomical regions a manually drawn ROI was created including the entire region. This was repeated for all planes comprising the concerning region and in these ROls the point of maximal activity was assessed. Consequently, the coordinates of these points of maximal activity were used as the centre of the smaller, circular ROls with a radius of $5 \mathrm{~mm}$. The data of this ROI were used for calculation of the SUV. For all anatomic subsites the SUV mean $_{\text {and }}$ SUV $V_{\max }$ were calculated.

The corpus of the third cervical vertebra was chosen as internal control site. In the area scanned, the vertebrae, clavicles and the cheek bones are the only bony structures clearly not affected in $\mathrm{HCl}$-patients. The vertebrae were considered the most appropriate because of their size. None of the scanned individuals, regardless of group, had neck conditions.

Total uptake of the skull was also assessed. ROls were created in the axial plane with the inside (A) and outside (B) boundaries of the skull (Figure 6.3). The uptake in the bone was drawn up by subtracting the data of $A$ from $B$. Next we calculated the average uptake in the entire skull. To accomplish this the average uptake in all planes (from the skull base to the vertex) were added and divided by the total volume (slice thickness of 1 region equals $4 \mathrm{~mm}$ ). With these data the SUVs of the ROls were calculated using the following formula:

$$
S U V[g / m l]=\frac{\text { TissueActivity }(\mathrm{kBq} / \mathrm{ml})}{\text { ActivityInjectedDose }(\mathrm{kBq}) / \operatorname{BodyWeight}(\mathrm{g})}
$$

\section{Statistical analysis}

Sample means, standard deviations and the range of SUV $\mathrm{Sean}_{\text {man }}$ and $\mathrm{SU}_{\text {max }}$ were calculated per group. Kolmogorov-Smirnov tests were performed for all continuous metric data to test for normality. Frequencies and percentages are given for categorical data.

Both the parametric analysis of variance (ANOVA) and the nonparametric KruskalWallis overall tests were performed to examine differences between the three groups. To compare $\mathrm{HCl}$ patients and non- $\mathrm{HCl}$ family members on the one hand and $\mathrm{HCl}$ patients and control subjects on the other hand, the parametric $t$ test and the MannWhitney test were used.

All data were analysed with SPSS PC version 16; $p$ values less than 0.05 were considered as denoting statistical significance. 


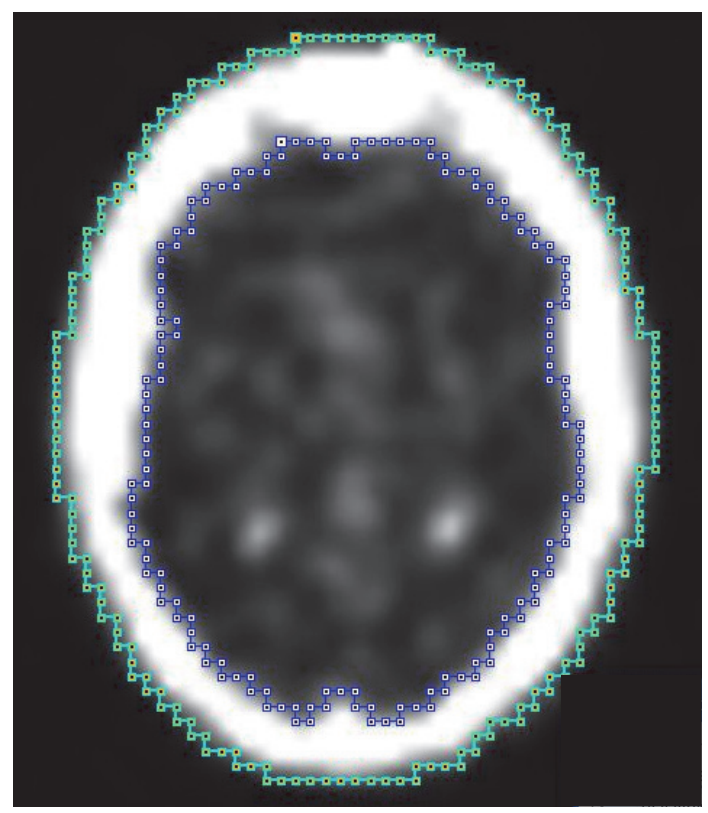

Figure 6.3 Measuring the total uptake of the skull using PMOD 2.95: A (inside) = inner dotted line, B (outside) = outer dotted line; total skull uptake per slice was calculated by subtracting the data of $A$ from $B(B-A)$. Results of all planes together (up from the skull base to the vertex) were added resulting in the total uptake of the bone.

\section{Results}

In group 1, 9 (affected) individuals were included (6 women and 3 men; mean age 32; range 11-68). Group 2 consisted of 7 non- $\mathrm{HCl}$ family members (5 women and 2 men; mean age 29; range 14-40). A total of 9 control subjects (group 3) were scanned ( 5 women and 4 men; mean age 60 ; range $42-75$ ).

\section{Visual assessment}

\section{General findings}

Skull sutures show enhanced uptake in all individuals, both affected as well as unaffected. In unaffected individuals minor physiological irregularities are sometimes observed at the endosteal side of the frontal bone area on CT as well. However, other parts of the cranial vault are always smoothly delineated in unaffected individuals. Hot spots unrelated to $\mathrm{HCl}$ (Figure 6.4) are for example areas of embryologically fused bone (i.e. clivus, sphenoid wing), the nasal bones and the temporomandibular joint. 

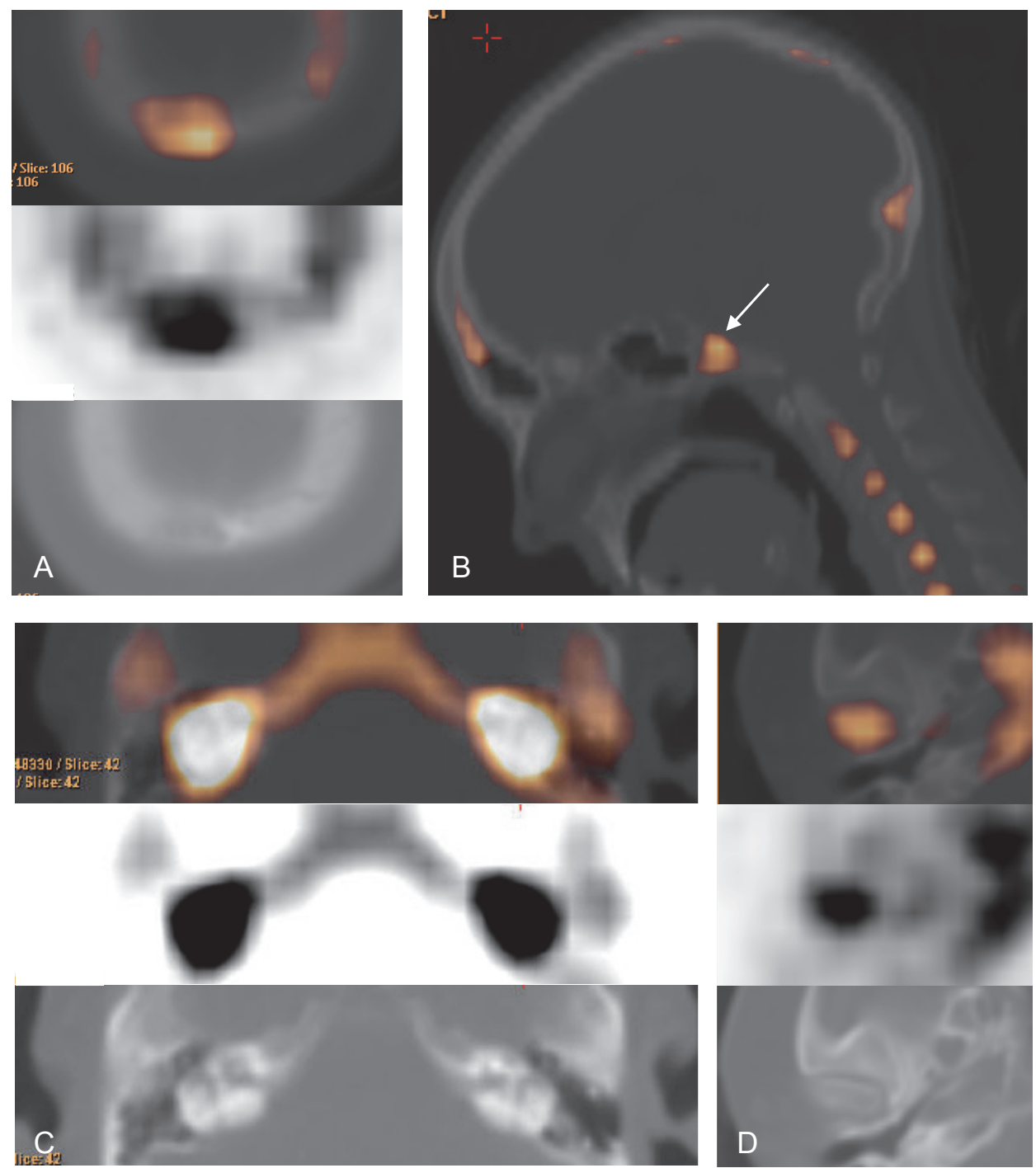

Figure 6.4 Hotspots unrelated to $\mathrm{HCl}$. First of paired images is fused PET/CT, second PET, third CT alone. (A) Occipital osteoma cranial to foramen magnum. (B) Hotspots visible in metabolically active bone regions. Note the clivus (arrow), which is a junction of two bone segments. The centre of the corpora of the vertebral column and the occipital protuberance show enhanced activity as well. (C) Bilateral enhancement of the labyrinth in a control subject with cochlear otosclerosis. (D) Hotspot at the caput mandibulae/ temporomandibular joint.

Hotspots and other interesting findings related to $\mathrm{HCl}$ are displayed in Figure 6.5. The majority of the hot spots (besides those found in the standardised measurement areas) are found in three different regions: the cranial part of frontal bone, the sphenofrontal suture and the occipital suture. 

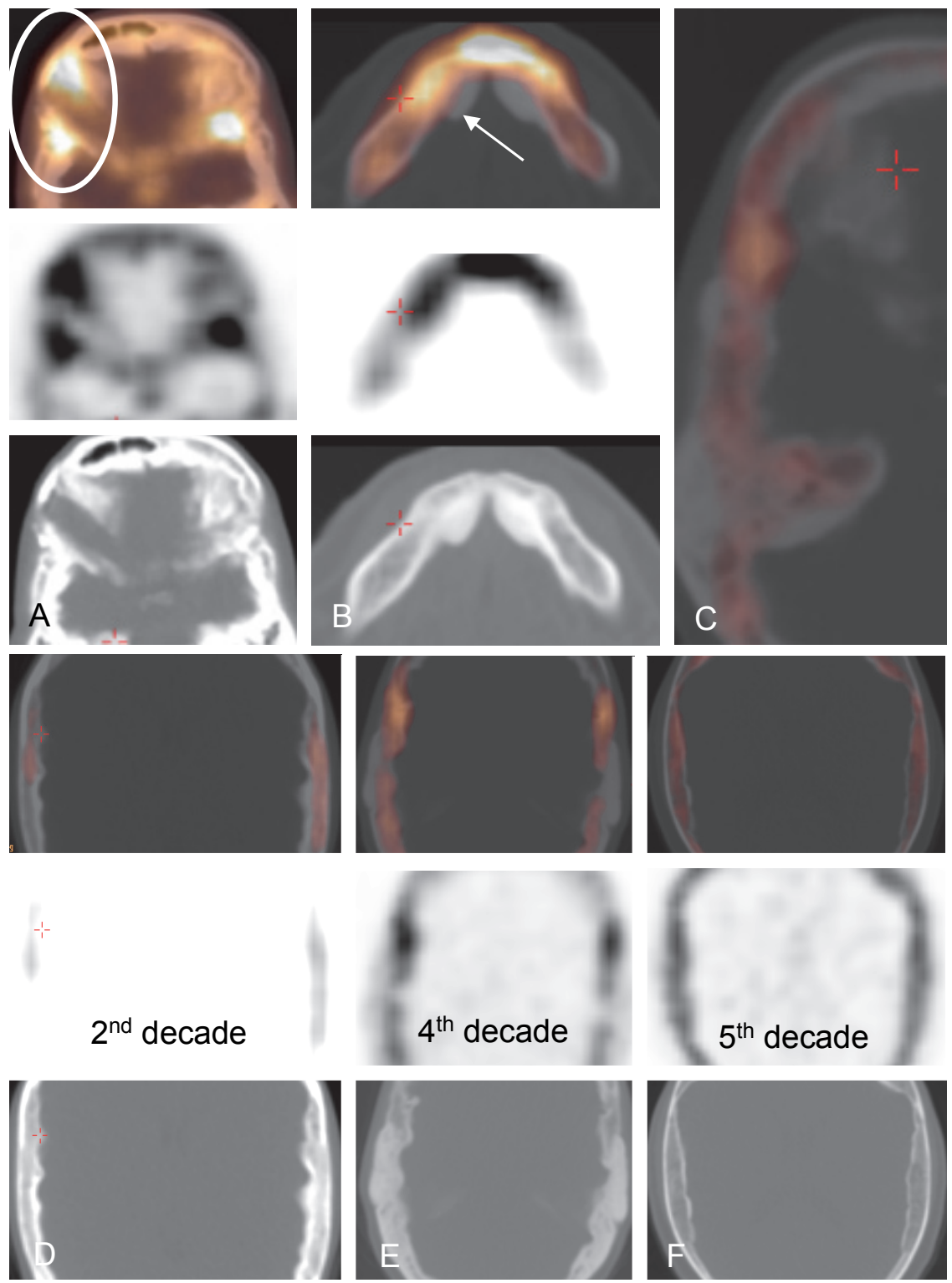

Figure 6.5 Hotspots and other findings in $\mathrm{HCl}$-affected individuals. First of paired images is fused PET/CT, second PET, third CT alone. (A) Postoperative status after optic nerve decompression at the right side in an affected individual. The oblique operation tract can still be seen (oval). Hotspot at the junction between the greater sphenoid wing, the frontal bone and the parietal bone at the left side. (B) Hotspot at the symphysis mandibulae. Typically the mandibular exostoses (arrow) do not show enhanced uptake; the symphysis mandibulae and the base of the exostoses do have enhanced uptake. (C) View of the whole right axial skull base of a 39-year old female. Note the activity is located at the base of the endosteal border of the hyperostosis. (DF) Enhanced activity of the parietal area. Note the activity is not located in the endosteal part solely, but mainly at the base of the hyperostotic border. 
In $\mathrm{HCl}$ the first abnormal findings are seen in the frontal bone (Figure 6.6). Generally, the endosteal abnormalities of the affected calvarial bones (frontal and parietal) are found at the base of the endosteal border of the hyperostotic region (Figure 6.5C-F and Figure 6.6).

\section{Frontal bone area}

The frontal bone area is a pathognomonic area in visual assessment. In young affected individuals (late first, early second decade), a typical enhancement pattern is observed (Figure 6.6). First subtle sclerotic changes of the skull are observed (CT). When abnormalities on CT are hardly visible, frontal endosteal activity is detected (Figure 6.6A). Hotspots are seen at sclerotic sites (CT) and diffusely enhanced areas are seen at hypodense hyperostotic areas (CT). Frontal bone uptake gradually becomes more explicit during the second decade and can become fulminant (Figure 6.6B). As soon as an endosteal border of bone apposition is visible, the abnormal activity is observed at the endosteal side of the diploë and not centrally in the endosteal border (Figure 6.6BC). Later (>30 years), frontal bone activity gradually decreases and the process of hyperostosis extinguishes (Figure 6.6D-E).

\section{Petrous bone area}

A varying interindividual degree of pneumatisation and increasing pneumatisation throughout life make it difficult to precisely quantify bone metabolism in this region. Therefore visual assessment of the scans of $\mathrm{HCl}$ patients is important in that it shows a typical enhancement pattern. Affected adolescents and patients in their 20s have diffuse enhancement of the petrous bone apex in the region of the internal auditory canal (Figure 6.7A-B), representing active osteosclerosis and hyperostosis of the medial part of the petrous bone (the region around the internal auditory canal containing the facial and vestibulocochlear nerves). From the age of 30 onward the typical endosteal enhancement pattern can be recognised as earlier in the frontal area (Figure 6.7C-D). There is a diffuse hyperactive border at both the anterior and posterior side of the petrous bone, the latter vanishing with increasing age (Figure 6.7E). Throughout life, there is no disease involvement of the mastoid, middle and inner ear visible with ${ }^{18} \mathrm{~F}$-fluoride PET, corresponding to the CT findings. 
Chapter 6
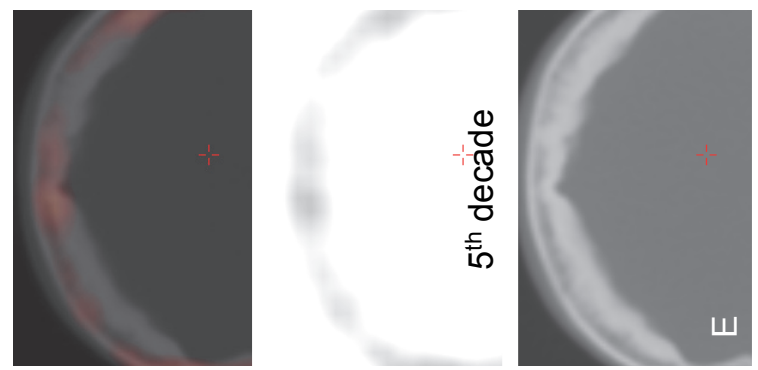

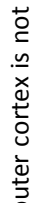
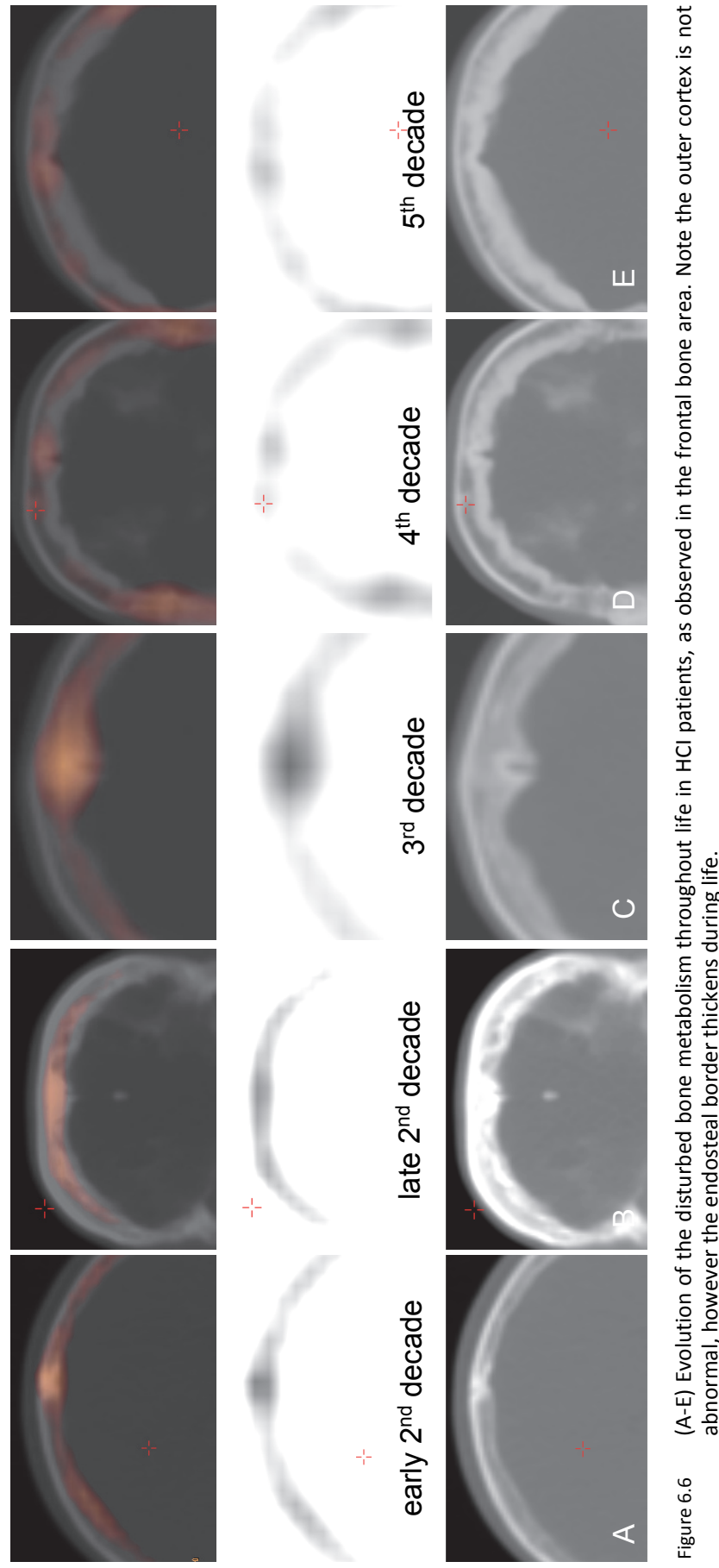
${ }^{18} \mathrm{~F}$-fluoride PET scans to measure bone metabolic activity in $\mathrm{HCl}$
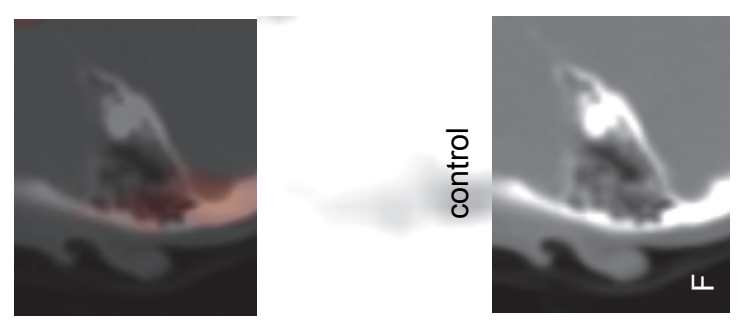

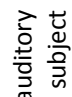

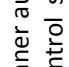

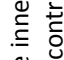

密
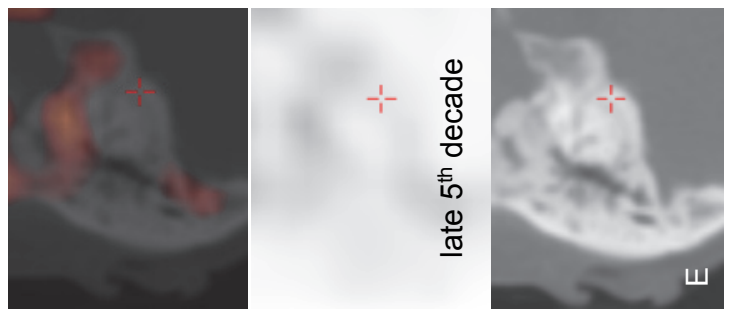

斌育

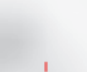

$-1-$
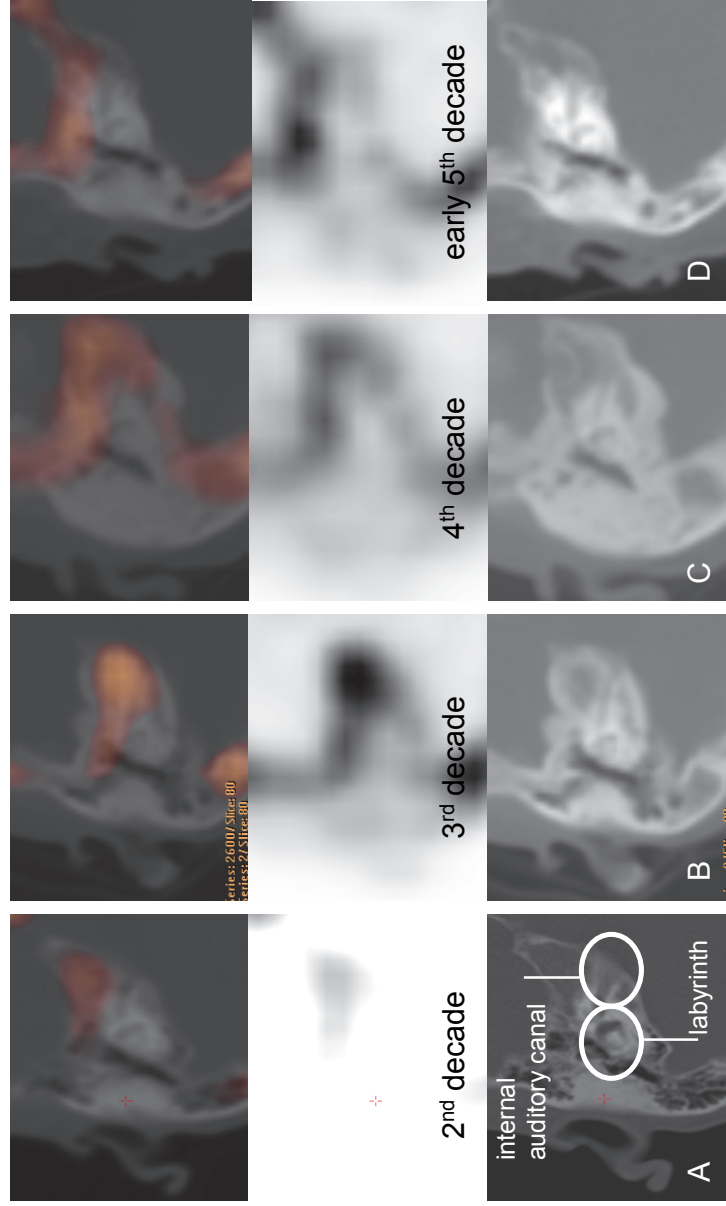

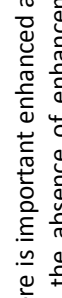

ब

둔

宫

v

$\mp$

등

흐 है

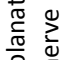

물

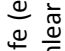

응

วิ

맘ำ

을

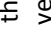

윰 $\frac{0}{\sigma}$

옹 $\frac{\pi}{4}$

过

일

壱

से

突

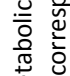

है :

음

ัญे จำ

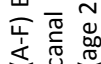

$\hat{\omega}$
$\stackrel{0}{0}$
$\underline{\bar{y}}$ 


\section{Sphenoid bone and temporal area}

At the sites of fusion of the great wing of the sphenoid bone and the temporal and frontal bone (sphenopetrosal and sphenofrontal suture) there is enhancement in both affected as well as unaffected individuals. No typical pattern is visible in the abnormalities of the sphenoid bone area. Affected individuals have more pronounced activity at the surrounding endosteal part of the greater sphenoid wing. During life, an impressive endosteal border of additional bone forms at the level of the greater sphenoid wing and parietal bone, which remains more active than the sphenoid area in healthy individuals.

\section{Data analysis}

The results of the standard measurements for all groups together are shown in Table 6.1. Table 6.2 shows a breakdown of SUV parameters per group. The average SUV seems to be higher in group 1 for all locations except for the control site of the third cervical vertebra.

Table 6.1 Descriptive statistics for SUV mean $_{\text {and }}$ SUV $V_{\max }$ for all locations and all individuals $(n=25)$.

\begin{tabular}{lcccccc}
\hline Location & Mean SUV $_{\text {mean }}$ & SD & Range & Mean SUV $_{\max }$ & SD & Range \\
\hline Total uptake & 1.56 & 0.48 & $0.83-2.62$ & - & - & - \\
Frontal bone & 3.67 & 1.34 & $1.91-7.50$ & 4.33 & 1.53 & $2.33-8.59$ \\
Clivus & 5.32 & 1.52 & $2.49-8.75$ & 6.01 & 1.77 & $2.87-9.85$ \\
Petrous bone (L\&R) & 4.09 & 1.35 & $1.86-8.27$ & 4.86 & 1.55 & $2.09-9.41$ \\
Sphenoid bone (L\&R) & 5.50 & 1.74 & $2.80-11.82$ & 6.21 & 2.01 & $3.34-13.77$ \\
$3^{\text {rd }}$ cervical vertebra & 7.83 & 2.34 & $4.09-15.42$ & 8.79 & 2.65 & $4.50-17.76$ \\
\hline
\end{tabular}

$\mathrm{SD}=$ standard deviation, $\mathrm{L} \& \mathrm{R}=$ average of left and right

Table 6.2 SUV mean $_{\text {and SUV }}$ for all bone locations for each of the different groups studied $(n=25)$.

\begin{tabular}{|c|c|c|c|c|c|c|}
\hline \multirow{3}{*}{ Location } & \multirow{3}{*}{ SUV } & \multicolumn{3}{|c|}{ Group } & \multicolumn{2}{|c|}{$p$-value } \\
\hline & & $1(n=9)$ & $2(n=7)$ & $3(n=9)$ & ANOVA & Kruskal- \\
\hline & & $\mathrm{HCl}$ & $\begin{array}{c}\text { Family } \\
\text { non- } \mathrm{HCl}\end{array}$ & Control & & Wallis \\
\hline Total uptake & Mean & $1.74 \pm 0.55$ & $1.49 \pm 0.21$ & $1.44 \pm 0.55$ & 0.412 & 0.427 \\
\hline \multirow[t]{2}{*}{ Frontal bone } & Mean & $4.51 \pm 1.65$ & $3.17 \pm 0.87$ & $3.23 \pm 0.94$ & 0.060 & 0.140 \\
\hline & Max & $5.22 \pm 1.87$ & $3.78 \pm 1.07$ & $3.87 \pm 1.13$ & 0.090 & 0.136 \\
\hline \multirow[t]{2}{*}{ Clivus } & Mean & $6.17 \pm 1.38^{* \#}$ & $5.70 \pm 1.36$ & $4.18 \pm 1.12^{* \#}$ & 0.010 & 0.016 \\
\hline & Max & $7.00 \pm 1.61^{* \#}$ & $6.43 \pm 1.70$ & $4.70 \pm 1.22^{* \#}$ & 0.011 & 0.023 \\
\hline \multirow[t]{2}{*}{ Petrous bone } & Max & $4.47 \pm 1.56^{*}$ & $3.93 \pm 1.31$ & $3.82 \pm 0.96$ & 0.534 & 0.542 \\
\hline & Mean & $5.36 \pm 1.61$ & $4.67 \pm 1.64$ & $4.52 \pm 1.19$ & 0.461 & 0.488 \\
\hline \multirow[t]{2}{*}{ Sphenoid bone } & Mean & $6.58 \pm 1.62^{*+}$ & $5.66 \pm 1.21^{\#}$ & $4.30 \pm 0.93^{* \#^{\dagger}}$ & 0.004 & 0.007 \\
\hline & Max & $7.48 \pm 1.88^{* \dagger}$ & $6.36 \pm 1.29^{\#}$ & $4.82 \pm 0.97^{* \#+}$ & 0.003 & 0.006 \\
\hline \multirow[t]{2}{*}{$3^{\text {rd }}$ cervical vertebra } & Mean & $7.28 \pm 1.71$ & $8.18 \pm 2.22$ & $8.09 \pm 3.05$ & 0.701 & 0.859 \\
\hline & Max & $8.17 \pm 1.93$ & $9.12 \pm 2.36$ & $9.16 \pm 3.54$ & 0.693 & 0.873 \\
\hline
\end{tabular}

"Significantly different, $p \leq 0.01$ (Bonferroni T-test); ", Significantly different, $p \leq 0.01$ (Mann-Whitney) 
The average SUV of the complete skull is not significantly higher for group 1 $(S U V=1.74 \pm 0.55)$ when compared to groups 2 and $3(1.49 \pm 0.21$ and $1.44 \pm 0.55)$.

Uptake of ${ }^{18} \mathrm{~F}$-fluoride in the frontal region $\left(\mathrm{SUV}_{\text {mean }}\right)$ is higher in the $\mathrm{HCl}$ group but no statistical significance is reached (ANOVA $p=0.06$, Kruskal-Wallis $p=0.14$ ). To investigate whether the outcomes were dependent on age, patients above and below the age of 40 were compared and on average the younger group had a 1.63 higher value, this difference being just barely statistically significant for the ANOVA $(p=0.049)$ and not quite for the Kruskal-Wallis ( $p=0.051)$.

The group average $\mathrm{SUV}_{\text {mean }}$ in the petrous bone region is higher in $\mathrm{HCl}$ patients as compared to the other groups (group $14.47 \pm 1.56$ versus group $23.93 \pm 1.31$ and group $33.82 \pm 0.96)$, but not statistically significant.

The clivus and the sphenoid bone regions have corresponding findings, although the sphenoid area is affected by $\mathrm{HCl}$ and the clivus does not show obvious hyperostosis. $\mathrm{SUV}_{\text {mean }}$ in the clivus area is $6.17 \pm 1.38$ in group $1,5.70 \pm 1.36$ in group 2 and $4.18 \pm 1.12$ in group 3 . There is a statistical significance between group 1 and group 3 for both $\mathrm{SUV}_{\text {mean }}$ and SUV $\mathrm{Sax}_{\text {max }}(t$ test $p=0.010$ and rank test $p=0.009) . \mathrm{SUV}_{\text {mean }}$ in the sphenoid area is $6.58 \pm 1.62$ in group $1,5.66 \pm 1.21$ in group 2 and $7.75 \pm 2.03$ in group 3 . SUV $V_{\max }$ values show comparable results. In both areas age seems to influence the SUV values: group 2 values are positioned in between group 1 and 3, 1 being the highest (with youngest average age) and 3 the lowest (with highest average age). For the sphenoid area a statistically significant difference between group 2 and 3 is also found.

In Table 6.3 the SUV values of the hotspots in $\mathrm{HCl}$-patients are displayed.

Table 6.3 Hot spots found in $\mathrm{HCl}$-patients.

\begin{tabular}{lcc}
\hline Location & SUV $_{\text {mean }}$ & SUV $_{\max }$ \\
\hline Frontal bone, skull base & 6.49 & 7.25 \\
& 7.78 & 9.47 \\
& 8.60 & 9.85 \\
& 8.68 & 10.69 \\
& 9.24 & 13.63 \\
Frontal bone, skullcap & 11.94 & 15.61 \\
& 12.91 & 6.45 \\
& & 8.78 \\
Occipital suture & 4.77 & 9.09 \\
& 7.57 & 13.73 \\
& 7.82 & 8.82 \\
\end{tabular}

The paired SUV mean and SUV max represent one hot spot in one patient. ${ }^{a}$ Results from the same patient. 


\section{Discussion}

\section{Technical considerations concerning ${ }^{18} \mathrm{~F}$-fluoride PET/CT}

To obtain reproducible outcome measurements several pharmacokinetic models have been described for ${ }^{18} \mathrm{~F}$-fluoride PET scans. Hawkins et al. developed a threecompartment model producing quantitative measurements for the net uptake of ${ }^{18} \mathrm{~F}$-fluoride into bone ${ }^{10}$. A rate constant $(\mathrm{K})$ for this uptake can be calculated as a macroparameter using the individual rate constants described in the model obtained by nonlinear regression methods (NLR). This $K_{N L R}$ provides a tool for measuring the bone turnover that correlates with biochemical data and bone histomorphometric analyses performed on biopsy samples ${ }^{14,15}$. However it requires blood sampling and is therefore not widely used in clinical practice. Brenner et al. recognised this and compared the $\mathrm{K}_{\mathrm{NLR}}$ to the more commonly used standardised uptake value (SUV) for semiquantitative metabolic bone measurements ${ }^{16}$. They found a strong positive linear correlation that was highly significant and reproducible. Thus, SUV is not only more practical and noninvasive but also equally reliable using ${ }^{18} \mathrm{~F}$-fluoride in PET imaging. Installé et al. confirmed this after comparing kinetic modelling, SUV and biochemical markers in monitoring the therapeutic response in Paget's disease of bone ${ }^{17}$. This study confirms the reproducibility of SUV in both unaffected as well as affected regions.

\section{Standardised measurements of ${ }^{18} \mathrm{~F}$-fluoride uptake in $\mathrm{HCl}$ compared to healthy controls and non-affected family members}

We analysed SUV $V_{\max }$ and $S U V_{\text {mean }}$ at different anatomic locations following a structured protocol. Both outcome measures give comparable results. Statistical power was limited by the small group sizes. Uptake in the third cervical vertebra served well as an internal control measurement. Statistically significant differences were found for various measurements of the sphenoid bone and clivus. With respect to the frontal measurement there is clearly a tendency, however missing power in the statistical analysis.

No significant differences were seen between the groups concerning the total uptake of the skull. A plausible explanation is the inclusion of normal bone tissue (the outer part of the skull) in group 1 within the ROls, averaging the scores. Measuring total uptake was time-consuming and considering the results obtained it does not appear to be an efficient contribution.

Uptake in the frontal bone showed nearly statistically significant differences between the study groups. We did expect this difference because this part of the skull base and skullcap is unequivocally affected in patients and abnormalities develop especially in the first decades. The findings do encourage our hypothesis that in the frontal area the process of hyperostosis and osteosclerosis peaks in the first decades of life and settles 
down thereafter. Typically there is no difference between group 2 and 3, regardless of the unequal age distribution.

The higher uptake of ${ }^{18} \mathrm{~F}$-fluoride in the petrous bone of $\mathrm{HCl}$-patients does correspond with our expectations, because the temporal bone is an affected region. Although the average uptake is higher in group 1 compared to group 2 and 3, this difference was not statistically significant. Different degrees of pneumatisation are encountered and cannot be corrected for in this area. Another explanation, that becomes clear after visually studying the PET and CT scans, is the fact that the affected region of the petrous bone is confined to the endosteal border only.

Uptake in the clivus and sphenoid region are both significantly higher for the patients compared to the control group as well as compared to the family-non-HCl-group. The mean uptake values of unaffected family members are obviously between group 1 and 3 and this demands explanation. As opposed to other sites, these anatomical regions have in common that they are active growth centres (skull base sutures), explaining an increased local fluoride uptake in bone tissue representing osteoblastic activity ${ }^{18,19}$. Increasing age is accompanied by a reduction of standard bone activity in these anatomical areas $^{20}$.

\section{Value of visual assessment in $\mathrm{HCl}$}

${ }^{18}$ F-fluoride PET is a very sensitive imaging technique. Hot spots are found long after surgical interventions (mastoidectomy, optic nerve decompression) and after facial trauma (nasal and cheek bones). Also, larger regions with a diffusely increased uptake are not necessarily pathological. Craniofacial sutures and growth centers (such as the clivus) have diffusely enhanced ${ }^{18} \mathrm{~F}$-fluoride uptake, congruent to the objective measurements.

PET activity in the petrous bone region is confirmed by clinical findings. Facial nerve palsy and vestibulocochlear nerve impairment generally occur in the first 30 years of life due to impingement of the nerve at the level of the internal auditory canal, where increased PET activity is then observed. Along with the lifetime progression of hyperostosis, one would expect progression to complete facial paralysis and deafness. Typically, the PET activity in this region surrounding the internal auditory canal decreases, explaining why the clinical symptomatology remains stable (Figure 6.7).

\section{Clinical application of ${ }^{18} \mathrm{~F}$-fluoride PET/CT for $\mathrm{HCl}$ and bone metabolic disorders in general}

In studies using ${ }^{18} \mathrm{~F}$-fluoride there is limited experience with SUV in spite of the advantages and proven reliability ${ }^{16,17}$. Uchida et al. demonstrated differences in SUVs in the lumbar spine after alendronate treatment in osteoporosis patients ${ }^{21}$. Reference SUV scores of different areas of normal bone with this tracer are scarcely described in 
literature. No other studies were found with a detailed description of average uptake values of unaffected bone in different anatomical sites.

CT scanning will remain the gold standard for the diagnosis of $\mathrm{HCl}$ because of its high resolution. However, there is a need to quantify the disease activity rather than to perform sequential CT scans. This study confirms that ${ }^{18} \mathrm{~F}$-fluoride PET/CT is a very sensitive imaging technique in determining disease activity, showing differences in small population sizes. The indolent character of this metabolic disorder raises an important limitation: there is a narrow window between normal and pathologic metabolic activity. Therefore SUV measurements should always be accompanied with the visual interpretation of changing bone activity patterns over time in different regions.

Age is the most important covariate to take into account in regions with a high bone turnover (i.e. sphenoid and clivus area) as osteoblastic activity diminishes with increasing age resulting in a lower uptake of ${ }^{18} \mathrm{~F}$-fluoride ${ }^{20}$. In this study we had difficulties finding young individuals to serve as appropriate control subjects. This caused an unequal age distribution in the different groups and was therefore potentially one of the most serious drawbacks of this study. To overcome this, group 2 (non-affected family members) with a similar age distribution as group 1 served as a secondary control group and showed similar results as group 3.

This study uses the semiquantitative SUV ratio for the first time in a case-control study. The use of a consistent internal control site is important as an internal validation check of correct SUV processing. ${ }^{18} \mathrm{~F}$-fluoride PET/CT, analysed by SUV, appears to be reliable since we found differences supporting our hypotheses. If the aforementioned limitations are taken into account, the combination of SUV measurements and visual interpretation can be of important value and might bring ${ }^{18} \mathrm{~F}$-fluoride PET/CT closer to being a diagnostic test for metabolic bone diseases. 


\section{References}

1. Manni JJ, Scaf JJ, Huygen PL, Cruysberg JR, Verhagen WI. Hyperostosis cranialis interna. A new hereditary syndrome with cranial-nerve entrapment. N Engl J Med 1990;322:450-454.

2. Waterval JJ, Stokroos RJ, Bauer NJ, De Bondt RB, Manni JJ. Phenotypic manifestations and management of hyperostosis cranialis interna, a hereditary bone dysplasia affecting the calvaria and the skull base. Am J Med Genet A 152A:547-555.

3. Beighton $P$, Barnard A, Hamersma $H$, van der Wouden $A$. The syndromic status of sclerosteosis and van Buchem disease. Clin Genet 1984;25:175-181.

4. Vanhoenacker FM, Balemans W, Tan GJ, Dikkers FG, De Schepper AM, Mathysen DG, Bernaerts A, Hul WV. Van Buchem disease: lifetime evolution of radioclinical features. Skeletal Radiol 2003;32:708-718.

5. Janssens K, Vanhoenacker F, Bonduelle M, Verbruggen L, Van Maldergem L, Ralston S, Guanabens N, Migone N, Wientroub S, Divizia MT, Bergmann C, Bennett C, Simsek S, Melancon S, Cundy T, Van Hul W. Camurati-Engelmann disease: review of the clinical, radiological, and molecular data of 24 families and implications for diagnosis and treatment. J Med Genet 2006;43:1-11.

6. Hamersma H, Gardner J, Beighton P. The natural history of sclerosteosis. Clin Genet 2003;63:192-197.

7. Superti-Furga A, Unger S. Nosology and classification of genetic skeletal disorders: 2006 revision. Am J Med Genet A 2007;143:1-18.

8. Blau M, Ganatra R, Bender MA. 18 F-fluoride for bone imaging. Semin Nucl Med 1972;2:31-37.

9. Blau M, Nagler W, Bender MA. Fluorine-18: a new isotope for bone scanning. J Nucl Med 1962;3: 332-334.

10. Hawkins RA, Choi Y, Huang SC, Hoh CK, Dahlbom M, Schiepers C, Satyamurthy N, Barrio JR, Phelps ME. Evaluation of the skeletal kinetics of fluorine-18-fluoride ion with PET. J Nucl Med 1992;33:633-642.

11. Grant FD, Fahey FH, Packard AB, Davis RT, Alavi A, Treves ST. Skeletal PET with 18F-fluoride: applying new technology to an old tracer. J Nucl Med 2008;49:68-78.

12. Blake GM, Park-Holohan SJ, Cook GJ, Fogelman I. Quantitative studies of bone with the use of $18 \mathrm{~F}-$ fluoride and 99mTc-methylene diphosphonate. Semin Nucl Med 2001;31:28-49.

13. Even-Sapir E, Metser U, Mishani E, Lievshitz G, Lerman H, Leibovitch I. The detection of bone metastases in patients with high-risk prostate cancer: 99mTc-MDP Planar bone scintigraphy, single- and multi-field-of-view SPECT, 18F-fluoride PET, and 18F-fluoride PET/CT. J Nucl Med 2006;47:287-297.

14. Messa C, Goodman WG, Hoh CK, Choi Y, Nissenson AR, Salusky IB, Phelps ME, Hawkins RA. Bone metabolic activity measured with positron emission tomography and [18F]fluoride ion in renal osteodystrophy: correlation with bone histomorphometry. J Clin Endocrinol Metab 1993;77:949-955.

15. Piert M, Zittel TT, Becker GA, Jahn M, Stahlschmidt A, Maier G, Machulla HJ, Bares R. Assessment of porcine bone metabolism by dynamic. J Nucl Med 2001;42:1091-100.

16. Brenner W, Vernon C, Muzi M, Mankoff DA, Link JM, Conrad EU, Eary JF. Comparison of different quantitative approaches to 18F-fluoride PET scans. J Nucl Med 2004;45:1493-500.

17. Installe J, Nzeusseu A, Bol A, Depresseux G, Devogelaer JP, Lonneux M. (18)F-fluoride PET for monitoring therapeutic response in Paget's disease of bone. J Nucl Med 2005;46:1650-1658.

18. Ishiguro K, Nakagaki H, Tsuboi S, Narita N, Kato K, Li J, Kamei H, Yoshioka I, Miyauchi K, Hosoe H, et al. Distribution of fluoride in cortical bone of human rib. Calcif Tissue Int 1993;52:278-282.

19. Narita N, Kato K, Nakagaki H, Ohno N, Kameyama Y, Weatherell JA. Distribution of fluoride concentration in the rat's bone. Calcif Tissue Int 1990;46:200-204.

20. Chan GK, Duque G. Age-related bone loss: old bone, new facts. Gerontology 2002;48:62-71.

21. Uchida K, Nakajima H, Miyazaki T, Yayama T, Kawahara H, Kobayashi S, Tsuchida T, Okazawa H, Fujibayashi $\mathrm{Y}$, Baba $\mathrm{H}$. Effects of alendronate on bone metabolism in glucocorticoid-induced osteoporosis measured by 18F-fluoride PET: a prospective study. J Nucl Med 2009;50:1808-1814. 


\section{Chapter 7}

Bone turnover markers and histology of hyperostosis cranialis interna

Jérôme J. Waterval

Paul P.C.A. Menheere

Pancras W.C. Hogendoorn

Myrurgia Abdulhamid

Robert J. Stokroos

Johannes J. Manni

Submitted 


\begin{abstract}
In hyperostosis cranialis interna, hyperostotic and sclerotic changes take place at the level of the calvaria and the skull base. It is not yet known whether this results from increased bone formation, decreased bone resorption or increased bone turnover. Biochemical examination of serum was performed on patients and unaffected family members to search for abnormalities in general and specific bone related serum markers. No significant differences were found between both groups in the levels of routine serum markers. Serum C-terminal propeptide of type I collagen (PINP), a marker of bone formation was found to be relatively lower in patients than the unaffected individuals. The value of this contradictory finding in this very slowly progressing and highly localised bone dysplasia remains unclear until the exact pathogenesis of the disorder is discovered. Furthermore histologic images are provided of bone biopsies obtained during a craniotomy of a patient with $\mathrm{HCl}$.
\end{abstract}




\section{Introduction}

Hyperostosis cranialis interna $(\mathrm{HCl})$ is a rare autosomal dominant sclerosing bone dysplasia with progressive hyperostosis and osteosclerosis of the calvaria and the skull base. Its clinical course and radiological findings have recently been described ${ }^{1,2}$. Patients mainly suffer cranial nerve dysfunction due to bony narrowing of the affected neuroforamina, especially facial nerve palsy, sensorineural hearing loss, anosmia and trigeminal neuropathy. The pathophysiologic mechanism is still unknown. The inner table of the calvaria thickens and becomes sclerotic, as well as the endosteal cortical bone layer of the skull base, beginning usually before the age of 10 (Figure 7.1).

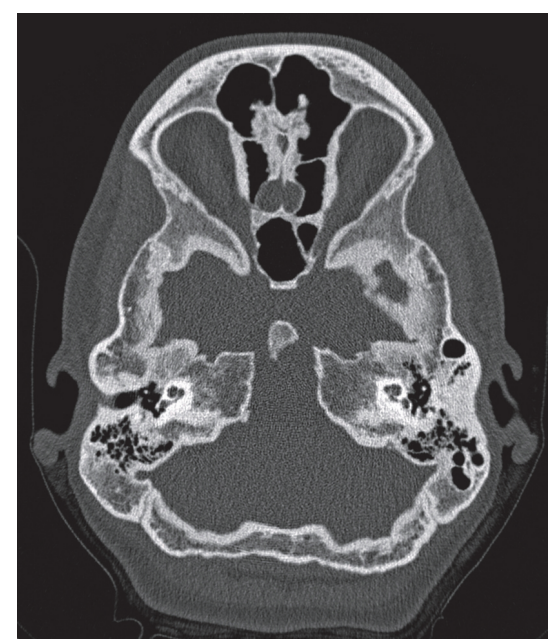

Figure 7.1 Axial computed tomography of a 23-year-old affected woman at the level of the orbits, the greater sphenoid wings, the temporal bones and the occipital bone. Note the remarkedly thickened and relatively hypodense endosteal cortices and the sclerotic olfactory area. The marrow space (diploë) is not obliterated and the outer table is spared.

To assess local bone metabolic activity ${ }^{18} \mathrm{~F}$-fluoride PET/CT has shown to be useful, generally displaying increased ${ }^{18}$ F-Fluoride in affected areas in patients with active disease, suggesting increased bone metabolism plays a role in the pathophysiological mechanism ${ }^{3}$. In this group of patients with $\mathrm{HCl}$ biochemical bone markers have been determined.

Even with present sensitive bone turnover markers it is a challenge - if possible at all to detect altered bone metabolism with clinical chemical markers in patients with highly localised disordered metabolism such as in $\mathrm{HCl}$. Biochemical markers have been proven to be reliable in other rare - systemic - bone dysplasias to assess disease 
activity or therapeutic response: Paget's disease ${ }^{4}$, osteogenesis imperfecta ${ }^{5,6}$, Van Buchem disease $^{7}$, Camurati-Engelmann disease ${ }^{8}$ and McCune-Albright syndrome ${ }^{9}$.

In patients with $\mathrm{HCl}$ the abnormal progression of cranial bone formation and osteosclerosis is most pronounced at the end of the first and during the second and third decades of life, later the process of hyperostosis gradually slows down. The bone density of the hyperostotic endosteal bone is radiologically less dense than the usual cortical bone ( $>1250$ Hounsfield Units on computed tomography and is called porous cortical bone (850-1250 HU) according to the classification proposed by Misch et al., used in the oral implantology ${ }^{10}$. An extra challenge in assessing (abnormal levels of) bone turnover markers in $\mathrm{HCl}$ rises realising that average bone mass in healthy individuals has a variable course: an increase until mid-20s (similar to the period of most active disease in $\mathrm{HCl}$ patients). After that there is stable bone mass until approximately 40, after which it decreases, more rapidly in postmenopausal women.

The aim of this study is to evaluate whether bone turnover markers in patients affected with $\mathrm{HCl}$ are altered compared to healthy individuals.

\section{Materials and methods}

Blood was drawn from 9 affected individuals (mean age 32 years, range 9-68 years) and 12 unaffected family members (mean age 19 years, range 3-42 years) (Figure 7.2). Given the results of genetic data (linkage analysis), some of the children are excluded with the diagnosis $\mathrm{HCl}$ although they have not yet reached the age at which radiological abnormalities become apparent (again Figure 7.2.) ${ }^{11}$. The young affected individuals do have radiological abnormalities.

The following clinical chemical investigations were performed: total serum calcium level, ionised serum calcium level, albumin, parathyroid hormone (PTH) and 25-hydroxy vitamin D. Reference values for serum levels of 25 -hydroxy vitamin D are subject to discussion in international literature ${ }^{12,13}$. A minimal reference value of $50 \mathrm{nmol} / \mathrm{l}$ was used. This value was chosen, since above this concentration there is no relation anymore between vitamin $D$ concentration and bone metabolism. However, it is known that for non-skeletal functions of vitamin D, much higher vitamin D concentrations are necessary ${ }^{14}$.

Serum C-terminal propeptide of type I collagen (PINP) was determined to measure bone formation. To measure bone resorption cross-linked telopeptide of type I collagen (ICTP) was determined in serum (the advantage of ICTP compared to other bone resorption markers such as pyridinoline and deoxypyridinoline is that no urine sampling is needed). Both were assessed by radioimmunoassay (Orion Diagnostica, Espoo, Finland). Paediatric PINP reference values were adopted from Crofton et al. ${ }^{15}$. For ICTP those provided by the manufacturer of the immunoassay were used. 


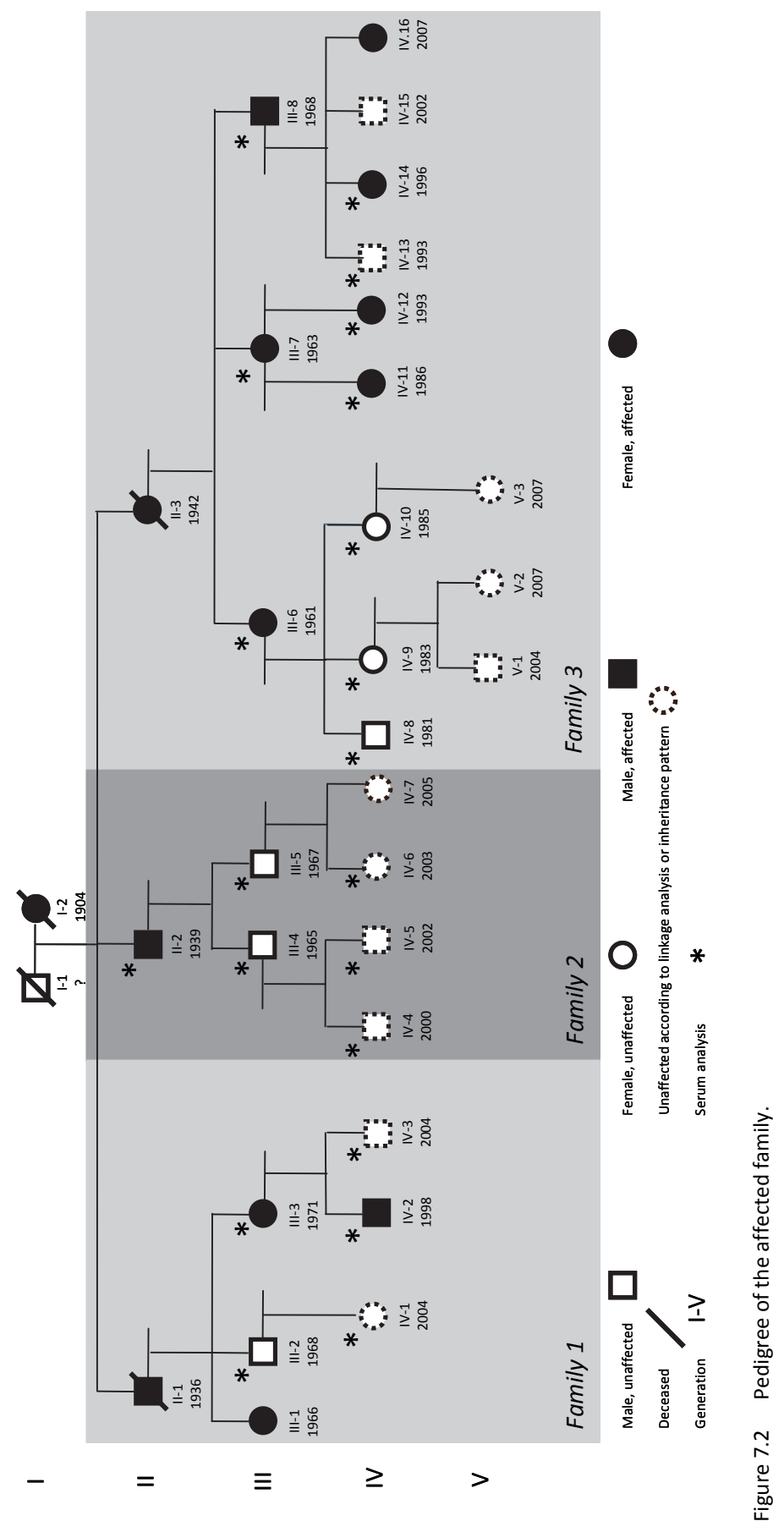


Bone biopsies were obtained during a craniotomy and embedded in paraffin in the Maastricht University Medical Center. The decalcification and sectioning of the tissue was performed in the Leiden University Medical Centre, a department specialised in handling and diagnosing bone specimens of rare disorders and bone tumours. Haematoxylin and eosin stainings were made in Maastricht again.

\section{Results}

\section{Serum markers}

All total serum calcium levels, ionised calcium levels, albumin levels and PTH levels were within the age-adjusted reference values in both affected individuals and the unaffected family members (Table 7.1). One patient had a low vitamin D level (III-6). ICTP and PINP levels are plotted with age-adjusted reference values in Figures 7.3 and 7.4 .

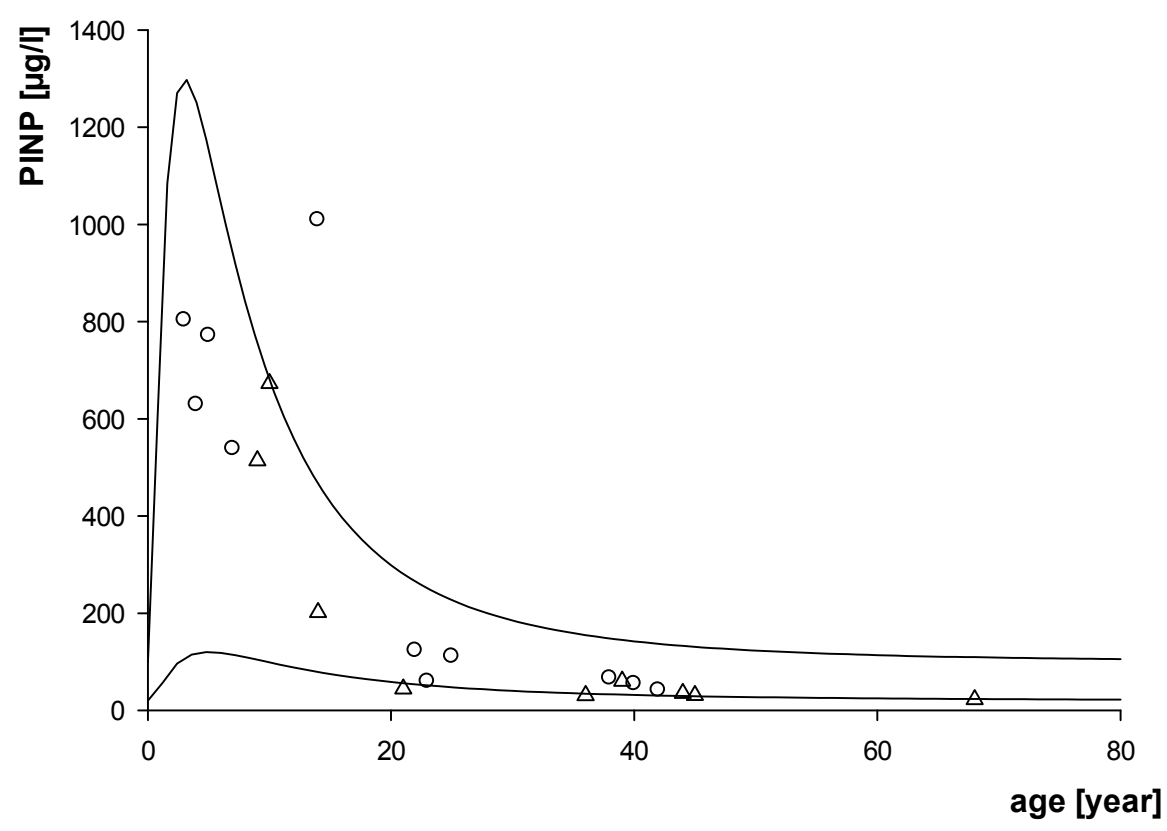

$\triangle$ PINP of affected individuals

- PINP of unaffected individuals

Figure 7.3 PINP values with references for both groups. The lines represent an approximation of the normal values of PINP concentrations with a four parameter log normal distribution (normal values cannot be calculated since the number of observations is too small). 


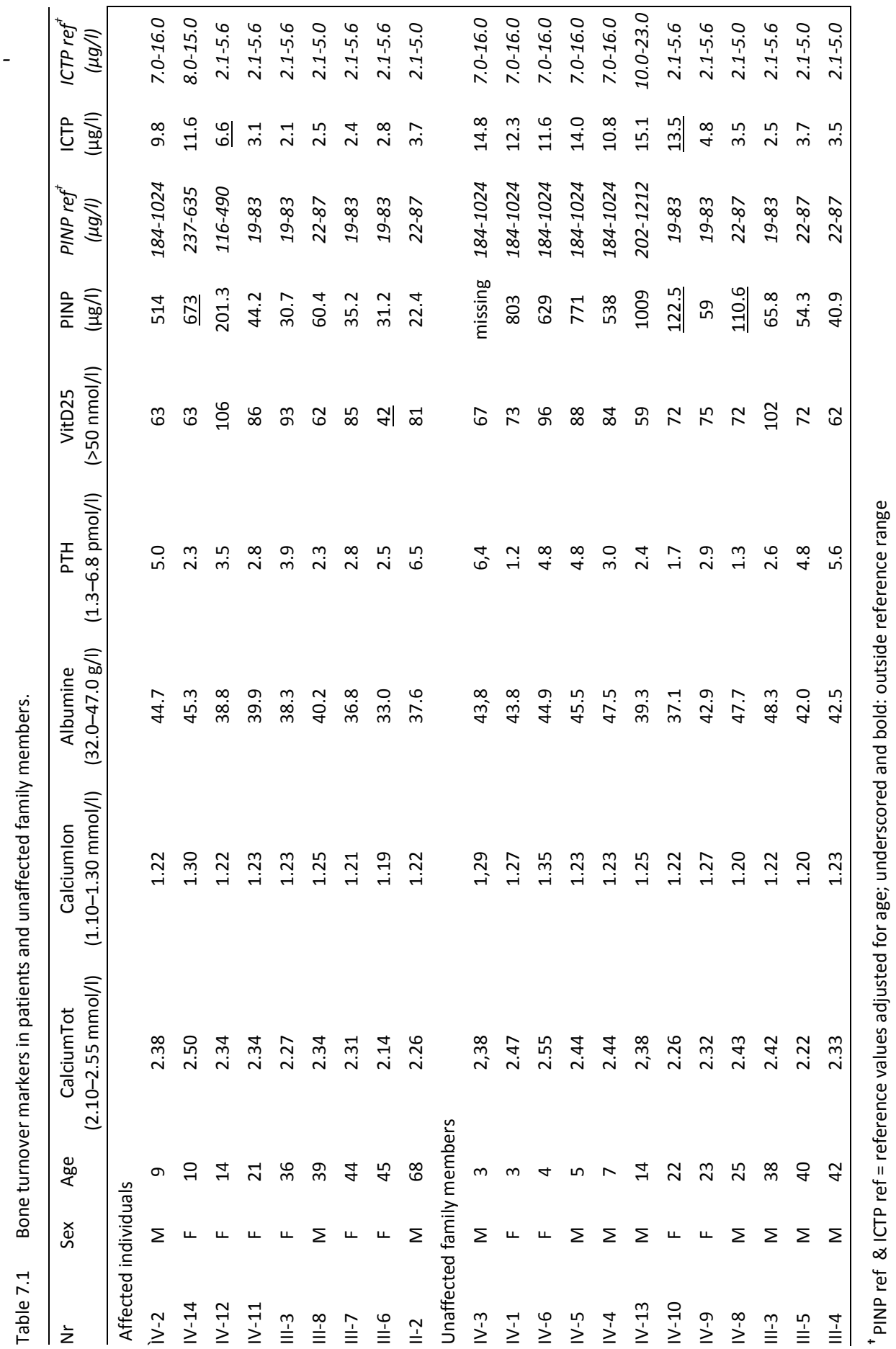




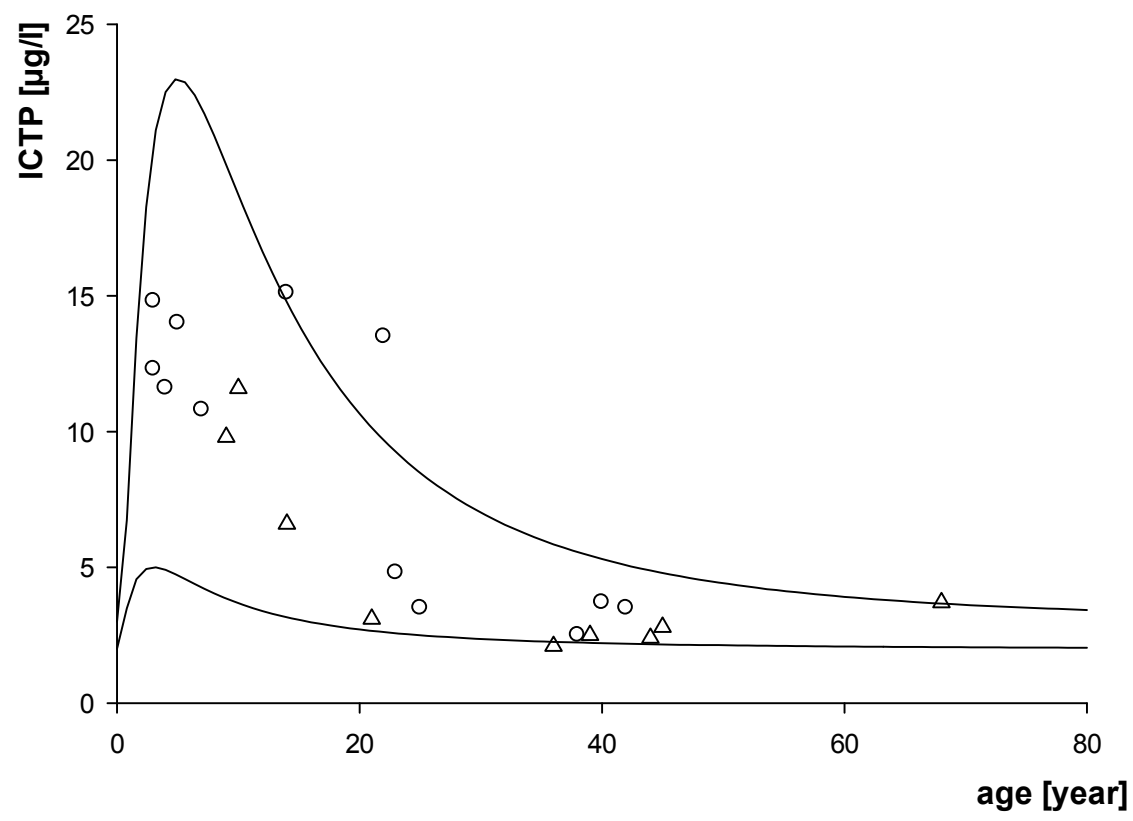

$\triangle \quad$ ICTP of affected individuals

ICTP of unaffected individuals

Figure 7.4 ICTP values with references for both groups. The lines represent an approximation of the normal values of ICTP concentrations with a four parameter log normal distribution (normal values cannot be calculated since the number of observations is too small).

Because the reference values of ICTP and PINP are greatly subject to age and gender and have a large spread, the outcome values $(x)$ of both patients and unaffected family members were compared to the mean reference value and its standard deviation (SD). Reference values for the kit used are set as the mean outcome (age-adjusted) \pm 2 SD. For each individual an age-adjusted Z-score was calculated (Table 7.2), representing the relative deviation off the average expressed in standard deviation:

$$
z=\frac{x-x_{\text {meanreferenceof agegroup }}}{S D}
$$

We performed non-parametric rank tests (Mann-Whitney test) to assess whether there was a difference in Z-scores between affected and unaffected individuals. It appeared that unaffected individuals had significantly more often higher PINP Z-scores than affected individuals ( $p=0.009$, Figure 7.5$)$, pointing towards relatively higher bone formation serum levels for unaffected individuals. An important difference between both groups was the presence of 5 children aged 7 or less in the group of unaffected 
family members. When subjects $<18$ years were censored, the difference between the $Z$-scores was statistically significant $(p=0.016)$. No differences were found between the Z-scores of ICTP in both groups.

Table 7.2 PINP and ICTP values with their Z-scores.

\begin{tabular}{|c|c|c|c|c|c|c|c|c|}
\hline $\mathrm{Nr}$ & Sex & Age & $\begin{array}{l}\text { PINP } \\
(\mu g / I)\end{array}$ & $\begin{array}{c}\text { PINP ref }^{+} \\
(\mu g / I)\end{array}$ & $\begin{array}{c}\text { Z-value } \\
\text { PINP }\end{array}$ & $\begin{array}{c}\text { ICTP } \\
(\mu \mathrm{g} / \mathrm{I})\end{array}$ & $\begin{array}{c}\text { ICTP ref }^{+} \\
(\mu g / I)\end{array}$ & $\begin{array}{c}\text { Z-value } \\
\text { ZICTP }\end{array}$ \\
\hline \multicolumn{9}{|c|}{ Affected individuals } \\
\hline ÌV-2 & $M$ & 9 & 514 & $184-1024$ & -0.43 & 9.8 & $7.0-16.0$ & -0.76 \\
\hline IV-14 & $\mathrm{F}$ & 10 & $\underline{673}$ & $237-635$ & 2.38 & 11.6 & $8.0-15.0$ & 0.06 \\
\hline IV-12 & $\mathrm{F}$ & 14 & $\overline{201.3}$ & $116-490$ & -1.09 & $\underline{6.6}$ & $2.1-5.6$ & 3.14 \\
\hline IV-11 & $\mathrm{F}$ & 21 & 44.2 & $19-83$ & -0.43 & $\overline{3.1}$ & $2.1-5.6$ & -0.86 \\
\hline III-3 & $\mathrm{F}$ & 36 & 30.7 & $19-83$ & -1.27 & 2.1 & $2.1-5.6$ & -2.00 \\
\hline III-8 & M & 39 & 60.4 & $22-87$ & 0.36 & 2.5 & $2.1-5.0$ & -1.45 \\
\hline III-7 & $\mathrm{F}$ & 44 & 35.2 & $19-83$ & -0.99 & 2.4 & $2.1-5.6$ & $-1,66$ \\
\hline III-6 & $\mathrm{F}$ & 45 & 31.2 & $19-83$ & -1.24 & 2.8 & $2.1-5.6$ & $-1,2$ \\
\hline $\mathrm{II}-2$ & $\mathrm{M}$ & 68 & 22.4 & $22-87$ & -1.98 & 3.7 & $2.1-5.0$ & 0.21 \\
\hline \multicolumn{9}{|c|}{ Unaffected family members } \\
\hline IV-3 & $\mathrm{M}$ & 3 & missing & $184-1024$ & missing & 14.8 & $7.0-16.0$ & 0.36 \\
\hline IV-1 & $\mathrm{F}$ & 3 & 803 & $184-1024$ & 0.95 & 12.3 & $7.0-16.0$ & 0.04 \\
\hline IV-6 & $\mathrm{F}$ & 4 & 629 & $184-1024$ & 0.12 & 11.6 & $7.0-16.0$ & 1.47 \\
\hline IV-5 & $M$ & 5 & 771 & $184-1024$ & 0.80 & 14.0 & $7.0-16.0$ & 1.11 \\
\hline IV-4 & M & 7 & 538 & $184-1024$ & -0.31 & 10.8 & $7.0-16.0$ & -0.31 \\
\hline IV-13 & M & 14 & 1009 & $202-1212$ & 1.20 & 15.1 & $10.0-23.0$ & -0.43 \\
\hline IV-10 & $\mathrm{F}$ & 22 & $\underline{122.5}$ & $19-83$ & 4.47 & $\underline{13.5}$ & $2.1-5.6$ & 11.03 \\
\hline IV-9 & $\mathrm{F}$ & 23 & 59 & $19-83$ & 0.5 & $\overline{4.8}$ & $2.1-5.6$ & 1.09 \\
\hline IV-8 & $M$ & 25 & $\underline{110.6}$ & $22-87$ & 3.45 & 3.5 & $2.1-5.0$ & -0.07 \\
\hline III-3 & $M$ & 38 & $\overline{65.8}$ & $19-83$ & 0.93 & 2.5 & $2.1-5.0$ & -1.54 \\
\hline III-5 & $M$ & 40 & 54.3 & $22-87$ & -0.01 & 3.7 & $2.1-5.0$ & 0.21 \\
\hline III-4 & $\mathrm{M}$ & 42 & 40.9 & $22-87$ & -0.84 & 3.5 & $2.1-5.0$ & -0.07 \\
\hline
\end{tabular}

${ }^{+}$PINP ref \& ICTP ref $=$reference values adjusted for age

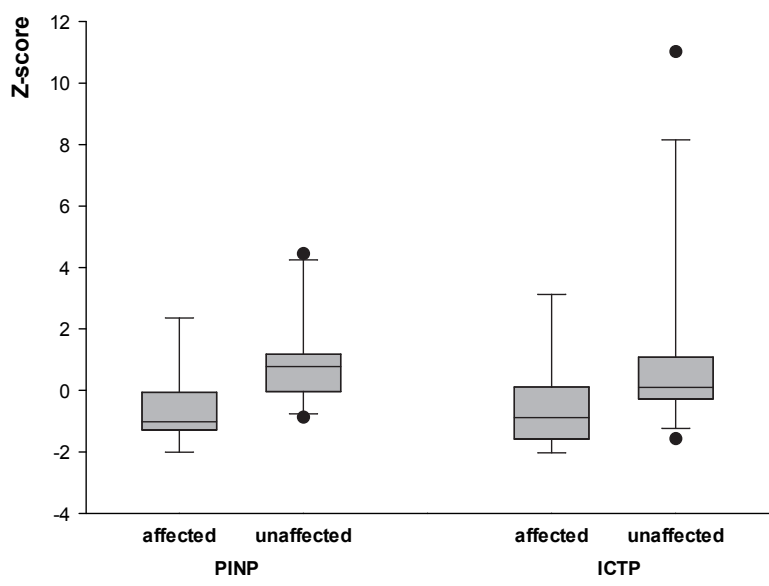

Figure 7.5 Box plots of affected and unaffected individuals for PINP and ICTP: the boxes correspond to the $25^{\text {th }}$ and the $75^{\text {th }}$ percentiles; the error bars show the $5^{\text {th }}$ and $95^{\text {th }}$ percentiles; the lines in the boxes correspond to the median. Outliers are indicated with a black dot. 


\section{Histology}

Figures 7.6-9 display the light micrographs of the sectioned biopsies. These are haematoxylin and eosin stainings showing irregular trabecular bone without evident osteoblastic lining. No obvious osteoclastic activity of note is present either. The bone trabeculae have irregular basophilic kit lines with irregular deposition of woven bone. Please note the presence of prominent bone tunnelling. The scale bar in each figure can be used as a reference.

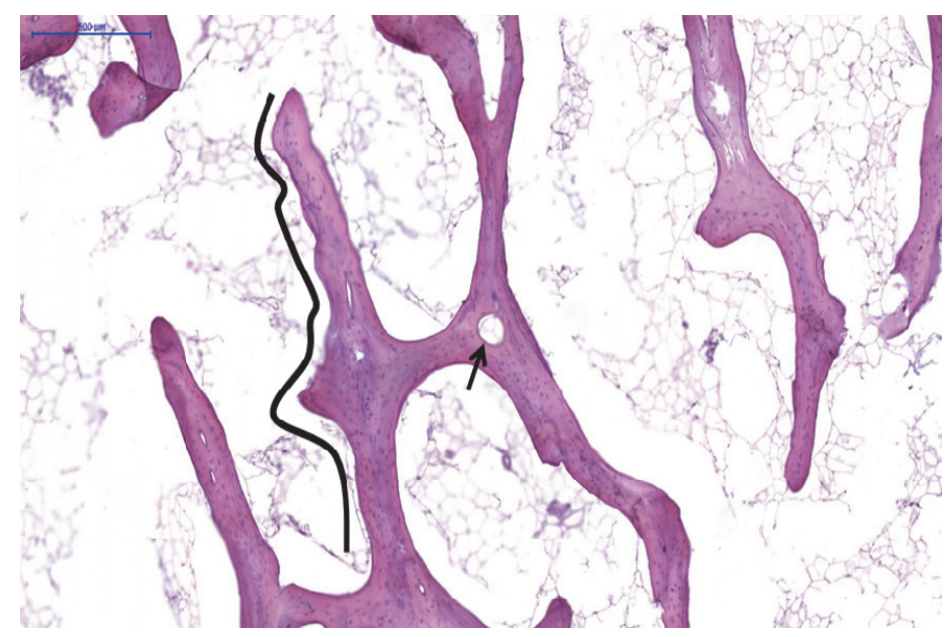

Figure 7.6 Haematoxylin and eosin staining of trabecular bone surrounded by fat. The scale bar in the upper left corner corresponds with $500 \mu \mathrm{m}$. The arrow indicates the prominent bone tunnelling. The trabecular bone is irregularly fomed (black curved line).

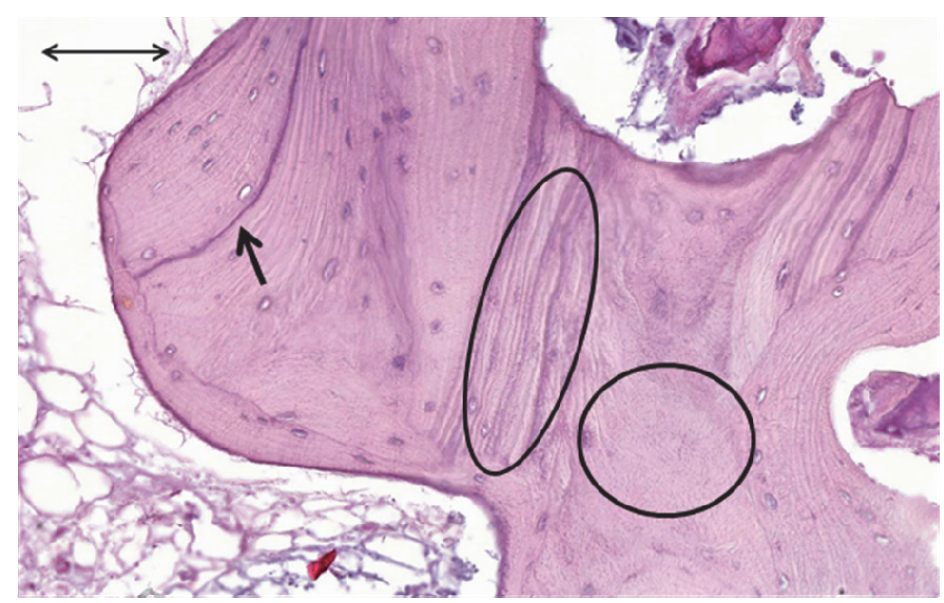

Figure 7.7. The scale bar in the upper left corner corresponds with $100 \mu \mathrm{m}$. The only present bone cells are 
osteocytes. Some areas are organised as lamellar bone (oval), but there are also areas with woven bone (circle). The arrow points at a basophilic kit line.

\section{Conclusion and discussion}

General bone-related serum markers do not differ in patients with $\mathrm{HCl}$. This is not surprising, taking into consideration that the skull accounts for only approximately $10 \%$ of the total bone mass and that the process of hyperostosis in $\mathrm{HCl}$ proceeds only very slowly. Any supposedly statistically significant difference, such as the Z-values of PINP being higher in the unaffected group, is therefore highly questionable, especially because the values of this sensitive bone formation marker are subject to many non$\mathrm{HCl}$-related factors. Moreover, there is a large (physiological) spreading of concentrations. Intuitively one would expect the bone formation markers to be higher in affected patients. If the observed difference with respect to PINP is disease-related, this would point to a disturbed balance of the bone metabolism. To conclude that there is a disbalance between formation and resorption of bone (in favour of formation), the ICTP values (bone resorption) would have to be relatively more decreased than the PINP values (bone formation) in affected individuals. However, ICTP does not show any tendency at all towards lower values to obtain this net difference. Consequently, the observed significant difference (relatively lower bone formation parameter PINP) is remarkable, but at this moment we do not know the etiology. Other markers of bone resorption should be looked for to discover the one that counteracts the lowered PINP in patients. Unfortunately however, patients' samples of our study population are exhausted.

The histologic part of this study reveals that the affected bone that is found in the biopsy consists of trabecular bone. Hardly any active bone cells were seen in the specimens, only osteocytes. It is peculiar to find woven bone at this location instead of lamellar bone, suggesting a local disturbance in the bone metabolism. Woven bone is usually found after a fracture or infection and in some bone tumours but not in slowly growing and remodelling bone tissue.

Ten to $20 \%$ of osteoblasts differentiate into osteocytes ${ }^{16}$. Osteocytes are supposed to produce an inhibitory signal to osteoblasts, which are involved in bone formation and consequently, they are important regulators of bone mass ${ }^{17}$. But the absence of osteoblasts and osteoclasts might be an indication of disturbance of this (local) regulation. It is conceivable, that the absence of osteoblasts and osteoclasts results in lowered PINP and ICTP. It is clear that a lot of research has to be done to unravel the very subtle mechanism of bone formation and degradation, especially in $\mathrm{HCl}$, this disease being so rare. 


\section{References}

1. Waterval JJ, Stokroos RJ, Bauer NJ, De Bondt RB, Manni JJ. Phenotypic manifestations and management of hyperostosis cranialis interna, a hereditary bone dysplasia affecting the calvaria and the skull base. Am J Med Genet A 2010;152A:547-555.

2. Manni JJ, Scaf JJ, Huygen PL, Cruysberg JR, Verhagen WI. Hyperostosis cranialis interna. A new hereditary syndrome with cranial-nerve entrapment. N Engl J Med 1990;322:450-454.

3. Waterval JJ, Van Dongen TM, Stokroos RJ, Teule JG, Kemerink GJ, Brans B, Nieman FH, Manni JJ. Bone metabolic activity in hyperostosis cranialis interna measured with (18)F-fluoride PET. Eur J Nucl Med Mol Imaging 2011;38:884-893.

4. Shankar S, Hosking DJ. Biochemical assessment of Paget's disease of bone. J Bone Miner Res 2006;21 Suppl 2: P22-27.

5. Astrom E, Magnusson P, Eksborg S, Soderhall S. Biochemical bone markers in the assessment and pamidronate treatment of children and adolescents with osteogenesis imperfecta. Acta Paediatr 2010;99:1834-1840.

6. Lund AM, Hansen M, Kollerup G, Juul A, Teisner B, Skovby F. Collagen-derived markers of bone metabolism in osteogenesis imperfecta. Acta Paediatr 1998;87:1131-1137.

7. Wergedal JE, Veskovic K, Hellan M, Nyght C, Balemans W, Libanati C, Vanhoenacker FM, Tan J, Baylink DJ, Van Hul W. Patients with Van Buchem disease, an osteosclerotic genetic disease, have elevated bone formation markers, higher bone density, and greater derived polar moment of inertia than normal. J Clin Endocrinol Metab 2003;88:5778-5783.

8. Hernandez MV, Peris P, Guanabens N, Alvarez L, Monegal A, Pons F, Ponce A, Munoz-Gomez J. Biochemical markers of bone turnover in Camurati-Engelmann disease: a report on four cases in one family. Calcif Tissue Int 1997;61:48-51.

9. Isaia GC, Lala R, Defilippi C, Matarazzo P, Andreo M, Roggia C, Priolo G, de Sanctis C. Bone turnover in children and adolescents with McCune-Albright syndrome treated with pamidronate for bone fibrous dysplasia. Calcif Tissue Int 2002;71:121-128.

10. Misch CE, Dietsh-Misch F, Hoar J, Beck G, Hazen R, Misch CM. A bone quality-based implant system: first year of prosthetic loading. J Oral Implantol 1999;25:185-197.

11. Borra VM, Waterval JJ, Stokroos RJ, Manni JJ, Van Hul W. Localization of the gene for hyperostosis cranialis interna to chromosome 8p21 with analysis of three candidate genes. Calcif Tissue Int 2013;93: 93-100.

12. Hollis BW. Circulating 25-hydroxyvitamin D levels indicative of vitamin D sufficiency: implications for establishing a new effective dietary intake recommendation for vitamin D. J Nutr 2005;135:317-322.

13. Hollis BW, Wagner CL. Normal serum vitamin D levels. N Engl J Med 2005;352: 515-6; author reply 515-516.

14. Holick MF. Vitamin D deficiency. N Engl J Med 2007;357:266-281.

15. Crofton PM, Evans N, Taylor MR, Holland CV. Procollagen type I amino-terminal propeptide: pediatric reference data and relationship with procollagen type I carboxyl-terminal propeptide. Clin Chem 2004;50:2173-2176.

16. Noble BS. The osteocyte lineage. Arch Biochem Biophys 2008;473:1061-11.

17. van Bezooijen RL, Papapoulos SE, Hamdy NA, ten Dijke P, Lowik CW. Control of bone formation by osteocytes. BoneKEy-Osteovision 2005;2:33-38. 


\section{Chapter}

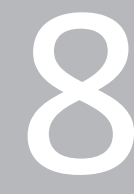

Localisation of the gene for hyperostosis cranialis interna to chromosome 8p21 with analysis of three candidate genes

Vere M. Borra

Jérôme J. Waterval

Robert J. Stokroos

Johannes J. Manni

Wim van Hul

Calcified Tissue International. 2013;93:93-100 


\begin{abstract}
Hyperostosis Cranialis Interna $(\mathrm{HCl})$ is a rare autosomal dominant disorder characterised by intracranial hyperostosis and osteosclerosis which is confined to the skull, especially the calvaria and the skull base. The rest of the skeleton is not affected. Progressive bone overgrowth causes nerve entrapment leading to facial nerve palsy, disturbance of the sense of smell, hearing and vision impairments, impairment of facial sensibility and disturbance of balance due to vestibular dysfunction. The treatment is symptomatic. Until today the disease has been described in only three related Dutch families with common progenitors and which consist of 32 individuals over five generations. $\mathrm{HCl}$ was observed in 13 family members over four generations. Patients are mildly to severely affected. Besides $\mathrm{HCl}$, several bone dysplasias with hyperostosis and sclerosis of the craniofacial bones are known. Examples are Van Buchem disease, sclerosteosis, craniometaphyseal dysplasia and Camurati-Engelmann disease. However, in these cases the long bones are affected as well.

Linkage analysis in a family with $\mathrm{HCl}$ resulted in the localisation of the disease-causing gene to a region on chromosome 8 p21 delineated by the markers D8S282 and D8S382. Interesting candidate genes in this region were BMP1, LOXL2 and ADAM28. Sequence analysis of these genes did not reveal any putative mutations. This suggests that a gene not previously involved in a sclerosing bone dysplasia is responsible for the abnormal growth in the skull of these patients.
\end{abstract}




\section{Introduction}

Sclerosing bone disorders are a group of skeletal abnormalities of varying severity with a wide range of clinical, radiologic and genetic features. These disorders are caused by decreased bone resorption, increased bone formation or increased bone turnover ${ }^{1}$. Identifying genes responsible for these conditions could give new insights in bone metabolism and could lead to new targets for the treatment of osteoporosis. In most conditions, the whole skeleton is affected.

Hyperostosis cranialis interna $(\mathrm{HCl})$ is a rare autosomal dominant disorder characterised by endosteal hyperostosis and osteosclerosis of the calvaria and the skull base. The remainder of the skeleton is unaffected. The disease was first described in 1990 by Manni et $a .{ }^{2}$.The facial appearance and the shape of the head are normal. Small mandibular exostoses develop intraorally later in life, one on each side. The first symptoms can occur in adulthood or even late in the first decade; however, the first radiological abnormalities are often seen in the first decade ${ }^{2,3}$. CT scans show bony overgrowth of the temporal bone and narrowing of the internal auditory canals, the optic canals and the orbital fissures (Figures 8.1-3). This leads to entrapment and dysfunction of cranial nerves I, II, V, VII and VIII, causing recurrent facial nerve palsy, disturbance of the sense of smell, anosmia, hearing and vision impairments and disturbance of balance due to vestibular dysfunction ${ }^{3}$. In addition, increased ocular and intracranial pressure can occur. The progressive functional impairment of facial and vestibulocochlear nerve function might be due to direct effect of pressure on the nerve fibers or impairment of the blood supply ${ }^{4,5}$. A slow progression of the disease can be seen until the age of 40 . After the fourth decade, radiological progression is minimal and progressive cranial nerve dysfunction is uncommon in most ${ }^{3,6}$. However, untimely death may occur in severely affected cases, due to decreased intracranial volume ${ }^{3}$.

The biopsy specimen of the iliac crest was normal ${ }^{2}$. Several markers of bone turnover were tested and calcium, albumin, parathyroid hormone and 1,25-dihydroxyvitamin $D_{3}$ showed no abnormal values.

To date, no causal treatment for $\mathrm{HCl}$ is available. Symptomatic treatment may consist of hearing aids in case of moderate sensorineural hearing loss. Decompressive surgery can be performed to treat facial and vestibulocochlear nerve compression ${ }^{3,5}$. Facial nerve decompression via middle cranial fossa approach has been successfully performed ${ }^{5}$. In case of threatened vision due to optical canal narrowing, optic nerve decompression can be performed.

Numerous bone dysplasias with hyperostosis of the calvaria and the skull base exist. Van Buchem disease ${ }^{7}$, Camurati-Engelmann disease ${ }^{8}$, and sclerosteosis $^{9}$ are examples of diseases with increased bone density with involvement of the skull. However, in these disorders, the long bones are affected as well, whereas in $\mathrm{HCl}$ only the skull is affected. In order to localise the gene for $\mathrm{HCl}$, we performed a genetic linkage study in a Dutch family with $\mathrm{HCl}$. 


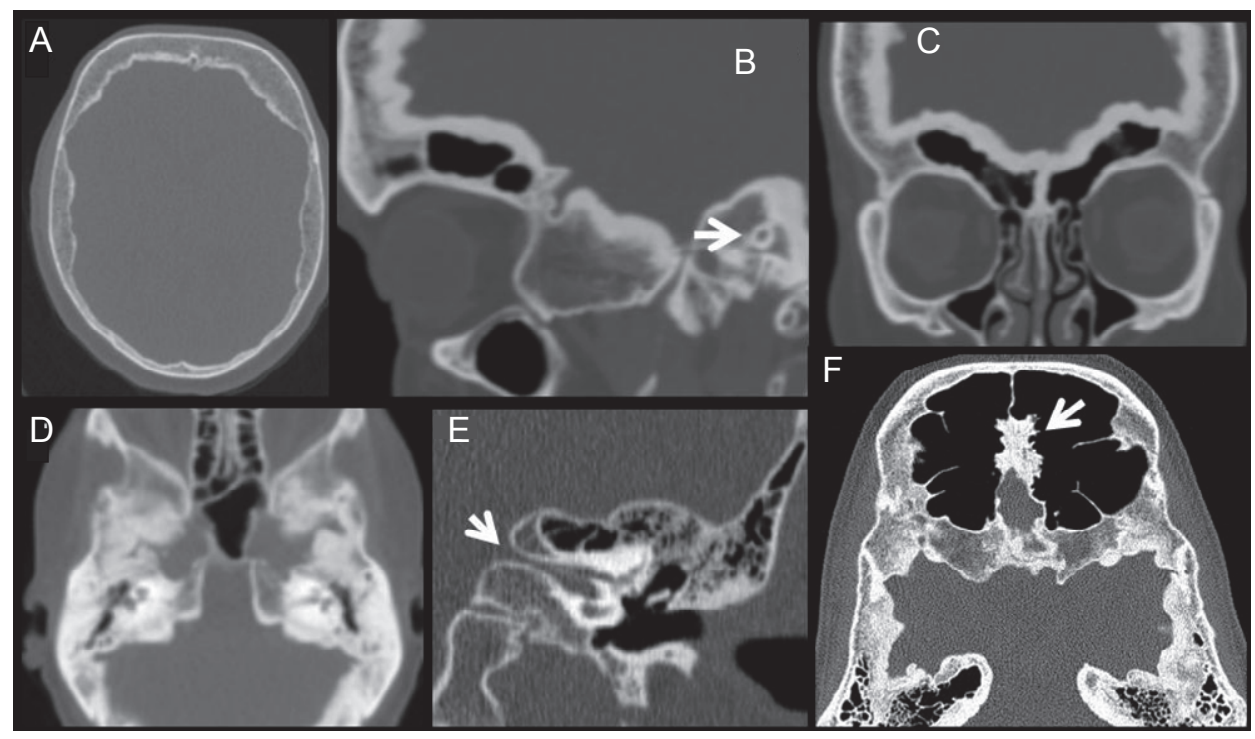

Figure 8.1 CT imaging. (A) Axial image of individual III.8. Note that the frontal and parietal bones are affected. Note the diploë is not obliterated. (B) and (C): Sagittal and coronal reconstructions of III.3. Evident endosteal apposition of bone at the base of skull, whereas the facial bones are unaffected. Arrow: narrowed internal auditory canal. (D) Axial image of III.6. Typically the region of the greater wing of the sphenoid bone and the squama temporalis are most severely affected. (E) Narrowing of the internal auditory canal due to endosteal apposition (arrow) in IV.14 (coronal reconstruction). (F) Axial image of the anterior and middle fossa of III.1. Arrow: osteosclerosis of the olfactory region. From: "Phenotypic manifestations and management of hyperostosis cranialis interna, a hereditary bone dysplasia affecting the calvaria and the skull base". Am J Med Genet A, 152A, 2010, p547-555 (C) Wiley-Liss, Inc. This material is reproduced with permission from John Wiley \& Sons, Inc. 


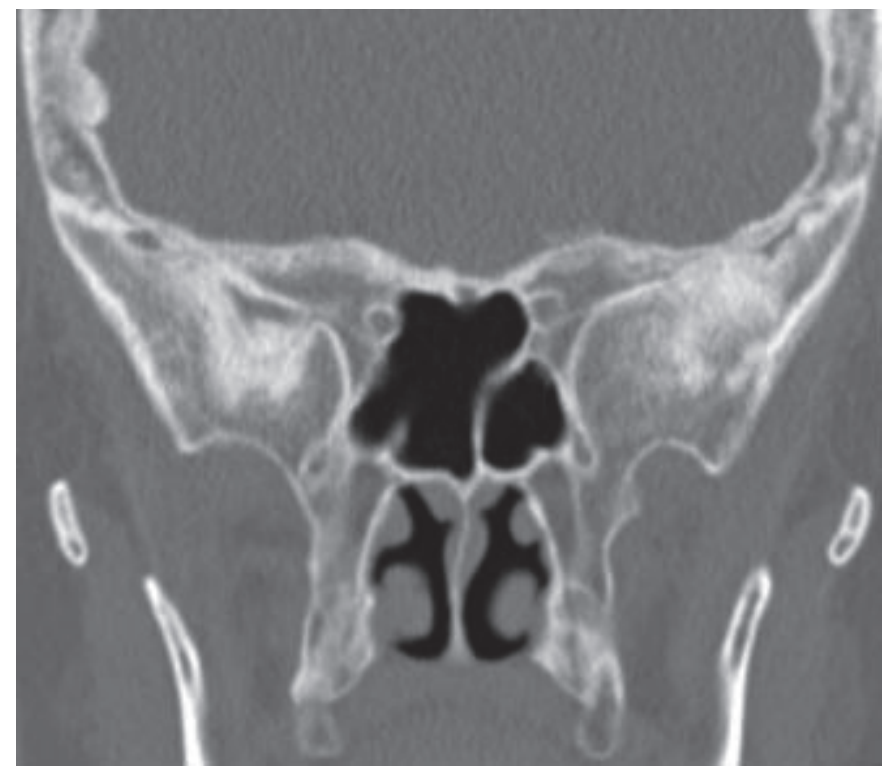

Figure 8.2 41-year-old woman. Coronal CT image at the level of the sphenoid sinus. There is endosteal hyperostosis of the greater and lesser wings of the sphenoid bones and of the parietal bones.

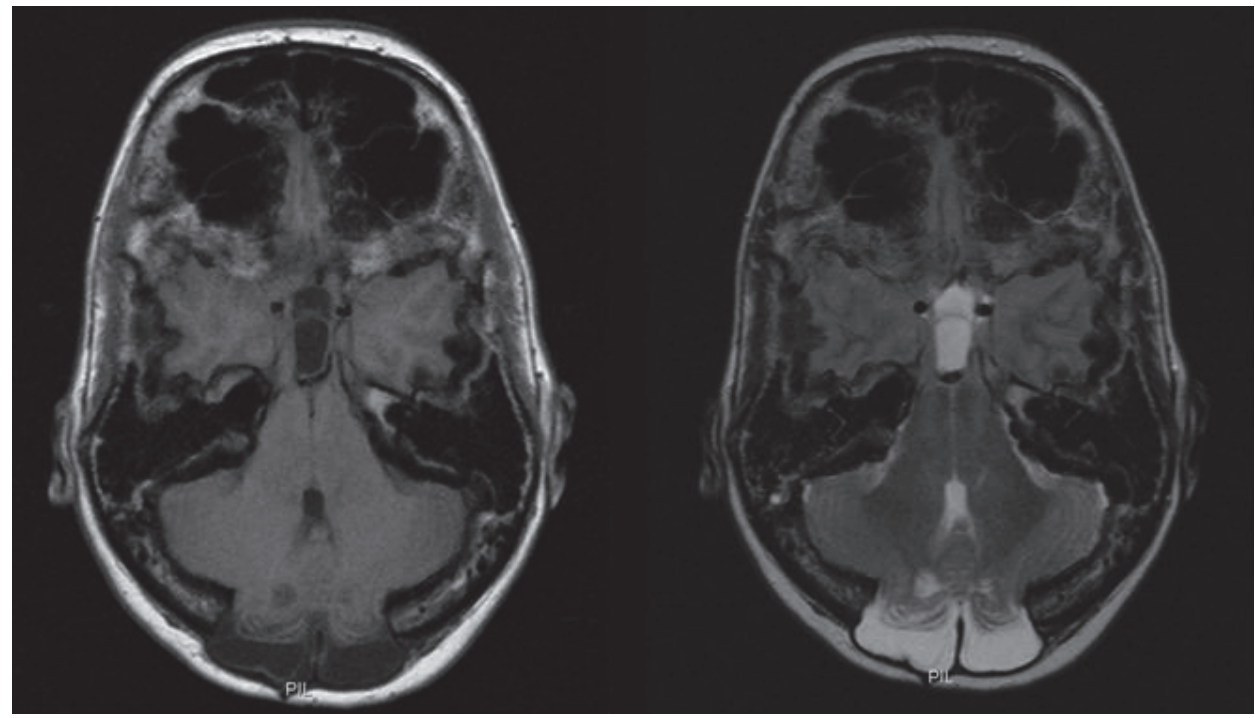

Figure 8.3 Patient (female, 38) with longstanding complaints of headache. A foramen magnum decompression was performed because of Chiari I malformation. Axial T1 (left) and T2 (right) images without contrast. Note the indentation of the temporal lobes. 


\section{Families and methods}

\section{Family}

To date, the disease has only been described in three related Dutch families. They have common progenitors and consist of 31 individuals in five generations ${ }^{2,3} . \mathrm{HCl}$ was observed in 13 family members over four generations (Figure 8.4). The disease is segregating in an autosomal dominant mode of inheritance and so far no evidence for incomplete penetrance is available.

The diagnosis of $\mathrm{HCl}$ is based on radiological and physiological examinations and confirmed by computed tomography. An individual without radiographic abnormalities at the age of 18 is considered unaffected as the median age of onset is $14^{3}$. Eleven individuals without abnormalities have not yet reached this age (Figure 8.4). All persons gave their informed consent prior to their inclusion to the study.

\section{Genotyping and linkage analysis}

Peripheral blood was collected from 24 family members and five nonrelated partners. Genomic DNA was isolated from these blood samples using standard procedures.

A whole-genome scan was performed on 11 patients (II.1-3, III.1, III.3, III.6-8, IV.11-12, IV.14), 6 unaffected family members (II.2, III.4-5, IV.8-10) and 5 unrelated partners (II.46, III.9-10). The Weber Lab Screening Set 16 was used. This set contains 404 fluorescently labelled, highly polymorphic microsatellite markers, covering the entire genome, with an average spacing of $9 \mathrm{cM}$. The markers are mainly tri- or tetranucleotides and have an average heterozygosity of $72 \%$. The markers were analysed by use of an automated DNA-sequencing apparatus (Applied Biosystems, Foster City, CA, USA). Extra markers for regions of interest were chosen from the Marshfield genetic map ${ }^{10}$. These markers were analysed by a GoTaq DNA polymerasemediated PCR (Promega, Madison, WI, USA), with fluorescently labelled primers ${ }^{11}$. Fragment analysis of amplified products was performed using an ABI PRISM ${ }^{\circledast} 3130$ XL Genetic Analyzer (Applied Biosystems). Allele identification was done with Gene mapper v3.7 software (Applied Biosystems).

Linkage analysis was performed using the EasyLinkage v4.01 program ${ }^{12,13}$. Multipoint LOD scores were calculated with SimWalk v2.91 under the assumption that $\mathrm{HCl}$ is an autosomal dominant disease with a disease frequency of $1 / 10,000$. For all calculations, a penetrance of $100 \%$ and a phenocopy rate of $0 \%$ were used. 


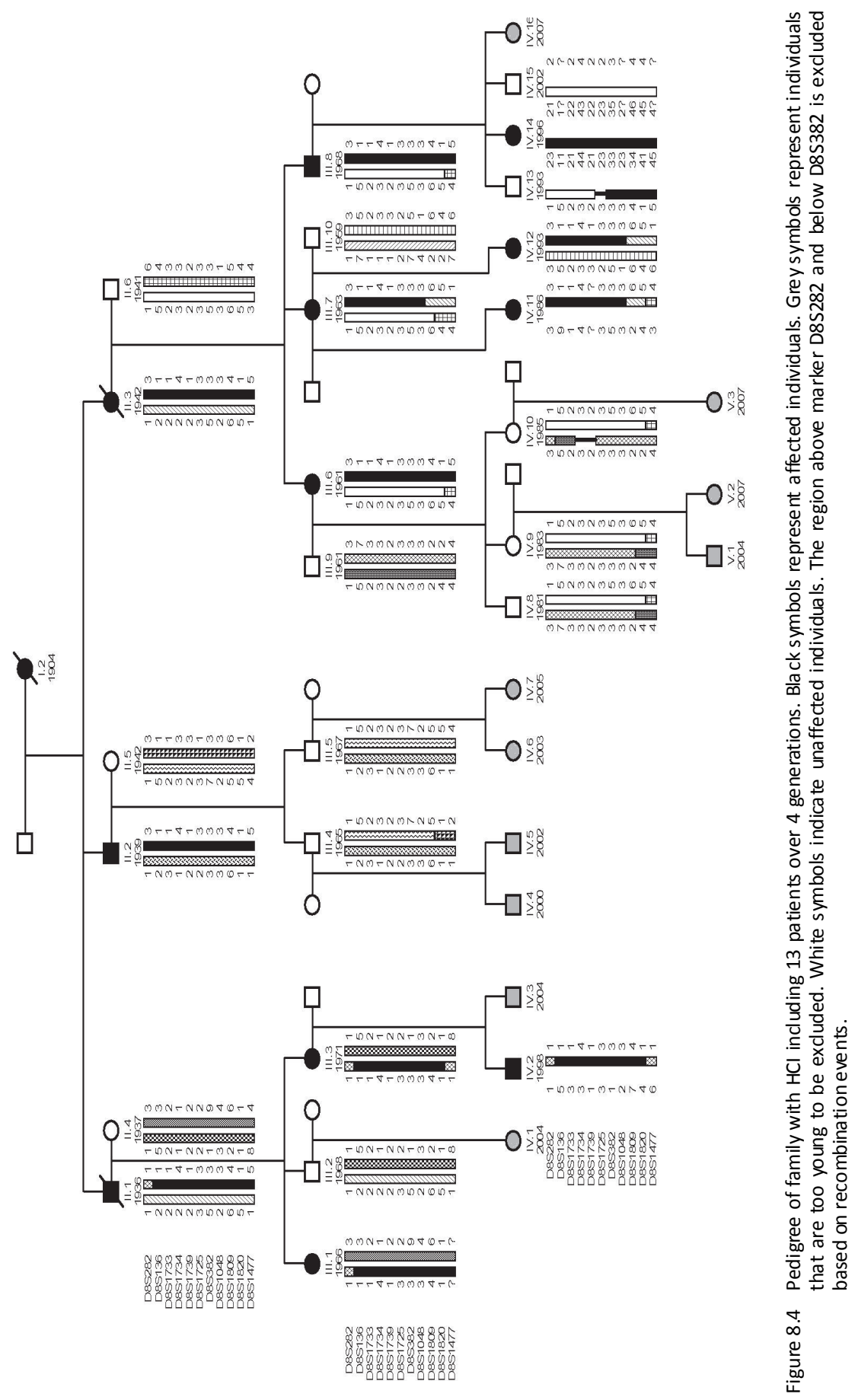




\section{Sequence analysis of candidate genes}

Sequence analysis was performed on DNA of one affected individual (IV.14, Figure 8.4), one healthy family member (IV.9, Figure 8.4) and an unrelated control sample. Genes were amplified by GoTaq DNA polymerase-mediated PCR. The PCR amplifications were carried out with a set of primers covering the exons and intron-exon boundaries. Primers for each exon were selected in an intronic sequence at approximately $100 \mathrm{bp}$ away from the intron-exon boundaries.

Sequencing reactions were performed using the ABI BigDye Terminator v1.1 Cycle Sequencing Ready Reaction Kit (Applied Biosystems, Foster City, California, USA). Purification with the BigDye Terminator Purifcation Kit (Applied Biosystems) was carried out to remove unincorporated BigDye terminators, after which fragments were analysed on an ABI 3130 Genetic Analyzer (Applied Biosystems).

\section{Results}

\section{Linkage analysis}

After testing 404 polymorphic microsatellite markers which covered the entire genome, multipoint LOD scores were calculated with EasyLinkage v4.01. Ninety-six percent of the chromosomal regions were immediately excluded based on multipoint LOD scores below -2 , while only one region showed LOD scores above +3 .

Genes known to cause sclerosing bone dysplasias with involvement of the skull, like LRP4, LRP5, SOST and TGFB1 could also be excluded as disease causing genes based on LOD scores below -2 .

Multipoint LOD scores showed positive LOD scores on the short arm of chromosome 8 with a maximum LOD score of 3.72 between markers ATAA018 and D8S1477. This region was further saturated with additional polymorphic markers from the Marshfield genetic map ${ }^{10}$. After saturation of this region, linkage was confirmed with a maximum LOD score of 4.09 (Figure 8.5).

\section{Delineation of the candidate region}

Pedigree and haplotypes were generated using the Cyrillic 2.1 software (Cyricllic Software, Oxfordshire, UK). The black haplotype is seen only in patients (Figure 8.4). Two additional individuals (IV.2 and IV.13) were analysed for this region. Their diagnosis was not clear at the time of the genome scan, but in the meantime it was confirmed that IV.2 is affected and IV.13 reached the age of 18 without any radiological abnormalities, so he is considered unaffected. Two recombination events delineate the region. At the distal side, there is a recombination proximal of marker D8S282 in individual II.1. At the proximal side a recombination occurs distally of D8S1809 in 
individual III.7. This delineates the region to $12.13 \mathrm{cM}$ (centiMorgan) or $6.65 \mathrm{Mb}$ (megabases) and contains 100 genes according to the NCBI database (http://www.ncbi.nlm.nih.gov/).

However, if we look at individual IV.13, who has reached the age of 18 without abnormalities, and is therefore considered unaffected, there is a recombination between markers D8S1739 and D8S382. Hence, the proximal part of the black haplotype can be excluded. This would further narrow the region to $8.3 \mathrm{cM}$ between markers D8S282 and D8S382. This region encompasses $4.35 \mathrm{Mb}$ and contains 64 genes according to the NCBI database.

\section{Selection and exclusion of candidate genes}

The genes in the region were prioritised using Suspects and Endeavour ${ }^{14-16}$. Both systems prioritise candidate genes based on a training set of genes, in this case, LRP4, $\angle R P 5$, SOST and TGFB1, since they are known to cause bone dysplasias with involvement of the skull. Interesting candidate genes in this region are BMP1, LOXL2 and $A D A M 28$. They are all ranked in the top ten of Suspects and Endeavour. Bone Morphogenetic Protein 1 (BMP1) is expressed in bone tissue and encodes a protein that is capable of inducing formation of cartilage. $B M P 1$ is not an authentic member of the BMP protein family but belongs to the astacin/BMP1/toloid (TLD)-like family of zinc metalloproteinases which are fundamental in the development and formation of the extracellular matrix ${ }^{17}$. BMP1 has been suggested to play essential roles in osteogenesis and extracellular matrix formation. It exerts influence over dorsal-ventral patterning through the indirect activation of some TGF $\beta$-like proteins ${ }^{18,19}$ and is involved in the proteolytic processing of the procollagen I C-propeptide for the generation of mature collagen type $1^{18}$. The BMP1-3 isoform of the BMP1-gene is significantly increased in patients with acute bone fracture and plays a critical role in bone fracture repair ${ }^{17}$. Mutations in BMP1 cause autosomal recessive Osteogenesis Imperfecta ${ }^{18,20}$. Homozygous $B M P 1^{t m 1}$ mice, in which the $B M P 1$ gene has been disrupted by deleting DNA sequences encoding the active site of the astacin-like protease domain common to all splice variants, have defects in skull development. They show reduction in the size of the frontal, parietal and interparietal membrane bones of the skull. Besides skull defects there are no other skeletal abnormalities in these mice ${ }^{21}$.

LOXL2 is a member of the lysyl oxidase family. It is essential for the biogenesis of connective tissue, encoding an extracellular copper-dependent amine oxidase that catalyses the first step in the formation of crosslinks in collagens and elastin. A study exploring the potential direct effects of $1,25(\mathrm{OH})_{2} \mathrm{D}_{3}$ on the quality of collagen in an osteoblastic cell culture system showed that LOXL2 was constantly and significantly upregulated by $1,25(\mathrm{OH})_{2} \mathrm{D}_{3}$. Although the function of LOXL2 in osteoblasts is not yet known, it seems to play a role in $1,25(\mathrm{OH})_{2} \mathrm{D}_{3}$-induced collagen phenotypes ${ }^{22}$. LOXL2 is also a major isoform in chondrocytes and is required for their differentiation. 
Chapter 8

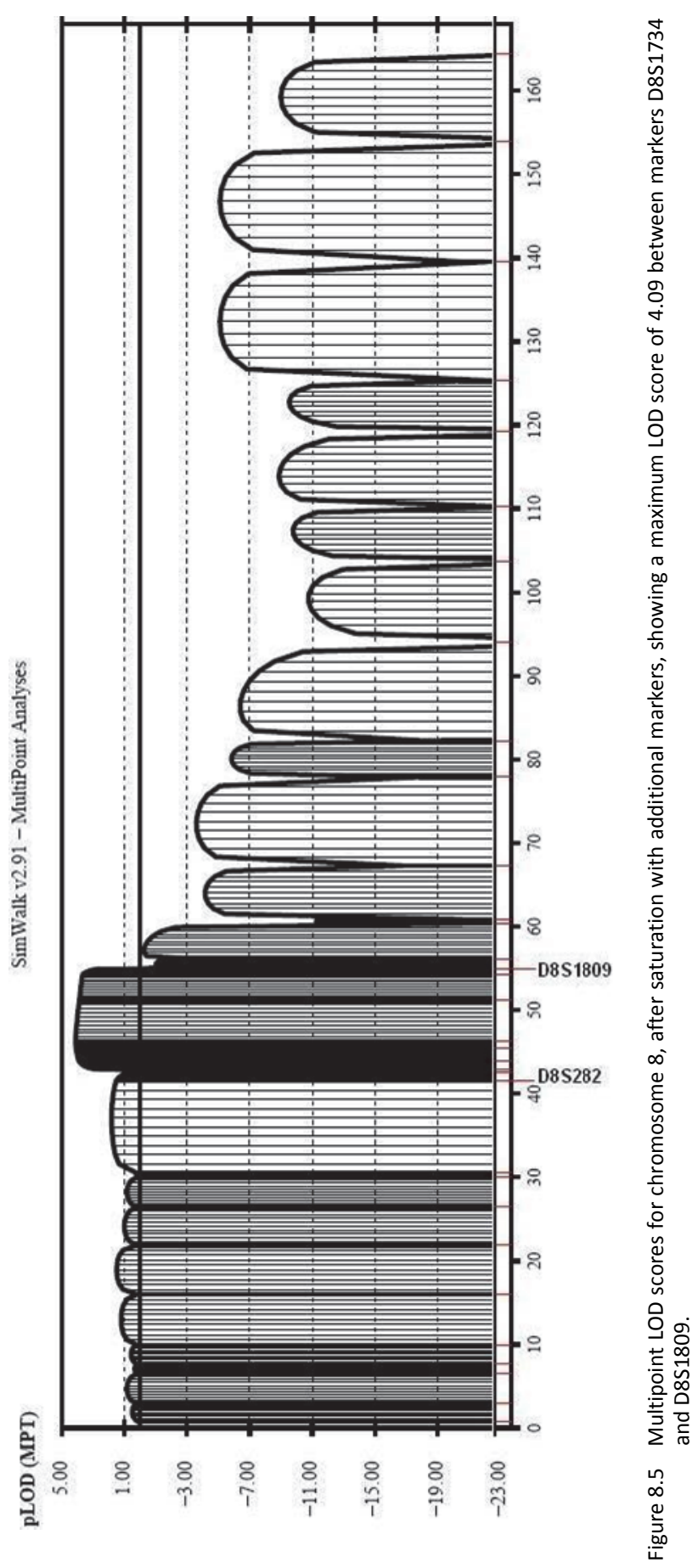


The LOXL2 expression pattern in healing fractures and in developing growth plates indicates abundant expression in chondrocytes ${ }^{23}$. Other members of the lysyl oxidase gene family may also play a role in bone homeostasis. Lysyl oxidase (LOX) catalyses cross-linking of elastin and collagen, which is essential for the structural integrity and function of bone tissue.

The expression of LOXL1-4 is significantly downregulated in bone tissue of LOX (-/-) mice $^{24}$.

ADAM28 is a member of the ADAM (a disintegrin and metalloprotease domain) family. There are no data available on the expression of this gene in bone tissue, nor is any function in bone metabolism known so far. However, it is an interesting candidate gene, since several other members of the ADAM family have been implicated in bone metabolism. Inactivation of ADAM9 by MT1-MMP regulates FGFR2 signalling and calvarial osteogenesis. MT1-MMP cleaves ADAM9 to protect FGFR2 from ectodomain shedding. Depletion of ADAM9 in MT1-MMP-deficient mice significantly rescued the calvarial defects via restoring FGF signalling ${ }^{25,26}$. Increased expression of ADAM8 enhances osteoclast formation, differentiation, and bone resorption per osteoclast and results in osteopenia in vivo, whereas loss of ADAM8 in vivo does not significantly affect normal bone homeostasis but blocks the osteoclast stimulatory effects of inflammatory cytokines such as TNF- $\alpha$, which is a major cytokine implicated in inflammatory bone loss $^{27}$. ADAM19 was suggestively associated with bone density in an extended genomewide association study of bone mineral density among Icelanders and a follow-up study in subjects of European descents ${ }^{28}$.

Sequence analysis of these genes did not reveal any mutations. To ensure that both copies of the gene are present and to rule out large deletions, SNPs were analysed. For each gene at least two heterozygous SNPs were found in patient IV.14 covering a major part of the genomic region of the gene (Table 8.1). This indicates that both copies of each gene are present.

Table 8.1 SNPs in BMP1, LOX2 and ADAM28 that were heterozygous in patient IV.14.

\begin{tabular}{llll}
\hline Gene & Number of exons & \multicolumn{2}{l}{ Intragenic polymorphisms } \\
& & rs number & Position (NCBI build 37.3) \\
\hline BMP1 & 20 & rs67774528 & Chr8:22035249:22035250 (intron 6-7) \\
NM_006129.4 & & rs4075478 & Chr8:22053123 (intron 13-14) \\
LOXL2 & 14 & rs3765215 & Chr8:23160778 (intron 11-12) \\
NM_002318.2 & & rs2280936 & Chr8:23155337 (3'UTR) \\
ADAM28 & 23 & rs6996616 & Chr8:24171051 (exon 6) \\
NM_014265.4 & & rs145612420 & Chr8:24187586 (exon 11) \\
& & rs2278467 & Chr8:24188844 (intron 12-13) \\
& & rs11994522 & Chr8:24196898 (intron 14-15) \\
& & rs7829944 & Chr8: 24207399 (exon 19) \\
& & rs7009516 & Chr8:24208847 (intron 20-21) \\
& & rs1058914 & Chr8:24212040 (3'UTR) \\
\hline
\end{tabular}




\section{Discussion}

Bone is constantly remodelled throughout life by bone formation and bone resorption. Normally, these processes are in balance. Disturbance of this balance can lead to different bone pathologies, with either increased or decreased bone density. Analysing families with an increased or decreased bone density can lead us to new genes involved in abnormal bone density. Identification of these genes can give new insights in the understanding of bone homeostasis.

Linkage studies have previously shown to be a successful way of identifying new genes in monogenic families. SOST was identified with positional cloning studies in families with Van Buchem disease ${ }^{7}$ and sclerosteosis ${ }^{9}$. In a kindred with High Bone Mass trait, LRP5 was identified as the causative gene ${ }^{29,30}$. Both genes are now known as important elements of the $\mathrm{Wnt} / \beta$-catenin pathway.

$\mathrm{HCl}$ is a sclerosing bone dysplasia of the skull. Besides $\mathrm{HCl}$, numerous sclerosing bone dysplasias with involvement of the skull exist, for example Van Buchem disease, sclerosteosis and Camurati-Engelmann disease. Van Buchem disease (OMIM 239100) and sclerosteosis (OMIM 269500) are both autosomal recessive disorders with similar clinical features like hyperostosis of the skull, mandible, clavicles, ribs and tubular bones. A typical feature is the enlarged mandible which is seen in most patients. The difference between Van Buchem disease and Sclerosteosis is that in the latter, patients show excessive height - sometimes even gigantism - and hand abnormalities ${ }^{31,32}$. This is absent in patients with Van Buchem disease. A $52 \mathrm{~kb}$ (kilobases) deletion located downstream of SOST is found in patients with Van Buchem disease ${ }^{33}$, whereas sclerosteosis is caused by missense mutations in $S O S T^{34}$. Mutations in LRP4 were identified in two isolated sclerosteosis-2 cases (OMIM 614305) ${ }^{35}$. Camurati-Engelmann disease (CED) also belongs to the group of craniotubular hyperostoses and is characterised by cortical thickening of the diaphyses of the long bones. Sclerotic changes at the skull base can occur as well. CED is caused by mutations in TGFB1 $1^{8,36}$. Finally, missense mutations in LRP5 were found in several High Bone Mass syndromes $^{29,37,38}$.

We were able to exclude all these genes mentioned above based on LOD scores below 2 , indicating there is no linkage between the phenotype and the chromosomal regions of these genes. Exclusion of these genes was not entirely unexpected since the whole skeleton is affected in these disorders whereas in $\mathrm{HCl}$ only the skull is affected.

We located the disease-causing gene for $\mathrm{HCl}$ in a $8.3 \mathrm{cM}$ region on chromosome 8 . This region encompasses 64 genes of which very few have a known function in bone metabolism. The region was delineated by two important recombination events. At the distal side, a recombination occurred proximal of D8S282. At the proximal side, a recombination occurred between D8S1739 and D8S382 in IV.13. This recombination can further narrow the region, and although this individual is considered healthy because he reached the age of 18 without any symptoms or radiological abnormalities, 
we will have to keep in mind that he is still young. We focused in our study on the 8.3 $\mathrm{cM}$ region, but keep in mind that it is possible that the disease causing gene might be in the larger $12.13 \mathrm{cM}$ region.

Genes were prioritised by Endeavour and Suspects. Suspects matches Gene Ontology terms, InterPro domains, and gene expression data built on top of the PROSPECTR candidate prioritisation system, which uses sequence features to rank genes in order of their likelihood of involvement in disease. Suspects drills down further to rank genes involved in specific complex traits and syndromes ${ }^{14}$. Endeavour matches candidate genes with training genes based on functional annotations, protein-protein interactions, regulatory information, expression data, sequence-based data and literature-mining data ${ }^{15,16}$. BMP1, ADAM28 and LOXL2 were the most interesting candidate genes, based on their ranking by Endeavour and Suspects, their expression in bone tissue and their function. Sequence analysis of these three genes did not reveal any mutations and SNP analysis ensured the presence of both copies of the genes. $A D A M 28$ is relatively well covered by heterozygous polymorphisms. This is less the case for BMP1 and LOXL2. Therefore, we cannot exclude small deletions only affecting a few exons in the latter genes. These results suggest that a gene not previously known in bone metabolism will be responsible for hyperostosis of the skull in this family. This could be a gene that shows specific expression in skull bones. Another possibility is a gene that is expressed in neighbouring tissues, which this way influences the metabolism of the adjacent skull bones. Further sequencing of genes in the region should be performed. Since there are still many genes in this region, exome sequencing could be considered since the combination of linkage studies with exome sequencing can lead to identification of new genes and gene pathways in bone formation ${ }^{39}$.

\section{Acknowledgments}

This work was supported by Grants from the FWO (Fund for Scientific Research) Vlaanderen (G0197.12N) and the University of Antwerp (NOI-BOF and TOP-BOF), all to W. Van Hul, and by a Ph.D. Grant of the Agency for Innovation by Science and Technology (IWT) to V. M. Borra. 


\section{References}

1. Perdu B, Van Hul W. Sclerosing bone disorders: too much of a good thing. Crit Rev Eukaryot Gene Expr 2010;20:195-212.

2. Manni JJ, Scaf JJ, Huygen PL, Cruysberg JR, Verhagen WI. Hyperostosis cranialis interna. A new hereditary syndrome with cranial-nerve entrapment. N Engl J Med 1990;322:450-454.

3. Waterval JJ, Stokroos RJ, Bauer NJ, De Bondt RB, Manni JJ. Phenotypic manifestations and management of hyperostosis cranialis interna, a hereditary bone dysplasia affecting the calvaria and the skull base. Am J Med Genet A 2010;152A:547-555.

4. Manni JJ, Huygen PL, Noten JF, Kuijpers W. Eighth cranial nerve dysfunction in hyperostosis cranialis interna. Acta Otolaryngol 1992;112:75-82.

5. Waterval JJ, Stokroos RJ, De Bondt RB, Manni JJ. Facial nerve decompression via middle fossa approach for hyperostosis cranialis interna: a feasible therapeutic approach. J Laryngol Otol 2009;123:1177-1180.

6. Waterval JJ, van Dongen TM, Stokroos RJ, De Bondt BJ, Chenault MN, Manni JJ. Imaging features and progression of hyperostosis cranialis interna. AJNR Am J Neuroradiol 2012;33:453-461.

7. Van Buchem F, Hadders H, Hansen J, Woldring M. Hyperostosis Corticalis Generalisata. Report of seven cases. Am J Med 1962;33:387-397.

8. Janssens K, Vanhoenacker F, Bonduelle M, Verbruggen L, Van Maldergem L, Ralston S, Guanabens N, Migone N, Wientroub S, Divizia MT, Bergmann C, Bennett C, Simsek S, Melancon S, Cundy T, Van Hul W. Camurati-Engelmann disease: review of the clinical, radiological, and molecular data of 24 families and implications for diagnosis and treatment. J Med Genet 2006;43:1-11.

9. Hansen H. Sklerosteose. Handbuch der Kinderheilkunde 1967;6:351-355.

10. Broman KW, Murray JC, Sheffield VC, White RL, Weber JL. Comprehensive human genetic maps: individual and sex-specific variation in recombination. Am J Hum Genet 1998;63:861-869.

11. Schuelke M. An economic method for the fluorescent labeling of PCR fragments. Nat Biotechnol 2000;18:233-234.

12. Hoffmann K, Lindner TH. easyLINKAGE-Plus--automated linkage analyses using large-scale SNP data. Bioinformatics 2005;21:3565-3567.

13. Lindner TH, Hoffmann K. easyLINKAGE: a PERL script for easy and automated two-/multi-point linkage analyses. Bioinformatics 2005;21:405-457.

14. Adie EA, Adams RR, Evans KL, Porteous DJ, Pickard BS. Speeding disease gene discovery by sequence based candidate prioritization. BMC Bioinformatics 2005;6:55.

15. Aerts S, Lambrechts D, Maity S, Van Loo P, Coessens B, De Smet F, Tranchevent LC, De Moor B, Marynen P, Hassan B, Carmeliet P, Moreau Y. Gene prioritization through genomic data fusion. Nat Biotechnol 2006;24:537-544.

16. Tranchevent LC, Barriot R, Yu S, Van Vooren S, Van Loo P, Coessens B, De Moor B, Aerts S, Moreau Y. ENDEAVOUR update: a web resource for gene prioritization in multiple species. Nucleic Acids Res 2008;36:W377-384.

17. Grgurevic L, Macek B, Mercep M, Jelic M, Smoljanovic T, Erjavec I, Dumic-Cule I, Prgomet S, Durdevic D, Vnuk D, Lipar M, Stejskal M, Kufner V, Brkljacic J, Maticic D, Vukicevic S. Bone morphogenetic protein (BMP)1-3 enhances bone repair. Biochem Biophys Res Commun 2011;408:25-31.

18. Asharani PV, Keupp K, Semler O, Wang W, Li Y, Thiele H, Yigit G, Pohl E, Becker J, Frommolt P, Sonntag C, Altmuller J, Zimmermann K, Greenspan DS, Akarsu NA, Netzer C, Schonau E, Wirth R, Hammerschmidt M, Nurnberg P, Wollnik B, Carney TJ. Attenuated BMP1 function compromises osteogenesis, leading to bone fragility in humans and zebrafish. Am J Hum Genet 2012;90:661-674.

19. Ge G, Greenspan DS. Developmental roles of the BMP1/TLD metalloproteinases. Birth Defects Res $C$ Embryo Today 2006;78:47-68.

20. Martinez-Glez V, Valencia M, Caparros-Martin JA, Aglan M, Temtamy S, Tenorio J, Pulido V, Lindert U, Rohrbach M, Eyre D, Giunta C, Lapunzina P, Ruiz-Perez VL. Identification of a mutation causing deficient BMP1/mTLD proteolytic activity in autosomal recessive osteogenesis imperfecta. Hum Mutat 2012;33: 343-350.

21. Suzuki N, Labosky PA, Furuta Y, Hargett L, Dunn R, Fogo AB, Takahara K, Peters DM, Greenspan DS, Hogan BL. Failure of ventral body wall closure in mouse embryos lacking a procollagen C-proteinase encoded by Bmp1, a mammalian gene related to Drosophila tolloid. Development 1996;122:3587-3595. 
22. Nagaoka H, Mochida Y, Atsawasuwan P, Kaku M, Kondoh T, Yamauchi M. 1,25(OH)2D3 regulates collagen quality in an osteoblastic cell culture system. Biochem Biophys Res Commun 2008;377: 674-678.

23. Iftikhar M, Hurtado P, Bais MV, Wigner N, Stephens DN, Gerstenfeld LC, Trackman PC. Lysyl oxidaselike-2 (LOXL2) is a major isoform in chondrocytes and is critically required for differentiation. $J$ Biol Chem 2011;286: 909-918.

24. Pischon N, Maki JM, Weisshaupt $P$, Heng N, Palamakumbura AH, N'Guessan P, Ding A, Radlanski R, Renz H, Bronckers TA, Myllyharju J, Kielbassa AM, Kleber BM, Bernimoulin JP, Trackman PC. Lysyl oxidase (lox) gene deficiency affects osteoblastic phenotype. Calcif Tissue Int 2009;85:119-126.

25. Chan KM, Wong HL, Jin G, Liu B, Cao R, Cao Y, Lehti K, Tryggvason K, Zhou Z. MT1-MMP inactivates ADAM9 to regulate FGFR2 signaling and calvarial osteogenesis. Dev Cell 2012;22: 1176-1190.

26. Wong HL, Cao R, Jin G, Chan KM, Cao Y, Zhou Z. When MT1-MMP meets ADAMs. Cell Cycle 2012;11: 2793-2798.

27. Ishizuka H, Garcia-Palacios V, Lu G, Subler MA, Zhang H, Boykin CS, Choi SJ, Zhao L, Patrene K, Galson DL, Blair HC, Hadi TM, Windle JJ, Kurihara N, Roodman GD. ADAM8 enhances osteoclast precursor fusion and osteoclast formation in vitro and in vivo. J Bone Miner Res 2011;26:169-181.

28. Styrkarsdottir U, Halldorsson BV, Gretarsdottir S, Gudbjartsson DF, Walters GB, Ingvarsson T, Jonsdottir T, Saemundsdottir J, Snorradottir S, Center JR, Nguyen TV, Alexandersen P, Gulcher JR, Eisman JA, Christiansen C, Sigurdsson G, Kong A, Thorsteinsdottir U, Stefansson K. New sequence variants associated with bone mineral density. Nat Genet 2009;41: 15-17.

29. Little RD, Carulli JP, Del Mastro RG, Dupuis J, Osborne M, Folz C, Manning SP, Swain PM, Zhao SC, Eustace B, Lappe MM, Spitzer L, Zweier S, Braunschweiger K, Benchekroun Y, Hu X, Adair R, Chee L, FitzGerald MG, Tulig C, Caruso A, Tzellas N, Bawa A, Franklin B, McGuire S, Nogues X, Gong G, Allen KM, Anisowicz A, Morales AJ, Lomedico PT, Recker SM, Van Eerdewegh P, Recker RR, Johnson ML. A mutation in the LDL receptor-related protein 5 gene results in the autosomal dominant high-bone-mass trait. Am J Hum Genet 2002;70:11-9.

30. Little RD, Recker RR, Johnson ML. High bone density due to a mutation in LDL-receptor-related protein 5. N Engl J Med 2002;347:943-944.

31. Beighton P, Barnard A, Hamersma $\mathrm{H}$, van der Wouden A. The syndromic status of sclerosteosis and van Buchem disease. Clin Genet 1984;25:175-181.

32. Beighton $\mathrm{P}$, Durr L, Hamersma $\mathrm{H}$. The clinical features of sclerosteosis. A review of the manifestations in twenty-five affected individuals. Ann Intern Med 1976;84: 393-397.

33. Balemans W, Patel N, Ebeling M, Van Hul E, Wuyts W, Lacza C, Dioszegi M, Dikkers FG, Hildering P, Willems PJ, Verheij JB, Lindpaintner K, Vickery B, Foernzler D, Van Hul W. Identification of a $52 \mathrm{~kb}$ deletion downstream of the SOST gene in patients with van Buchem disease. J Med Genet 2002;39: 91-97.

34. Balemans W, Ebeling M, Patel N, Van Hul E, Olson P, Dioszegi M, Lacza C, Wuyts W, Van Den Ende J, Willems P, Paes-Alves AF, Hill S, Bueno M, Ramos FJ, Tacconi P, Dikkers FG, Stratakis C, Lindpaintner K, Vickery B, Foernzler D, Van Hul W. Increased bone density in sclerosteosis is due to the deficiency of a novel secreted protein (SOST). Hum Mol Genet 2001;10:537-543.

35. Leupin O, Piters E, Halleux C, Hu S, Kramer I, Morvan F, Bouwmeester T, Schirle M, Bueno-Lozano M, Fuentes FJ, Itin PH, Boudin E, de Freitas F, Jennes K, Brannetti B, Charara N, Ebersbach H, Geisse S, Lu CX, Bauer A, Van Hul W, Kneissel M. Bone overgrowth-associated mutations in the LRP4 gene impair sclerostin facilitator function. J Biol Chem 2011;286:19489-19500.

36. Janssens K, Gershoni-Baruch R, Guanabens N, Migone N, Ralston S, Bonduelle M, Lissens W, Van Maldergem L, Vanhoenacker F, Verbruggen L, Van Hul W. Mutations in the gene encoding the latencyassociated peptide of TGF-beta 1 cause Camurati-Engelmann disease. Nat Genet 2000;26:273-275.

37. Van Wesenbeeck L, Cleiren E, Gram J, Beals RK, Benichou O, Scopelliti D, Key L, Renton T, Bartels C, Gong Y, Warman ML, De Vernejoul MC, Bollerslev J, Van Hul W. Six novel missense mutations in the LDL receptor-related protein 5 (LRP5) gene in different conditions with an increased bone density. Am J Hum Genet 2003;72:763-771.

38. Whyte MP, Reinus WH, Mumm S. High-bone-mass disease and LRP5. N Engl J Med 2004;350:2096-2099. 
Chapter 8

39. Bailey-Wilson JE, Wilson AF. Linkage analysis in the next-generation sequencing era. Hum Hered 2011;72:228-236. 


\section{Part IV

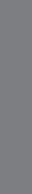

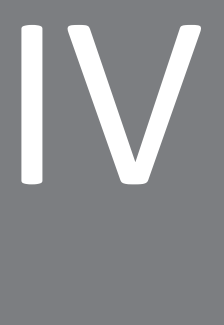

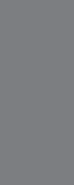

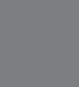

\section{Casuistics}

(a)

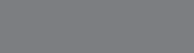

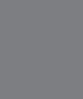

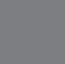

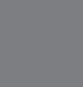

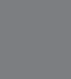

(

2

(

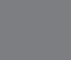

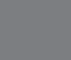

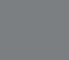

(

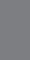




\section{Chapter}

Facial nerve decompression via middle fossa approach for hyperostosis cranialis interna is feasible

Jérôme J. Waterval

Robert J. Stokroos

Bert-Jan de Bondt

Johannes J. Manni

The Journal of Laryngology \& Otology 2009;123:1177-1180 


\begin{abstract}
Hyperostosis cranialis interna $(\mathrm{HCl})$ is an autosomal dominant disorder characterised by endosteal hyperostosis and osteosclerosis of the skull base and calvaria, leading to compression and dysfunction of cranial nerves I, II, VII and VIII. We report on bilateral surgical decompression of the internal auditory canal in $\mathrm{HCl}$. An eight year old girl presented with bilateral facial palsy due to $\mathrm{HCl}$. Via a middle fossa craniotomy both internal auditory canals were unroofed and the cranial nerves VII and VIII were decompressed. The mimic function recovered and one year postoperatively House-Brackmann grade I and II respectively were observed. Concluding, this is the first report on surgical decompression of the internal auditory canal in $\mathrm{HCl}$. Surgical decompression of the internal auditory canal is recommended therapeutically, but may also be performed prophylactically in younger patients with $\mathrm{HCl}$.
\end{abstract}




\section{Introduction}

Hyperostosis cranialis interna $(\mathrm{HCl})$ is a disorder that is characterised by hyperostosis and osteosclerosis limited to the calvaria and skull base. This leads to narrowing of cranial nerve foramina and hence cranial nerve entrapment, mainly of cranial nerves I, II, VII and VIII. Smell, taste and vision impairment, facial palsy and vestibulocochlear dysfunction may occur at young age. Besides, increased ocular and intracranial pressure can occur. $\mathrm{HCl}$ has an autosomal dominant transmission pattern and was first described in $1990^{1}$.

Craniofacial hyperostotic disorders can lead to dysmorphic, functional and neurological symptoms. No causal treatment modalities are known. Symptomatic treatment can exist of cranial vault decompression ${ }^{2}$ or cranial nerve decompression. Successful vestibulocochlear and optic nerve decompression have been described in other craniofacial hyperostotic disorders ${ }^{3-5}$.

In this report we like to communicate our experience, the technique and functional outcome of the first (bilateral) surgical decompression of the internal auditory canal (IAC) via middle fossa approach in a patient with facial palsy due to $\mathrm{HCl}$.

\section{Case report}

An 8-year-old girl presented with sudden paresis of the left side of the face evolving to a paralysis within 2 days (House-Brackmann grade $\mathrm{VI}$ ). The referring otolaryngologist prescribed antibiotics and steroids. Her left-sided paralysis partially resolved after treatment with antibiotics and prednisolone, House-Brackmann (HB) grade III. Her medical history was uneventful. There was a remarkable family history of facial palsy due to $\mathrm{HCl}$. The facial appearance was otherwise normal. The otoscopic aspect of the eardrums was normal, there was no impairment of other cranial nerves and the ophthalmologic examination was normal.

Audiometry revealed normal hearing levels. The stapedial muscle reflex was absent at the left side. Vestibular examination and brainstem audiometry were normal. Routine laboratory investigation revealed no abnormalities.

Radiological imaging by means of computed tomography (CT) was performed. Bilaterally, the middle and the medial part of the IAC were narrowed (Figure 9.1A and 9.11B) down to 2-3 $\mathrm{mm}$. The middle and inner ear displayed no abnormalities. The skull showed diffuse hypodense hyperostotic areas and a hypodense enlarged endosteal cortex of the greater wing of the sphenoid bones and the petrous bones (Figure 9.2). The calvaria were not enlarged. Magnetic resonance imaging (MRI) revealed no supplementary information.

Clinical symptoms, findings and imaging results confirmed the diagnosis $\mathrm{HCl}$. The facial nerve function did not further recover. Because of the age of the patient and the 
knowledge that at older age osteosclerosis may progress along with deterioration of facial nerve function, it was decided to discuss with the parents a surgical decompression of the facial nerve via a middle fossa approach. The parents gave consent.

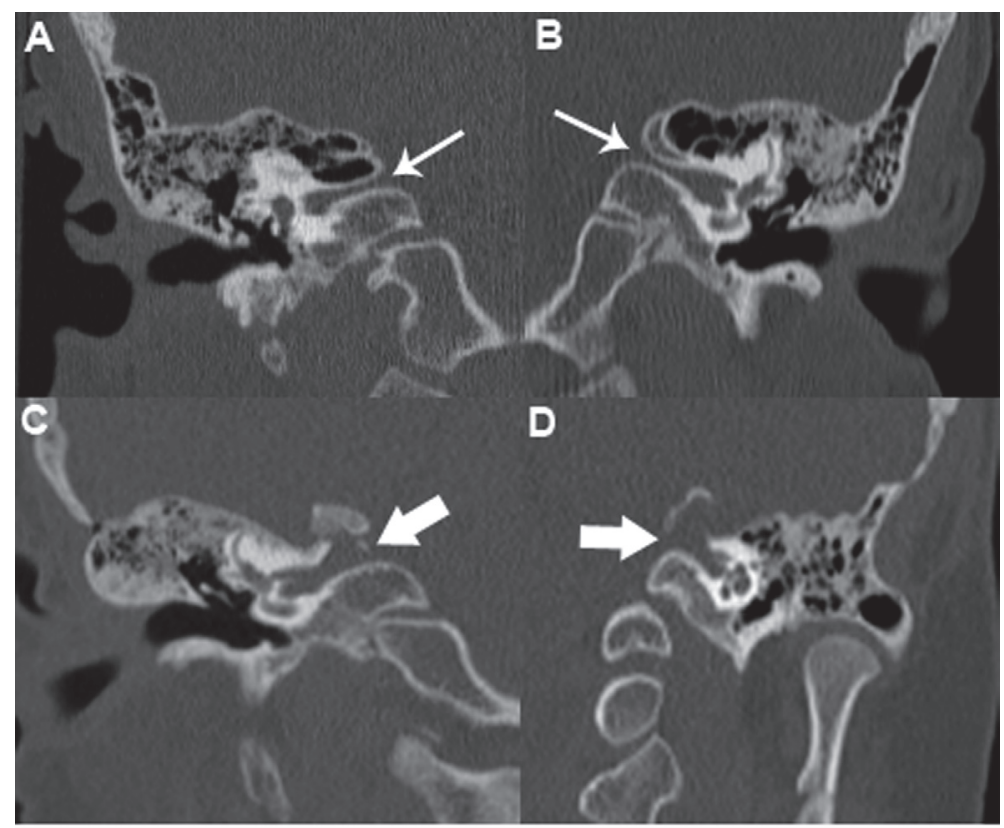

Figure 9.1 Sagittal reconstructions, the internal acoustic canal is indicated with arrows. (A) pre-operatively right, (B) pre-operatively left, (C) post-operatively right, (D) post-operatively left.

Ten months after the initial left paralysis she developed a sudden right-sided facial palsy. ENT-examination revealed a partially recovered left facial palsy HB grade III and a right facial palsy HB grade VI (with absent stapedial muscle reflex), whereas all other investigations remained normal. Treatment with prednisolone resulted in a partial recovery (HB grade IV).

The patient was scheduled for surgery at the right side first; it was argued that a shorter period of impairment may increase the chance of recovery. One year later the left side was operated, which had remained HB grade III.

The surgical procedures were performed with the head fixed in the Mayfield frame. Routine monitoring of facial nerve function (NIM-2 XL Nerve Integrity Monitoring System, Medtronic, Minneapolis, USA) and of hearing by auditory brain stem response monitoring were used throughout the operation. A neuronavigation system was used (Medtronic Surgical Navigation Technologies, Louisville, Colo., USA). Cranial to the ear, an inverted $\mathrm{v}$-shaped incision was made. The temporal muscle was split in an inverted 
T-shape. Through a $5 \times 3 \mathrm{~cm}$ trepanation and elevation of the dura mater the middle fossa was approached. The superior petrosal sinus and the cranioposterior petrosal bone were identified. The routine landmarks to identify the position of the IAC could not be applied. Especially the subarcuate eminence, or the greater superior petrosal nerve (GSPN) could not be found. The superior semicircular canal lay buried under an abnormally thickened layer of bone which contained several large cells. The IAC was identified at the bottom of one of these cells. The consistency and aspect of the bone was normal. The IAC was pear-shaped with its narrowest point medially. The superior and the medial part of the IAC were drilled thin and subsequently removed.

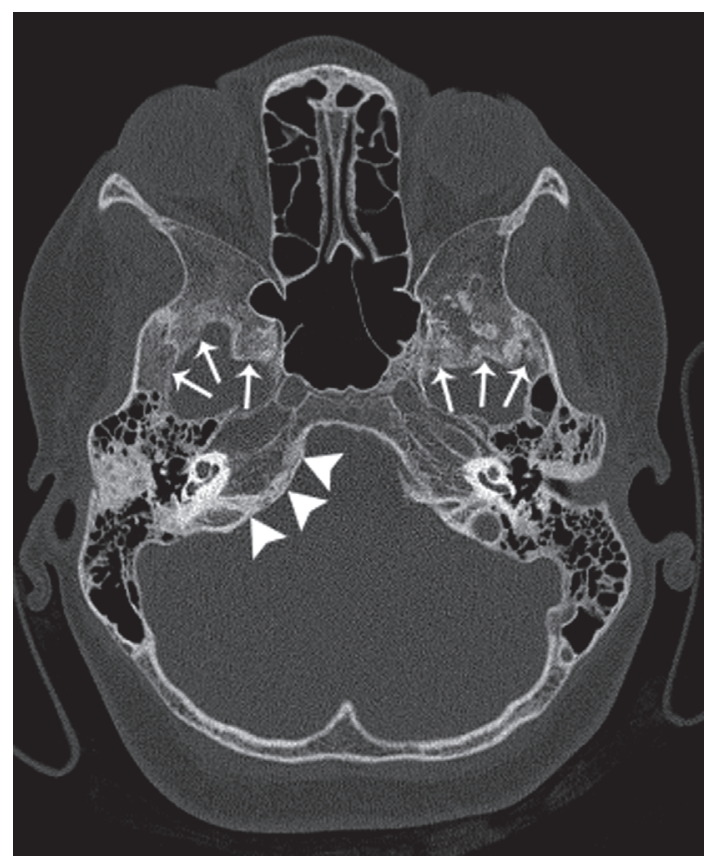

Figure 9.2 Coronal CT-scan at the level of the sphenoid bone and middle skull base displaying diffuse abnormal findings. There is marked increased endosteal bone formation of the squama temporalis and the corpus temporalis bilaterally (arrows). The arrowheads indicate hyperostosis of the petrous bone.

During the first operation (right side) the nerves of the IAC were found to blossom out into the overlying air cells. A small defect in the posterior fossa dura was repaired with a free muscle graft and fibrin glue (Tissuecol ${ }^{\circledR}$, Baxter, Deerfield, IL., USA). A lumbar drain was placed for a few days. The facial nerve function was HB grade IV pre- and post-operatively and was completely restored (HB grade I) one year after the operation. 
The contralateral side was operated one year later. During this similar procedure, at the time of opening the IAC, the facial nerve bulged out instantly. This normalised after administration of $4 \mathrm{mg}$ intravenous dexamethasone. One year after each operation the right and left facial nerve function were restored to $\mathrm{HB}$ grade I and II respectively. Postoperative CT-scans revealed a significantly enlarged medial IAC bilaterally (Figure 9.1C and 9.1D).

\section{Discussion}

In our patient with $\mathrm{HCl}$, a marked medial IAC stenosis was present bilaterally, whereas the lateral IAC, the labyrinthine, the tympanic and mastoid segments of the Fallopian canal were normal. This justifies exploration of the middle and medial IAC only. Furthermore, exploration of the unaffected lateral IAC would superimpose the unnecessary risk of damaging the facial nerve and the labyrinth. Both surgical decompressions had the desired effect: nearly complete recovery of the facial nerve function. The decision to perform the surgical decompression was based on the following arguments: the early age of symptomatic $\mathrm{HCl}$ and the assumption that at older age the osteosclerosis increases, as is seen in several other family members. A bilateral palsy occurred in four other family members when nerve monitoring was not yet available. Their facial nerve functions never recovered after conservative treatment. Reports on decompressive facial nerve decompressive surgery for cranial hyperostotic disorders via middle fossa approach have only been published scarcely. Thorough analysis of the literature reveals eight reports. Hamersma mentions four cases of labyrinthine and meatal decompressions in sclerosteosis (by Hamersma, Fisch and House) ${ }^{6}$. Miyamoto et al. report this procedure in two patients with CamuratiEngelmann disease ${ }^{7}$. Benecke et al. report a successful total facial nerve decompression in a patient with Camurati-Engelmann disease and a middle fossa approach for decompression of the IAC and labyrinthine segment in a 3-year old boy with recessive osteopetrosis $^{8}$. Based on their experiences and observations of (intracranial) complications, the authors conclude that facial nerve decompression should be avoided in such severe cases. Tibesar et al. report on IAC decompression via middle fossa approach for sensorineural hearing loss due to vestibulocochlear nerve encroachment in a patient with Camurati-Engelmann disease ${ }^{9}$.

Two mechanisms can be thought of to cause the facial nerve dysfunction. First, the direct compression of the nerve by progressive hyperostotic changes of the skull base and its neuroforamina, and second, the impairment of the perineural microvasculature. The reversibility of the cranial nerve function of our case suggests an important role of the latter mechanism: (transient) ischaemia leads to facial nerve oedema.

Although $\mathrm{HCl}$ is a rare disorder, this procedure can be thought of in other hyperostotic craniofacial disorders, like osteopetrosis, osteopathia striata, Camurati-Engelman 
disease, craniodiaphyseal disease, Lenz-Majewski syndrome, Van Buchem disease, sclerosteosis and craniometaphyseal dysplasia ${ }^{10}$.

\section{Conclusion}

In our patient IAC decompression has shown to be effective in reversing facial nerve dysfunction due to encroachment in a patient with $\mathrm{HCl}$. The varying manifestations of $\mathrm{HCl}$ and the lack of prognostic factors indicating progression of disease make it difficult to predict the clinical course. However, based on experience with other patients with facial nerve paralysis due to $\mathrm{HCl}$ we do not expect the facial nerve function to improve with conservative treatment only. These findings plea for surgical decompression at early age. Moreover, in patients without pronounced hyperostosis and osteosclerosis of the skull, the operative landmarks are still recognisable. Therefore in young patients with $\mathrm{HCl}$, in which progressive hyperostosis is to be expected, prophylactic surgical decompression of a narrowed IAC can be considered.

\section{Summary}

$\mathrm{HCl}$ is a disorder that is characterised by hyperostosis and osteosclerosis limited to the calvaria and skull base. This leads to narrowing of cranial nerve foramina and hence cranial nerve entrapment, mainly of cranial nerves I, II, VII and VIII.

In this patient with $\mathrm{HCl}$ there was an isolated bilateral stenosis of the medial internal auditory canal. Facial nerve decompression via middle fossa approach can be successfully performed in patients with cranial nerve entrapment due to a hyperostotic and narrowed IAC. Despite the technical advances of surgical decompression of the IAC, it is considered advisable in patients without pronounced hyperostosis and osteosclerosis of the skull when the operative landmarks are still recognisable. 


\section{References}

1. Manni JJ, Scaf JJ, Huygen PL, Cruysberg JR, Verhagen WI. Hyperostosis cranialis interna. A new hereditary syndrome with cranial-nerve entrapment. N Engl J Med 1990;322:450-454.

2. Mocco J, Komotar RJ, Zacharia BE, Feldstein NA, Bruce JN. Aggressive cranial vault decompression for cranial hyperostosis: technical case report of two cases. Neurosurgery 2005;57:E212.

3. Hellier WP, Brookes GB. Vestibular nerve dysfunction and decompression in Engelmann's disease. J Laryngol Otol 1996;110:462-465.

4. Hwang JM, Kim IO, Wang KC. Complete visual recovery in osteopetrosis by early optic nerve decompression. Pediatr Neurosurg 2000;33:328-332.

5. Vanier V, Miller NR, Carson BS. Bilateral visual improvement after unilateral optic canal decompression and cranial vault expansion in a patient with osteopetrosis, narrowed optic canals, and increased intracranial pressure. J Neurol Neurosurg Psychiatry 2000;69:405-406.

6. Hamersma H. Total decompression of the facial nerve in osteopetrosis (marble bone disease-morbus Albers-Schonberg). ORL J Otorhinolaryngol Relat Spec 1974;36:21-32.

7. Miyamoto RT, House WF, Brackmann DE. Neurotologic manifestations of the osteopetroses. Arch Otolaryngol 1980;106:210-4.

8. Benecke JE, Jr. Facial nerve dysfunction in osteopetrosis. Laryngoscope 1993;103:494-497.

9. Tibesar RJ, Brissett AE, Shallop JK, Driscoll CL. Internal auditory canal decompression and cochlear implantation in Camurati-Engelmann disease. Otolaryngol Head Neck Surg 2004;131:1004-1006.

10. Warman ML, Cormier-Daire V, Hall C, Krakow D, Lachman R, LeMerrer M, Mortier G, Mundlos S, Nishimura G, Rimoin DL, Robertson S, Savarirayan R, Sillence D, Spranger J, Unger S, Zabel B, SupertiFurga A. Nosology and classification of genetic skeletal disorders: 2010 revision. Am J Med Genet A 2011;155A:943-968. 


\section{Chapter 10}

Cerebral vasospasm after auditory brainstem implantation in a patient with hyperostosis cranialis interna

Jérôme J. Waterval

Robert J. Stokroos

Jim Dings

Koo J. van Overbeeke

Johannes J. Manni

Clinical Neurology and Neurosurgery. 2011;113:904-908 


\begin{abstract}
Hyperostosis Cranialis Interna $(\mathrm{HCl})$ is a hereditary bone dysplasia with autosomal dominant transmission pattern characterised by progressive hyperostosis and osteosclerosis of the cranial vault and the skull base (MIM 144755). Encroachment of neuroforamina causes function loss of cranial nerves I, II, V, VII and VIII. We present a 44-year-old female with bilateral sensorineural deafness caused by $\mathrm{HCl}$ in whom an auditory brainstem implant was placed for auditory revalidation via retrosigmoidal approach. Although the auditory result was satisfactory, this procedure was complicated by neurological deficit caused by postoperative cerebral vasospasm. To our knowledge this is the first report of a postoperative cerebral vasospasm after this procedure. This report discusses the possible aetiology of this complication and offers suggestions in performing auditory brainstem implantation in a novel candidate population of patients with hyperostotic skull disorders.
\end{abstract}




\section{Introduction}

Auditory brainstem implantation $(A B I)$ is indicated in case of bilateral neural deafness. The majority of the patients suffers from bilateral vestibular schwannomas related to neurofibromatosis type $2^{1}$. Possible other indications for $A B I$ are bilateral severe ossification of the cochlea due to otosclerosis, cochlear obliteration due to meningitis, cochlear aplasia and traumatic cochlear nerve avulsion ${ }^{2}$. $\mathrm{ABI}$ can also be considered in case of bilateral vestibulocochlear neuropathy in patients with craniofacial hyperostotic disorders, such as Camurati-Engelmann disease, sclerosteosis, osteopetrosis and craniometaphyseal dysplasia. $\mathrm{HCl}$ is such a hyperostotic hereditary disease characterised by endosteal hyperostosis and osteosclerosis of the cranium and the skull base and to a minimal extent also the mandible (MIM 144755) ${ }^{3}$. The transmission pattern is autosomal dominant. Patients are affected to a different extent. Skull base hyperostosis causes cranial nerve entrapment (I, II, V, VII and VIII) due to narrowing of their foramina. Hyperostosis of the cranial vault is most profound in the frontal and temporal regions. Severe hyperostosis causes reduced space in the pontocerebellar cistern and can eventually cause brainstem compression.

Patients generally become symptomatic in the second decade or late in the first decade. Facial palsy and vestibulocochlear impairment are often the first symptoms due to encroachment of the medial part of the internal auditory canal. Symptomatic patients are best treated by (sub)acute decompression of the internal auditory canal ${ }^{4}$, possibly followed by cochlear implantation. However, in case of prolonged existing profound sensorineural hearing loss due to advanced hyperostosis and osteosclerosis of the skull base and an obliterated internal auditory canal, an auditory brainstem implant can be considered. To our knowledge, this is the first report on auditory brainstem implantation in a patient with skull base hyperostosis.

\section{Case report}

The proband is a 44-year-old woman with $\mathrm{HCl}$. Multiple cranial nerve entrapment due to hyperostosis has caused progressive functional losses: around the age of 10 she presented with bilateral successive facial nerve palsies. In her early 20s, a right-sided sudden deafness occurred (typically during pregnancy; hormonal influences are often seen in $\mathrm{HCl}$, presumably perineural oedema causes sudden nerve entrapment), whereas her left-sided deafness was slowly progressive. She underwent right optic nerve decompression at the age of 37 because of deteriorating vision with pre-existing optic neuropathy. Her senses of smell and taste are completely lost. Moreover, she suffers from episodes of stabbing headaches.

Fundoscopy revealed optic atrophia at the right side and no abnormalities at the left side. Ocular pressure was $16 \mathrm{mmHg}$ at the right and 24 at the left side. Facial nerve 
function was scored as grade 4 at both sides according to the House Brackmann scale. Pure tone audiometry revealed complete bilateral deafness. Otoacoustic emissions were absent. Calorisation of the vestibular apparatus showed bilateral areflexia of the lateral semicircular canals.

Computed tomography revealed profound endosteal hyperostosis and osteosclerosis of the calvaria and the base of skull. The porus of the internal auditory canals were obliterated. The labyrinth and the middle ear were not affected. Additional magnetic resonance revealed obstruction of the cerebellopontine cisterns and a decreased amount of cerebrospinal fluid surrounding the brainstem at the level of the foramen magnum and the posterior fossa (Figure 10.1).

It was decided to place an auditory brainstem implant for auditory rehabilitation, because of severe communicative impairment. The procedure was performed at the left side because the duration of auditory deprivation at this side had been shorter.

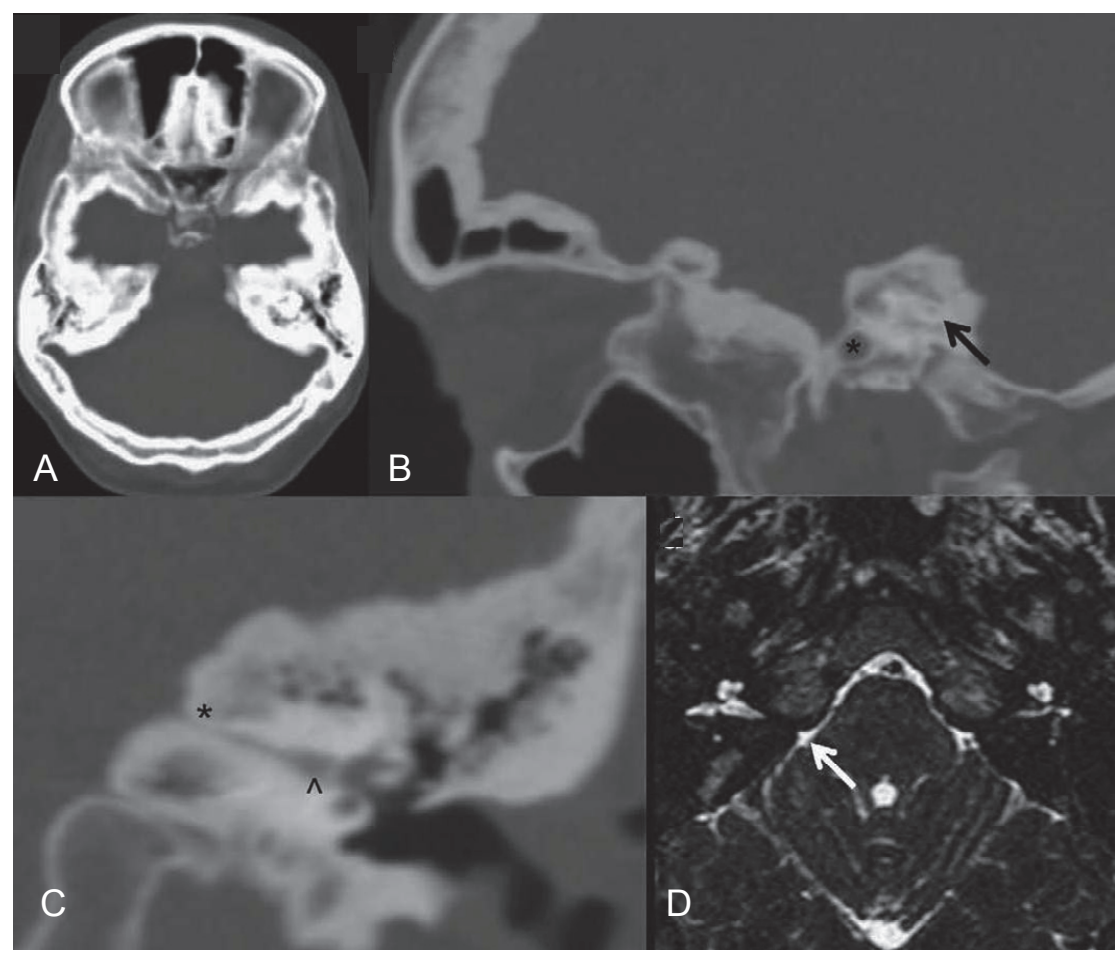

Figure 10.1 (A) Preoperative axial CT image: remarked endosteal hyperostosis of the petrous bone and the skull surrounding the temporal lobes, as well as the ethmoid area. (B) Sagittal reconstruction of the right middle and frontal skull base. The arrow indicates the former internal auditory canal. The carotid artery (asterisk) is not affected. (C) Coronal reconstruction of the left internal auditory canal, showing a patent fundus (arrow head) and stenotic porus at its maximal diameter (asterisk). (D) T2-weighted axial MRI image: obliterated internal auditory canal (arrow) and limited space for cerebrospinal fluid surrounding the brainstem and the cerebellum. 


\section{Intervention}

During the procedure, facial nerve and glossopharyngeal nerve function monitoring were used (NIM-2 XL Nerve Integrity Monitoring System, Medtronic, Minneapolis, USA), as well as neuronavigation (Medtronic Surgical Navigation Technologies, Louisville, CO, USA).

A retrosigmoidal approach was used. The dura was very adherent to the thickened skull, causing some bleeding from the sigmoid sinus which could easily be stopped. Subsequently, the arachnoid was opened and the cerebellum was retracted. The basal cistern was opened leading to optimal exposition of the extremely narrow cerebellopontine angle. The medial part of the internal auditory canal could be identified, using the neuronavigation. The vestibulocochlear, facial and lower cranial nerves were identified. There was no excessive blood loss. A Nucleus 24 ABI (Cochlear ${ }^{\mathrm{TM}}$, Sydney, AUS) was inserted into the lateral recess of the fourth ventricle adjacent to the dorsal cochlear nucleus with good intraoperative electrically-evoked auditory brainstem responses.

\section{Postoperative course}

Immediately postoperatively the patient reported increased headache and nausea which improved after the administration of dexamethasone. Discharge followed one week postoperatively in a fair to good overall clinical condition. However, ten days postoperatively, she developed a state of confusion, agitation and impaired coordination. There was disorientation in time, place and person. Photophobia and meningismus were present. Further neurological examination revealed a left-sided Babinski plantar response. A CT scan revealed generalised cerebral oedema. Furthermore, bifrontal and biparietal hypodense areas and focal patchy enhancement after intravenous contrast administration were seen (Figure 10.2). The differential diagnosis was meningitis, cerebritis or diffuse infarction. There is no suspicion for sinus thrombosis or subarachnoidal haemorrhage.

Two weeks postoperatively she develops a paralysis of the right leg and a paresis of the right arm (grade IV) along with urinary incontinence. Because of these sudden focal neurological symptoms, cerebral vasospasm is considered clinically. Headache, lethargia, disorientation and meningismus supported this diagnosis. MR angiography was relatively contraindicated because of the brainstem implant and would cause major artifacts due to the magnet. CT angiography was performed. The hypodense areas were unchanged. The circle of Willis and the anterior and medial cerebral arteries were very thin and fragile, compatible with diffuse cerebral vasospasm (Figure 10.3). There seemed to be a combined anterior ( $A C A)$ and middle cerebral artery (MCA) syndrome, leading to incontinence and confusion (ACA) and paresis (MCA). Transcranial Doppler was impossible due to the thickness of the skull. The patient was treated with nimodopine and hypertensive treatment (volume expansion and catecholamines). 


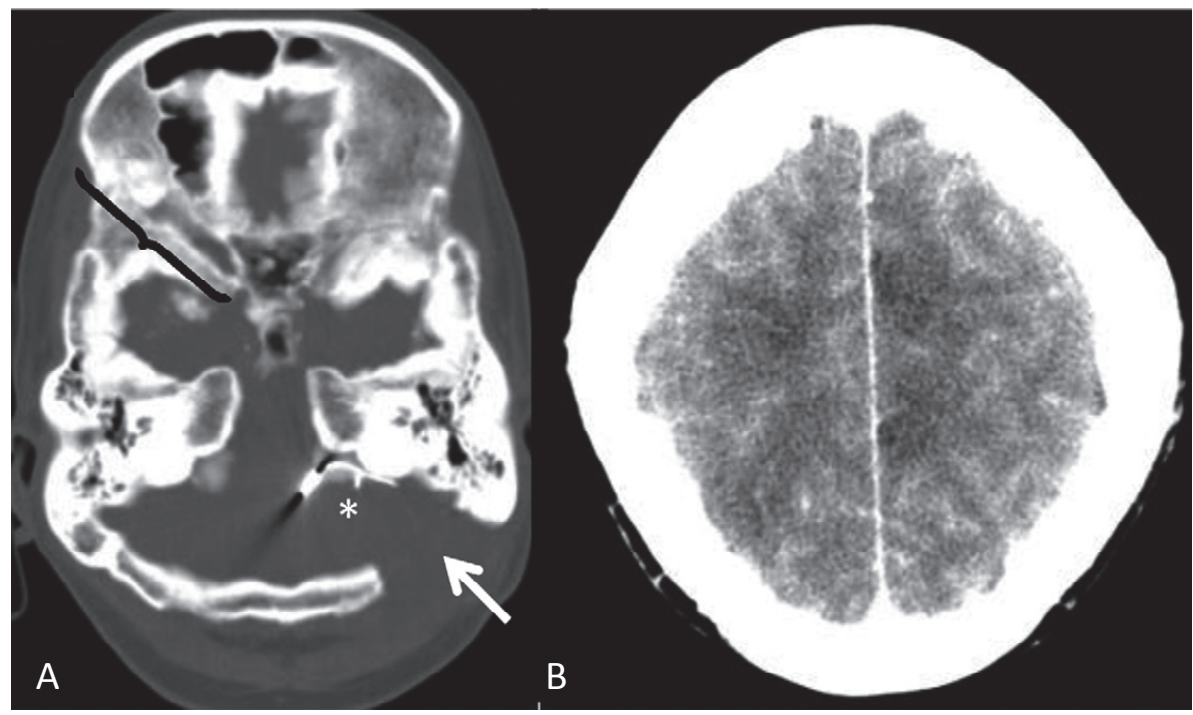

Figure 10.2 (A) Postoperative $C T$ scan of $A B I$ (asterisk) and the retrosigmoidal trepanation (arrow). The brace demonstrates the operation defect of the optic canal decompression. (B) Patchy cerebral enhancement with hypodense parietal areas.

Due to the intensive physical rehabilitation the first fitting session was postponed for 2 months. Out of 21 electrodes, 4 electrodes caused a pure somatosensory response, 2 caused an unpleasantly loud auditory response, and 5 caused a mixed auditory and somatosensory response at higher stimulation levels. 10 electrodes with various pitch and loudness levels were switched on.

One year after the incident, independent walking was still impossible and fine motor skills of the upper extremity were limited. The results of the auditory implant are subjectively excellent, and objectively good. Six months after implantation free-field tone thresholds are $40 \mathrm{~dB}$. She scored 60 to $85 \%$ on a close-set speech test and is reluctant to remove the speech processor at night. 


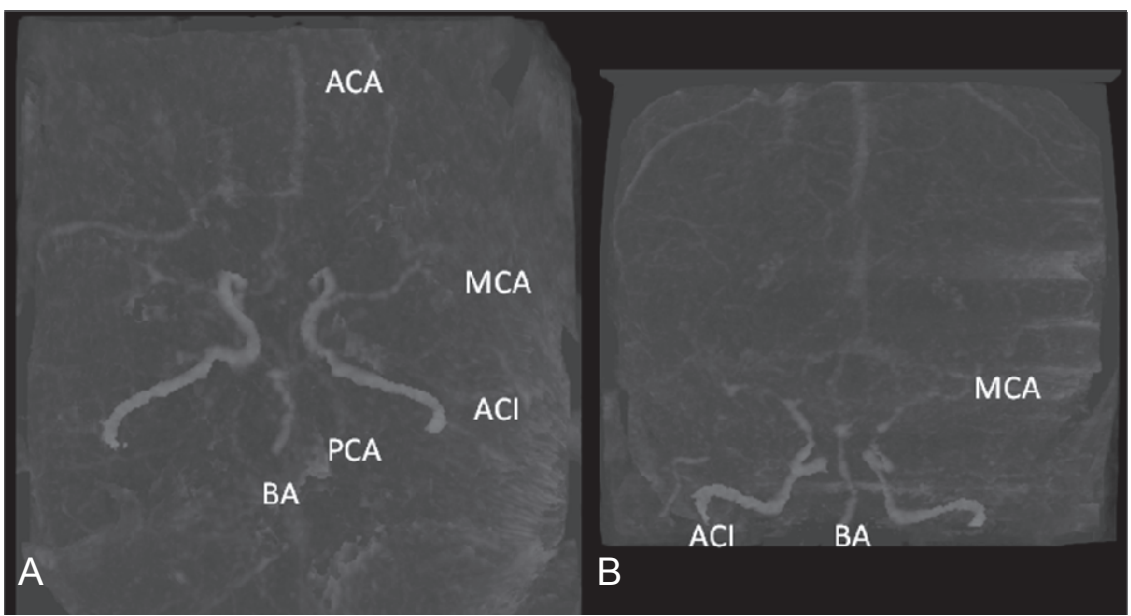

Figure 10.3 Postoperative transversal (A) and coronal (B) CT arteriographic 3D-reconstruction of the intracranial arteries. In contrast to the internal carotid arteries (ACI) and the basilar artery (BA), the middle cerebral (MCA) and the anterior cerebral arteries (ACA) have a smaller calibre than expected suggesting cerebral vasospasms.

\section{Discussion}

In this paper we report on diffuse cerebral vasospasm after auditory brainstem implantation for the first time in literature. Cerebral vasospasm occurs most frequently as a result of subarachnoid haemorrhage (SAH), usually between 6 and 8 days after haemorrhage ${ }^{5}$. The presence of vasoactive blood substances and nitric oxide in the basal cisterns are thought to enhance vasospasms in the case of $\mathrm{SAH}^{6}$.

Cerebral vasospasm after intracranial surgery is a very rare complication, of which the exact pathogenesis is only partially understood. Hypotheses of risk factors are postulated in an extensive review by Almubaslat ${ }^{7}$. Vasospasm after tumour resection has been reported after craniopharyngioma resection ${ }^{8}$, transsphenoidal hypophysectomy ${ }^{9}$, vestibular schwannoma and cranial base (posterior fossa) meningioma resection ${ }^{10,11}$. In a large retrospective study of 470 cranial base tumour resections, cerebral vasospasm was reported 9 times, an incidence of $1.9 \%{ }^{12}$.

Risk factors can be roughly divided into mechanical or biochemical aetiology. Mechanical risk factors were found to be large tumour size, extensive operative time and vessel encasement ${ }^{13}$. Direct vascular damage to the arterial wall during surgery, mainly in (supra)sellar surgery is postulated ${ }^{13}$. Possible biochemical aetiologies of vasospasm after brain surgery are partially analogous to the pathogenesis of vasospasm after SAH (blood products in the basal cisterns). Moreover, liberation of vasoactive substances during intracranial tumour removal ${ }^{14,15}$ and a disturbed level of 
cathecholamines after pituitary or hypothalamic surgery ${ }^{16}$ are mentioned as causative factors. The stress of surgery in general is supposed to change the vascular tone due to prostaglandins, although this evidence is not strong ${ }^{17}$. A delayed onset of vasospasm after mechanical stress can be caused by chemoactive substances released by the surrounding tissue ${ }^{18}$.

The reason for postsurgical vasospasm presented in this report is peculiar because the operation is not in proximity of the suprasellar area. There has been no intraoperative cisternal bleeding. The craniotomy in our severe hyperostotic patient mimics a decompressive craniotomy, causing significant tissue shifting. Intracranial pressure changes occur along with changes in vascular tone. This change in vascular tone could be responsible for vasospasm induction. Furthermore, analogous to decompression of Chiari-I malformation, there is a sudden increase of cerebrospinal fluid (CSF) velocity as well as intracranial compliance because the cisterns are not longer obstructed ${ }^{19,20}$. Although in our patient the intracranial pressure is not quantified (lumbar puncture is contraindicated due to the risk of brainstem herniation), intraoperative findings suggest increased pressure due to the hyperostotic skull. An impressed dura mater and bulging of the cerebellum after opening the dura mater were observed.

Cerebral vasospasm has never been published after craniotomy of a severe hyperostotic skull nor after auditory brainstem implantation before. This complication should be suspected in case of delayed deterioration of the neurologic condition of a patient, particularly with coexistence of focal neurologic deficits. Upon planning surgery, one must be aware of the distorted anatomy in a patient with a hyperostotic skull and of the changes that occur in CSF dynamics after decompression of the brain. If, in the future, we were to perform a retrosigmoidal craniotomy in such a patient, we would consider closing the craniotomy without the trepanated skull. A retrosigmoidal approach has been chosen to maximise exposition of the pontocerebellar cistern and to perform optimal decompression. Although generally retrosigmoidal and translabyrinthine approach have equal results, in this case a translabyrinthine approach would not have caused unnecessary cerebellar traction, whereas the afunctional inner ear structures can be sacrificed without consequences. In advance we had waived the option to perform a cochlear implant, because of the longstanding complete function loss of both the vestibular and cochlear nerves. Prior to cochlear implantation, decompression of the internal auditory canal via middle fossa approach would have been necessary. One could argue that internal canal decompression could have been favourable for the facial nerve as well and - if cochlear implantation would not have led to a satisfactory audiological result - auditory brainstem implantation would still have been possible. Promontory tests could have been useful to choose between auditory brainstem or cochlear implantation after internal auditory canal decompression. There is one report about successive internal auditory canal decompression and cochlear implantation in Camurati-Engelmann disease, however the patient still had minimal residual hearing a normal facial nerve function ${ }^{21}$. 


\section{References}

1. Lesinski-Schiedat A, Frohne C, Illg A, Rost U, Matthies C, Battmer RD, Samii M, Lenarz T. Auditory brainstem implant in auditory rehabilitation of patients with neurofibromatosis type 2: Hannover programme. J Laryngol Otol Suppl 2000:15-17.

2. Colletti V, Shannon R, Carner M, Veronese S, Colletti L. Outcomes in nontumor adults fitted with the auditory brainstem implant: 10 years' experience. Otol Neurotol 2009;30:614-618.

3. Manni JJ, Scaf JJ, Huygen PL, Cruysberg JR, Verhagen WI. Hyperostosis cranialis interna. A new hereditary syndrome with cranial-nerve entrapment. N Engl J Med 1990;322:450-454.

4. Waterval JJ, Stokroos RJ, De Bondt RB, Manni JJ. Facial nerve decompression via middle fossa approach for hyperostosis cranialis interna: a feasible therapeutic approach. J Laryngol Otol 2009:1-4.

5. Weir B, Grace M, Hansen J, Rothberg C. Time course of vasospasm in man. J Neurosurg 1978;48: 173-178.

6. Kistler JP, Crowell RM, Davis KR, Heros R, Ojemann RG, Zervas T, Fisher CM. The relation of cerebral vasospasm to the extent and location of subarachnoid blood visualized by CT scan: a prospective study. Neurology 1983;33:424-436.

7. Almubaslat $\mathrm{M}$, Africk $\mathrm{C}$. Cerebral vasospasm after resection of an esthesioneuroblastoma: case report and literature review. Surg Neurol 2007;68:322-328; discussion 328.

8. Sutton LN. Vascular complications of surgery for craniopharyngioma and hypothalamic glioma. Pediatr Neurosurg 1994;21 Suppl 1:124-128.

9. Camp PE, Paxton HD, Buchan GC, Gahbauer H. Vasospasm after trans-sphenoidal hypophysectomy. Neurosurgery 1980;7:382-386.

10. Kusunose M, Fukuda O, Saito T, Takaku A, Endo S. [Diffuse cerebral artery vasospasm following total resection of posterior fossa meningioma: a case report]. No Shinkei Geka 1997;25:953-957.

11. LeRoux PD, Haglund MM, Mayberg MR, Winn HR. Symptomatic cerebral vasospasm following tumor resection: report of two cases. Surg Neurol 1991;36:25-31.

12. Bejjani GK, Sekhar LN, Yost AM, Bank WO, Wright DC. Vasospasm after cranial base tumor resection: pathogenesis, diagnosis, and therapy. Surg Neurol 1999;52:577-583; discussion 583-584.

13. Aoki N, Origitano TC, al-Mefty O. Vasospasm after resection of skull base tumors. Acta Neurochir (Wien) 1995;132:53-58.

14. Duff TA, Feilbach JA, Yusuf $Q$, Scott G. Bilirubin and the induction of intracranial arterial spasm. J Neurosurg 1988;69:593-598.

15. Mawk JR. Vasospasm after pituitary surgery. J Neurosurg 1983;58:972.

16. Wilkins RH. Hypothalamic dysfunction and intracranial arterial spasms. Surg Neurol 1975;4:472-480.

17. Maeda Y, Tani E, Miyamoto T. Prostaglandin metabolism in experimental cerebral vasospasm. J Neurosurg 1981;55:779-785.

18. Nilsson B. Vasospasm and the pathophysiology of concussive head injury. In: Wilkins R, editor. Cerebral arterial spasm. Baltimore, London: Wiliams \& Wilkins; 1980:488-495.

19. Alperin N, Sivaramakrishnan A, Lichtor T. Magnetic resonance imaging-based measurements of cerebrospinal fluid and blood flow as indicators of intracranial compliance in patients with Chiari malformation. J Neurosurg 2005;103:46-52.

20. Sivaramakrishnan A, Alperin N, Surapaneni S, Lichtor T. Evaluating the effect of decompression surgery on cerebrospinal fluid flow and intracranial compliance in patients with chiari malformation with magnetic resonance imaging flow studies. Neurosurgery 2004;55:1344-1350; discussion 1350-1351.

21. Tibesar RJ, Brissett AE, Shallop JK, Driscoll CL. Internal auditory canal decompression and cochlear implantation in Camurati-Engelmann disease. Otolaryngol Head Neck Surg 2004;131:1004-1006. 
General discussion, summary and addendum

(n)

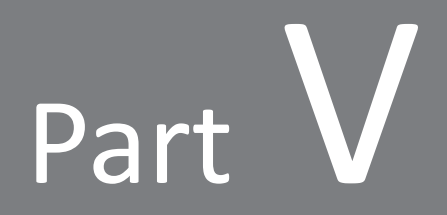 \\ Part V

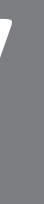

(1)

General discussion, summary and addendum

$x^{2}$

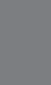

,

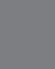




\section{Chapter 11}

General discussion, conclusions and future perspectives 
Chapter 11 


\section{General discussion and conclusions}

\section{Concerning pathogenesis}

The unique feature of hyperostosis cranialis interna $(\mathrm{HCl})$ is that there is intracranial hyperostosis and bone alteration only in the skull base and the calvarial bones and, to a lesser extent, in a localised area of the mandible. The rest of the skeleton and even the rest of the facial bones are not affected. There can only be speculated about the pathogenetic mechanism until the exact genetic and molecular basis of the disease have been uncovered. In some way processes must be going on in this areas of bone or adjacent tissue which do not occur elsewhere in the human body. In chapter 2 the embryology of the skull and skull base are discussed with emphasis on the type of bone formation, endochondral and intramembranous ossification. It seems logical to suspect a defect in one of these mechanisms, however they are both affected - so indirectly it can be concluded that there is no direct causal relationship with the type of ossification. One can look at ossification - and a defect mechanism of it - from another perspective: bone grows, remodels and regenerates in function of growth factors. The most important growth factors for bone are the bone morphogenetic proteins (BMPs). BMPs belong to the transforming growth factor $\beta$ superfamily. BMPs play an important role in the embryonic development of bone, postnatal growth and adult remodelling of bone $^{1}$. Involvement of BMP1 - one BMP in the candidate region has been excluded (chapter 8) $)^{2}$.

The expression of the growth factors is different in various parts of the skull and is also different during different stages of development. A lot of research on this subject has been performed after it has been observed that juvenile mammals (also humans) are able to regenerate calvarial defects, whereas adult animals lack this capacity. The first report on this topic was already published in $1979^{3,4}$. Many substances of the healing calvarial complex have been suggested ever since as being important regulators of this age-related difference in regenerative capacity. Examples of growth factors that were found in altered concentrations in juvenile calvaria are Runx2, BMP-2, BMP-4, BMP-7 and pleiotrophin ${ }^{5-7}$.

Mabbutt demonstrated in 1979 that regeneration of calvarial bone not only occurred from the margins, but also newly deposited bone appeared in the middle of the calvarial defect of the neonatal rabbits ${ }^{4}$. This suggested - apart from the regenerating capacity of neighbouring bone - also bone regeneration capacity of other adjacent structures (Figure 11.1). A regulatory role for the dura mater and the pericranium was proposed. A defect in this mechanism could play a role in the pathogenesis of $\mathrm{HCl}$, however some affected structures (mandible, stylomastoid process) are not adjacent to the dura mater at all. 

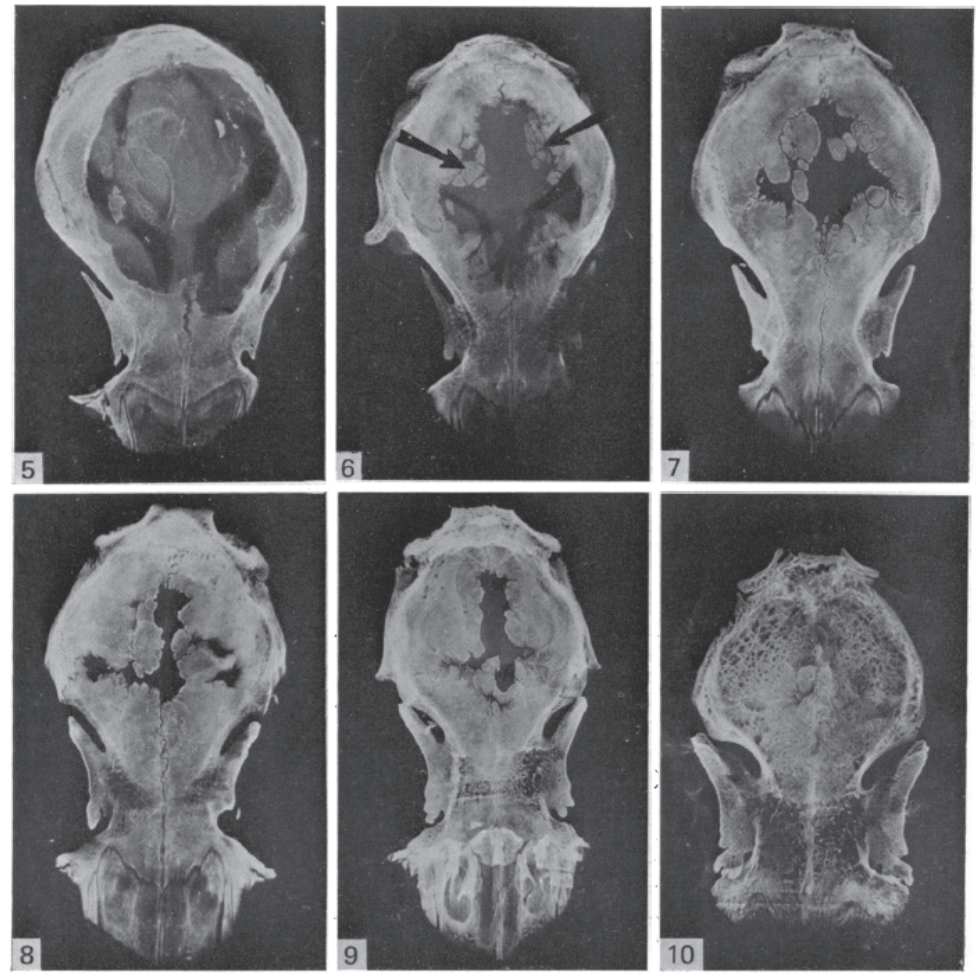

Figure 11.1 Radiographs from Mabbutt's study in 1979 of craniectomised neonatal rabbits showing gradual osteoneogenesis from both the dissection margins as well as adjacent to the margins ${ }^{4}$. Photo 6 $=$ at 2 weeks, photo $8=$ at 8 weeks, photo $9=$ at 12 weeks and photo $10=$ at 26 weeks.

In 1981 Takagi demonstrated that iatrogenic calvarial defects in rats, not healing spontaneously, healed after being filled with a bovine BMP fraction (note: different types of BMP were not yet discovered at that time) ${ }^{8}$. Again, there was not only ingrowth from the bony edge of the trepanation, but also proliferation of perivascular mesenchymal-type cells (pericytes) of the dura mater. Under the influence of BMP, dural pericytes differentiated into chondroid and woven bone. Similar studies in the 80s have been performed in monkeys, sheep and dogs ${ }^{9-11}$.

A defect in one of the regulatory mechanisms of bone differentiation/growth in the skull seems plausible in the case of $\mathrm{HCl}$. This mechanism could either be paracrine (cell reaction to a locally increased concentration of a substance) or juxtacrine (contactdependent signalling). 


\section{Concerning clinical care}

\section{Diagnosis}

\section{(Family) history, physical examination}

There is a reason for each doctor's visit. Recurrent and especially familial occurring facial palsy should draw attention to $\mathrm{HCl}$ or another (skull base) bone dysplasia. All cranial nerves should be tested in this case, of course also in the light of other diseases in the differential diagnosis. In case of familial occurrence, the age of onset, variance of severity and sex differences should be asked for to get an idea of possible inheritance pattern and possibly incomplete penetrance.

Dozens of causes of (bilateral or recurrent) facial palsies have been reported (see overview in the article of Oosterveer and also in the introduction of this thesis ${ }^{12}$. However, often the palsy remains idiopathic in many patients who have recurrent facial palsy $(84 \%)^{13}$ or bilateral facial palsy ${ }^{14}$. There have been studies about familial clustering of Bell's palsy ${ }^{15-18}$. Serology of neurotropic pathogens should definitely be investigated in every case.

\section{Imaging and skeletal survey}

Imaging is indicated in case of deterioration of the palsy despite treatment with steroids and in case of recurrent and familial facial palsy. CT imaging is the gold standard in case structural bone abnormalities are suspected. MR imaging shows possible neuritis, neural oedema, soft tissue abnormalities or osteomyelitis. In case of (suspicion of) a bone dysplasia a complete skeletal survey is mandatory, also in children.

The calvarial and skull base abnormalities will not be discussed again as they have been extensively discussed in chapter 5 . The changes in the mandible, detected during the radiological study, deserve some attention here. They have been observed in all adult patients of the family (except for one, of whom CT images of the mandible are not available, individual III-1), whereas (affected) children and unaffected adults do not have any mandibular abnormalities. It is tempting to involve this torus mandibularis in the phenotype of $\mathrm{HCl}$, especially because unaffected family members do not display this variant.

However, torus mandibularis (and also torus palatinus) do also exist as an anatomical variant on its own, sometimes in hereditary form ${ }^{19,20}$, with a prevalence of approximately $15 \%$ and even much higher in certain ethnic groups, up to $68 \%$ in Icelanders and $85 \%$ in Inuit $^{19,21,22}$, almost never in children ${ }^{22}$. Torus mandibularis is described as cortical exostoses formed by dense cortical and limited amount of bone marrow, located on the internal side of the horizontal branch of the mandible, above the mylohyoid line and at the level of the premolar or the canine area (which is the case 
in $\mathrm{HCl})^{23}$. It has been proposed that these exostoses occur by osteogenesis due to the stimulation of dormant osteoblasts and pluripotential cells from the inner layer of the periosteum after microtrauma of the periosteum ${ }^{24,25}$.

\section{Genetic testing}

Even though the diagnosis can be established by CT once abnormalities become visible, it is also possible to set the diagnosis with genetic testing, since the discovery of the disease-causing region on chromosome $8 \mathrm{p} 21$ and more specifically since the detection of the mutation in the ZIP14 gene, which is most probably responsible for the disorder. Genetic testing can be important, for example, for counselling reasons or if there is uncertainty about the diagnosis upon CT images. In general, genetic testing in asymptomatic patients is not favoured, for the simple fact that a positive diagnosis makes the subject a patient all of a sudden. Parents, however, often insist on knowing the faith of their child. Besides, early diagnosis in the presymptomatic phase gives more time to prepare the parents on the major implications and possible surgical interventions that might follow. This is a typical example of tailored medicine which has to be done in dialogue with the patient and/or the parents.

Genetic testing during pregnancy would also be possible, however this has not yet been performed. All patients of the family have been informed about this possibility. We have discussed the ethical aspects of this possibility with the colleagues of the Department of Genetics in the Maastricht University Medical Center. The preliminary conclusion is that before any type of invasive testing is to be performed, extensive counselling of the parents by both geneticist and physician would have to take place. The parents have to be informed extensively about the burden of a child with this disorder, and at the other side the capacity of the parents to deal with the possibly related problems in case their child is affected needs to be assessed. Also if prenatal diagnostics are considered (i.e. amniocentesis), obviously the goal and the potential risks of the procedure should also be discussed by the geneticist.

\section{Treatment}

Of course, one of the goals of this thesis is to elaborate possible treatment options in order to be able to support and counsel the affected patients. Unfortunately, the section with possible treatment options for this disorder is limited. Treatment cannot be standardised due to the different course and severity of the disease in different patients. We do think that centralising care for the patients and check them regularly is one of the key points we have learned. Patients become familiar with the disease, get educated about important symptoms and on the other hand, the doctors get insight in the course of a particular individual. The physician can gradually inform the patient and prepare for what might be coming in the future.

Until now, treatment is only supportive and symptomatic. Since the detection of the area of the genetic defect it is possible to diagnose the disease with certainty in the 
presymptomatic period. In our experience, the parents greatly appreciate the possibility to be informed about this. We provided ample counselling to the parents after the diagnosis was made. Information about anatomy, possible related symptoms, the need for regular check-up as well as imaging and possible treatment options gives parents and patients insight in the disease.

The most common presenting symptom is facial nerve palsy, generally occurring in the first or second decade. This has a very high impact on both the patient as well as parents. Initial treatment with steroids is indicated to decrease what is thought to be perineural oedema. Imaging should then give insight in the exact location of facial nerve compression. Compression in the first intratemporal part of the facial nerve is observed most often, more specifically the porus of the internal auditory canal. If the skull base anatomy is not too much distorted, internal auditory canal decompression is a good option and facial nerve function recovery is observed in our case (chapter 9). If hearing deterioration due to porus compression would be the first presenting symptom, the same treatment would be suitable. We have one case of (left) facial palsy in a 5-year-old girl with only minor abnormalities at the level of the skull base. Probably the compression takes place in the labyrinthine part of the facial nerve (osteosclerosis in this area); the child has normal hearing. It was considered too dangerous for the hearing to decompress the nerve in this part.

Nerve compression in the third part of the intratemporal course of the facial nerve has not been documented in $\mathrm{HCl}$, but should not be overlooked. Bone deposition in this area is possible as well and facial nerve decompression at this level in would be less dangerous.

Later on in life, symptoms tend to be less predictable, largely depending on the severity and location of the hyperostosis. Several individuals in the family have longstanding facial palsies. Facial nerve function tends not to deteriorate during life. Late facial nerve decompression is not considered because functional improvement is not expected due to neural degeneration. Most often - in older patients - hearing decreases gradually and only rarely suddenly. Hearing aids can be opted for if speech discrimination is adequate.

In case of severe to profound bilateral sensorineural hearing loss conventional acoustic hearing aids will not be sufficient. Two options can be thought of: cochlear implantation and auditory brainstem implantation. Cochlear implantation will most probably not be feasible due to the dysfunctional cochlear nerve at the level of the internal auditory canal, especially in case of longstanding auditory deprivation. However, if the deafness is not longstanding and is (probably) due to the internal auditory canal, decompression can be opted for. If the hearing does not recover and there is cochlear nerve integrity (upon auditory brainstem response or promontory stimulation) cochlear implantation can be performed. This procedure has been performed successfully in a patient with Camurati Engelmann disease ${ }^{26}$. If the nerve is not functional, an auditory brainstem implant can be considered. However, the risks of 
the operation - especially due to the disturbed anatomy of the posterior fossa and the altered cerebrospinal fluid dynamics should be weighted against the benefits of gain of hearing ${ }^{27}$. Detection of sound or maybe closed set speech recognition are the maximal audiological results, as discussed in chapter 10 .

The two previous subparagraphs illustrate the dilemma of treatment timing. Ideally surgical treatment is performed not long after beginning of the symptoms, because of the reversibility of the nerve function. The disadvantage of late internal auditory canal decompression could be a difficult anatomy with the extra risk of labyrinth damage. Moreover problems related to cerebrospinal fluid circulation are more realistic if the operation is performed at later age, when the intracranial volume is limited due to hyperostosis. On the other hand, patients must be prepared for major surgical interventions, especially in the light of the possible complications.

Pain due to trigeminal neuropathy is treated in a similar way as classical trigeminal neuralgia. Carbamazepine, oxcarbazepine, gabapentin and opioids play a role in the medical treatment, which should be tailored in cooperation with an anesthaesiologist/pain specialist. Pain is often replaced by numbness after a period of time. In case of insufficient effect of medical treatment there might be role for radiofrequency thermocoagulation of the gasserian ganglion. This treatment is only an option if the foramen ovale is reasonably patent. If this is not the case, gamma knife radiosurgery could be an option.

Optic nerve integrity monitoring is decribed in detail in chapter 4. Summarised, we favour surgical decompression of the optic nerve in two circumstances: in the first place in case of (sub)acute vision loss with proven radiographic optic canal encroachment. Furthermore we opt for decompression in case of significant deterioration of neurophysiologic parameters (visual evoked potentials), of course with radiological proof of optic canal narrowing.

The lower cranial nerves are not affected, not even in the most severely affected patients. If there should be dysfunction of cranial nerves IX-XI, an MRI of the posterior should be made to check for Arnold-Chiari malformation. Whether the detected Arnold-Chiari malformation has clinical implications can be investigated by means of functional MRI: 4D-phase contrast imaging ${ }^{28,29}$. With this technique cerebrospinal fluid dynamics can be visualised. In case of a symptomatic and radiologically confirmed Arnold-Chiari malformation, a foramen magnum decompression should be performed.

Disputable is the coincidence of Arnold-Chiari malformation and trigeminal neuralgia. There has been at least one patient with trigeminal neuralgia without significant hyperostosis at the level of the gasserian ganglion or the level of the superior orbital fissure $\left(\mathrm{NV}_{1}\right)$ and the neuroforamina $\left(\mathrm{NV}_{2}\right.$ and $\left.\mathrm{NV}_{3}\right)$. In this patient, who was treated in another center, the trigeminal neuralgia resolved after a foramen magnum decompression. She had an Arnold-Chiari malformation with concurrent nausea and 
headaches. Before, the patient had been treated medically and with radiofrequency thermocoagulation (for her trigeminal neuralgia), without success.

The association between Arnold-Chiari malformation and trigeminal neuralgia was first suggested by neurosurgeon Walter Dandy ${ }^{30}$. In 2008, this topic was elaborated by Papanastassiou et al. reviewing the 19 cases in literature with this combination treated with foramen magnum decompression ${ }^{31}$. Several mechanisms have been proposed how Chiari malformation can cause trigeminal neuralgia, such as demyelinisation of the nerve due to stretching of the nerve and vascular compression at the root entry zone of the nerve.

Generalised headache is also observed in patients with severe hyperostosis. Most probably, this is a direct symptom of increased intracranial pressure. Ophthalmologic examination should be performed to rule out papilloedema. A lumbar punction to evaluate the intradural pressure is absolutely contraindicated because there is a potential risk of cerebellar tonsillar herniation. Intracranial hypertension can be treated with acetazolamide, especially in older patients when the hyperostosis is not likely to progress anymore. In younger patients, a decompressive craniotomy should be performed. If there is a concurrent Arnold-Chiari malformation, it should of course be a foramen magnum decompression. The most extensive description of a series of decompressive craniotomies for increased intracranial pressure due to cranial hyperostosis is published by Du Plessis in $1993^{32}$. The paper describes the treatment in patients with sclerosteosis, which - with calvarial bone up to $4 \mathrm{~cm}$ thick - has a much more severe course than $\mathrm{HCl}$. The most important advice is that in case of increased intracranial pressure due to extreme hyperostosis decompression should be performed in a staged and downward fashion: first a bifrontal or bifrontotemporal craniotomy, later a posterior fossa decompression. Two cases in which posterior fossa decompression was performed without supratentorial decompression died because of downward migration of the medulla oblongata. It should be noted that this is not expected in $\mathrm{HCl}$ because the hyperostosis is less extensive.

\section{Future perspectives}

Obviously it is important for patients to unravel the cause and the pathophysiology of any unknown disease, even when there is only one affected family. Because of the effort of the whole team the course of the disease is now better understood and the causal gene region on chromosome 8 p21 has been discovered (chapter 8 and addendum). It is however comprehensible that one questions the need of further investigations of a rare disease knowing that this does probably not lead to a new or causal treatment. Critics might weigh expenses of research against the (short-term) benefits. Well, it is the collaboration with the department of Medical Genetics of the University of Antwerp that proofs the opposite. We do believe that it is important for 
any patient as well as the treating physician to be informed about the nature of a disease. Besides, sometimes it is only because of the discovery of the pathogenesis of rare disorders like $\mathrm{HCl}$ that the complex physiology of normal (bone) metabolism is better understood or can it be a key to the development of treatment options. A promising example is the discovery of the exact mechanism of the SOST-related bone dysplasias, causing disorders with generalised excessive bone formation. It is expected that drugs interacting with this mechanism become a cornerstone in the treatment of osteoporosis in the nearby future.

As the clinically oriented research on $\mathrm{HCl}$ is now more or less completed, the road is cleared for the focus on genetic and biochemical studies after the discovery of the causal $\mathrm{HCl}$ gene on chromosome 8 by the Antwerp group. We hope to stay involved sideways in the ongoing research of this fascinating disorder and to provide clinical feedback whenever necessary. The unpublished data are part of the PhD thesis of colleague Vere Borra and are brought up as addendum in this thesis. Without the clinical research this study could not have been performed. This study is added to the thesis as addendum, ensuring all available information on $\mathrm{HCl}$ is provided.

With exome sequencing a mutation was discovered in the ZIP14 gene (also known as SLC39A14), encoding for a transmembrane protein (see addendum). The ZIP14 protein serves as a zinc transporter ${ }^{33-35}$ and is mostly expressed in liver, pancreas and heart tissue $^{36}$. Whereas its function in bone metabolism is not yet clarified, ZIP proteins generally promote zinc transport from extracellular fluid or intracellular vesicles into the cytoplasm. ZIP14 is expressed in osteoblasts and preosteocytes, but not in osteoclasts, suggesting the protein plays a role in bone formation rather than bone resorption. In this study it is proven in an in vitro setting that the mutation prevents the transporter protein from expressing at its usual site at the cell membrane. Instead it accumulates in the cytoplasm and in the nucleus, leading to impaired transport of zinc into the cell. A KS483 cell lineage has been used: murine preosteoblastic progenitor cells.

Human and mouse Zip14 are highly conserved. To investigate the phenotype in an animal model, ZIP14 wildtype mice $\left(\right.$ Zip14 $\left.^{+/+}\right)$and ZIP14 knock-out mice (Zip14 ${ }^{-/}$) have been developed. There is an obvious relation of ZIP14 with bone formation as knocking out the ZIP14 gene causes growth retardation measured with micro-CT, confirming the results of an earlier conducted study ${ }^{37}$. However, this genotype has no visible influence on the craniofacial skeleton.

The next phase of the study is a mouse model overexpressing the mutant Zip14 protein (instead of knocking in or out the entire protein) to get more insight in how the identical mutation affects (craniofacial) bone metabolism and subsequent growth.

We hope that gradually we gain more insight in the pathogenesis of the disorder. Eventually there has to be an answer to the riddle why there is only locally disturbed bone metabolism: does the mutant protein bind to another protein, which is specifically expressed in the skull? Is there a relation with the locally expressed 
signalling proteins - by the dura mater - involved in growth of the skull? Once the mechanism of this site-specific disturbance is known, the question remains whether this leads to the development of site-specific pharmacological therapy? 


\section{References}

1. Chen D, Zhao M, Mundy GR. Bone morphogenetic proteins. Growth Factors 2004;22:233-241.

2. Borra VM, Waterval JJ, Stokroos RJ, Manni JJ, Van Hul W. Localization of the gene for hyperostosis cranialis interna to chromosome 8p21 with analysis of three candidate genes. Calcif Tissue Int 2013;93: 93-100.

3. Aalami OO, Nacamuli RP, Lenton KA, Cowan CM, Fang TD, Fong KD, Shi YY, Song HM, Sahar DE, Longaker MT. Applications of a mouse model of calvarial healing: differences in regenerative abilities of juveniles and adults. Plast Reconstr Surg 2004;114:713-720.

4. Mabbutt LW, Kokich VG. Calvarial and sutural re-development following craniectomy in the neonatal rabbit. J Anat 1979;129: 413-422.

5. Aalami OO, Nacamuli RP, Salim A, Fong KD, Lenton KA, Song HM, Fang TD, Longaker MT. Differential transcriptional expression profiles of juvenile and adult calvarial bone. Plast Reconstr Surg 2005;115: 1986-1994.

6. Franceschi RT, Xiao G, Jiang D, Gopalakrishnan R, Yang S, Reith E. Multiple signaling pathways converge on the Cbfa1/Runx2 transcription factor to regulate osteoblast differentiation. Connect Tissue Res 2003;44 Suppl 1:109-16.

7. Yang X, Tare RS, Partridge KA, Roach HI, Clarke NM, Howdle SM, Shakesheff KM, Oreffo RO. Induction of human osteoprogenitor chemotaxis, proliferation, differentiation, and bone formation by osteoblast stimulating factor-1/pleiotrophin: osteoconductive biomimetic scaffolds for tissue engineering. J Bone Miner Res 2003;18:47-57.

8. Takagi K, Urist MR. The reaction of the dura to bone morphogenetic protein (BMP) in repair of skull defects. Ann Surg 1982;196:100-9.

9. Ferguson D, Davis WL, Urist MR, Hurt WC, Allen EP. Bovine bone morphogenetic protein (bBMP) fraction-induced repair of craniotomy defects in the rhesus monkey (Macaca speciosa). Clin Orthop Relat Res 1987:251-258.

10. Lindholm TC, Lindholm TS, Alitalo I, Urist MR. Bovine bone morphogenetic protein (bBMP) induced repair of skull trephine defects in sheep. Clin Orthop Relat Res 1988;227:265-268.

11. Sato K, Urist MR. Induced regeneration of calvaria by bone morphogenetic protein (BMP) in dogs. Clin Orthop Relat Res 1985:301-311.

12. Oosterveer DM, Benit CP, de Schryver EL. Differential diagnosis of recurrent or bilateral peripheral facial palsy. J Laryngol Otol 2012;126:833-836.

13. Navarrete ML, Cespedes R, Mesa M, Grasa J, Perez M, Raguer N, Fortuny P, Calderon R. [Recurrent Bell's facial palsy: our experience]. Acta Otorrinolaringol Esp 2001;52:682-686.

14. Keane JR. Bilateral seventh nerve palsy: analysis of 43 cases and review of the literature. Neurology 1994;44:1198-1202.

15. Amit R. Familial juvenile onset of Bell's palsy. Eur J Pediatr 1987;146:608-609.

16. Willbrand JW, Blumhagen JD, May M. Inherited Bell's palsy. Ann Otol Rhinol Laryngol 1974;83:343-346.

17. Doner F, Kutluhan S. Familial idiopathic facial palsy. Eur Arch Otorhinolaryngol 2000;257:117-119.

18. Yanagihara N, Yumoto E, Shibahara T. Familial Bell's palsy: analysis of 25 families. Ann Otol Rhinol Laryngol Suppl 1988;137:8-10.

19. Al-Bayaty HF, Murti PR, Matthews R, Gupta PC. An epidemiological study of tori among 667 dental outpatients in Trinidad \& Tobago, West Indies. Int Dent J 2001;51 300-304.

20. Sonnier KE, Horning GM, Cohen ME. Palatal tubercles, palatal tori, and mandibular tori: prevalence and anatomical features in a U.S. population. J Periodontol 1999;70:329-336.

21. Bruce I, Ndanu TA, Addo ME. Epidemiological aspects of oral tori in a Ghanaian community. Int Dent J 2004;54:78-82.

22. Rouas A, Midy D. About a mandibular hyperostosis: the torus mandibularis. Surg Radiol Anat 1997;19: 41-43.

23. Garcia-Garcia AS, Martinez-Gonzalez JM, Gomez-Font R, Soto-Rivadeneira A, Oviedo-Roldan L. Current status of the torus palatinus and torus mandibularis. Med Oral Patol Oral Cir Bucal 2010;15:e353-360.

24. Siegel WM, Pappas JR. Development of exostoses following skin graft vestibuloplasty: report of a case. J Oral Maxillofac Surg 1986;44:483-484. 
25. Hegtvedt AK, Terry BC, Burkes EJ, Patty SR. Skin graft vestibuloplasty exostosis. A report of two cases. Oral Surg Oral Med Oral Pathol 1990;69:149-152.

26. Tibesar RJ, Brissett AE, Shallop JK, Driscoll CL. Internal auditory canal decompression and cochlear implantation in Camurati-Engelmann disease. Otolaryngol Head Neck Surg 2004;131:1004-1006.

27. Waterval JJ, Stokroos RJ, Dings J, Van Overbeeke JJ, Manni JJ. Cerebral vasospasm after auditory brainstem implantation in a patient with hyperostosis cranialis interna. Clin Neurol Neurosurg 2011;113:904-908.

28. Bunck AC, Kroeger JR, Juettner A, Brentrup A, Fiedler B, Crelier GR, Martin BA, Heindel W, Maintz D, Schwindt W, Niederstadt T. Magnetic resonance 4D flow analysis of cerebrospinal fluid dynamics in Chiari I malformation with and without syringomyelia. Eur Radiol 2012;22:1860-1870.

29. Bunck AC, Kroger JR, Juttner A, Brentrup A, Fiedler B, Schaarschmidt F, Crelier GR, Schwindt W, Heindel $W$, Niederstadt T, Maintz D. Magnetic resonance $4 \mathrm{D}$ flow characteristics of cerebrospinal fluid at the craniocervical junction and the cervical spinal canal. Eur Radiol 2011;21:1788-1796.

30. Dandy W. Concerning the cause of trigeminal neuralgia. Am J Surg 1934;24:447-455.

31. Papanastassiou AM, Schwartz RB, Friedlander RM. Chiari I malformation as a cause of trigeminal neuralgia: case report. Neurosurgery 2008;63: E614-615.

32. du Plessis JJ. Sclerosteosis: neurosurgical experience with 14 cases. J Neurosurg 1993;78:388-392.

33. Liuzzi JP, Aydemir F, Nam H, Knutson MD, Cousins RJ. Zip14 (Slc39a14) mediates non-transferrin-bound iron uptake into cells. Proc Natl Acad Sci U S A 2006;103:13612-13617.

34. Taylor KM, Morgan HE, Johnson A, Nicholson RI. Structure-function analysis of a novel member of the LIV-1 subfamily of zinc transporters, ZIP14. FEBS Lett 2005;579:427-432.

35. Tominaga K, Kagata T, Johmura Y, Hishida T, Nishizuka M, Imagawa M. SLC39A14, a LZT protein, is induced in adipogenesis and transports zinc. FEBS J 2005;272:1590-1599.

36. Aydemir TB, Sitren HS, Cousins RJ. The zinc transporter Zip14 influences c-Met phosphorylation and hepatocyte proliferation during liver regeneration in mice. Gastroenterology 2012;142:1536-1546 e5.

37. Hojyo S, Fukada T, Shimoda S, Ohashi W, Bin BH, Koseki H, Hirano T. The zinc transporter SLC39A14/ZIP14 controls G-protein coupled receptor-mediated signaling required for systemic growth. PLoS One 2011;6:e18059. 
Summary 


\section{Summary}

Hyperostosis cranialis interna is a bone dysplasia which is confined to the skull. There is intracranial hyperostosis and osteosclerosis of the calvaria (skull cap) and the the skull base. The disease has an autosomal dominant inheritance pattern.

To compare the disease to similar bone dysplasias, a review is presented in Chapter 2. The ossification of the skull is described in detail, especially the neurocranium, the bone surrounding the brain. As in the rest of the body, in the skull two types of ossification take place: intramembranous ossification is bone formation initiated by mesenchymal stem cells. The calvaria originate largely from intramembranous ossification. Endochondral bone formation is bone formation out of cartilage occurring in different stages. The skull base is largely formed out of endochondral bone formation.

In the review it becomes clear that almost all bone dysplasias display abnormalities throughout the whole skeleton, although predominant involvement of the craniofacial area is common. The disorders can be divided based on metabolic differences: dysplasias with decreased bone resorption (e.g. osteopetroses, craniometaphyseal disease, dysosteosclerosis), increased bone turnover (e.g. Paget's disease of bone) and increased bone formation (e.g. high-bone-mass phenotype, Van Buchem disease, Camurati-Engelmann disease). In the past years many genetic - and hence concurrent molecular - underlying causes of the different diseases have been detected, giving more insight in the pathology and, eventually equally important, different pathways that are essential in bone homeostasis.

In Chapter 3 the clinical course of $\mathrm{HCl}$ is described containing data of 14 patients. Hyperostosis of the skull base causing narrowing of the neuroforamina gives the early symptoms in $\mathrm{HCl}$. Almost all patients present with facial palsy as their first symptom (first or second decade), due to narrowing of the (porus) of the internal auditory canal and entrapment of the facial and vestibulocochlear nerves. Facial palsy is HouseBrackmann grade II-IV after an initial temporary complete paralysis. Subclinical hearing loss is often present. Sensorineural hearing loss occurs gradually and is often mild to moderate, but can be severe or profound and also acute. (Bilateral) internal auditory canal decompression is definitely advised in young symptomatic patients, in which skull base anatomy is not grossly distorted.

Anosmia due to hyperostosis of the rima olfactoria is another possible symptom. There is no treatment for this symptom. Neuropathy of the trigeminal nerve should be treated if it presents as neuralgia. Optic neuropathy can occur in severely affected patients and can lead to vision loss, either (sub)acute or slowly progressive.

Symptoms due to decreasing intracranial volume occur later in life and only in severely affected patients. Arnold-Chiari malformation, chronic headache and intracranial hypertension are documented. 
In Chapter 4, the value of several neurophysiological tests, related to the clinical course of the disorder, is investigated. Ten affected individuals and 13 unaffected family members are tested with visual evoked potentials, masseter reflex, blink reflex, pure tone and speech audiometry, stapedial reflexes, otoacoustic emissions, brainstem evoked response audiometry and electronystagmography.

Apart from tonal and speech audiometry, BERA appears to be very useful to monitor the cochlear nerve function, because a presymptomatic increase of latency time peak I$\mathrm{V}$ is common. (Periodic) vestibular function tests are reliable and of vital importance, because vestibular dysfunction develops gradually and has major clinical impact, especially if present bilaterally. Visual evoked potentials are important to monitor optic nerve function in combination with radiological and ophthalmologic examinations and can be decisive for surgical intervention. We do not advise the routine use of blink and masseter reflex.

In Chapter 5 the radiologic features of $\mathrm{HCl}$ are described. CT scans of affected individuals are analysed and compared to scans of unaffected family members as well as to an age- and sex-matched control group. Linear measurements of the inner table (tabula interna), the diploë (medulla), and the outer table (tabula externa) of different skull locations are performed. Furthermore bone density measurements of the same regions are presented. Neuroforamina widths are recorded as well.

The first radiological abnormalities are subtle: both within the calvaria as well as the skull base small hypodense vesicular islands arise within the medulla. Then focal hyperdense sclerotic spots arise at the border of inner table and the inner diploë, initially without significant thickening of the inner table. Gradually, the hyperdense spots merge, enlarge and form a hyperostotic inner table. In adult patients, there is significant thickening of the skull in the frontal, parietal, temporal, and occipital regions, which is mainly due to thickening of the inner table of the skull. The density of the deposited hyperostotic bone is lower than normal cortical bone.

The width of the porus of the internal auditory canal can decrease to less than $1 \mathrm{~mm}$ compared to $4 \mathrm{~mm}$ in unaffected individuals. Generally there is extensive pneumatisation of both the paranasal sinuses, as well as the mastoid. Mastoid air cells, however, are gradually replaced by sclerotic bone. Other important radiological landmarks are a sclerotic and enlarged stylomastoid process, unaffected middle and inner ear and subtle mandibular exostoses.

In Chapter 6 site-specific bone metabolism of patients with $\mathrm{HCl}$ was measured using ${ }^{18}$ F-Fluoride PET/CT. Unaffected family members and unrelated patients were used as controls. Apart from visual assessment of the PET scans, standardised uptake values (SUVs) at different anatomical sites are assessed: frontal bone, sphenoid bone, petrous bone, clivus and control sites. The ${ }^{18}$ F-fluoride uptake in the entire skull is also measured assessing the uptake in successive axial slides. 
It is found that fluoride uptake is statistically significantly higher in the sphenoid bone and clivus regions of patients. No significant differences are seen between the groups concerning the total uptake of the skull. Furthermore, visual assessment confirms CT findings concerning the pathogenesis of calvarial hyperostosis: visually the metabolic activity is located mainly at the transition of the medulla and the base of the hyperostotic border.

This study confirms that ${ }^{18} \mathrm{~F}$-fluoride PET/CT is a very sensitive imaging technique in determining metabolic activity, showing differences in small population sizes, even in conditions with an indolent character. Whereas ${ }^{18} \mathrm{~F}$-fluoride PET/CT is a reliable imaging modality useful in research setting, there is no place for its routine use in $\mathrm{HCl}$ patients. Performing this study, ${ }^{18} \mathrm{~F}$-fluoride has been reintroduced as a potentially useful tracer for other bone-related disorders.

Chapter 7 gives an overview of all biochemical bone-related markers that have been assessed in the patients (and non-affected family members): total serum calcium, ionised serum calcium, albumin, parathyroid hormone (PTH) and 25-hydroxy vitamin D were all compared to normative values and no significant differences were found in any marker. C-terminal propeptide of type I collagen (PINP, marker of bone formation) and cross-linked telopeptide of type I collagen (ICTP, marker of bone resorption) were also assessed, but these are more difficult to compare due to age-dependent differences. PINP was found to be relatively lower in affected patients. Furthermore, in chapter 7 histologic images are shown of biopsy specimens of affected bone.

In Chapter 8 the results of genetic linkage analysis are reported. A genomic search is performed on this family. More than 400 polymorphic markers spread across the genome are analysed. With these results, LOD scores (logarithm of odds) are calculated for each chromosome. Based on the results of the LOD score calculations, genes already known to cause bone dysplasias with involvemwent of the skull such as SOST, LRP5, LRP4, ANKH and TGFB1 can be excluded as disease causing genes in this family because of LOD scores below -2 . One region shows a LOD score of +4.09 : a region of 8.3 $\mathrm{cM}$ at chromosome $8 \mathrm{p} 21$. This region encompasses $4.35 \mathrm{Mb}$ and contains 64 genes. It can be concluded that the gene responsible for $\mathrm{HCl}$ is located within this part of the genome. Sequence analysis of three bone-related candidate genes in this region (BMP1, LOXL2 and ADAM28) does not show any mutations.

Chapter $\mathbf{9}$ and $\mathbf{1 0}$ are casuistics. Both chapters are about the consequences of internal auditory canal narrowing. In chapter 9 bilateral internal auditory canal decompression via middle fossa approach is described in a child with bilateral short-term facial palsy with good postoperative recovery of facial nerve function. Chapter 10 describes auditory brainstem implantation in a patient with long-term complete bilateral sensorineural hearing loss due to internal auditory canal narrowing. Although 
audiologically succeeded, we are faced with an important complication, likely to be caused by the altered cerebrospinal fluid dynamics in a severely hyperostotic skull. These reports underscore that surgical intervention is favoured early in life and that extensive counselling about potential risks is essential.

Chapter 11 comprises the general discussion, conclusions and future perspectives of this research. 
Samenvatting 


\section{Samenvatting}

Hyperostosis cranialis interna $(\mathrm{HCl})$ is een botaandoening die zich beperkt tot de schedel. De ziekte kenmerkt zich door intracraniële hyperostose (overmatige botaanmaak) en osteosclerose (bot met een toegenomen botdichtheid) van zowel het schedeldak als de schedelbasis. De aandoening heeft een autosomaal dominant overervingspatroon.

In Hoofdstuk 2 wordt er een overzicht gepresenteerd om de aandoening te kunnen plaatsen in het scala van vergelijkbare botaandoeningen. Allereerst wordt hierin de ossificatie van de schedel beschreven, met name het neurocranium, het bot rondom de hersenen. Zoals elders in het lichaam kent ook de schedel twee types verbening: intramembraneuze en endochondrale ossificatie. De calvariën (het schedeldak) worden grotendeels intramembraneus gevormd, dat wil zeggen directe botvorming uit mesenchymale stamcellen, vanuit bindweefsel. De schedelbasis wordt grotendeels gevormd door endochondrale botvorming. Hierbij vindt groei plaats vanuit meerdere groeikernen en ontstaat bot vanuit kraakbeen. In de review komt naar voren dat bijna alle botdysplasieën afwijkingen in het gehele skelet vertonen, alhoewel craniofaciale afwijkingen vaak overheersen. Er wordt in de literatuur vaak een metabole classificatie gemaakt van de verschillende aandoeningen: aandoeningen waarbij er sprake is van verminderde botresorptie (bv. osteopetroses, craniometaphyseal disease, dysosteosclerosis), verhoogde botombouw (bv. Paget's disease of bone) en toegenomen botaanmaak (bv. high-bone-mass phenotype, ziekte van Van Buchem, Camurati-Engelmann disease). In de afgelopen jaren is er bij veel ziekten een genetische - en daarmee vaak ook een moleculaire - oorzaak gevonden. Dit heeft bij veel aandoeningen inzicht gegeven in de pathofysiologie. Vaak gaf ook het ontdekken van de pathofysiologie van een bepaalde aandoening nieuwe inzichten in verschillende stappen en cascades van de normale botstofwisseling.

In Hoofdstuk 3 wordt het klinisch beloop van $\mathrm{HCl}$ beschreven aan de hand van data van 14 patiënten. Vroege symptomen van $\mathrm{HCl}$ worden doorgaans veroorzaakt door hyperostose van de schedelbasis. Hierdoor treedt er vernauwing op van de verschillende neuroforamina. Bijna alle patiënten presenteren zich initieel met een facialisparese (eerste of tweede decade) ten gevolge van vernauwing van de porus van de meatus acusticus internus (ofwel inwendige gehoorgang) en dus beknelling van de nervus facialis en nervus vestibulocochlearis. Een facialisparese is meestal HouseBrackmann graad II tot IV na een tijdelijke volledige paralyse. Ten tijde van de facialisparese is er ook al vaak presymptomatisch gehoorverlies. Perceptief gehoorverlies is langzaam progressief en is doorgaans mild tot matig, maar kan ook ernstig zijn. Acuut gehoorverlies is ook beschreven. (Bilaterale) decompressie van de inwendige gehoorgang is absoluut aangewezen bij jonge symptomatische patiënten, waarbij de anatomie van de schedelbasis nog niet significant verstoord is. 
Anosmie ontstaat ten gevolge van hyperostose ter plaatse van de rima olfactoria. Hier bestaat geen behandeling voor. Neuropathie van de nervus trigeminus moet behandeld worden als er sprake is van neuralgie. Neuropathie van de nervus opticus kan optreden bij ernstig aangedande patiënten en kan leiden tot visusverlies, (sub)acuut ofwel langzaam progressief. Symptomen ten gevolge van een verminderd intracranieel volume ontstaan pas later en alleen bij ernstig aangedane patiënten. Er zijn gevallen van Arnold-Chiari malformatie, chronische hoofdpijn en een verhoogde intracraniële druk.

In Hoofdstuk 4 wordt de waarde van verschillende neurofysiologische tests onderzocht. Bij 10 aangedane en 13 niet-aangedane familieleden werden visual evoked potentials, masseter reflex, blink reflex, toon- en spraakaudiometrie, stapediusreflexen en otoakoestische emissies, hersenstamaudiometrie (BERA) en elektronystagmografie afgenomen.

Behalve toon- en spraakaudiometrie bleek BERA zeer waardevol voor het monitoren van de functie van de nervus cochlearis. Bij BERA-onderzoek worden vaker verlengde piek I-V latentietijden gevonden voordat patiënten symptomatisch zijn. (Periodieke) vestibulaire functietesten zijn betrouwbaar en zeer belangrijk, aangezien vestibulaire dysfunctie geleidelijk ontstaat. Vestibulaire dysfunctie kan een zeer belangrijke invloed hebben op patiënten, vooral als het bilateraal aanwezig is.

Visual evoked potentials zijn belangrijk voor het opvolgen van de functie van de nervus opticus, in combinatie met radiologisch en oogheelkundig onderzoek. Het resultaat kan doorslaggevend zijn in de besluitvorming omtrent chirurgische decompressie van de zenuw. De resultaten van de blink en de masseter reflex zijn onzes inziens niet consistent en routinegebruik van deze testen is dan ook niet aanbevolen.

In Hoofdstuk 5 worden de radiologische karakteristieken van $\mathrm{HCl}$ beschreven. CT-scans van aangedane individuen worden geanalyseerd en vergeleken met scans van nietaangedane familieleden en met een controlegroep gematcht op leeftijd en geslacht. De resultaten van lineaire metingen van de tabula interna, de diploë (medulla) en de tabula externa worden getoond. Verder worden er densiteitsmetingen uitgevoerd van dezelfde regio's; ook wordt de breedte van verschillende neuroforamina gemeten en vergeleken.

De eerste radiologische afwijkingen zijn subtiel: zowel ter plaatse van de calvaria als ook de schedelbasis ontstaan er kleine hypodense blazige eilandjes in de medulla. Later ontstaan er focaal hyperdense sclerotische laesies op de grens van de tabula interna met (de binnenzijde van) de medulla. De hyperdense laesies conflueren, vergroten en vormen uiteindelijk een volledig hyperostotische tabula interna die progressief verdikt. Bij volwassen patiënten wordt er een significante verdikking gevonden van het schedelbot in de frontale, pariëtale, temporale en occipitale regio's, voornamelijk ten 
gevolge van hyperostose van de tabula interna. Verder wordt er aangetoond dat de densiteit van het pathologisch afgezette bot lager is dan dat van normaal corticaal bot. De porus van de inwendige gehoorgang vernauwt doorgaans tot minder dan $1 \mathrm{~mm}$ in vergelijking met circa $4 \mathrm{~mm}$ bij gezonde volwassenen. In het algemeen is er bij de patiënten sprake van uitgesproken pneumatisatie van de neusbijholtes en ook het mastoïd. De luchtcellen in het mastoïd maken langzaam plaats voor sclerotisch bot. Andere belangrijke radiologische kenmerken zijn: een sclerotische en verbrede processus stylomastoideus, een niet aangedaan middenoor en binnenoor en kleine mandibulaire exostoses.

In Hoofdstuk 6 wordt de mate van botmetabolisme bij patiënten op verschillende gemeten door gebruik te maken van ${ }^{18}$ F-Fluoride PET/CT. Niet-aangedane familieleden en niet-gerelateerde patiënten worden als controles gebruikt. Behalve visuele beoordeling van de PET-scans wordt de SUV (standardised uptake value) gemeten op verschillende anatomische lokaties: os frontale, os sphenoidale, os petrosum, clivus en controle-plekken. De ${ }^{18} \mathrm{~F}$-fluoride opname in de gehele schedel wordt ook gemeten door de opname in opeenvolgende axiale coupes te bepalen.

Er wordt vastgesteld dat de fluoride uptake significant hoger is bij $\mathrm{HCl}$ patiënten in de regio van het os sphenoidale en de clivus. Er werd geen significant verschil gevonden wat betreft de totale ${ }^{18} \mathrm{~F}$-fluoride opname van de schedel. Visuele analyse van de $\mathrm{PET} / \mathrm{CT}$ scans bevestigt het beeld dat bij de CT-studie werd verkregen over de pathogenese van de hyperostose ter hoogte van de calvaria: de metabole activiteit bevindt zich met name ter hoogte van de overgang van de medulla naar de basis van de hyperostostische tabula interna.

Deze studie bevestigt dat ${ }^{18} \mathrm{~F}$-fluoride PET/CT een zeer gevoelige beeldvormende techniek is wat betreft de bepaling van botmetabole activiteit. Er worden verschillen aangetoond in kleine groepen bij een aandoening met een indolent beloop. ${ }^{18} \mathrm{~F}$-fluoride $\mathrm{PET} / \mathrm{CT}$ heeft vooralsnog dus een meerwaarde in het kader van wetenschappelijk onderzoek, er is echter geen plaats voor routine ${ }^{18} \mathrm{~F}$-fluoride PET/CT in klinische setting. Deze studie heeft ${ }^{18} \mathrm{~F}$-fluoride opnieuw op de kaart gezet als potentieel nuttige tracer bij dynamisch beeldvormend onderzoek voor andere botgerelateerde aandoeningen.

Hoofdstuk 7 geeft een overzicht van de biochemische botgerelateerde merkers die bij de patiënten (en niet-aangedane familieleden) bepaald zijn: totaal serum calcium, geïoniseerd serum calcium, albumine, parathyroïd hormoon (PTH) en 25-hydroxyvitamine D. Alle waardes zijn vergeleken met normatieven en er worden geen significante verschillen gevonden. C-terminal propeptide van type I collagen (PINP, botvormingsmerker) en cross-linked telopeptide van type I collagen (ICTP, botresorptiemerker) zijn ook gemeten, maar onderlinge vergelijking is moeilijker in verband met de leeftijdsgebonden verschillen in de waardes. PINP was relatief lager in de aangedane individuen. Verder worden er in dit hoofdstuk afbeeldingen getoond van histologische coupes van aangedaan bot. 
In Hoofdstuk 8 worden de resultaten van de genetische koppelingsanalyse getoond. $\mathrm{Er}$ is een genoomstudie werd verricht bij de familie. Meer dan 400 polymorfe merkers verspreid over het hele genoom zijn geanalyseerd. Met de resultaten zijn LOD-scores (logarithm of odds) berekend voor elk chromosoom. Op basis van de resultaten van de LOD-scores $(<-2)$ zijn bepaalde genen met belangrijke betrokkenheid bij botstofwisseling worden uitgesloten van betrokkenheid bij $\mathrm{HCl}$ : SOST, LRP5, LRP4, ANKH en TGFB1. Eén regio toont een LOD-score van +4.09: een regio van $8.3 \mathrm{cM}$ op chromosoom 8p21. Deze regio bevat $4.35 \mathrm{Mb}$ met daarin 64 genen. Er wordt geconcludeerd dat het gen dat verantwoordelijk is voor $\mathrm{HCl}$ zich bevindt in dit gebied van het genoom. Sequentieanalyse van drie botgerelateerde kandidaatgenen in deze regio (BMP1, LOXL2 en ADAM28) tonen geen mutaties.

Hoofdstuk 9 en 10 bevatten casuïstiek. Beide hoofdstukken hebben te maken met de gevolgen van vernauwing van de inwendige gehoorgang. In hoofdstuk 9 wordt de bilaterale decompressie van de inwendige gehoorgang beschreven bij een kind met (relatief) kortstondige bilaterale facialisparese met goed post-operatief resultaat. Hoofdstuk 10 gaat over het plaatsen van een "auditory brainstem implantaat" bij een patiënt met langdurige bilaterale volledige doofheid. Hoewel de ingreep een audiologisch succes is, treedt er een belangrijke complicatie op, mogelijkerwijs deels ten gevolge van de veranderde liquorcirculatie in de ernstig hyperostotische schedel. Deze casus onderstrepen het belang van vroege chirurgische interventie, indien mogelijk, en ook het belang van uitgebreide inlichting van patiënten over de risico's van dergelijke ingrepen.

Hoofdstuk 11 is een algemene beschouwing. Ook worden de conclusies van het onderzoek genoemd en worden de toekomstperspectieven van het onderzoek geschetst. 
Dankwoord 


\section{Dankwoord}

Hoewel de woorden die op papier staan in deze bundel geschreven zijn door mijzelf, is het geheel niet denkbaar zonder de steun van de mensen om mij heen. Er zijn van die momenten dat ik me besef hoe fijn het is dat ik zó een waardevolle groep van naasten en dierbaren om mij heen heb opgebouwd. En nu... tijdens het schrijven van dit dankwoord sta ik daar wel degelijk bij stil: ik heb heel veel mensen die me dankzij, maar gelukkig nog meer die me ondanks mijn promotieonderzoek dierbaar zijn. Omdat het onderzoek voor een belangrijk gedeelte naast mijn gewone werk tot stand is gekomen, is er menig avond, weekenddag of ander verloren moment in op gegaan en is bij tijd en wijlen een vriendschap op de proef gesteld.

Professor Stokroos, Robert, ik wil je op de eerste plaats bedanken voor de aanleiding om KNO-arts te worden. Bij jou ben ik in - ik denk - 2002 of 2003 binnengelopen met de vraag of het mogelijk was eens een dag bij de KNO in Maastricht mee te kijken. Mijn co-schap KNO in Brisbane met jou als Maastrichtse begeleider was de klapper! Ik was verkocht. Eenmaal als arts-assistent begonnen werd je mijn promotor. Ik wil je bedanken voor je begeleiding, met name voor de "adelaarsvisie", de "big picture" die je nooit uit het oog verloor. Je wist met rake opmerkingen vaak de kern te raken als ik weer eens op een dwaalspoor zat. Bovendien heb je me als opleider enthousiast gemaakt voor de otologie, waar ik veel van heb geleerd in Maastricht.

Professor Manni, Hans (dat mag ik zeggen vanaf het vliegveld van Brussel), wat ben ik blij dat je mijn promotor bent. Je motivatie is onvoorwaardelijk. Niet zelden kreeg ik een telefoontje van je vanuit de trein op weg naar een vliegtuig op weg naar een ver land: "op bladzijde 4... de referentie is verkeerd geschreven...". Als geestelijk vader van hyperostosis cranialis interna ben je onvoorstelbaar betrokken geweest en terecht ook trots. We hebben meerdere keren in de avonduren in je werkkamer gezeten in Meerssen. Ik weet dat ik iedere keer weer buitengewoon onder de indruk was van de werkkamer: zóóveel Afrika. Dat ik 3-4 jaar geleden al eens vroeg of ik een mee mocht gaan naar Ethiopië na het zien van de foto's. Toen kreeg ik een ontwijkend antwoord. Blij dat ik heb doorgezet, want mijn deelname aan het Eardrop team in februari 2012 was voor mij een onbeschrijflijke maatschappelijke ervaring en ook een ultieme kans om mijn promotor in zijn tweede natuurlijke habitat te leren kennen. Hans, je bent voor mij een zeer inspirerende leermeester.

Geachte leden van de beoordelingscommissie, hartelijk dank voor het kritisch doorlezen van mijn manuscript.

Professor Kremer, Bernd, bedankt voor mijn 5 mooie jaren bij de KNO in Maastricht. De manier waarop ik bij KNO-Maastricht ben beland heeft veel weg van een ogenschijnlijk 
overhaaste transfer in de voetbalwereld. Binnen één week was de zaak beklonken: donderdag hypofyse-OK bij Martin Lacko (Martin ook bedankt!), zaterdagavond een e-mail aan Robert Stokroos, dinsdag telefoon van Marèse of ik woensdagmorgen wilde solliciteren (mogelijk de enige succesvolle sollicitant ooit zonder pak), woensdagmiddag overleg met professor Beuls van neurochirurgie en donderdagmorgen zat ik bij je aan het bureau voor het "ja-woord". Maar wát een goede keuze, achteraf kan ik me geen mooiere plaats voorstellen om opgeleid te worden. Je hebt een vertrouwen in mij getoond, dat inspirerend heeft gewerkt. Je combinatie van blijk van waardering en (Duitse) strengheid hebben op de afdeling een teamgeest doen ontstaan waar je heel trots op mag zijn. Ik heb dan ook met weemoed afscheid genomen in juni 2012, met het gevoel dat ik een rijke medisch-inhoudelijke en persoonlijke opleiding heb afgerond.

Beste familieleden, onderwerp van dit proefschrift, jullie bedanken geeft natuurlijk een buitengewoon dubbel gevoel. Voor jullie bestond hyperostosis cranialis interna natuurlijk best helemaal niet. Bedankt voor jullie openheid en vertrouwen in ons team, jullie bereidwilligheid, het overbruggen van die afstand. Vóór jullie ligt nu een belangrijke stap richting het begrijpen van $\mathrm{HCl}$, maar ook een stapje richting behandeling en draaglijk maken van de aandoening. Jullie kunnen op me blijven rekenen, in welk ziekenhuis ik ook werk.

Beste Gerrit Kemerink, Boudewijn Brans, Servé Halders, professor Teule en Bert-Jan de Bondt, jullie bijdrage aan het "beeldvorming"-gedeelte van dit proefschrift is van grote waarde geweest. Gerrit, dank voor je geduldige uitleg aan Thijs en mij over de fysica van PET-scans die mij vaak boven de pet gingen. Servé, bedankt voor de tomeloze inzet bij het vervaardigen van de scans. Boudewijn, bedankt voor de fantastische inhoudelijke bijdrages, voor mij een verademing als nucleaire leek.

Beste Noël Bauer, Lucien Anteunis, Yvonne Extra, Herman Kingma, Danny Hilkman, Mickey Chenault, Fred Nieman, Jim Dings, Koo van Overbeeke, Myrurgia Abdulhamid, professor Hogendoorn en Paul Menheere, dank voor jullie bijdrages aan mijn proefschrift. Jullie respectievelijk oogheelkundige, audiologische, vestibulaire, neurofysiologische, statistische, neurochirurgische, histopathologische en kinisch chemische bijdrages bewijzen dat dit proefschrift niet een puur KNO-proefschrift is. Een multidisciplinaire aandoening met een multidisciplinaire aanpak. Dank aan mijn promotoren die ze over zo'n uitgebreid kennisnetwerk beschikken. Ik ben trots dat het me gelukt is een klein gedeelte van jullie kennis in mijn boekje te krijgen.

Beste Thijs van Dongen en Martijn Bischoff, zonder jullie toegewijde werk als wetenschapsstudenten was ik nu nog bezig met het schrijven van ik weet niet welke "Materials \& Methods", klaar zou ik in ieder geval nog niet zijn. Ik wil jullie bedanken in 
het in mij gestelde vertrouwen als stagebegeleider, voor mij natuurlijk ook de eerste keer. Dankzij jullie hoop ik dat dit niet de laatste keer was als stagebegeleider. Thijs, ik was blij te zien dat je allesbehalve was afgeknapt op de wetenschap na je stage bij mij; sterker nog, met het verschijnen van je New England artikel ben je me alweer ruimschoots gepasseerd. Martijn, ik ken weinig mensen die zo consciëntieus de wetenschap bedrijven als jij; je bent een aanwinst voor de wetenschap. Succes met het maken van je beroepskeuze!

Beste Wim van Hul en Vere Borra, op dezelfde trein in een andere wagon (van nietItaliaanse makelij). De samenwerking met jullie voelde vanaf het begin vertrouwd. We konden wetenschappelijk niet zonder elkaar, wij leverden de klinische gegevens en het patiëntenmateriaal, jullie gingen op zoek naar een genetisch antwoord voor de kliniek. Wim, ik hoop oprecht op het voortbouwen op onze samenwerkingsverbanden in de toekomst. Vere, hopelijk vind je een mooie nieuwe uitdaging (of nóg een opleiding!?).

Beste collega's arts-assistenten en later ook fellows van 2007 tot 2012, we zaten allemaal in hetzelfde schuitje: een opleiding in 5 jaar afronden en tegelijk werken aan de wetenschap. Gevloek en getier in verband met een afgewezen manuscript wisselden zich af door jubelstemming in verband met binnengehaalde resultaten in de assistentenkamer. De assistentenkamer... het epicentrum van de roddel, van de koffie en van het gesprek over het leven buiten het ziekenhuis. Dank jullie voor het delen van lief en leed, voor het verwerken van beide in Café Zuid (of toch liever ergens anders?), voor de assistentenweekenden, voor Porto, voor de mooie tijd! Veel van jullie zijn maatjes geworden en dat wil ik - ondanks dat we over het land uitvliegen - graag zo houden!

Beste collega's stafleden in Maastricht, bedankt voor jullie gezelligheid en ook voor jullie begrip voor de promoverende assistenten, bedankt voorál ook jullie onderwijs en opleiding. "Education is the most powerful weapon which you can use to change the world" (Nelson Mandela) [zie stellingen]. Janny Hof, bedankt voor je inzet voor mij als mentor en je meedenken over werk na Maastricht. Kenneth Kross - spontane mentor ad interim - bedankt voor je goede adviezen omtrent moeilijke keuzes en periodes.

Beste Glorious Bastards, Jan Wouter Brunings, Kenneth Kross, Guido Dees, Jeroen Mooren, Rick van de Langenberg, Raymond van de Berg, met 15988 Whatsappberichten in exact 1 kalenderjaar wil ik jullie niet ongenoemd laten. Een forum voor lol, lief en leed. Altijd een welterusten of een goedemorgen; in correcte volgorde. Wat is de bestemming van onze trip?

Beste polidames KNO in het azM, beste Marèse Gordijn, Edith Berry, Ester Paquay en Nicole Schobbe, bedankt voor de ondersteuning van mijn onderzoek en van mijn 
spreekuren en voor opbeurende woorden bij klaagzangen zoals die er soms waren. Goede ondersteuning maakt het werk en ook onderzoek zó veel aangenamer. Marèse, bedankt voor je onuitputtelijke persoonlijke interesse. Wat een mensenkennis! Edith bedankt voor je persoonlijke inzet voor mij, het heeft me echt geraakt.

Beste professor Offeciers, Erwin, stafleden, medewerkers van het European Institute of Otorhinolaryngology in Wilrijk - Antwerpen. Het is een buitengewone eer geweest jullie vakgroep te mogen versterken en op jullie prachtige dienst - vooral inhoudelijk, maar ook persoonlijk en wat betreft uitstraling - te mogen werken als fellow oorheelkunde. Zonder uitzondering allemaal uitblinkers in de menselijkheid en patiëntgerichtheid. Jullie passie voor het vak werkt echt aanstekelijk! Bedankt voor jullie medeleven met mijn laatste loodjes "doctoraat". Erwin, bedankt voor je lessen in, tja, otologie, filosofie, gastronomie, literatuur, cinematografie, politicologie en niet onbelangrijk: Aantwaarps! Uitdrukkingen als "veel volk in de staosse" (een grote boezem) en " $m$ 'n schup afkuisen" (vertrekken) waren mij nu anders volstrekt vreemd geweest.

Beste nieuwe collega's in het AMC, Wytske, Erik, Fenna, Bert, Piet (oude nieuwe collega of nieuwe oud-collega?), alle stafleden, arts-assistenten, collega's van de polikliniek en de OK. Bedankt dat jullie mij zo hartelijk ontvangen als nieuw staflid. Wytske en otologen, bedankt voor jullie vertrouwen in mij als otoloog, persoon en wetenschapper. Nog even doorzetten en na juni kan ik me volledig op het AMC richten; ik heb zin in de tijd die volgt!

Professor Hamersma, graag wil ek u van harte bedank vir die onvergeetlike ontmoeting in Pretoria. Selde is ek as vreemdeling so hartlik ontvang, en wel met die woorde: "Ons gaan vreet! Ons gaan zuip!" Ek het ons gesprekke rakende $\mathrm{HCl}$ en sclerosteose asook die patogenese van 'n Bell's palsy besonders waardevol gevind, maar soveel te meer dan ook ons diskussies rakende Suid-Afrika in die hede, privaat wildplase en die Springbokke. Versuim asseblief nie om ' $n$ draai te kom maak volgende keer wat $u$ Nederland kom besoek nie!

Beste Tiny Wouters, bedankt voor je supersnelle en degelijke ondersteuning. Met jou kan ik zaken doen! Diech mos Limburg noets verloate!

Dear Andy, thank you for your contribution to my PhD project from the island of Tasmania. We are looking forward to walking the Milford Track together...

Beste vrienden oud-Navigators, in het bijzonder Pieter, Kaas, Frank, Bom, Bob, Joey en Carapiet; als dit boekje er niet was geweest, had ik zeker meer woensdagen in de Falstaff kunnen spenderen. Dank voor de mogelijkheid tegen jullie te mogen klagen af en toe. Bedankt vooral ook voor mooie avonden, zeilweekenden en "wat dies meer zij". 
Beste Frenk van Hooijdonk, heel wat kilometers ben ik je chauffeur geweest tijdens mijn studententijd. Bedankt voor je in mij gestelde vertrouwen. Jouw optimisme is voor mij nog steeds een heel belangrijk voorbeeld; je rolt inmiddels langer dan je loopt en onderneemt alleen maar meer. Bedankt dat je er vandaag ook bent.

Beste vrienden, Peter en Kim Bollars, Wendy Cuijpers, Lauretta Vaassen, Jules Janssen, Josine Stammen, bedankt voor jullie gezelschap, gezellige weekenden en leuke avonden in Maastricht.

Beste Quigères, René Keijers, ook al snap je geen snars van geneeskunde en kun je een tikkeltje hypochondrie niet ontkennen, je begrijpt wat afzien is, zowel geestelijk (CFA examens) als lichamelijk (Patersberg, Koppenberg, Wall of Geraardsbergen et al. 2011). Bedankt voor wat we samen hebben meegemaakt! Jouw trouw als vriend waardeer ik enorm.

Beste Rabano's, Jan Scholte, Guy Raven en Lukas Ricker, dank voor de vele onvergetelijke reizen met ludieke momenten, stages en belevenissen. Struinen door Drakensbergen, zeilen bij de Whitsunday Islands en boottochten door nét-niet-door-deFARC-bezet gebied in Colombia. Moge die reizen een rode draad door ons gemeenschappelijk leven blijven. Fijn dat we eerlijk tegen elkaar zijn, ook over moeilijke keuzes en momenten. Jullie maakten het mogelijk zin te blijven houden in het succesvol afronden van dit proefschrift.

Beste Johns (of inmiddels toch echt Jeans?), George Driessen, Stijn Rutten en Luc Sijben, bedankt voor jullie ongelofelijk dierbare vriendschap, "keeping things cool since 1995". De noches en de hóóólidays zijn van onschatbare waarde. Immers "mens sana in corpore sano". We kennen elkaar nu net zo lang wel als niet, wow! Nien in het bijzonder bedankt voor het ter beschikking stellen van je huisje, dat heeft Helmond en Eindhoven tijdens de opleiding heel veel draaglijker gemaakt! Dries, ik heb bewondering voor je. Ging jij nou nog promoveren ;-)? Aso, jij een boek over gastronomie? In ieder geval, mes Jeans, we blijven een team: "per aspera ad astra"!

Beste familie, beste Francy en Henk, bedankt voor jullie continue belangstelling. "A man who doesn't spend time with his family can never be a real man", aldus Don Vito Corleone in de Godfather. Ik had misschien wat beter op moeten letten tijdens die film. Ik heb het gevoel dat jullie er vaker voor mij waren, bedankt!

Lieve oma, sorry dat ik er niet zo vaak voor $\mathrm{u}$ ben. Ik weet hoe trots $\mathrm{u}$ op me bent. Een van de weinige Nederlanders die nog spreekt over een "neus-keel-oorarts". Opa of "oom Freerk", wetenschapper pur sang, een medisch equivalent van uw gouden 
Conrad-medaille van het Koninklijk Instituut van Ingenieurs zal voor mij waarschijnlijk nooit weggelegd zijn. Begrijpen van al uw theorieën deed ik niet veel; maar wat ik nooit vergeten zal, is dat $u$ als mens prachtig in elkaar zat: eenvoudig, bescheiden en lief. Een voorbeeld.

Beste paranimfen, Laurens Kaas en Jan Scholte, bedankt voor het creëren van de nodige academische competitie. Met trots en gevoel van competitie werd de ander steeds weer op de hoogte gesteld van een nieuwe publicatie. Laurens, samen met jou is het allemaal begonnen in de wetenschap: turven, tellen

Lieve papa en mama, wat ik ook zeg over jullie, hoe dankbaar ik ook ben richting jullie, ik weet dat jullie trots altijd groter is. Jullie zijn dan ook mijn papa en mama. Toch probeer ik het: bedankt dat jullie altijd voor me klaar staan. Van mijn eerste werkstuk op de basisschool tot het nakijken van mijn eerste artikel, bedankt voor jullie eeuwige betrokkenheid. Ik weet dat jullie dit proefschrift zien als een soort afsluiting van een door jullie gesteunde studieperiode. Papa, jouw doorzettingsvermogen en algemene interesses, mama, jouw nauwkeurigheid en regeltalent hebben mij deels gevormd tot wie ik ben.

Lieve Stephanie, het belangrijkste in mijn leven, wat is het een ongekend voorrecht om jou naast me te hebben in mijn leven: lief, trouw, charmant, vrolijk, sociaal en bekwaam masseuse voor als het werk zwaar viel. Ik zou het heel veel mensen gunnen, maar dan heb ík je niet meer, laten we daarom maar snel trouwen! Je hebt geen enkel moment geklaagd (misschien heel soms dan) als ik mijn maîtresse Toshiba weer eens meer aandacht gaf dan jou. Je weet me altijd moed te geven als er weer eens een kleine tegenslag was, jij hebt vertrouwen in me. We zijn een rotsvast team, met hopelijk nog heel veel uitwedstrijden. Met jou geniet ik van het leven, in een ver land, maar ook gewoon thuis. Met jou word ik oud en door jou blijf ik jong. Bedankt dat je er altijd voor me bent.

Florian, baasje!, ik krijg tranen in mijn ogen als ik dit schrijf, wat ben ik trots om jouw pa te mogen zijn. Voor altijd maatjes? 
Bibliography 


\section{Bibliography}

2014 JJ Waterval, M Bogaerts, J Van Dinther, T Somers, A Zarowski, FE Offeciers. Treatment of traumatic stapediovestibular luxation: case report with the introduction of a new technique and review of literature. Otology \& Neurotology 2014;35(4):582-8.

2013 JJ Waterval, V Borra, W Van Hul, RJ Stokroos, JJ Manni. Sclerosing bone dysplasias with craniofacial involvement. Bone 2013;60C:48-67.

2013 VM Borra, JJ Waterval, RJ Stokroos, JJ Manni, W Van Hul. Localization of the gene for hyperostosis cranialis interna to chromosome 8p21 with exclusion of candidate genes. Calcified Tissue International 2013;93:93-100.

2013 JJ Waterval, MPH Bischoff, RJ Stokroos, LJ Anteunis, DMW Hilkman, H Kingma, JJ Manni. Neurophysiologic, audiometric and vestibular function tests in patients with Hyperostosis Cranialis Interna. Clinical Neurology \& Neurosurgery 2013;115:1701-8.

2013 JJ Waterval, M Vallinga, B Brans, S Halders, B Winkens, RJ Stokroos. ${ }^{18} \mathrm{~F}$-fluoride PET/CT scan for quantification of bone metabolism in the inner ear in patients with otosclerosis - a pilot stud. Clinical Nuclear Medicine 2013;38:677-685.

2012 JJ Waterval, RJ Stokroos, J Dings. Middle fossa approach. Invited book chapter in Atlas of Operative Otorhinolaryngology and Head and Neck Surgery. $1^{\text {st }}$ edition, B.T. Hathiram (ed.). Chapter 39: Middle fossa approach.

2012 JJ Waterval, RJ Stokroos. Cochlear otosclerosis displayed with ${ }^{18}$ F-Fluoride PET/CT. Case of the Week (June $18^{\text {th }}$ 2012), American Journal of Neuroradiology.

2012 JJ Waterval, TMA Van Dongen, RJ Stokroos, BJ De Bondt, MN Chenault, JJ Manni. Imaging features and progression of hyperostosis cranialis interna. AJNR American Journal of Neuroradiology 2012; 33:453-461.

2011 JJ Waterval, RJ Stokroos, J Dings, JJ Van Overbeeke, JJ Manni. Cerebral vasospasm after auditory brainstem implantation in a patient with hyperostosis cranialis interna. Clinical Neurology \& Neurosurgery 2011;113:904-908.

2011 S Vöö, TMA Van Dongen, JJ Waterval, P Willems, FM Mottaghy, B Brans. Nieuwe ontwikkelingen in de botscintigrafie: oude wijn in nieuwe vaten. Nederlands Tijdschrift Voor Geneeskunde 2011;155:A2792.

2011 JJ Waterval, TMA Van Dongen, RJ Stokroos, GGJ Teule, GJ Kemerink, B Brans, FHM Nieman, JJ Manni. Bone metabolic activity in hyperostosis cranialis interna measured with ${ }^{18} \mathrm{~F}$-fluoride PET. European Journal of Nuclear Medicine and Molecular Imaging 2011;38:884-893. 
2010 JJ Waterval, RJ Stokroos, NJC Bauer, RBJ De Bondt, JJ Manni. Phenotypic manifestations and management of hyperostosis cranialis interna, a hereditary bone dysplasia affecting the calvaria and thes. American Journal of Medical Genetics - part A 2010;152A:547-555.

2009 JJ Waterval, RJ Stokroos, RB De Bondt, JJ Manni. Facial nerve decompression via middle fossa approach for hyperostosis cranialis interna: a feasible therapeutic approach. The Journal of Laryngology \& Otology 2009; 2009;123(10):1177-1180.

2007 CA Schroeter, L Kaas, JJ Waterval, PM Bos, HA Neumann. Successful treatment of periungual warts using photodynamic therapy: a pilot study. Journal of European Academic Dermatology and Venereology 2007;21:11701174. 
About the author 


\section{Curriculum Vitae}

Jérôme Joseph Waterval was born on May $10^{\text {th }} 1982$ in Heerlen, The Netherlands. He did classical studies (gymnasium) at the Bernardinuscollege in Heerlen and started his medical studies at the University of Maastricht in 2000. As a medical student he did several electives abroad (Bangkok, Brisbane and Trinidad \& Tobago), his passion for travelling being born. Shortly after finishing medical school in 2006 he worked as a resident in the field of neurosurgery during five months (Maastricht University Medical Centre), however the fascination for otorhinolaryngology, his last elective, did not get out of his mind. In 2007 he enrolled in his otorhinolaryngology training with great enthusiasm in the same hospital, with prof. dr. Bernd Kremer and prof. dr. Robert Stokroos as his supervisors. At the same time he started this PhD project. Part of the training consisted of working at the Catharina Hospital in Eindhoven (under supervision of dr. Frank Adriaansen, dr. Nies Mateijsen and dr. Maarten Tabor) and at the Elkerliek Hospital in Helmond (under supervision of dr. Paul Schuil, drs. Harm Kahmann and drs. Martijn Alles). Before finishing his general training he spent two months as a medical observer at the Royal Victorian Eye \& Ear Hospital in Melbourne with prof. Stephen O'Leary and assoc. prof. Robert Briggs. The otologic group in this hospital have had a pioneering role ever since the development of the first cochlear implants. Furthermore, at the end of the last year of his training he joined Eardrop for a medical mission in Ethiopia. In September 2012 he started a fellowship in otology \& neurotology at the European Institute for Otorhinolaryngology headed by prof. dr. Erwin Offeciers and dr. Thomas Somers (Wilrijk - Antwerp), where he was given the chance to participate in one of the leading European otologic groups. In February 2014 he started working at the Academic Medical Centre in Amsterdam as staff member otology with dr. Fenna Ebbens, drs. Erik van Spronsen and prof. dr. Bert van der Baan at the department led by prof. dr. Wytske Fokkens.

He lives together with his partner Stephanie Bukkems and their son Florian. 
